\title{
METHODOLOGY DEVELOPMENT FOR THE SYNTHESIS OF IMINOSUGARS
}

\author{
BY \\ ALEXANDER ALAN HUNT-PAINTER
}

A thesis

submitted to the Victoria University of Wellington in fulfilment of the requirements for the degree of

Doctor of Philosophy 
"true nobility is being superior to your former self."

\section{Ernest Hemingway}




\section{Abstract}

This thesis investigated the development and application of methodology for the synthesis of iminosugars. The first portion of this thesis (Chapters 2 and 3) explored the scope of previously established protecting-group-free Vasella-reductive-amination and $\mathrm{I}_{2}$-mediated carbamate annulation methodology initially developed within the Stocker-Timmer group for the synthesis of pyrrolidines and piperidines from aldose sugars. In this thesis, the Vasella-reductive-amination methodology was extended to include the use of ketose sugars as starting materials, thereby allowing for the synthesis of primary amines directly from in situ formed ketones under protecting-group-free conditions. The scope of the carbamate annulation was then explored, whereby it was determined that both steric and electronic effects appear to affect transition state energies during the annulation reaction. Here, formation of pyrrolidines with the 2,5-trans and 3,4-cis relationships are favoured, however, in circumstances were conflicting electronic- and steric-effects are present, steric-effects dominate thereby favouring the formation of the 2,5-trans product. Using a combination of this Vasella-reductive-amination and carbamate annulation methodology, 2,5-dideoxy-2,5-imino-L-iditol was thus synthesised in 6 steps and 18\% overall yield from D-fructose. Next, the same methodology was applied to the synthesis of the promising molecular chaperone 2,5-dideoxy-2,5-imino-D-altritol. Thus, 2,5-dideoxy-2,5-imino-D-altritol was synthesised over 7 steps and in $22 \%$ yield from D-tagatose, which is the most efficient synthesis of this iminosugar to date.

The second part of this thesis (Chapters 4 and 5) focused on the optimisation and development of synthetic methodology that would allow for the highly efficient synthesis of a variety of iminosugars including piperidines and azepanes. To this end, modifications to existing synthetic methodology allowed for the rapid synthesis of a variety of iodoglycosides, which are important synthons. Next, reductive amination/cyclisation methodology that allowed for the direct transformation of methyl iodoglycosides or isopropylidene-protected iodoglycosides into iminosugars was developed. As such, the piperidines 1-Deoxynojirimycin, 1Deoxymannojirimycin (DMJ), L-1-Deoxygalactojirimycin (L-DGJ), and $(3 R, 4 r, 5 S)$-piperidine3,4,5-triol were prepared in 4 steps and good overall yields $(44 \%, 62 \%, 67 \%$, and $53 \%$, respectively). In the case of DMJ and $(3 R, 4 r, 5 S)$-piperidine-3,4,5-triol, these are the most efficient syntheses of these materials to date. Factors influencing the stereochemical outcome of the reductive amination reaction were also explored, and evidence suggests that the reduction occurs from the least sterically hindered face of an intermediate cyclic imine, whereby the preferred conformation of the imine is the one which places the largest number of substituents in the pseudo-equatorial position. Using analogous methodology, the azepane $(3 S, 4 R, 5 S, 6 R)$-azepane3,4,5,6-tetraol was also prepared in 4 steps and good yield (53\%). 


\section{Acknowledgements}

First, I'd like to thank my supervisors Mattie Timmer and Bridget Stocker. You both offered me the opportunity to peruse study at this level, through which I leant an immeasurable amount. It has been a privilege.

Thank you to the people in the lab and whom I worked with. Stefan, thank you. Ben, lol. Kris, the time has been great. Michael, thank you for the last stretch.

Many SCPS staff have been there when I have needed them. A few I'd like to mention: Ian, for constantly being available and so positive. T and Jackie K, for equipment, goss, and a laugh. Lisa, for the chats and administrative advice. Nick, Alan, Manu, Grant- true lads that made the time here far more bearable. And last but not least, Patricia Stein, thank you for everything, seriously. Many friends have helped me stay true to this goal and helped define this time for me. The first I'd like to mention is Daniel Counihan. Thank you, my bro, I couldn't have done it without you. Megan Neill, you've been an invaluable friend from the moment you showed up. Simon, Gus, for the constant open-door policy. Erik, for teaching me about capitalism and to take what is mine. Pawel and Donna, thank you. Mark Johnston, the dinners with you and Neil, the chats, thank you. Ian, for being a constant reality check and source of loud noises. The Clifton flat, for bearing the burden I left behind. Raj, Muhammad and the rest of the crew from the wellington airport, well enjoyed time. Callum, Keswick, Rayner, total lads. Meg, Phoebe, Bas, the banter was real. Kara Dean, for the surf and solid games of pool.

Dr. Neil Wilson. Your support was fundamental to this thesis being written. I will be forever grateful.

Lastly, I'd like to acknowledge my Parents. Wayne Martin, dad, I couldn't ask more from you, you've been the source of my grit. Vicki Martin, this work is one of the many results of everything you've done for me. Mum and Dad, this is for you both. Thank you. 


\section{Copyright notice}

This is a notice that the work contained herein is subject to copyright, 2018, by Alex Hunt-Pinater, all rights reserved.

Some of this work described in this thesis has been reported in the following publications:

A. A. Hunt-Painter, G. J. Moggre, P. C. Tyler, B. L. Stocker and M. S. M. Timmer, Chemistryselect, 2017, 2, 8028-8032.

A. A. Hunt-Painter, B. L. Stocker and M. S. M. Timmer, Tetrahedron, 2018, DOI:https://doi.org/10.1016/j.tet.2018.01.011. 


\section{Table of Contents}

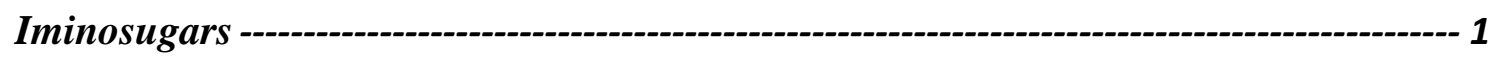

1.1 Introduction - 1

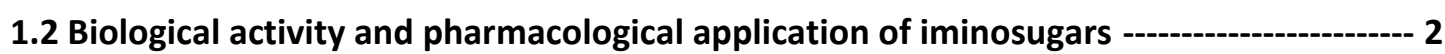

1.3 Syntheses of iminosugars ---on 6

1.4 Thesis Outline---18

Synthesis of 2,5-bis-hydroxymethyl pyrrolidines ---------------------------------------------20

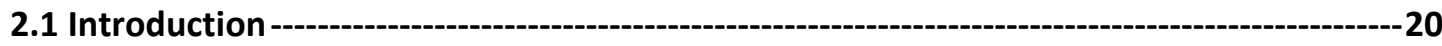

2.2 The synthesis of 2,5-bis-hydroxymethyl pyrrolidines from D-fructose---------------------21

2.3 Factors impacting stereoselectivity during carbamate annulation ------------------------28

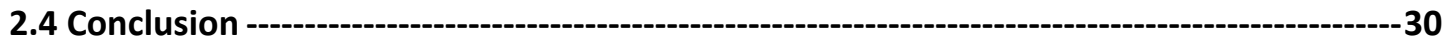

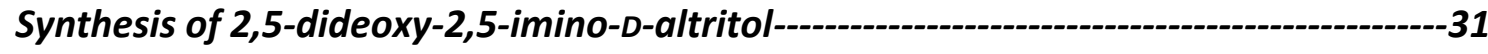

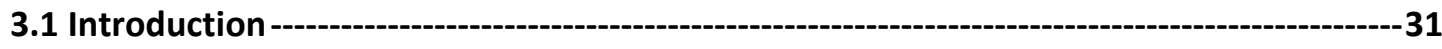

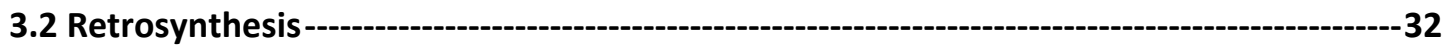

3.3 Synthesis of 2,5-dideoxy-2,5-imino-D-altritol and 2,5-dideoxy-2,5-imino-L-altritol -----33

3.4 Asymmetric synthesis of 2,5-dideoxy-2,5-imino-D-altritol ---------------------------------37

3.5 Conclusion --

Novel DMJ synthesis -------------------------------------------------------------------------------39

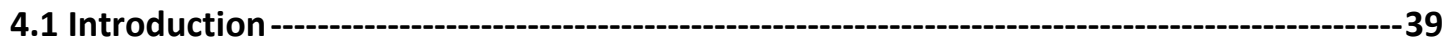

4.2 Acid mediated decomposition of 2-0-Methyl-6-deoxy-6-iodo-D-Fructofuranoside-----39

4.3 Attempted Vasella-reductive-amination of 6-deoxy-6-iodo-D-fructose (95)--------------42

4.3 Optimising the synthesis of 1-deoxymannojirimycin (DMJ) --o-1

4.4 The mechanism of DMJ formation from 6-deoxy-6-iodo-D-fructose (94) ------------51

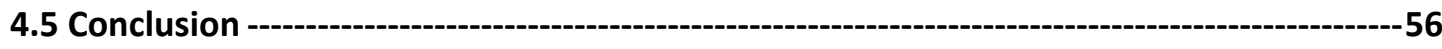

Novel synthesis of piperidines and an azepane-------------------------------------------58

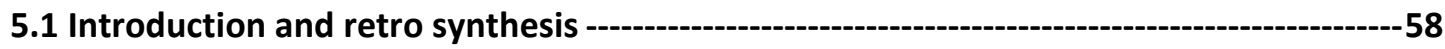

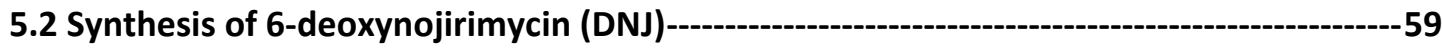


5.3 Synthesis of L-1-deoxygalactojirimycin (L-DGJ)-- 61

5.5 Synthesis of $(3 R, 4 r, 5 S)$-piperidine-3,4,5-triol--_e- 63

5.6 Synthesis of $(3 S, 4 R, 5 S, 6 R)$-azepane-3,4,5,6-tetraol---on- 66

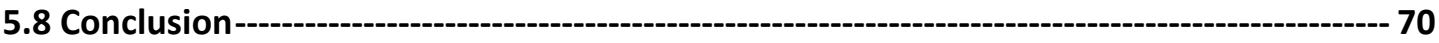

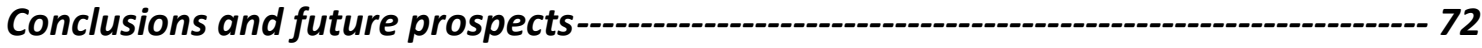

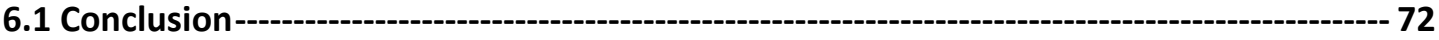

6.2 Future prospects--- 74

Experimental -------------------------------------------------------------------------------------------- 77

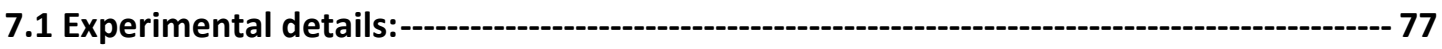

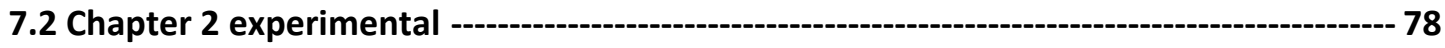

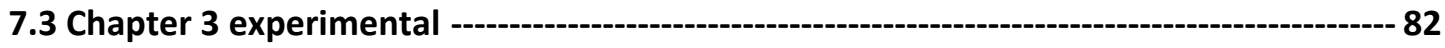

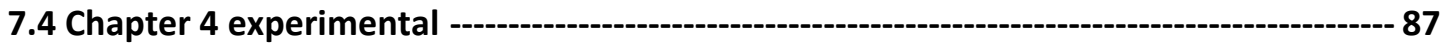

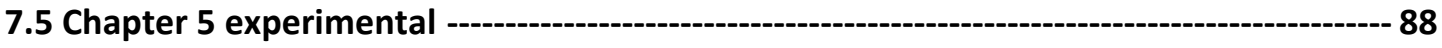

References------------------------------------------------------------------------------------------------- 94

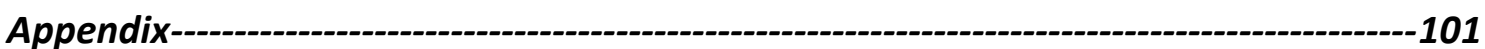

Chapter 2 spectra - 101

Chapter 3 spectra - 125

Chapter 4 Spectra - 151

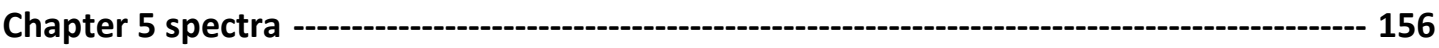




\section{List of abbreviations}

\begin{tabular}{|c|c|}
\hline$\alpha-G a l$ & Alpha-galactsidase \\
\hline Ac & Acytel \\
\hline $\mathrm{AD}$ & $\begin{array}{l}\text { Asymmetric } \\
\text { dihydroxylation }\end{array}$ \\
\hline $\mathrm{Bn}$ & Benzyl \\
\hline $\mathrm{CBz}$ & Carboxylbenzyl \\
\hline CMT & Chaperone mediated therapy \\
\hline COSY & Correlation spectroscopy \\
\hline$d$ & Doublet \\
\hline DCM & Dichloromethane \\
\hline$d d$ & Doublet of doublets \\
\hline$d d d$ & $\begin{array}{l}\text { Doublet of doublet of } \\
\text { doublets }\end{array}$ \\
\hline DAJ & 1-Deoxyallonojirimycin \\
\hline DGJ & 1-Deoxygalactojirimycin \\
\hline DIA & \\
\hline DIP & Diisopinocampheyl \\
\hline DMF & $N, N$-dimethyl formaldehyde \\
\hline DMJ & 1-Deoxymannojirimycin \\
\hline DMDP & $\begin{array}{l}(2 S, 3 S, 4 R, 5 S)-2,5- \\
\text { dihydroxymethyl-3,4- } \\
\text { dihydroxypyrrolidine }\end{array}$ \\
\hline DNJ & 1-Deoxynojirimycin \\
\hline ER & Endoplasmic reticulum \\
\hline ERT & $\begin{array}{l}\text { Enzyme replacement } \\
\text { therapy }\end{array}$ \\
\hline $\mathrm{EtOH}$ & Ethanol \\
\hline FSA & $\begin{array}{l}\text { D-fructose-6-phosphate } \\
\text { aldolase }\end{array}$ \\
\hline GBA1 & Glucocerebrosidase-1 \\
\hline GCS & $\begin{array}{l}\text { Glucosylceramidase } \\
\text { synthase }\end{array}$ \\
\hline GlcCer & Glucosylceramide \\
\hline HMBC & $\begin{array}{l}\text { Heteronuclear Multiple } \\
\text { Bond Correlation }\end{array}$ \\
\hline HRMS & $\begin{array}{l}\text { High resolution mass } \\
\text { spectrometry }\end{array}$ \\
\hline HSQC & $\begin{array}{l}\text { Heteronuclear single } \\
\text { quantum coherence }\end{array}$ \\
\hline LG & Leaving group \\
\hline$m$ & Multiplet \\
\hline $\mathrm{MeOH}$ & Methanol \\
\hline Ms & Mesyl \\
\hline NMO & $\begin{array}{l}N \text {-Methylmorpholine } N \text { - } \\
\text { oxide }\end{array}$ \\
\hline
\end{tabular}

NMR Nuclear magnetic resonance

$\mathrm{Nu} \quad$ Nucleophile

PG Protecting group

PGF Protecting group free

$\mathrm{Ph} \quad$ Phenyl

PPTS pyridinium

paratoluenesulfonate

Pyr pyridine

$s \quad$ Singlet

Sat Saturated

Soln Solution

SRT substrate reduction therapy

TBAF Tert- $\boldsymbol{n}$-butylammonium

fluoride

TBDPS O-tert-butyldiphenylsilyl

$\mathrm{ONH}_{2}$ hydroxylamine

$t d \quad$ Triplet of doublets

Tf Triflate

TFA Trifluoroacetic acid

THF Tetrahydrofuran

TLC Thin layer chromatography 


\section{Chapter 1}

\section{Iminosugars}

\subsection{Introduction}

Iminosugars are naturally occurring structural analogues of native carbohydrates, where the ring oxygen is replaced with a nitrogen. By virtue of being carbohydrate analogues, iminosugars have interesting biological activity and consequently have multiple pharmacological uses. Accordingly, iminosugars are an important target for synthetic chemists, with methodology development for the efficient synthesis of known and novel iminosugars remaining a pressing goal.

Unlike most naturally occurring compounds, iminosugars were initially synthesised before being isolated as natural products. The almost simultaneous publications by Jones, ${ }^{1,2}$ Paulsen, ${ }^{3}$ and Hanessian ${ }^{4}$ on the synthesis towards various stereoisomers of iminosugar 1 (Figure 1) was swiftly followed by nojirimycin (2) being isolated from Streptomyces reseochromogenes, where it was found to have anti-microbial activity and inhibit glycoside hydrolase enzymes. ${ }^{5}$ The more stable 1-deoxynojirimycin (DNJ, 3), synthesised in 1967 by Paulsen, ${ }^{6}$ was also found to be a potent $\alpha$-glycosidase inhibitor. ${ }^{7}$ Ten years after the isolation of nojirimycin, the first five-membered iminosugar (or pyrrolidine) was extracted from the leaves of Derris ellepticain, identified as $(2 S, 3 S, 4 R, 5 S)$-2,5-dihydroxymethyl-3,4-dihydroxypyrrolidine (DMDP, 4), ${ }^{8}$ and later found to be an effective glycosidase inhibitor. ${ }^{9}$ The bicyclic pyrrolidine-containing iminosugars also exhibit interesting biological activity, with pyrrolizidine casuarine (5) being identified as a potential chemotherapeutic agent ${ }^{10}$ and indolizidine (-)-swainsonine 
(6, the first bicyclic alkaloid to be discovered) showing $\alpha$-mannosidase II inhibitory and potential anti-cancer activity. ${ }^{11}$ The most recently discovered class of pyrrolidinecontaining iminosugars are the nortropanes and include members such as calstegine A3 (7), which was first isolated from the roots of calstegia sepium in $1988 .{ }^{12}$

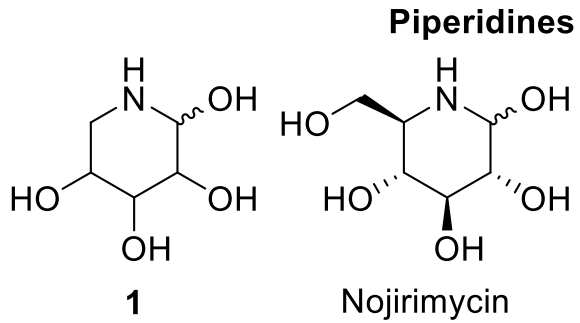

2<smiles>OC[C@H]1NC[C@@H](O)[C@H](O)[C@@H]1O</smiles>

Deoxynojirimycin (DNJ)

\section{Pyrrolidine}<smiles>OC[C@H]1N[C@H](CO)[C@@H](O)[C@H]1O</smiles>

DMDP

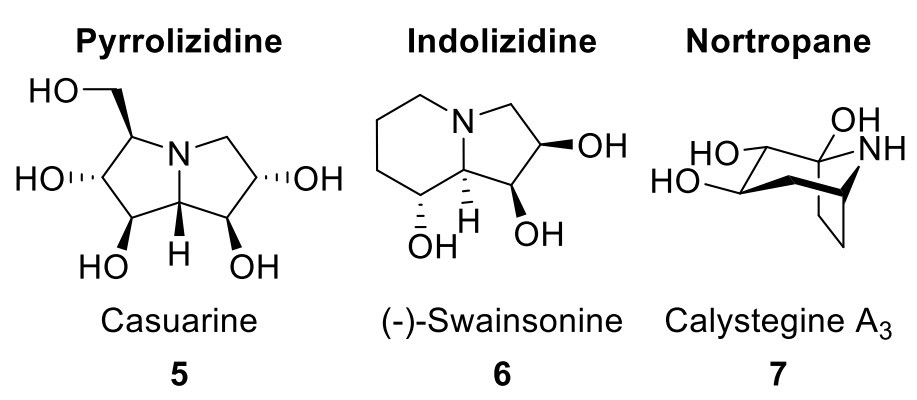

Figure 1: Examples of each class of iminosugar.

\subsection{Biological activity and pharmacological application of iminosugars}

The most renowned biological activity of iminosugars is the ability to reversibly bind to the active site of glycosidases, and to a lesser extent, glycosyltransferases. ${ }^{13}, 14$ Glycosylation is a fundamental cellular process that is key to many biochemical pathways, including the synthesis of endoplasmic reticulum (ER) derived proteins. ${ }^{15}$ These glycosidase enzymes follow a retaining or inverting reaction pathway, as shown in Scheme 1 (A and B respectively). ${ }^{16}$ Both pathways begin with the hydrolysis of the glycosidic bond, passing through an oxocarbenium transition state. Whilst the inversion pathway sees hydrolysis and monosaccharide release in one step, the retaining pathway passes through an intermediate where the monosaccharide is bound to the enzyme. The distance between the two catalytic acid residues in the active site determines if the enzyme will have a retaining or inverting mechanism. ${ }^{17}$ 

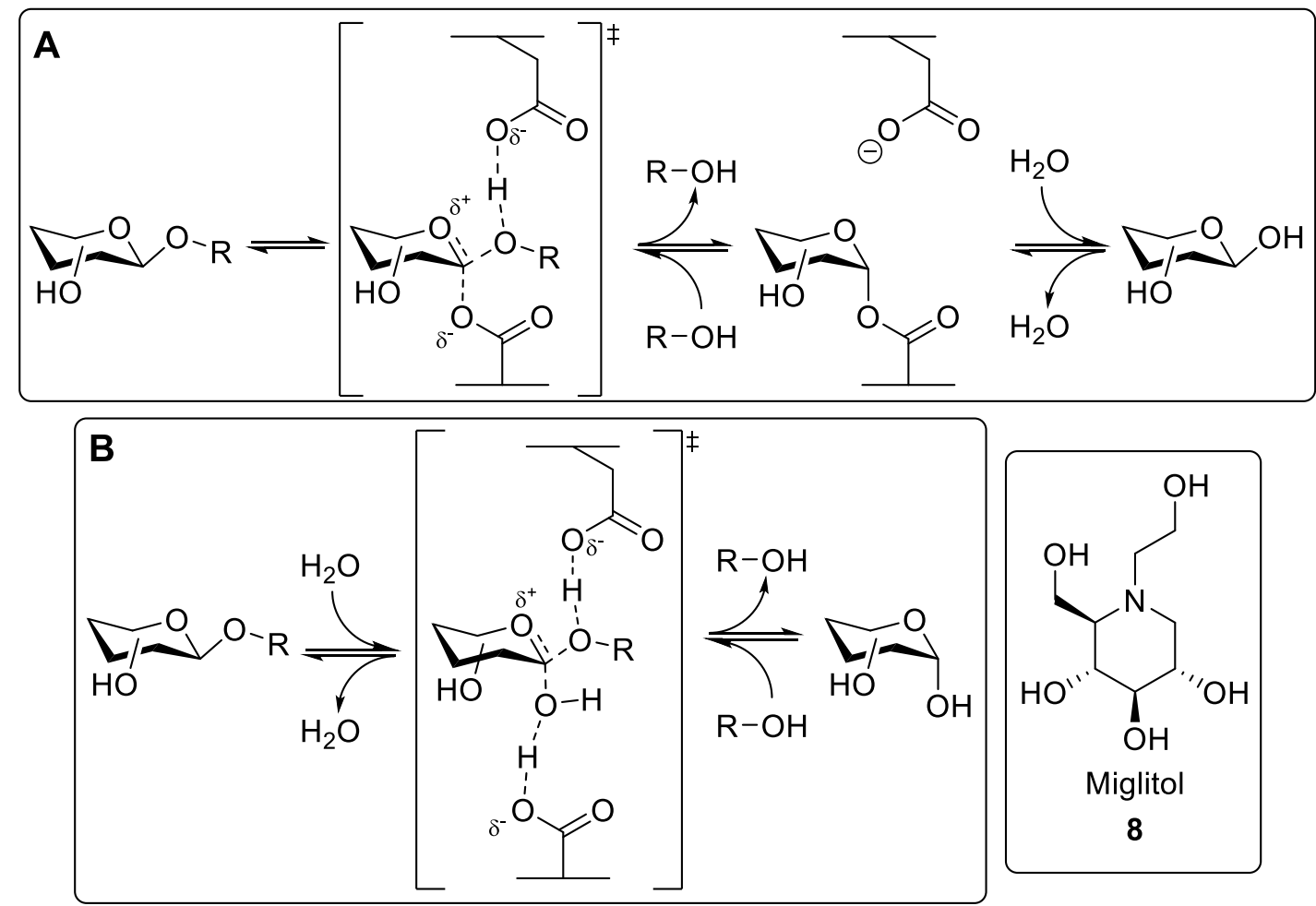

Scheme 1: The retaining (A) and inverting (B) mechanisms of glycoside hydrolase enzymes; Boxed: the diabetic drug miglitol (8).

At physiological $\mathrm{pH}$, the ring nitrogen present in an iminosugar is protonated, making iminosugars able to mimic the oxocarbenium transition state and thus reversibly bind to the active site of carbohydrate handling enzymes. As a result, iminosugars have found pharmacological application in the treatment of various diseases, including type II diabetes. In particular, Miglitol (8, Scheme 1) is a commercial drug that inhibits the glycosidases responsible for breaking down complex polysaccharides in the body. ${ }^{18}$ Miglitol (8) is able to selectively bind to alpha-glycosidases by closely mimicking the structure and stereochemistry of the oxocarbenium transition state of alphaglycosidases. ${ }^{19}$

Another commercially available iminosugar is $\operatorname{Miglustat}(\mathbf{9}$, Scheme 2), which is used to treat Gaucher disease. ${ }^{20}$ Gaucher disease is an inherited lysosomal storage disorder where glucosylceramide (GlcCer, 12) accumulates within the lysosomes of cells and certain organs. ${ }^{21,22}$ Normally, GlcCer is generated by the glucosylceramidase synthase (GCS) catalysed condensation of UDP-glucose (10) with ceramide (11), where glucocerebrosidase 1 (GBA1) prevents accumulation of GlcCer and allows recycling of 
ceramide and glucose. ${ }^{23}$ The accumulation of GlcCer occurs when GBA1 is either in low abundance or shows abnormal catalytic abilities. ${ }^{21,22}$
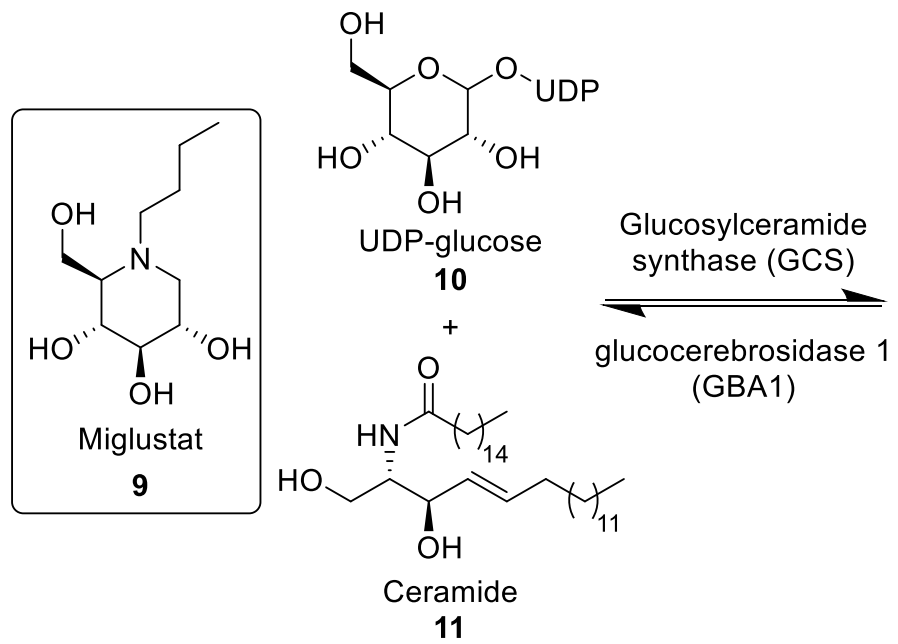

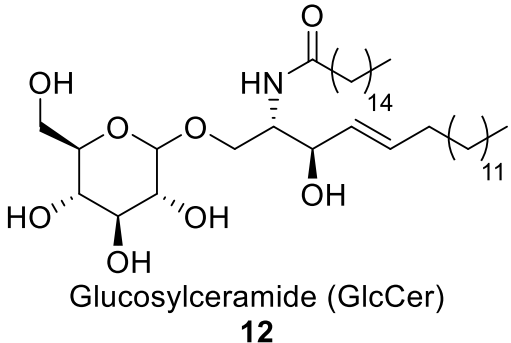

12

Scheme 2: Simplified biosynthesis and bio-decomposition of glucosylceramide; Boxed: glucosylceramidase synthase inhibitor Miglustat (9).

Miglustat can be used to treat Gaucher disease through substrate reduction therapy (SRT, Figure 2A) by reversibly binding to GCS, thus reducing the biosynthesis and resulting accumulation of GlcCer (12). ${ }^{24,25}$ While Miglustat was approved by the Food and Drug Administration and European Medicines Agency in 2003 for SRT of Gaucher disease, ${ }^{26}$ Miglustat has also been investigated as a pharmacological chaperone for chaperone mediated therapy (CMT) of Gaucher disease. ${ }^{27}$ Most simply, a pharmacological chaperone is a compound that reversibly binds to a specific enzyme, usually at the active site, stabilising the enzyme or re-shaping the active site. In this way, a pharmacological chaperone may assist in protein folding, reshaping a deformed protein, or help stabilise a protein to minimalise normal degradation processes during transport. ${ }^{28}$ The restoration of GBA1 activity through CMT restores the equilibrium between biosynthesis and degradation of GlcCer, thus normalising GlcCer concentrations. 


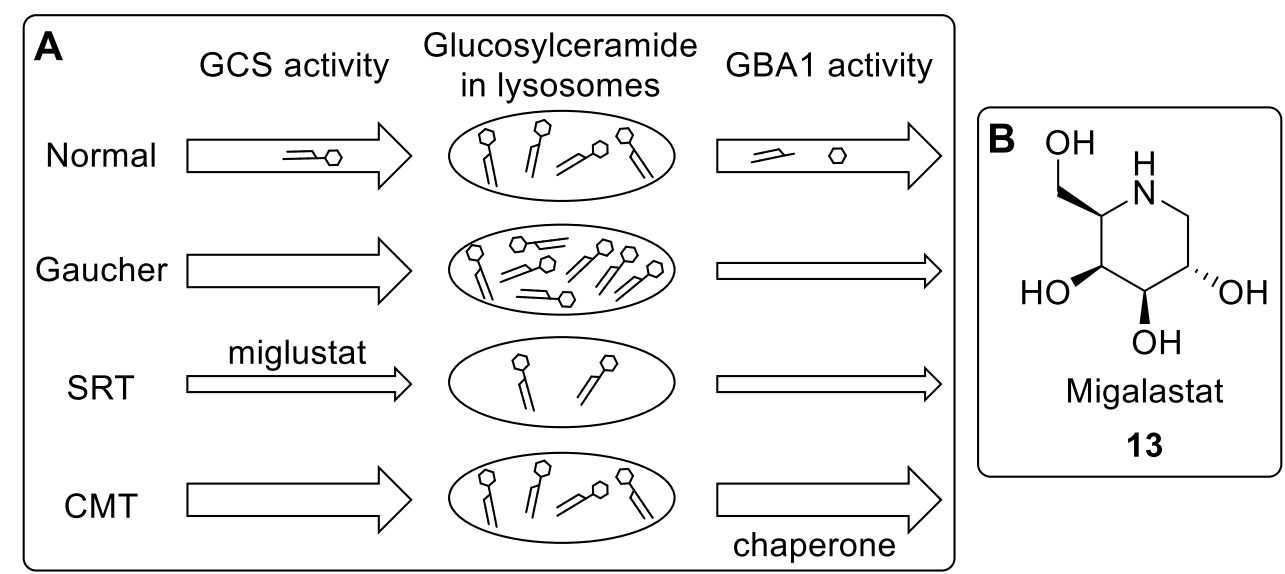

Figure 2: A) Schematic representation comparing normal GlcCer biosynthesis with that observed in Gaucher disease patients and those undergoing substrate reduction therapy (SRT) and chaperone mediated therapy (CMT); B) Pharmacological chaperone migalastat (13) used to treat Fabry disease.

Similarly, the galacto-configured Migalastat (or DGJ, 13, Figure 2B) is used for CMT of Fabry disease. ${ }^{29}$ Migalastat reversibly binds to $\alpha$-galactosidase, the enzyme lacking in patients with Fabry disease that leads to the undesired accumulation of globotriaosylceramide. ${ }^{30}$ Iminosugars are also under investigation for SRT and CMT of other lysosomal storage diseases such as Tay-Sachs, Sandhoff, Niemann-Pick, and pompe diseases. $^{31-33}$

In addition to their ability to bind to carbohydrate-active enzymes associated with lysosomal storage diseases, iminosugars have also shown promise in the treatment of viral infections such as HIV,${ }^{34,}{ }^{35}$ hepatitis $\mathrm{C},{ }^{36}$ herpes,${ }^{37}$ dengue virus, ${ }^{38}$ Japanese encephalitis virus, ${ }^{39}$ and influenza viruses. ${ }^{40}$ In this context, the ability of certain gluco- and galactoconfigured iminosugars (e.g. Miglustat (9), Migalastat (13), and the DNJ derivatives 1417, Figure 3) to treat viral infections stems from their ability to competitively bind to endoplasmic reticulum (ER) $\alpha$-glucosidases, which disrupts normal protein folding processes that may lead to retention or degradation of these enzymes. ${ }^{41}$ During infection and replication, a virus manipulates host cell processes for protein synthesis. In this way, infected cells use natural protein synthesis pathways more than a healthy cell, meaning partial inhibition of ER- $\alpha$-glucosidases disrupts assisted protein folding enough to selectively inhibit or kill infected cells. Unlike more common viral-directed treatments such as vaccines, iminosugar treatment is host directed and thus thought to be less susceptible to viral resistance. ${ }^{42}$ Note that the key challenge in applying imunisuagrs toward the treatment of viral infection is the various side-effecs of iminosugars (e.g. 
inhibition of gastrointestinal tract glycosidases), requiring the development of either more selecetive or potent (lower dose) inhibitors. ${ }^{43}$

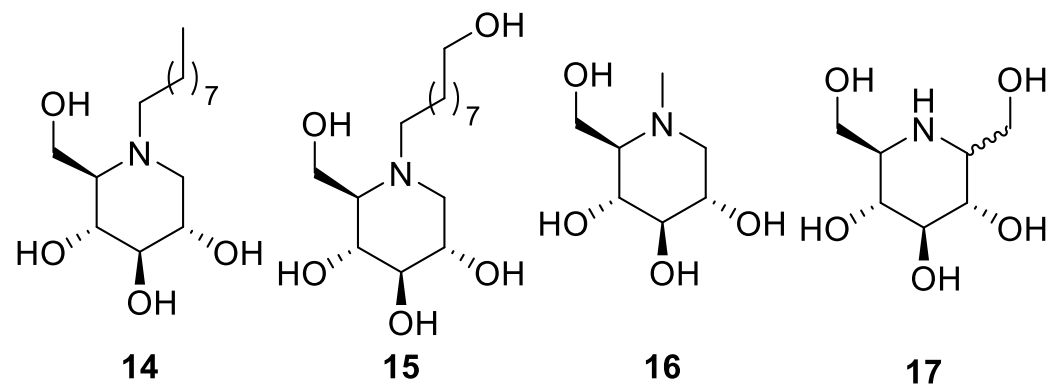

Figure 3: Iminosugars under investigation as potential anti-viral agents.

\subsection{Syntheses of iminosugars}

The low natural abundance and growing pharmacological applications of iminosugars has led to this class of compounds remaining a relevant and interesting target for synthetic chemists. As such, there is a large body of work retaining to the synthesis of iminosugars, of which the reader is directed to the relevant reviews. ${ }^{44-47}$ To give context to the work described within this thesis, specific examples are explored below that show the possible strategies used to synthesise iminosugars from simple carbohydrates, specifically with and without the use of protecting groups.

\subsubsection{Syntheses using Protecting groups}

The use of protecting groups (PG) is ubiquitous in carbohydrate chemistry. The commonality of PG arises from the numerous hydroxyls present in native carbohydrates, making regio- and chemo-selectivity difficult to achieve. The use of PG has not only advanced carbohydrate chemistry, but also facilitated the initial syntheses of iminosugars. Despite that use of PG increases the number of steps for a synthesis (from instalment and subsequent removal), there are a number of synthetic routes that, through the use of PG, have allowed for the efficient syntheses of several classes of iminosugars.

The first example discussed here, reported by Behr and Guillerm in 2007, achieved $\mathrm{N}$ cyclisation though a double substitution (Scheme 1). ${ }^{48}$ The synthesis began with the Fischer glycosidation of L-xylose (18) with methanol, followed by benzylation and anomeric deprotection to give the protected glycoside 19. Grignard addition and mesylation of the protected glycoside 19 then gave the di-mesylate 20. Dihydroxylation, 
which resulted in the formation of the diastereomers $\mathbf{2 1}$, followed by isopropylidene protection then gave the protected mesylates $22 \mathbf{a}$ and $\mathbf{2 2 b}$ in a 60:40 ratio, respectively, which were separated by silica gel flash column chromatography. The protected mesylate 22b was treated with $\mathrm{BnNH}_{2}$ and globally deprotected to give homoDMDP (23) in a $1.4 \%$ overall yield (9 steps). Similarly, the protected mesylate 22a was treated to $\mathrm{BnNH}_{2}$, which after isopropylidene deprotection gave the protected iminosugar 24. Oxidative cleavage reduction, and global deprotection of the vinyl diol of the iminosugar 24 was then performed to give DMDP (4) in 1.4\% overall yield (11 steps). It was noted that for both 22a and 22b, like other di-mesylates used in $N$-cyclisation, high temperatures and long reaction times were required to obtain high yields.

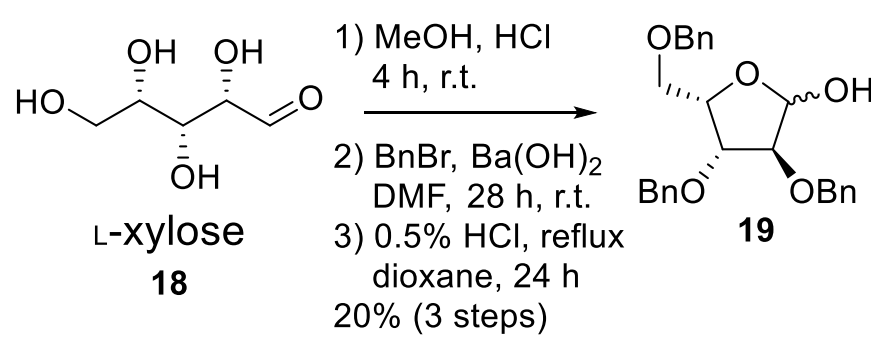

1) vinylMgBr<smiles>CCN(C)C(=O)OC[C@H](OC)[C@@H](OCc1ccccc1)[C@H](OC)OCc1ccccc1</smiles>

DCM

$53 \%$ (2 steps) $\quad \mathrm{OsO}_{4}, \mathrm{NMO}$ acetone $/ \mathrm{H}_{2} \mathrm{O}$ $80 \%$

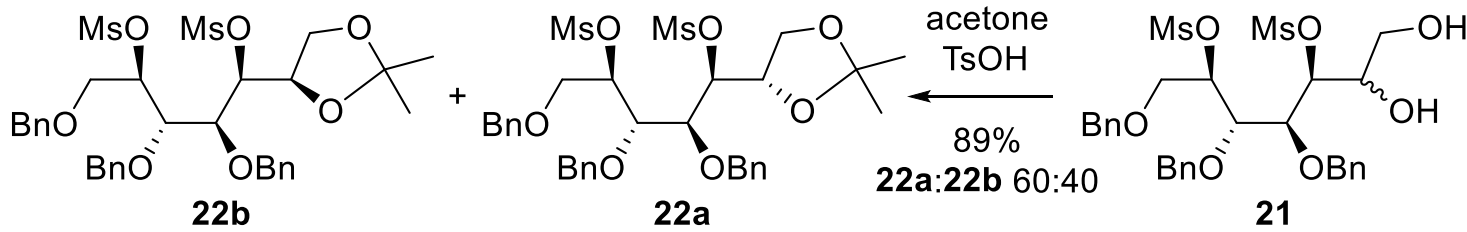

1) $\mathrm{BnNH}_{2}, 120{ }^{\circ} \mathrm{C}$

2) $80 \% \mathrm{HCOOH}$

\begin{tabular}{l|l}
$80 \% \mathrm{HCO} \mathrm{H}_{2}, \mathrm{Pd}(\mathrm{OH})_{2} / \mathrm{C}$ & 2) $5 \%$ TFA, DCM \\
$73 \%(2$ steps $)$
\end{tabular} $48 \%$ (2steps)<smiles>OC[C@H](O)[C@@H]1N[C@H](CO)[C@@H](O)[C@H]1O</smiles>

23

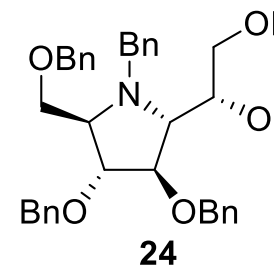

24
1) $\mathrm{BnNH}_{2}, 120^{\circ} \mathrm{C}$

$73 \%$ (2 steps)

Scheme 3: The Synthesis of DMDP (4) homoDMDP (23) by Behr and Guillerm utilising a double substitution for $\mathrm{N}$ - cyclisation.

Fleet et al. has elegantly exemplified the strategy of instaling an amine functionality suitable to undergo $\mathrm{N}$-cyclisation via reductive amination in his synthesis of L-DGJ (Scheme 4). ${ }^{49}$ The synthesis began with the isopropylidine protection of D-tagatose (25) to form the protected glycoside 26, followed by triflation (giving 27) and azide 
substitution to give the protected azide 28. Following acid-mediated deprotection, the azide in 29 is then reduced using $\mathrm{Pd} / \mathrm{C}$, with the resultant amine undergoing immediate cyclisation via intramolecular reductive amination to give L-DGJ (30) over 5 steps and in $85 \%$ overall yield. Note that this synthetic strategy led to the original synthesis of iminosugars by Jones, ${ }^{1,2}$ Paulsen, ${ }^{3}$ and Hanessian, ${ }^{4}$ and was also used in the first synthesis of DMDP by Card and Hitz in $1985 .^{50}$<smiles>O=C(CO)[C@@H](O)[C@@H](O)[C@H](O)CO</smiles>

25

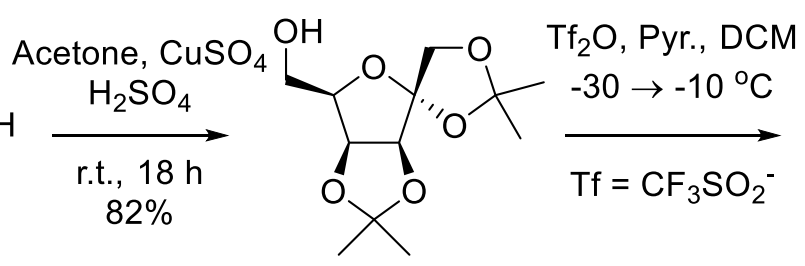

26

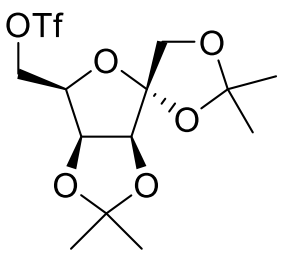

27<smiles>OC[C@H]1NC[C@@H](O)[C@H](O)[C@@H]1O</smiles>

30
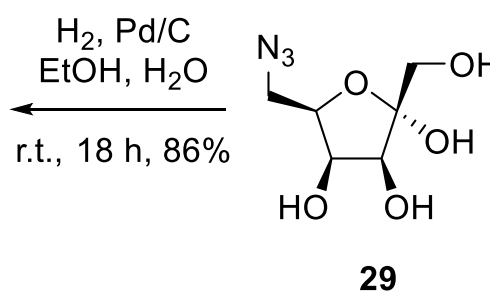

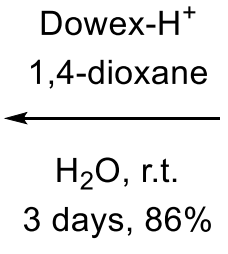

3 days, $86 \%$

29

Scheme 4: Fleet's synthesis of L-DGJ (30) utilising an intralocular reductive amination during $N$-cyclisation.

Racine and co-workers used the ketone of D-fructose (31) to form an imine that, in the presence of a good leaving group, facilitates $N$-cyclisation (Scheme 5) ${ }^{51}$ In the first step of this strategy, D-fructose (31) is cyclised under Fischer glycosidation conditions in the presence of allylic alcohol to give the pyranose 32. Subsequent global benzylation and acid-mediated anomeric deprotection then gave the protected ketone 33. Imine formation via the treatment of ketone $\mathbf{3 3}$ with $O$-tert-butyldiphenylsilylhydroxylamine $\left(\mathrm{TBDPSONH}_{2}\right)$ in the presence of pyridinium paratoluenesulfonate (PPTS) followed by mesylation resulted in the formation of the protected imine 34. Tetra- $n$-butylammonium fluoride (TBAF)-mediated deprotection of the silyl group then facilitated $N$-cyclisation to give the oxy-imine 35, which after deprotection under reducing conditions, gave DMJ (36) in $8.4 \%$ overall yield (8 steps). 
<smiles>C=CCOC1(O)OC[C@@H](O)[C@H](O)C1(O)O</smiles>

1) $\mathrm{NaH}, \mathrm{BnBr}$

THF:DMF 1:3

$n-\mathrm{Bu}_{4} \mathrm{NI}$ cat.

$0{ }^{\circ} \mathrm{C} \rightarrow$ r.t. $20 \mathrm{~h}, 93 \%$

2) $2 \mathrm{~N} \mathrm{aq.} \mathrm{HCl}$ dioxane, $85^{\circ} \mathrm{C}$ 16 h, $96 \%$<smiles>O[C@H]1CO[C@@H](O)[C@@H](OCc2ccccc2)[C@@H]1OCc1ccccc1</smiles>

33

1) $\mathrm{TBDPSONH}_{2}$ PPTS cat. $12 \mathrm{~h}$ toluene, reflux

2) $\mathrm{Et}_{3} \mathrm{~N}, \mathrm{MsCl}$, DCM, $19 \mathrm{~h}$ $0^{\circ} \mathrm{C} \rightarrow$ r.t. $84 \%$ (2 steps)<smiles>OC[C@H]1NC[C@H](O)[C@H](O)[C@@H]1O</smiles>

1) $\mathrm{H}_{2}, \mathrm{Pd} / \mathrm{C}$ $\mathrm{MeOH}, \mathrm{HCl}$ $13 \mathrm{~h}$

2) Dowex- $\mathrm{H}^{+} \mathrm{BnO}$ $83 \%$ (2 steps)<smiles>[O-][N+]1=C(COCc2ccccc2)[C@@H](O)[C@@H](OCc2ccccc2)[C@H](Br)C1</smiles>

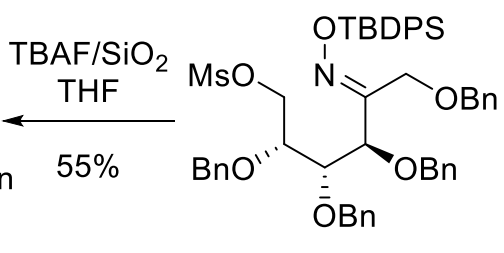

34

Scheme 5: DMJ (36) synthesis via imine facilitated $\mathrm{N}$-cyclisation as reported by Racine.

$N$-cyclisation via reductive amination can also be achieved through the reaction of dicarbonyl derivatives. A recent example by Matassini et al. ${ }^{52}$ (Scheme 6) demonstrates this with D-mannose (37) first undergoing isopropylidene and $O$-benzyl protection to form the protected furan 38. Selective deprotection and oxidative cleavage then gives the protected aldehyde 39. Subsequent imine formation, followed by primary imine reduction, double benzyl deprotection, and intramolecular reductive amination in the presence of $\mathrm{Pd}(\mathrm{OH})_{2} / \mathrm{C}$ and $\mathrm{H}_{2}$ gave the protected iminosugar 40. Finally, acid-catalysed deprotection of $\mathbf{4 0}$ gave 3,4,5-trihydroxypiperidine $\mathbf{4 1}$ over 7 steps and in 53\% overall yield. Matassini et al. then went on to demonstrate the scope of such a double reductive amination strategy, however, it is worth noting that the orthogonality of the protecting groups quickly became an issue during synthesis of derivitives, where several additional steps were required. 


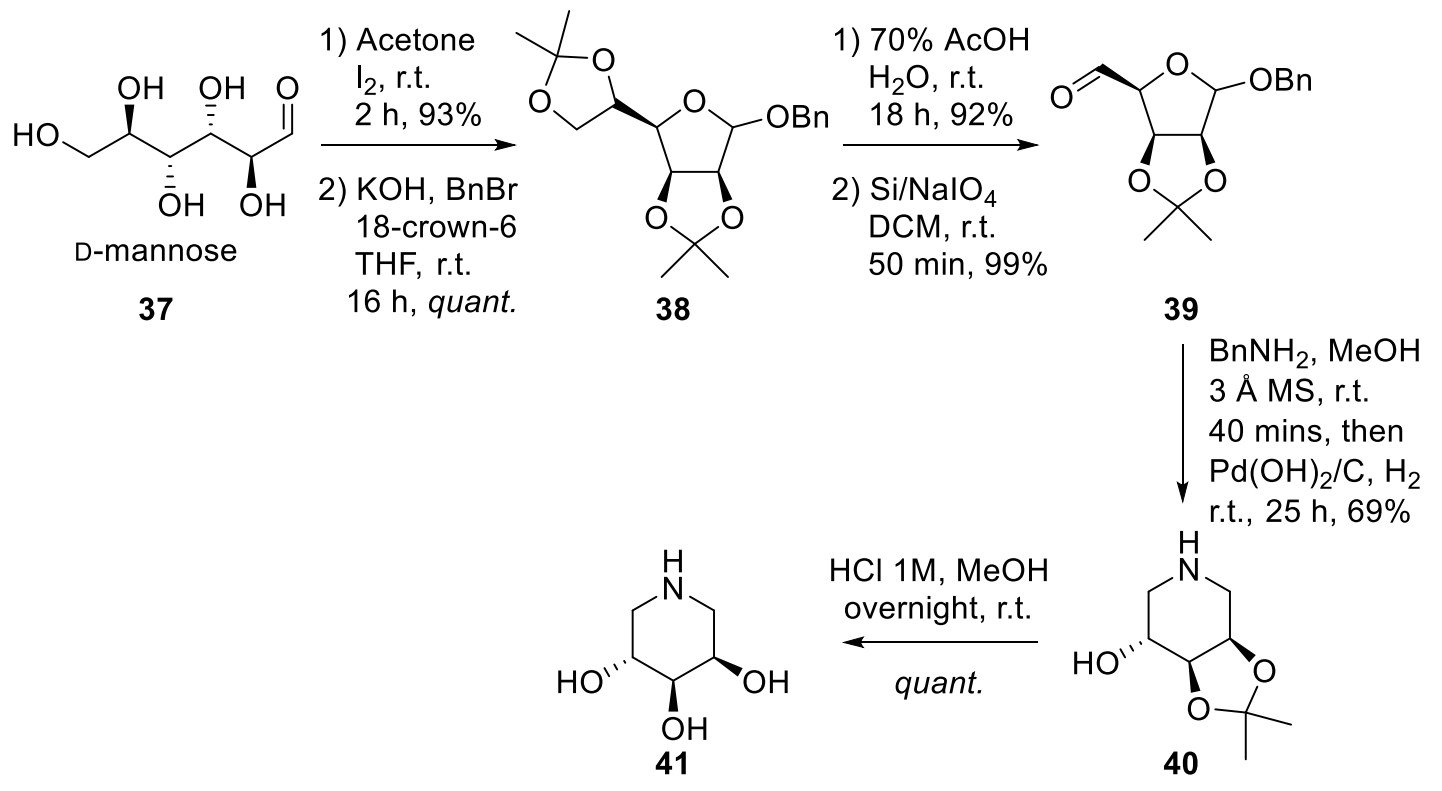

Scheme 6: The synthesis of 3,4,5-trihydroxypiperidine 41 utilising a double reductive amination by Matassini et al.

\subsubsection{Protecting group free synthesis of iminosugars}

Initially, the use of PG was essential in organic syntheses, however, PG manipulations remain a significant portion of many synthetic strategies. In developing the PGF synthesis of known and novel iminosugars, it is possible to simultaneously reduce synthetic steps and increase overall yields. ${ }^{53,54}$ This in turn makes a synthetic route more efficient, impacting factors such as atom economy and financial costs. Increased efficiency makes the synthesis of a compound more economical, something of vital importance to industry. ${ }^{55}$ While developing protecting group free (PGF) syntheses is a significant challenge, there are some elegant examples described below that showcase the preparation of iminosugars using minimal or no protecting groups.

The use of enzymes in chemical synthesis is an area of research that has seen much growth over recent years because enzymatic reactions display excellent chemo- and stereoselectivity on minimally or unprotected substrates. Through careful enzyme selection, the synthesis of iminosugars such as DNJ and its $\mathrm{N}$-alkylated derivatives can be realised on large scales. For example, the patent by Clapes Saborit et al. describes the use of a known enzymatic aldol addition ${ }^{56}$ in the large-scale synthesis of a variety of iminosugars and $\mathrm{N}$ functionalised derivatives. ${ }^{57}$ Clapes Saborit's method was exemplified by the total synthesis of fagomine (45) shown in Scheme 7. Beginning with 3-amino-pran-1-ol (42), 
the amine of $\mathbf{4 2}$ is carboxybenzyl $(\mathrm{CBz})$ protected and the remaining alcohol oxidised to give the aminoaldehyde 43. Next, D-fructose-6-phosphate aldolase (FSA) catalysed the aldol addition of dihydroxyacetone to give the ketone $44 .{ }^{58}$ After Pd-catalysed deprotection and subsequent reductive amination, fagomine (45) was obtained in $42 \%$ overall yield (4 steps), with the stereochemistry of the secondary hydroxyls of $\mathbf{4 4}$ determined by the enzyme.

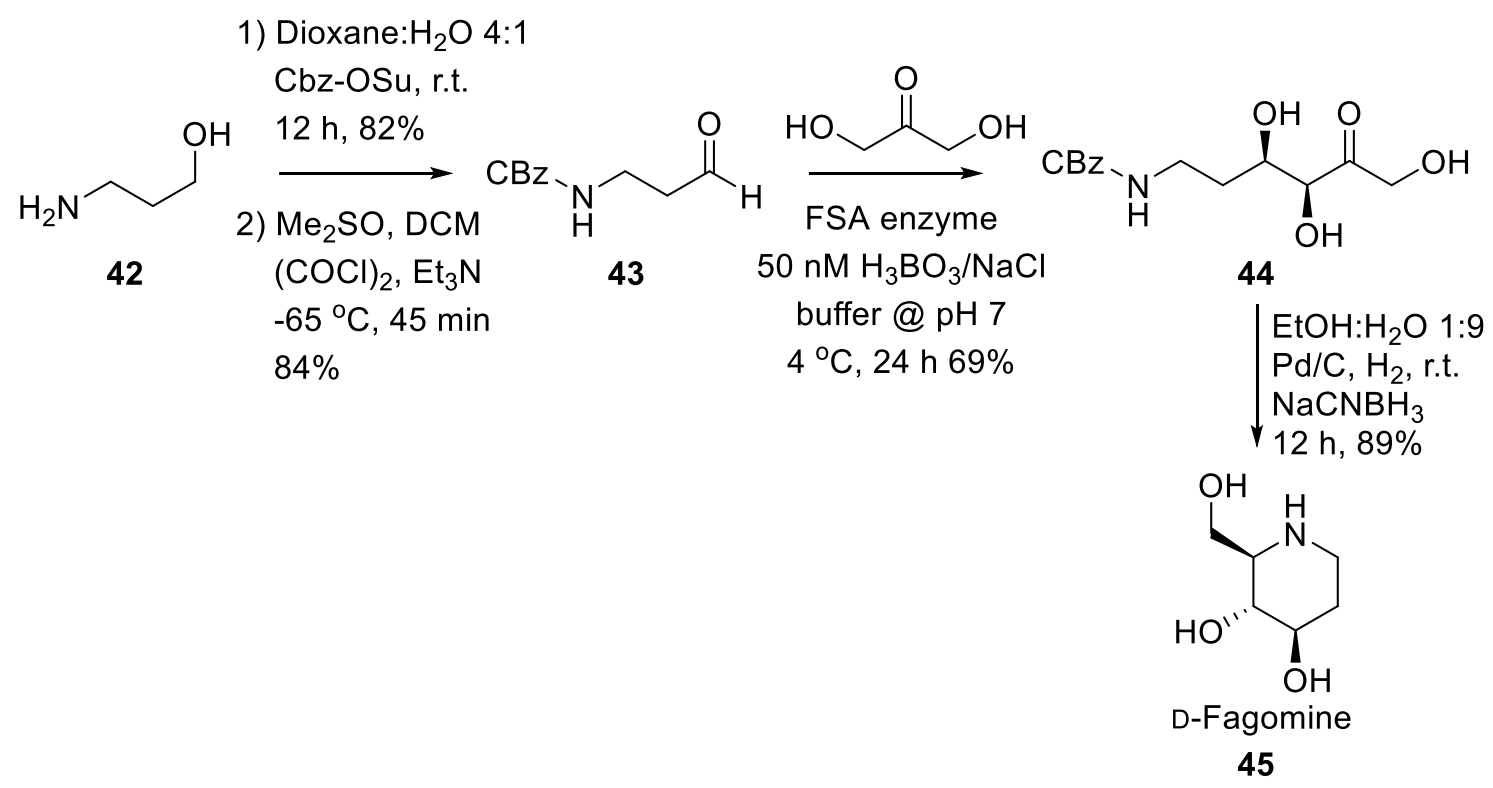

Scheme 7: The synthesis of D-fagomine (45) utilising an enzymatically driven aldol addition.

The efficiency of enzymatic syntheses is further demonstrated in the patent of Sethi et al. utilising the selective 5-hydroxy oxidation of various readily avaliable 1-amino-gluitols (46, Scheme 8). ${ }^{59}$ Here, a 1-amino-gluitol, made in one step from D-glucose via a simple reductive amination, is selectively oxidised by gluconobacter roseus in an acidic $\mathrm{NaH}_{2} \mathrm{PO}_{3}$ buffer at room temperature for 48 hours to give the respective iminosugar in quantitative yields. 
<smiles>[R]NCC(O)[C@H](O)[C@@H](O)[C@H](O)CO</smiles>

46
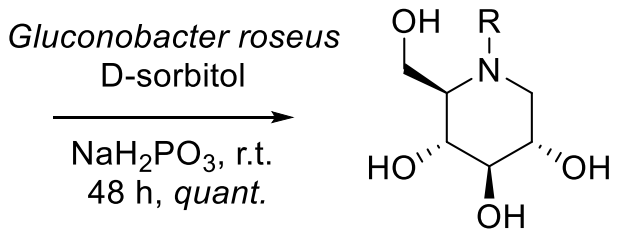

$$
\begin{aligned}
\mathrm{R} & =\mathrm{H}=\mathrm{DNJ}(\mathbf{3}) \\
& =\mathrm{CH}_{2} \mathrm{CH}_{2} \mathrm{OH}=\text { Miglitol (8) } \\
& =n-\mathrm{Bu}=\text { Miglustat (9) }
\end{aligned}
$$

Scheme 8: Enzyme catalysed oxidation and subsequent cyclisation via reductive amination of 1-amino-gluitols 46.

Similarly, the galacto-configured azepane 49 was efficiently synthesised using galactose oxidase catalase in studies by Andreana et al. (Scheme 9). ${ }^{60}$ Readily available $O$-benzypyrano-D-galactose (47) was chemoselectively oxidised by galactose oxidase catalase at the 6-position to give aldehyde 48. After deprotection and sequential reductive amination in the presence of $\mathrm{HO}-\mathrm{NH}_{2}, \mathrm{H}_{2}$, and $\mathrm{Pd}(\mathrm{OH})_{2}$, the azepane 49 was formed in $98 \%$ yield. While a powerful synthetic strategy, galactose oxidase catalase, however, is limited to carbohydrates and analogues that have galacto-stereochemistry.

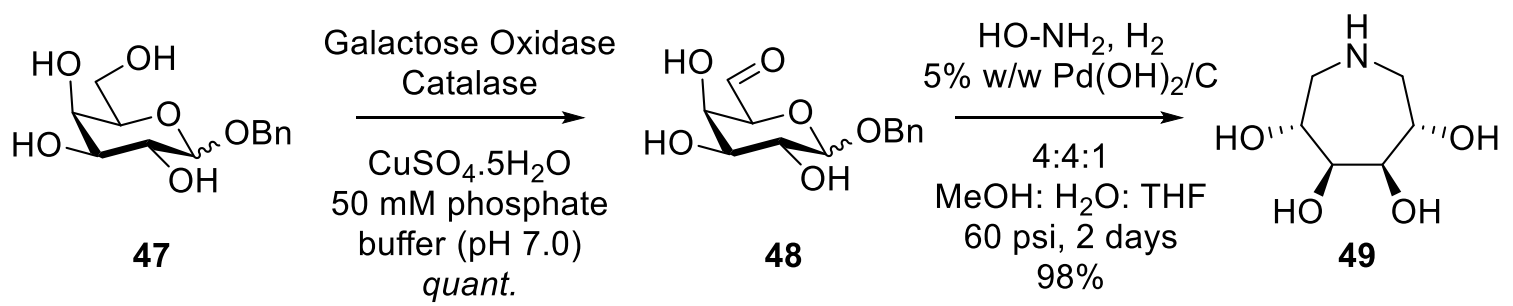

Scheme 9: Azepane synthesis via chemoselective enzymatic oxidation and subsequent reductive amination by Andreana et al.

Enzyme mediated synthesis is efficient, selective, and can often lead to a very short total synthesis. However, enzymes are often very specific and the use of starting materials that differ in functionality or chirality can impede the enzymatic reaction. Additionally, enzymes are not always cheap or readily accessible outside of industry. As a result, the need for alternative efficient syntheses of iminosugars remains.

In 2005, Lindstrom et al. reported on a PGF synthesis of 2-(1,2-dihydroxyethyl)-3,4pyrrolidinediol 53 by utilising two consecutive substitution reactions (Scheme 10). ${ }^{61}$ In this work, the starting material, dibromo alkene 50, was subjected to a Sharpless 
asymmetric dihydroxylation followed by hydrolysis to give the triol $\mathbf{5 1}$ in high yields and with excellent (97\%) enantiomeric excess (ee). Subsequent asymmetric epoxidation using a peroxotungstate catalyst gave the epoxide 52, which underwent spontaneous ring closure in the presence of aqueous $\mathrm{NH}_{3}$ to give the iminosugar 53 in $60 \%$ overall yield (4 steps). Note that Lindstrom used ammonia as the nucleophilic source of amine, allowing the final compound to be formed without requiring deprotection.

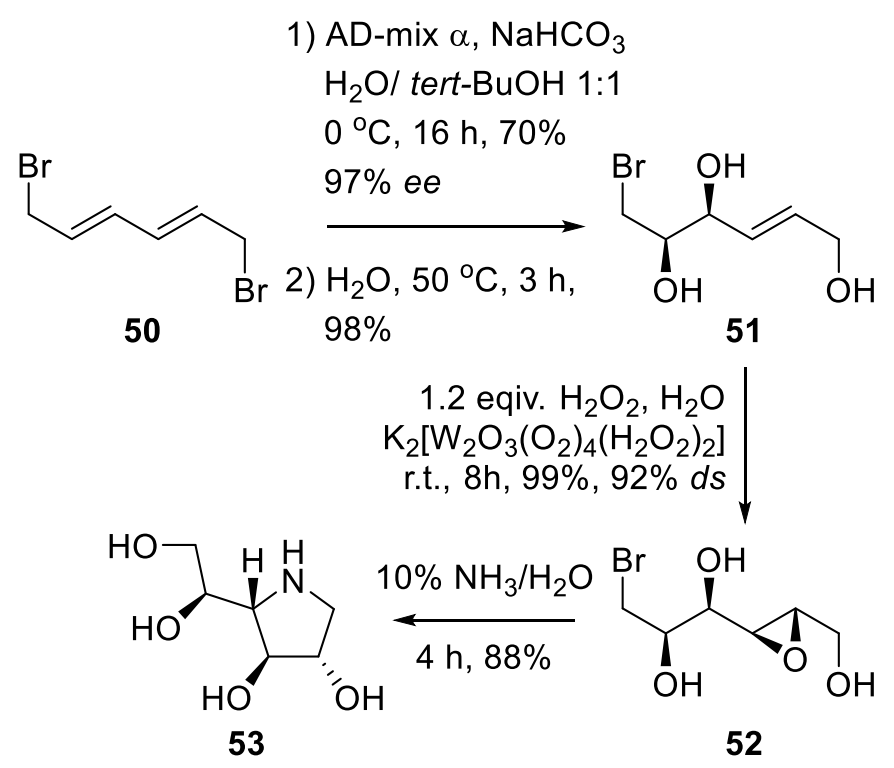

Scheme 10: The efficient PGF synthesis of 2-(1,2-dihydroxyethyl)-3,4-pyrrolidinediol 53, as reported by Lindstrom et al.

In 2009, the Stocker-Timmer group reported the first of several PGF syntheses of iminosugars utilising the novel Vasella-reductive-amination and carbamate annulation methodologies (Scheme 11). ${ }^{62}$ This synthesis began with the Fischer glycosidation and subsequent iodination of D-Xylose (54) to give the methyl iodoglycoside $\mathbf{5 5}$. The methyl iodoglycoside $\mathbf{5 5}$ was then subjected to Vasella-reductive-amination conditions to give alkenylamine 56, followed by $\mathrm{I}_{2}$-mediated carbamate annulation to give the carbamate $\mathbf{5 7}$ stereoselectively and in 90\% yield (two steps). Base hydrolysis then gave 1,4-dideoxy1,4-imino-D-xylitol (58) in 57\% yield over the 5 steps. 

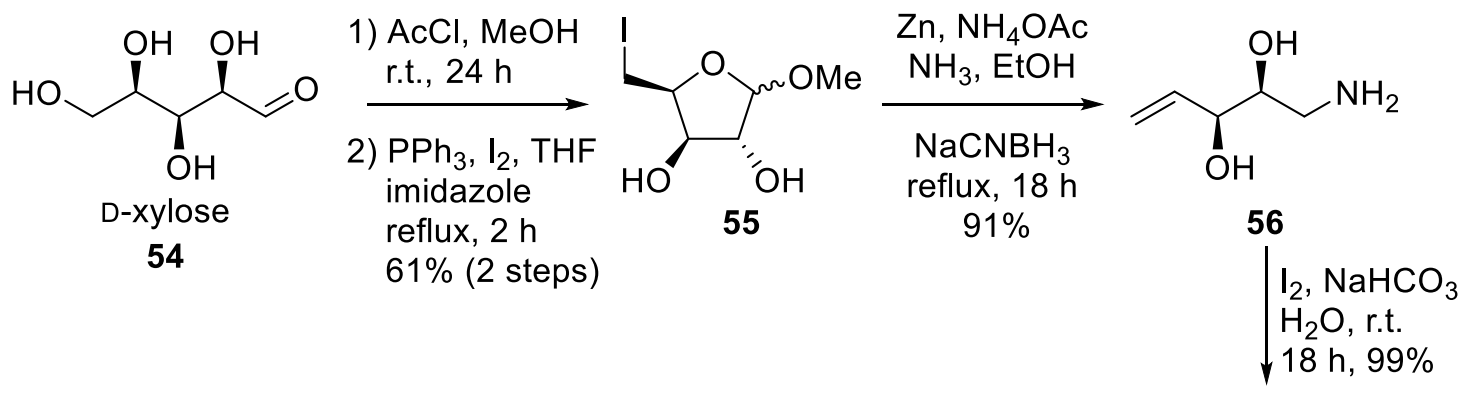

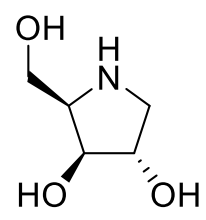

58
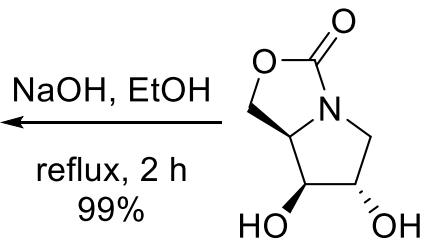

57

Scheme 11: The protecting group free synthesis of 1,4-dideoxy-1,4-imino-D-xylitol (58) as reported by the Stocker-Timmer group.

The synthetic strategy employing the Vasella-reductive-amination and carbamate annulation has been expanded to include the synthesis of piperidines. For example, synthesis of DGJ (13) began with the Fischer glycosidation of D-galactose (59), followed by selective iodination to give the methyl iodoglycoside 60 (Scheme 12) ${ }^{63}$ Subsequent Vasella-reductive-amination gave the alkenylamine 61, which after $\mathrm{I}_{2}$-mediated carbamate annulation gave a mixture of furan 62 and carbamates 63 and 64 in 1:1:3 ratio, respectively. From this reaction mixture the carbamate 63 was isolated via silica gel column chromatography, with the remaining mixture of furan 62 and carbamate 64 being further reacted as a mixture. Following hydrolysis, the desired product DGJ (13) was purified by silica gel flash chromatography, resulting in a $16 \%$ overall yield of this compound. 

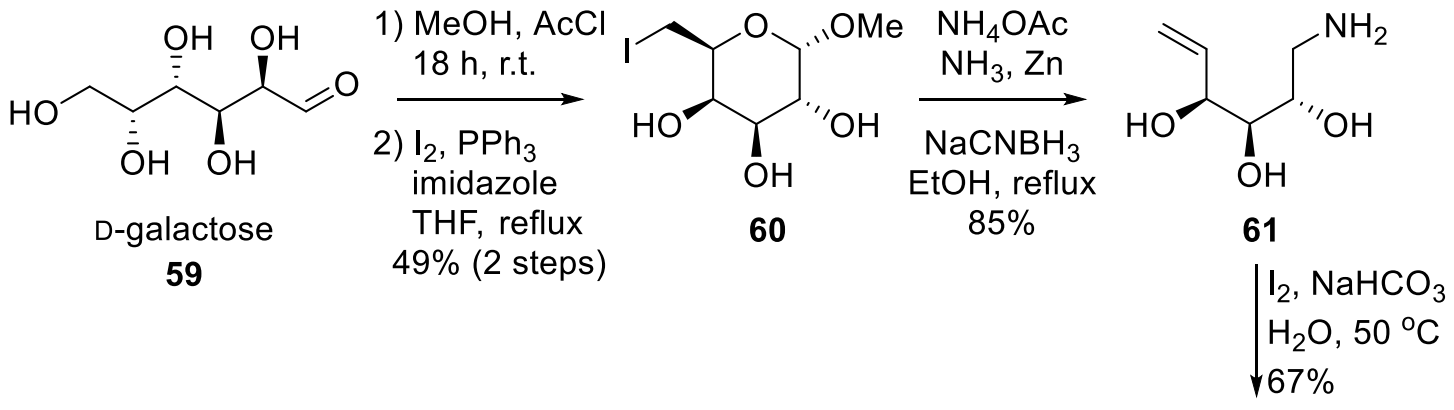<smiles>OC[C@H]1NC[C@@H](O)[C@H](O)[C@@H]1O</smiles>

DGJ

13

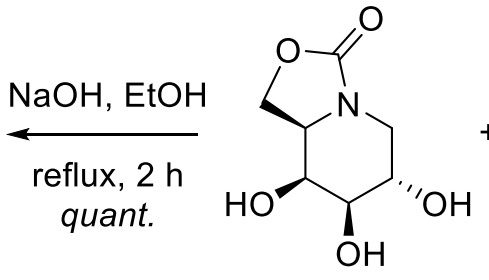

64<smiles>O=C1OC[C@@H]2[C@H](O)[C@H](O)[C@H](O)CN12</smiles>

63<smiles>O=C1NC[C@@H]2COC[C@@H](O2)[C@@H](O)[C@@H]1O</smiles>

62

$3: 1: 1$

Scheme 12: Piperidine synthesis utilising the novel methodologies developed by the Stockter-Timmer group.

Unlike in the synthesis of pyrrolidines, the carbamate annulation of alkenylamine $\mathbf{6 1}$ was not stereoselective, with both possible stereoisomers 63 and 64 forming together with byproduct 62. Whilst the formation of the 4,5-cis carbamate $\mathbf{6 4}$ forms preferentially in a 3:1 ratio with carbamate 63 (respectively), minimalising O-cyclisation was desired. Selectivity for $N$-cyclisation over $O$-cyclisation was achieved by increasing the reaction temperature to $50{ }^{\circ} \mathrm{C}$ and iodine concentration, raising the ratio of 62:63:64 from 3:1:3 to 1:1:3 (respectively). This decrease in selectivity was later observed in a similar synthesis by Corkran, with multiple products forming during carbamate annulation. ${ }^{64}$ However, formation of the desired carbamates was favoured only when higher equivalents of iodine was present, with increased temperature favouring by-product formation.

\subsubsection{The Vasella-Reductive-Amination}

When developing the PGF Vasella-reductive-amination protocol, a key challenge was preventing the undesired dimerisation of the product amine with the in situ formed aldehyde (Scheme 13). In a specific example, the Vasella-reductive-amination reaction pathway begins with zinc-mediated Vasella ring opening of the methyl iodoglycoside 55, followed by the reductive amination of the resulting aldehyde (65) using aqueous $\mathrm{NH}_{3}$ to 
generate the desired alkenylamine 56. However, undesired dimerisation occurs when the aldehyde $\mathbf{6 5}$ undergoes reductive amination with the newly formed alkenylamine $\mathbf{5 6}$ to give the dimer 66. This dimerisation occurs because the primary amine of alkenylamine 56 is more nucleophilic than $\mathrm{NH}_{3}$. Whilst it was initially observed that the use of excess $\mathrm{AcONH}_{4}$ salt gave reasonable yields of desired alkenylamine 56 with dimer $\mathbf{6 6}$ (1:1 ratio), it was the use of both excess aq. $\mathrm{NH}_{3}$ (60 equiv.) and $\mathrm{AcONH}_{4}$ (sat.) that gave a 20:1 selective formation of alkenly amine $\mathbf{5 0}$ to dimer $\mathbf{6 1}$ (respectively) in $96 \%$ yield. During optimisation it was deduced that the combination of excess $\mathrm{NH}_{3}$ and the correct balance between free and protonated $\mathrm{NH}_{3}$ was essential to the optimisation of this reaction, with the use of excess aq. $\mathrm{NH}_{3}$ (60 equiv.) giving the ratio of protonated to deprotonated $\mathrm{NH}_{3}$ required. ${ }^{62}$<smiles>CO[C@H]1O[C@H](CI)[C@@H](O)[C@H]1O</smiles>

55

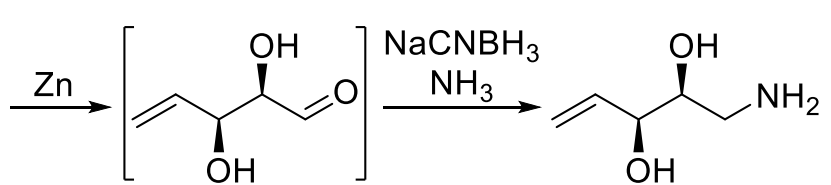

65

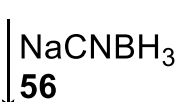<smiles>C=C[C@H](O)[C@@H](O)CNC[C@H](O)[C@H](O)C=C</smiles>

66

Scheme 13: Vasella-reductive amination of 55 to give desired alkenylamine 56 and undesired dimer 66.

\subsubsection{The Carbamate Annulation}

To date, all alkenylamines containing a primary amine undergo a carbamate annulation favouring the formation of pyrrolidines with the corresponding 3,4-cis stereochemistry. ${ }^{65-}$ ${ }^{70}$ Similarly, 4,5-cis stereochemistry is favoured in piperidine synthesis, however the annulation is not stereoselective. ${ }^{63,64}$ In the case of pyrrolidine formation beginning from the alkenylamine 67, the carbamate annulation is postulated to proceed through an $\mathrm{I}_{2}-$ alkene complex, followed by intramolecular nucleophilic attack passing through a 5membered ring transition state to form the iminoiodide intermediate 68 (Scheme 14). 
Following this, intermediate $\mathbf{6 8}$ undergoes carbamate formation either by iodide displacement to form carbonate $\mathbf{6 9}$ or through amine attack of $\mathrm{CO}_{2}$ to form carbamide $\mathbf{7 0}$, where it remains unclear which path dominates to ultimately give carbamate $\mathbf{7 1} .^{68}$

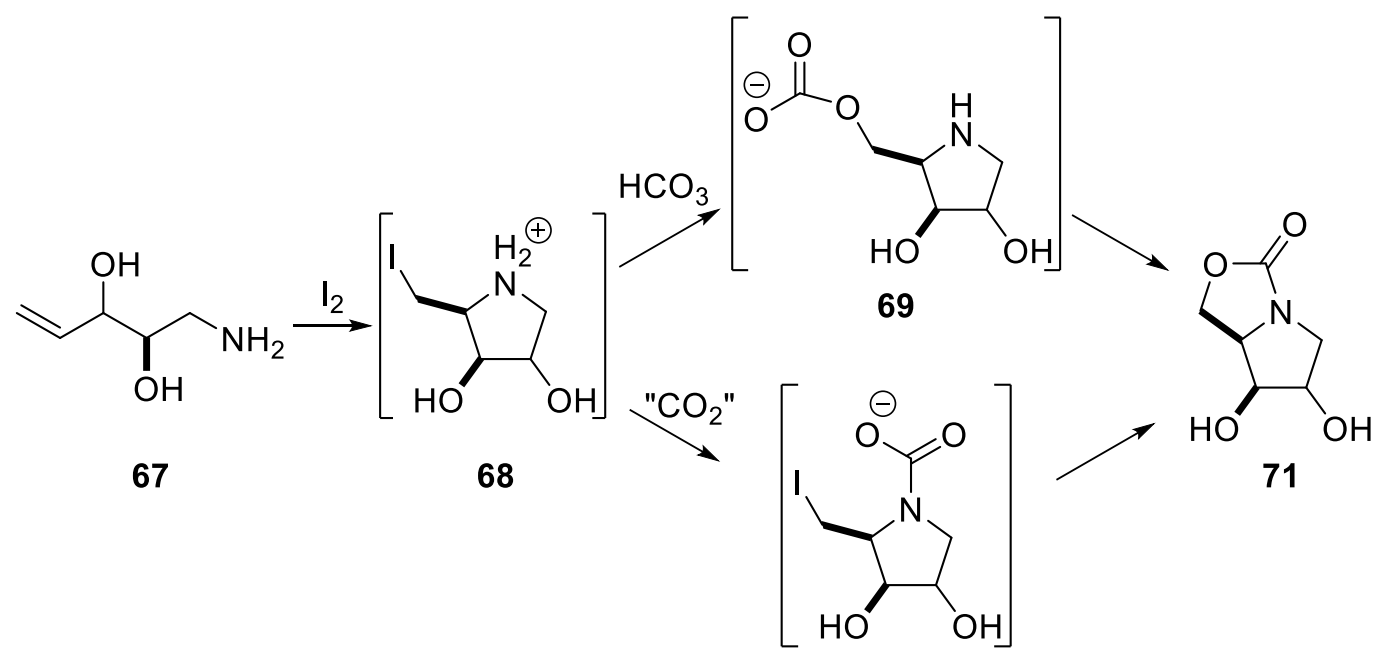

70

Scheme 14: The proposed reaction pathways of the carbamate annulation of alkenylamine 67.

The selective formation of the 3,4-cis configuration in carbamate $\mathbf{7 1}$ is rationalised through the possible orbital overlap between the alkene $\pi_{\mathrm{C}=\mathrm{C}}$ orbitals and the neighbouring electron-withdrawing $\sigma^{*} \mathrm{C}-\mathrm{O}$ orbital during formation of intermediate $\mathbf{6 8}$, illustrated in Figure $4 .^{70}$ During cyclisation two possible conformations are possible, with the 3 hydroxyl being either in-plane (A) or perpendicular (B) to the neighbouring alkene undergoing nucleophilic attack. Conformation $\mathbf{A}$, with the 3-hydroxyl in the plane of the alkene, minimalises the unfavourable overlap between the alkene $\pi_{\mathrm{C}=\mathrm{C}}$ and $\sigma^{*} \mathrm{C}-\mathrm{O}$ orbitals. Conversely, conformation $\mathbf{B}$ has the Hydrogen in-plane with the alkene, causing $\pi_{\mathrm{C}=\mathrm{C}}$ and $\sigma^{*} \mathrm{C}-\mathrm{O}$ orbital overlap. This $\pi_{\mathrm{C}=\mathrm{C}}$ and $\sigma^{*} \mathrm{C}-\mathrm{O}$ orbital overlap deactivates the alkene though weak delocalisation of the $\pi_{\mathrm{C}=\mathrm{C}}$ electrons to the $\sigma^{*}{ }_{\mathrm{C}-\mathrm{O}}$ orbital, thus increasing the activation energy for the formation of the $\mathrm{I}_{2}$-alkene complex, favouring the $\mathrm{O}$-in-plane pathway which leads to the observed stereoselectivity during carbamate annulation. ${ }^{67,68}$ 


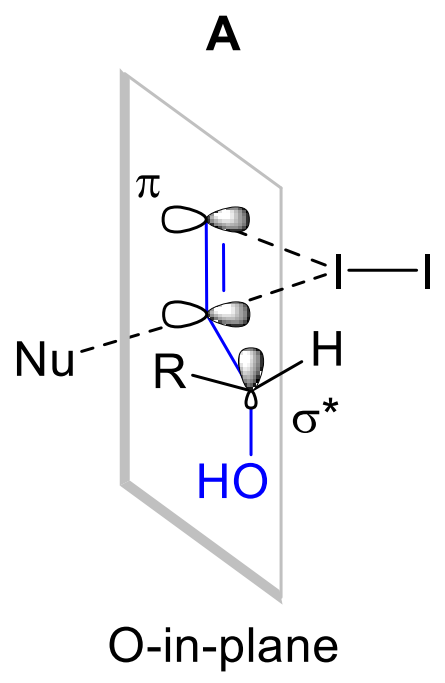

Favoured
B

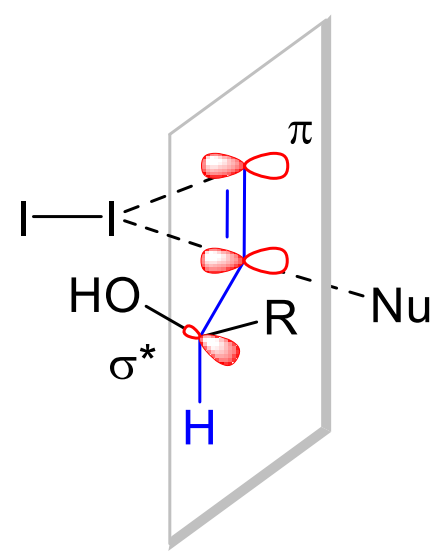

$\mathrm{H}$-in-plane

Disfavoured

Figure 4: O-in-plane vs $\mathrm{H}$-in-plane conformations during carbamate annulation.

The formation of carbamates leading to piperidine formation is proposed to occur through the same reaction pathway, with formation of the respective 6 membered ring intermediate similarly preferring a 4,5-cis relationship to minimalise $\pi_{\mathrm{C}=\mathrm{C}}$ and $\sigma^{*} \mathrm{C}-\mathrm{O}$ orbital overlap. However, unlike in a 5-membered ring, the 1,3-diaxial interactions of each hydroxyl significantly impacts the transition state energy, further complicating the conformational requirements during cyclisation. As a result, other reactions such as $O$ cyclisation can become energetically favourable, causing undesired side products to form. $^{64}$

\subsection{Thesis Outline}

The research in this thesis explores the development of synthetic methodology in order to efficiently synthesise known and novel iminosugars through the minimal use of PG. Chapter 2 builds on the PGF-synthesis of iminosugars reported by the Stocker-Timmer group that utilises the Vasella-reductive-amination and carbamate annulation, with the added challenge of applying these approaches to synthesis of iminosugars from the ketose sugar D-fructose (31). Chapter 3 reports the application of the synthetic strategy developed in chapter 2 to D-tagatose, leading to the efficient synthesis of 2,5-dideoxy2,5-imino-D-altritol (DIA). Chapter 4 describes the discovery and subsequent development of a novel imine-ring-closing methodology, leading to the efficient 
synthesis of DMJ (36) from D-fructose (31). The methodology developed in Chapter 4 is explored in Chapter 5, where the scope and effect of carbohydrate starting materials is examined. Finally, Chapter $\mathbf{6}$ covers future prospects and conclusions. 


\section{Chapter 2}

\section{Synthesis of 2,5-bis-hydroxymethyl pyrrolidines}

\subsection{Introduction}

To date, a protecting-group-free (PGF) approach has been successfully applied to the syntheses of mono-substituted pyrrolidines (e.g. 1,4-dideoxy-1,4-imino-D-xylitol, 58) with high over-all yield and stereoselectivity, ${ }^{62}$ and also for the syntheses of piperidines (e.g. DGJ, 13), ${ }^{63}$ and deoxygenated derivatives. ${ }^{64}$ Key in these synthetic strategies was the use of a PGF Vasella-reductive-amination reaction ${ }^{71}$ and an $\mathrm{I}_{2}$-mediated carbamate annulation. ${ }^{68}$ However, for the synthesis of piperidines, avoiding protecting groups was challenging and on occasion, mixtures of products were formed. ${ }^{63,64}$

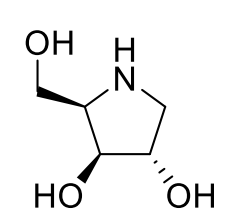

58<smiles>OC[C@H]1NC[C@@H](O)[C@H](O)[C@@H]1O</smiles>

13

Figure 5: Representative piperidines and pyrrolidines.

To further explore the scope of the reductive amination and carbamate annulation methodologies, it was desired to apply the PGF-route to the synthesis of more complex pyrrolidines, such as the 2,5-bis-hydroxymethyl derivatives (Scheme 15). It was desired to understand how the use of a keto-sugar starting material would affect the 
stereochemistry of the reductive amination and subsequent carbamate annulation. While it was envisioned that base-mediated hydrolysis would readily allow for the synthesis of pyrrolidine I from carbamate II, it was not known if the formation of carbamate II, which could in principle be achieved via an $\mathrm{I}_{2}$-mediated carbamate annulation from alkenylamine III, ${ }^{62}$ would be stereoselective. Previously, it was demonstrated that the carbamate annulation is highly 4,5-cis stereoselective for pyrrolidines without a substituent at the 2-position, however the syntheses of amino-imino-hexitols using protecting groups ${ }^{66,67}$ revealed that the stereochemistry of the 2-substituent can affect the stereochemical outcome of the annulation. ${ }^{62,68,69}$ Others have also revealed that steric effects can influence the outcome of related electrophilic cyclisations. ${ }^{68}$ To synthesise the alkenylamine III, it was envisioned that a PGF-free Vasella-reductive-amination using iodomethyl-furan IV could be undertaken, ${ }^{71}$ thereby establishing the stereocentre at the 2-position in the target pyrrolidine. The Furan IV, in turn, was envisioned to be available from keto sugar $\mathbf{V}$ via Fischer glycosidation and regioselective iodination of the 6position.<smiles>OCC1NC(CCl)C(O)C1O</smiles>

I<smiles>O=C1OCC2C(O)C(O)C(CO)N12</smiles>

II<smiles>C=CC=CC(O)C(O)C(N)CO</smiles>

III<smiles>C1CCCCC1</smiles><smiles>O=C(CO)C(O)C(O)C(O)CO</smiles>

V<smiles>COC1(CO)OC(CI)C(O)C1O</smiles>

IV

Scheme 15: Retrosynthesis of 2,5-bis-hydroxymethyl pyrrolidines (I).

\subsection{The synthesis of 2,5-bis-hydroxymethyl pyrrolidines from D- fructose}

To begin the synthesis, readily available D-fructose (31) was subjected to Fischer glycosidation with methanol under kinetic conditions, ${ }^{72}$ which yielded a 9:1 ratio of methyl furanoside 72 to pyranoside 73 , respectively (Scheme 16). Separation of the 
desired furanose product, while possible by silica gel flash column chromatography, was not necessary as purification was more convenient after the next step. Regioselective iodination at the most sterically accessible 6-position of furanoside $\mathbf{7 2}$ gave methyl iodoglycoside 74 in $65 \%$ yield over 2-steps, as evidenced by the diagnostic $\mathrm{CH}_{2} \mathrm{I}{ }^{13} \mathrm{C}$ NMR signals of the $\alpha$ - and $\beta$-anomers of 74 at $\delta 5.2$ and $6.9 \mathrm{ppm}$, respectively. ${ }^{73}$ The successful synthesis of methyl iodoglycoside 74 was achieved by slowly adding a solution of $\mathrm{I}_{2}$ in THF to the reaction vessel. A complex mixture of products was observed via TLC if $\mathrm{I}_{2}$ was added too quickly.
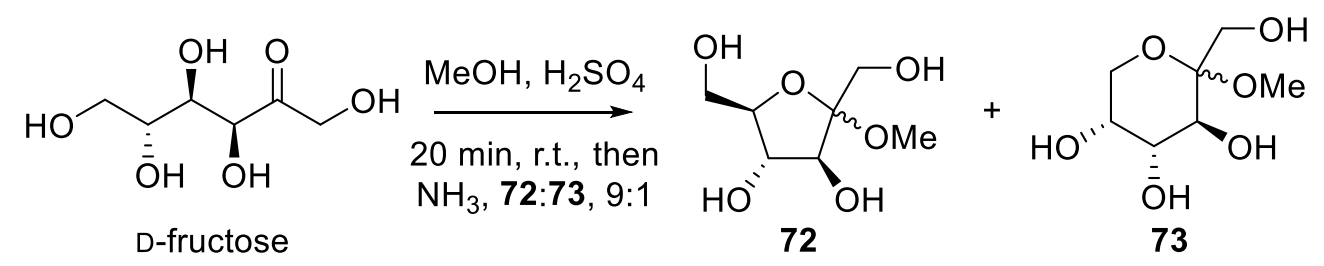

31

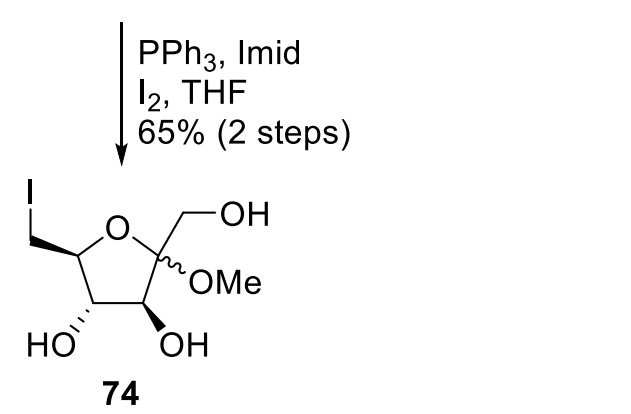

Scheme 16: Synthesis of methyl iodofucoside 74.

Next, the Vasella-reductive-amination of methyl iodoglycoside $\mathbf{7 4}$ was attempted. Conditions previously optimised for the PGF Vasella-reductive-amination of pentoses, which utilised buffered conditions involving the use of excess $\mathrm{NH}_{4} \mathrm{OAc}$ in $\mathrm{NH}_{3}(\mathrm{pH}=$ 12), ${ }^{62}$ were applied to the methyl iodoglycoside 74 (Entry 1, Table 1). Following this, however, no identifiable product was observed by ${ }^{1} \mathrm{H}$ NMR of crude reaction mixtures. In order to assist in the optimisation of the reductive amination step, the isolation of intermediate ketone (VI) was attempted (entry 2). In the absence of ammonium and hydride reducing agent, the Vasella reaction rapidly went to completion, as determined by TLC $\left(\mathrm{R}_{f}=0.4\right.$, petroleum ether/ethyl acetate, $\left.1 / 1, \mathrm{v} / \mathrm{v}\right)$ and HRMS $(\mathrm{m} / z$ calcd. for $\left[\mathrm{C}_{6} \mathrm{H}_{10} \mathrm{O}_{4}+\mathrm{H}\right]^{+}:$147.0652, obsd: 147.0655). However, analysis of the crude reaction product, after filtration and concentration, by ${ }^{1} \mathrm{H}$ NMR spectroscopy showed a complex mixture of products, which were attributed to the polymerisation of the trihydroxyketone. Thus, further attempts to isolate ketone VI were abandoned, with focus returning to a one 
pot procedure. As the reductive amination of ketone VI appeared to be sluggish, weakacid catalysis was employed to enhance the rate of the reductive amination. In a two-step one-pot protocol, methyl iodoglycoside $\mathbf{7 4}$ was first subjected to zinc in ethanol at room temperature, and after the disappearance of the starting material ( $1 \mathrm{~h}$, as gauged by TLC), $\mathrm{NaBH}_{3} \mathrm{CN}$, AcOH and $\mathrm{NH}_{4} \mathrm{OAc}$ were added (Entry 5). Gratifyingly, this procedure led to the isolation of the desired alkenylamine $\mathbf{7 5}$ in a 1:1 diasteromeric mixture, albeit in a very modest yield (13\%). Following the same conditions except for heating the reaction mixture to reflux, the yield of alkenylamine $\mathbf{7 5}$ was slightly improved to $21 \%$ (entry 4 ). Greater yields could be obtained by adding all reagents to the reaction vessel at once, followed by refluxing the mixture for 3 days (entry 5), which improved the yield to $42 \%$ and simplified the protocol. Finally, methyl iodoglycoside $\mathbf{7 4}$ was treated with $\mathbf{Z n}$, $\mathrm{NaBH}_{3} \mathrm{CN}, \mathrm{AcOH}$ and $\mathrm{NH}_{4} \mathrm{OAc}$ in $\mathrm{EtOH}$ under reflux for 7 days, which led to a much improved (65\%) yield of $\mathbf{7 5}$ in a 1:1 disastereomeric ratio (entry 6). However, treating $\mathbf{7 5}$ to the same reaction conditions for shorter or longer lengths of time did not improve the reaction yield. 
Table 1: Optimisation of the PGF Vasella-Reductive-Amination.

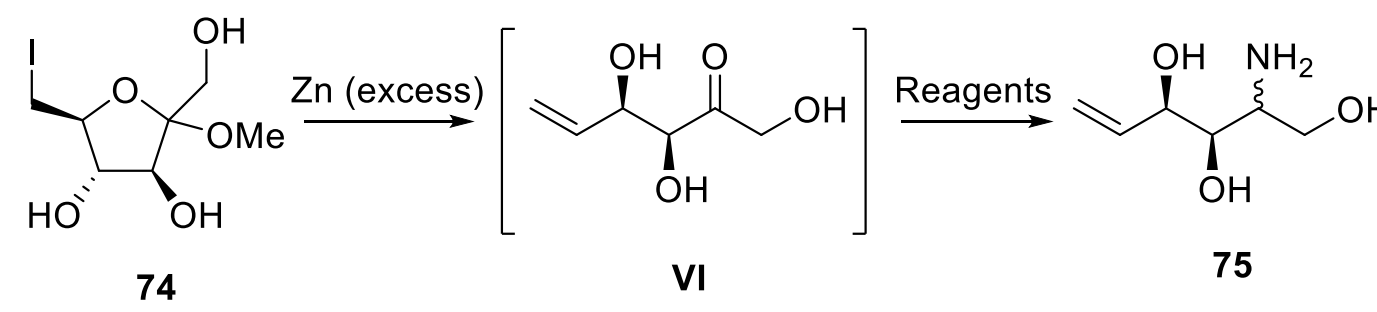

\begin{tabular}{|c|c|c|c|c|c|}
\hline Entry & Reagents $^{\mathrm{a}}$ & $\begin{array}{l}\text { Solvent } \\
\text { (conc.) }\end{array}$ & Temp. (time) & $\mathrm{pH}$ & $\begin{array}{l}\text { Yield }^{\mathrm{e}, \mathrm{f}, \mathrm{g}} \\
(\mathbf{7 5})\end{array}$ \\
\hline $1^{\mathrm{b}}$ & $\begin{array}{l}\mathrm{NH}_{3} \text { (aq.) }(144 \text { equiv.), } \\
\mathrm{NH}_{4} \mathrm{OAc} \text { (130 equiv.) }\end{array}$ & $\begin{array}{c}\mathrm{EtOH} \\
(28 \mathrm{~mL} / \mathrm{mmol})\end{array}$ & $\begin{array}{l}\text { Reflux } \\
\text { (2 days) }\end{array}$ & 11 & NA \\
\hline $2^{\mathrm{b}, \mathrm{c}}$ & AcOH (17 equiv.) & $\begin{array}{c}\mathrm{EtOH} \\
(5 \mathrm{~mL} / \mathrm{mmol})\end{array}$ & Reflux (1 h) & 6 & $\begin{array}{l}\text { Ketone } \\
\text { VI }\end{array}$ \\
\hline $3^{\mathrm{d}}$ & $\begin{array}{l}\text { AcOH (17 equiv.), } \\
\mathrm{NH}_{4} \mathrm{OAc}(10 \text { equiv.) }\end{array}$ & $\begin{array}{c}\mathrm{EtOH} \\
(5 \mathrm{~mL} / \mathrm{mmol})\end{array}$ & r.t. (3 days) & 6 & $13 \%$ \\
\hline $4^{\mathrm{d}}$ & $\begin{array}{l}\text { AcOH (17 equiv.), } \\
\mathrm{NH}_{4} \mathrm{OAc} \text { (10 equiv.) }\end{array}$ & $\begin{array}{c}\mathrm{EtOH} \\
(5 \mathrm{~mL} / \mathrm{mmol})\end{array}$ & $\begin{array}{l}\text { Reflux } \\
\text { (3 days) }\end{array}$ & 6 & $21 \%$ \\
\hline $5^{\mathrm{b}}$ & $\begin{array}{l}\text { AcOH (17 equiv.), } \\
\text { NH4OAc (10 equiv.) }\end{array}$ & $\begin{array}{c}\mathrm{EtOH} \\
(5 \mathrm{~mL} / \mathrm{mmol})\end{array}$ & $\begin{array}{l}\text { Reflux } \\
\text { (3 days) }\end{array}$ & 6 & $42 \%$ \\
\hline $6^{\mathrm{b}}$ & $\begin{array}{l}\text { AcOH (17 equiv.), } \\
\mathrm{NH}_{4} \mathrm{OAc}(10 \text { equiv.) }\end{array}$ & $\begin{array}{c}\mathrm{EtOH} \\
(5 \mathrm{~mL} / \mathrm{mmol})\end{array}$ & $\begin{array}{l}\text { Reflux } \\
\text { (7 days) }\end{array}$ & 6 & $65 \%$ \\
\hline \multicolumn{6}{|c|}{ a) All reactions used 5 equiv. of $\mathrm{Zn}$ and 3 equiv. of $\mathrm{NaBH}_{3} \mathrm{CN}$. } \\
\hline \multicolumn{6}{|c|}{ c) Only attempted to isolate intermediate Ketone VI. } \\
\hline \multicolumn{6}{|c|}{$\begin{array}{l}\text { d) Two step reaction in which } \mathrm{NaCNBH}_{3}, \mathrm{AcOH} \text {, and } \mathrm{NH}_{4} \mathrm{OAc} \text { were added after } \\
\text { completion of the Vasella reaction. }\end{array}$} \\
\hline \multicolumn{6}{|c|}{ e) $\mathrm{NA}=$ product not detected by ${ }^{1} \mathrm{H}$ NMR from the reaction mixture. } \\
\hline \multicolumn{6}{|c|}{ f) All reported yields are calculated from isolated product. } \\
\hline g) All r & tions gave a $1: 1$ mixtu & of diasterome & & & \\
\hline
\end{tabular}

Unfortunately, separating the two disasteromers of 75 via silica gel flash chromatography proved problematic, and attempts to increase the diastereoselectivity of the reductive amination using $\mathrm{Ti}\left(\mathrm{O}^{\mathrm{i}} \mathrm{Pr}\right)_{4},(+)$-DIP-Chloride, $\mathrm{NaBH}(\mathrm{OAc})_{3}, \mathrm{~B}(\mathrm{OMe})_{3}, \mathrm{Mn}(\mathrm{OAc})_{2}$, or $\mathrm{MnCl}_{2}$ as chiral catalysts or chelating agents also did not alter the diastereoselectivity. ${ }^{74-}$ 77 As a result, the diastereomic mixture of $\mathbf{7 5 a}$ and $\mathbf{7 5 b}$ was used for the subsequent carbamate annulation, with the hope that the carbamate diastereomers could be more readily separated by column chromatography. 
To this end, a solution of $\mathrm{I}_{2}$ (1.5 equiv.) in sat. aq. $\mathrm{NaHCO}_{3}$ was added to alkenylamines 75 using the previously reported protocol ${ }^{62}$ (Scheme 17). This resulted in the complete consumption of the starting material after 18 hours, as observed by TLC analysis. Following work-up and ${ }^{1} \mathrm{H}$ NMR analysis of the crude reaction mixture, it was evident that one major and one minor carbamate product had been formed in a ratio of 10:1. At this stage it was not possible to determine which isomers had been formed, however subsequent analysis (vide infra) revealed the major carbamate to be 76a, with 2,5-trans and 4,5-cis relationships, while the minor carbamate was 76b with 2,5-trans and 4,5-trans relationships. Attempts to separate the carbamate diastereomers using silica gel column chromatography proved unsuccessful.

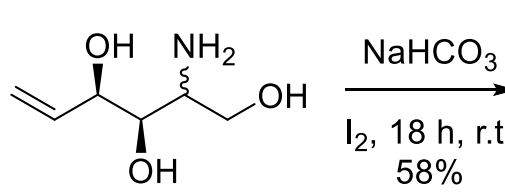

$75 R: S=1: 1$
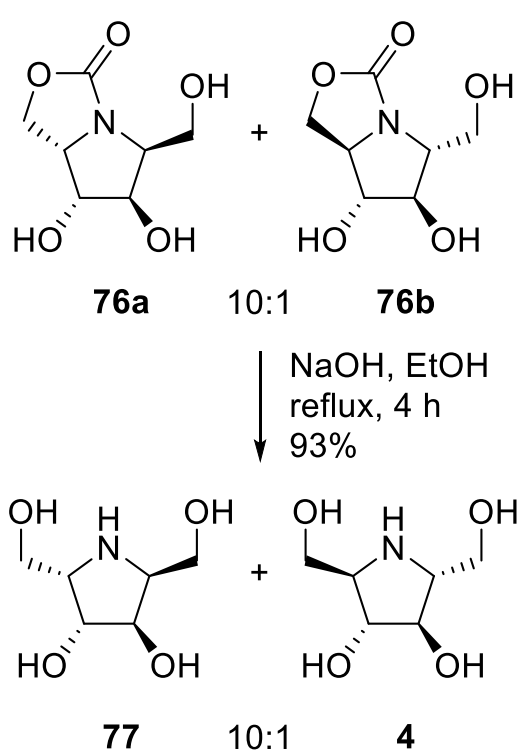

Scheme 17: Synthesis of 2,5-dideoxy-2,5-imino-L-iditol (77) and 2,5-dihydroxymethyl-2,5imino-D-mannitol (DMDP, 4).

The mixture of carbamates was then subjected to base mediated hydrolysis to give the target pyrrolidines 77 and $\mathbf{4}$ in 93\% total yield, and again in a 10:1 ratio (Scheme 17). The stereochemistry of the resulting pyrrolidines could now be established by comparison of the ${ }^{1} \mathrm{H}$ - and ${ }^{13} \mathrm{C}-\mathrm{NMR}$ data to those reported in literature, which confirmed that the major pyrrolidine to be the $\alpha$ - and $\beta$-glucoside inhibitor 5-dideoxy-2,5-imino-L-iditol (77). ${ }^{62,78,79}$ Key in the structural elucidation of L-iditol 77 was the presence of only three resonances in the ${ }^{13} \mathrm{C}-\mathrm{NMR}\left(\mathrm{D}_{2} \mathrm{O}\right)$ spectrum at $\delta 74.5,62.8$ and $57.4 \mathrm{ppm}$, immediately implying a symmetrical structure. The minor pyrrolidine was also symmetrical, with three carbon resonances in the ${ }^{13} \mathrm{C}-\mathrm{NMR}\left(\mathrm{D}_{2} \mathrm{O}\right)$ at $\delta 74.1,62.3$ and $57.7 \mathrm{ppm}$, correlating to the 
known 2,5-dihydroxymethyl-2,5-imino-D-mannitol (DMDP, 4). ${ }^{8}{ }^{80}$ Notwithstanding, our difficulties in separating these two products made the overall route unfeasible.

While we demonstrated that the Vasella reductive amination using $\mathrm{NH}_{4} \mathrm{OAc} / \mathrm{AcOH}$ was successful when using ketose sugars as starting materials, our inability to separate the alkenylamine diastereomers necessitated a modified protocol. To this end, we envisioned that the use of a bulky amine nucleophile might lead to better diastereoselectivity during the reductive amination and/or assist with the purification of the target amines. Thus, the methyl iodoglycoside $\mathbf{7 4}$ was subjected to the optimised Vasella-reductive-amination conditions, but with the use of diphenylmethylamine as the amine nucleophile (Scheme 18). This resulted in the formation of alkenylamines $\mathbf{7 8 a}$ and $\mathbf{7 8 b}$ in $85 \%$ total yield and in an, albeit modest, improved 3:2 ratio, in favour of the anti-Felkin Ahrn product. ${ }^{81}$

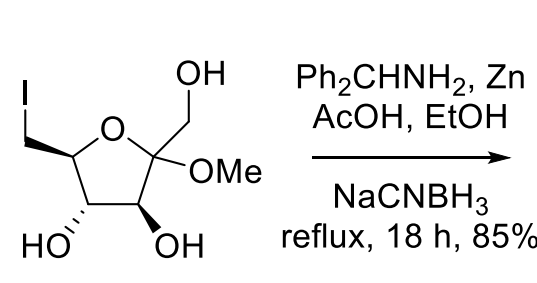

74

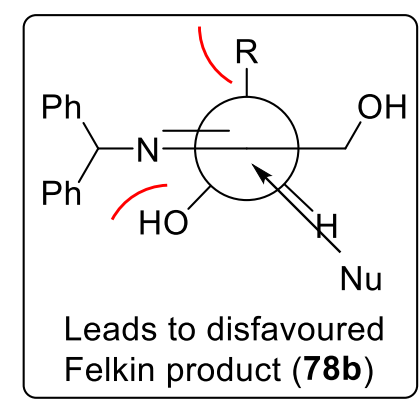<smiles>C=C[C@@H](O)[C@H](O)[C@H](CO)NC(c1ccccc1)c1ccccc1</smiles>

$78 \mathrm{a}$

$3: 2$

$\downarrow \begin{aligned} & \mathrm{TFA}, \mathrm{Et}_{3} \mathrm{SiH} \\ & 54 \%\end{aligned}$<smiles>C=C[C@H](O)[C@H](O)[C@H](CO)NC(c1ccccc1)c1ccccc1</smiles>

78b

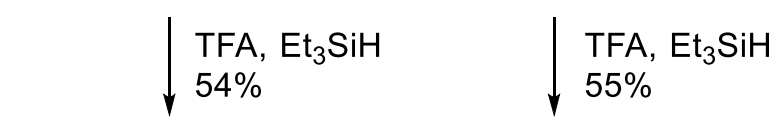<smiles>C=C[C@H](O)[C@@H](O)[C@@H](N)CO</smiles><smiles>C=C[C@@H](O)[C@@H](O)[C@H](N)CO</smiles>

Scheme 18: Synthesis of alkenylamines $\mathbf{7 5 a}$ and $\mathbf{7 5 b}$ using diphenylmethylamine. Insert: Newman projection showing the disfavoured steric interactions resulting in $\mathbf{7 8 b}$ forming as the minor product.

Formation of the desired product was evidenced by HRMS $\left(\mathrm{m} / \mathrm{z}\right.$ calcd. for $\left[\mathrm{C}_{19} \mathrm{H}_{24} \mathrm{NO}_{3}\right]^{+}$: 314.1751, obsd.: 314.1752) and also by NMR analyses, where an HMBC between the benzylic proton and the C-2 carbon established the incorporation of the nitrogen atom onto the sugar framework. Fortunately, these diastereomers were readily separable by silica gel flash column chromatography. Each diastereomer was then subjected to TFA and $\mathrm{Et}_{3} \mathrm{SiH}$ at reflux to remove the diphenylmethyl group, giving the deprotected amines 75a and 75b in 54\% and 55\% yield, respectively (Scheme 18). 


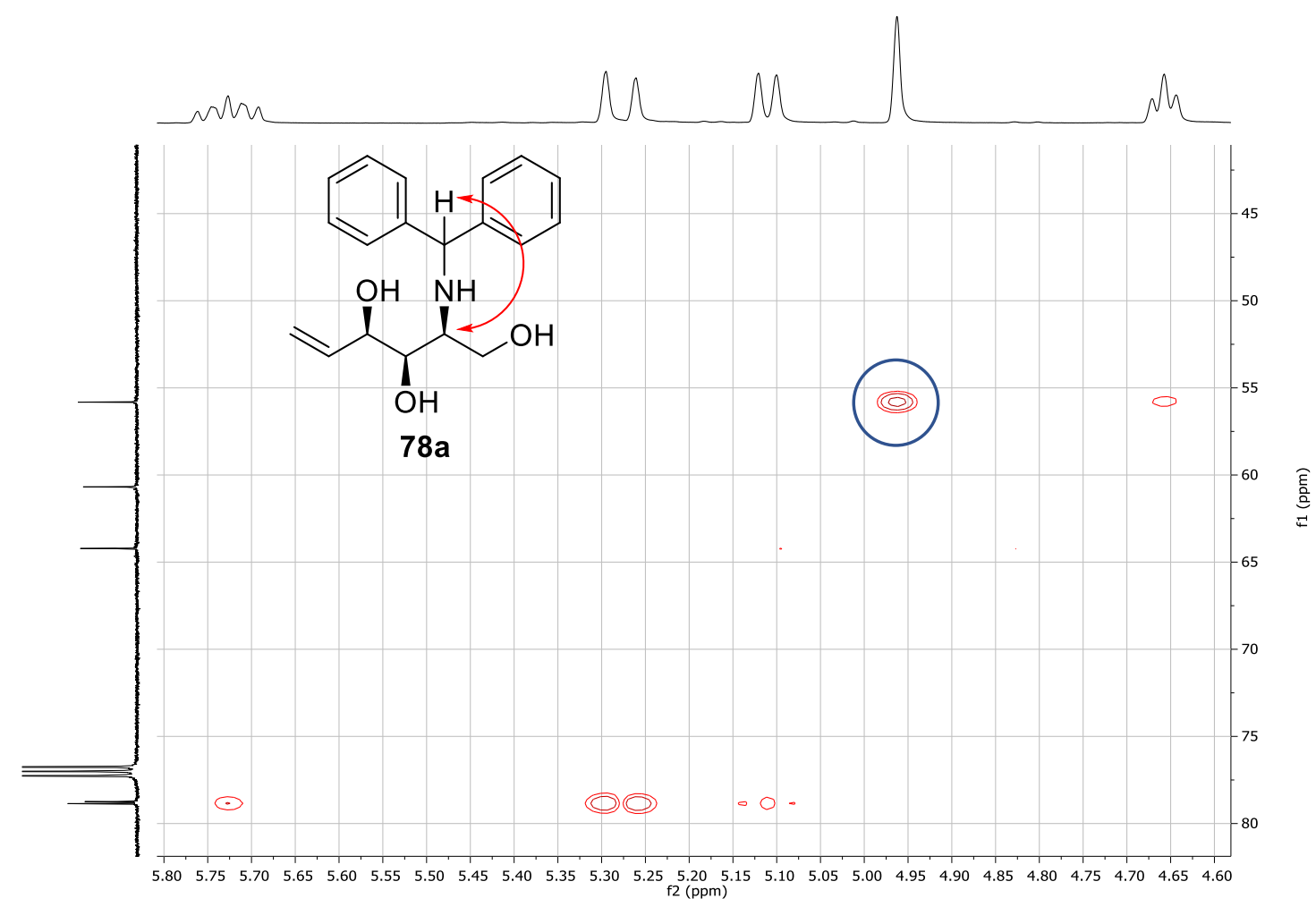

Figure 6: $H M B C$ spectrum of alkenylamine 78a showing the correlation between the benzylic proton and the C-2 carbon (circled).

With the alkenylamines $\mathbf{7 5 a}$ and $\mathbf{7 5 b}$ in hand, the respective carbamate annulations were performed, followed by subsequent base hydrolysis (Scheme 19). As anticipated, alkenylamine 75a gave carbamate 76a which, after hydrolysis, gave the $\alpha$-fucosidase and $\alpha$ - and $\beta$-glucoside inhibitor 2,5-dideoxy-2,5-imino-L-iditol (4) ${ }^{62,78,79}$ in an excellent $98 \%$ yield over the two steps. There have been several total syntheses of L-iditol 4 to date, ${ }^{82-85}$ however two particularly notable examples include the 5-step and 6-step syntheses by Shing and co-workers ${ }^{86,87}$ and Wong and co-workers, ${ }^{79}$ respectively, both of which commence from D-mannitol (45\% in 5 steps and $60 \%$ in 4 steps, respectively). The synthesis of L-iditol 77 reported here was achieved in 6-steps and in $18 \%$ overall yield, and though lower yielding, it minimises the use of protecting groups, which is a new challenge in synthetic chemistry. ${ }^{54}$ 
<smiles>C=C[C@@H](O)[C@@H](O)[C@@H](N)CO</smiles>

$75 a$<smiles>C=C[C@@H](O)[C@@H](O)[C@H](N)CO</smiles>

$75 b$<smiles>O=C1OC[C@H]2[C@@H](O)[C@H](O)[C@H](CO)N12</smiles>

$76 a$

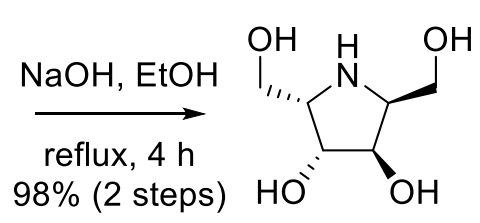

77<smiles>O=C1OC[C@H]2[C@H](O)[C@H](O)[C@@H](CO)N1[C@H]2CO</smiles>

Scheme 19: Synthesis of 2,5-dideoxy-2,5-imino-l-iditol (77) and DMDP (4).

Although the carbamate annulation of alkenylamine 75a proceeded smoothly, the attempted annulation of $\mathbf{7 5} \mathbf{b}$ gave a complex mixture of products, despite full-conversion of starting material, as observed by TLC analysis. Purification of these products proved difficult and it is proposed that a mixture of pyrrolidines, piperidines, and O-cyclised products formed, as previously observed during the development of other PGF-syntheses of piperidines from aldoses. ${ }^{63,64}$ Thus the annulation mixture of $\mathbf{7 5 b}$ was subjected to base hydrolysis, which gave a mixture of iminosugars in which DMDP (4) could be identified as the major product, but in a much lower yield over the two steps (16\%) as compared to the 4,5-cis product 77 (98\%).

\subsection{Factors impacting stereoselectivity during carbamate annulation}

To explain the observed stereochemistry of the carbamate products and the respective yields for the annulation reactions of alkenylamines $\mathbf{7 5 a}$ and $\mathbf{7 5} \mathbf{b}$, it is instructive to first describe the potential pyrrolidine products from the annulation reaction (Figure 7). Each diastereomer of $\mathbf{7 5}$ can form two products, for which the transition state needs to adopt a conformation in which either the allylic $\mathrm{OH}$ or allylic $\mathrm{H}$ is in the plane of the double bond. Computational studies by Gouverneur and co-workers ${ }^{88}$ and empirical observations by Chamberlin et al. ${ }^{89-91}$ and within the group ${ }^{68}$ have identified that the $\mathrm{OH}$-in-plane conformer has a lower transition state energy, due to minimal overlap of the electron 
withdrawing $\sigma^{*} \mathrm{C}-\mathrm{O}$ and reacting $\pi \mathrm{C}=\mathrm{C}$ orbitals, which in turn favours the formation of 3,4-cis products. The configuration at the 2-position, however, can significantly reduce the diastereoselectivity of the annulation. ${ }^{66,67}$ As illustrated for the $2 S$ alkenylamine $75 \mathbf{a}$ (Figure 7A), the $\mathrm{OH}$-in-plane conformer $(\rightarrow \mathbf{7 6 a})$ has the electronically favourable 3,4cis configuration and the sterically favourable 2,5-trans relationship between the hydroxylmethyl and iodomethyl groups. Conversely, the less electronically favoured $\mathrm{H}$ in-plane transition state $(\rightarrow \mathbf{7 6 c})$ also has the sterically unfavourable 2,5 -cis relationship and as a consequence, diastereomer 76a is formed in the cyclisation of $2 S$-alkenylamine 75a.
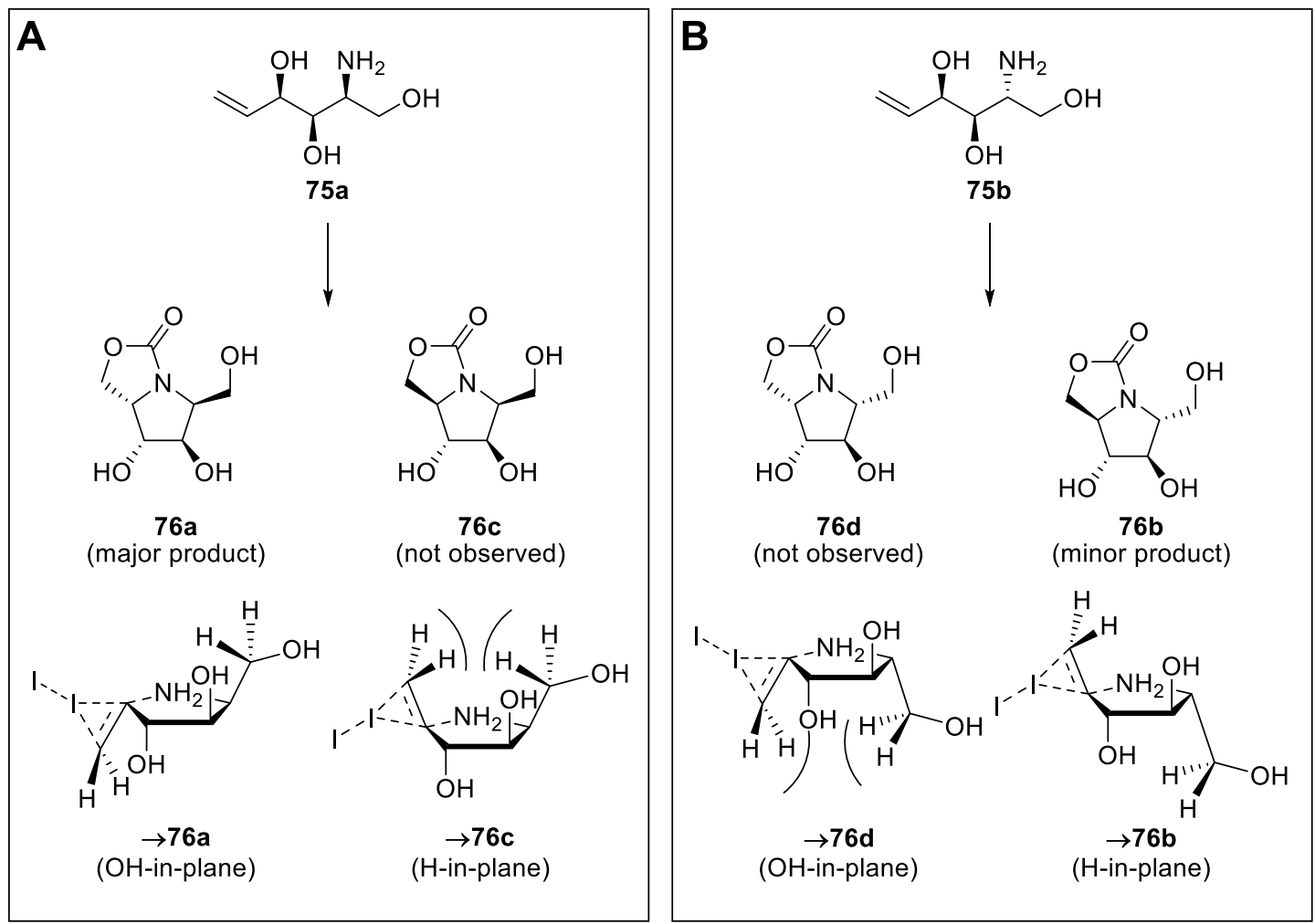

Figure 7: Transition states for the formation of diastereomers 76a-d.

On the other hand, for $2 R$ isomer 75b (Figure 7B) the OH-in-plane conformation leads to an unfavourable 2,5-trans relationship, while the 2,5-cis conformer suffers from an unfavourable electronic interaction in the $\mathrm{H}$-in-plane transition state. Consequently, there is no obvious lowest energy transition state for the cyclisation of $\mathbf{7 5} \mathbf{b}$, and only a small amount of isomer $\mathbf{7 6} \mathbf{b}$ is isolated, meaning that the 2,5-interaction overrides the electronic effect of the allylic alcohol. Indeed, this finding is consistent with the work of Davies and Bouix, whereby halocyclisation of a protected alkenylamine resulted in the preferential formation of the cross-ring trans isomer..$^{92,93}$ 


\subsection{Conclusion}

In summary, the synthesis of 2,5-dideoxy-2,5-imino-L-iditol (77) has been achieved in 6steps and in $18 \%$ overall yield. This synthesis is comparable to other existing syntheses, and moreover, the route reported here minimises the use of protecting groups. In achieving the target compound, it was also demonstrated that the Vasella-reductiveamination methodology could be applied to the amination of ketones, although the diastereoselectivity of this reaction was poor. This may be attributed to the chirality of the starting iodo-sugar and is explored further in Chapter 3. Moreover, during this total synthesis it was demonstrated that the $\mathrm{I}_{2}$-mediated carbamate annulation favours the formation of pyrrolidines with the 2,5-trans, 3,4-cis relationships. This finding can be translated to the synthesis of other 2,5-bis(hydroxymethyl)-pyrrolidines as the chirality of the intermediate alkenylamine will allow one to better predict the success and diastereoselectivity of the ensuing carbamate annulation. 


\section{Chapter 3}

\section{Synthesis of 2,5-dideoxy-2,5-imino-D-altritol}

\subsection{Introduction}

In recent years, remarkable progress has been made towards the treatment of Fabry disease. Notably, in 2001, enzyme replacement therapy (ERT) was approved, thereby enhancing the quality and length of life for Fabry patients. ${ }^{94}$ ERT, however, is restricted to the non-neuronopathic forms of the disease because the proteins cannot pass the bloodbrain barrier. ${ }^{95}$ Moreover, the therapy has no benefit for the prevention of premature stroke and fails to remove accumulated Gb3 from kidney podocytes and blood vessel walls. ${ }^{96}$ Accordingly, the development of pharmacological chaperones to assist with the correct folding of the mutant $\alpha-\mathrm{Gal} \mathrm{A}$ is a promising treatment for Fabry disease that has gained much traction in recent years. In particular, the $\alpha$-Gal A inhibitor 1deoxygalactonojirimycin (DGJ, 13, Figure 8) ${ }^{97}$ can stabilise the native folding state of $\alpha$ Gal A and allow for the trafficking of the enzyme to the lysosome. ${ }^{98}$ Once in the lysosome, the residual activity of the mutant $\alpha$-Gal A is sufficient to allow for the breakdown of Gb3. ${ }^{97,} 99$ Pharmacological chaperones may also improve the efficacy of ERT $^{96}$ and this has sparked further interest in the development of small molecule inhibitors for $\alpha-G a l$ A and other enzymes associated with lysosomal storage disorders. ${ }^{96}$, 98, 100-102 
<smiles>OC[C@H]1NC[C@@H](O)[C@H](O)[C@@H]1O</smiles>

DGJ<smiles>OC[C@H]1N[C@H](CO)[C@@H](O)[C@H]1O</smiles>

DIA

13

79

Figure 8: Molecular chaperones for Fabry disease.

There are several classes of small molecule molecular chaperones that have shown promise for the treatment of Fabry disease, ${ }^{102}$ however, the potential of furanose sugar mimetics for this purpose was only realised in 2010 with the discovery that 2,5-dideoxy2,5-imino-D-altritol (DIA, 79) was a powerful competitive inhibitor of $\alpha$-Gal A. ${ }^{103}$ In this work DIA, which was isolated from the roots of Adenophora triphylla, inhibited $\alpha$-Gal A with a $\mathrm{K}_{\mathrm{i}}$ value of $0.5 \mu \mathrm{M}$, improved the thermostability of $\alpha$-Gal A in vitro, and increased intracellular $\alpha$-Gal $A$ activity by almost 10 -fold, thus demonstrating that DIA has very real potential as a pharmacological chaperone. Notwithstanding, there are few reported syntheses of DIA, with the most efficient being those by Fleet et al. from a protected glucuronolactone derivative (9 steps, $16 \%$ overall yield) ${ }^{84}$ and Singh and Han from a previously synthesised olefin starting material ( 7 steps, $3.5 \%$ yield). ${ }^{104}$

\subsection{Retrosynthesis}

As better access to DIA would allow for more in depth investigations into the potential of this molecule as a treatment for Fabry disease, it was desired to establish a highly efficient route for its preparation by utilising the previously developed carbamate annulation methodology (see Chapter 2). It was envisioned that 2,5-dideoxy-2,5-iminoD-altritol (79) could be synthesised via base-mediated hydrolysis of the corresponding carbamate 80, with $\mathbf{8 0}$ being formed via the $\mathrm{I}_{2}$-mediated carbamate annulation of alkenylamine 81 (Scheme 20). The work in Chapter 2 demonstrated that the application of carbamate annulations en route to the synthesis of 2,5-dideoxy-2,5-imino-L-iditol (77) favours the 2,5-trans, 4,5-cis configuration, which makes $\mathbf{8 1}$ an ideal substrate from which to generate DIA. In turn, it was envisioned that alkenylamine $\mathbf{8 1}$ could be synthesised from the corresponding iodo-glycoside 82 via a Vasella reaction and diastereoselective reductive amination of the ensuing ketone functionality. Initially it was 
proposed that $\mathbf{8 2}$ could be prepared without the need for protecting groups $\left(\mathrm{R}^{1}=\mathrm{H}, \mathrm{R}^{2}=\right.$ $\mathrm{Me}$ ), as the annulation strategy is amenable to such an approach, ${ }^{105}$ however, the synthesis of iminosugars in the absence of PGs is not without its challenges ${ }^{63,64}$ and thus, the use of PGs was also considered in the retrosynthetic plan $\left(\mathrm{R}^{1}=\mathrm{R}^{2}=\mathrm{PG}\right)$. Finally, methyl iodo-glycoside 82 could be prepared from commercially available D-tagatose (25).<smiles>OCC1N[C@H](CO)C(O)[C@@H]1O</smiles>

79<smiles>O=C1OC[C@H]2[C@@H](O)[C@H](O)[C@@H](CO)N12</smiles>

80<smiles>C=CC=C</smiles><smiles>C=CC(O)[C@H](O)[C@H](N)CO</smiles>

81<smiles>O=C(CO)[C@H](O)[C@H](O)[C@H](O)CO</smiles>

D-tagatose

25

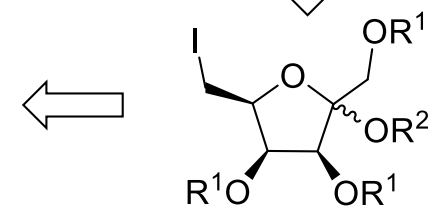

$82 \begin{aligned} R^{1} & =H, P G \\ R^{2} & =M e, P G\end{aligned}$

Scheme 20: Retrosynthesis for 2,5-dideoxy-2,5-imino-d-altritol (DIA, 79).

\subsection{Synthesis of 2,5-dideoxy-2,5-imino-D-altritol and 2,5- dideoxy-2,5-imino-L-altritol}

For this synthesis, it was initially proposed a PGF approach whereby D-tagatose (25) would be converted to the methyl furanoside, iodinated at the 6-position, and then subjected to a two-step one-pot Vasella-reductive-amination to yield alkenylamine $\mathbf{8 1}$ (see Chapter 2). Accordingly, D-tagatose (25) was subjected to a Fischer glycosidation with methanol ${ }^{8,106}$ to give an anomeric mixture of methyl glycosides 83 and 84 in a 2:3 ratio and in $85 \%$ overall yield (Scheme 21). Subsequent regioselective iodination at the 6-position of methyl glycosides $\mathbf{8 4}(\rightarrow \mathbf{8 5})$, however, proved difficult, with TLC revealing the formation of a complex mixture of products resulting from the reaction. Therefore, the 1,2- and 3,4-positions in D-tagatose (25) were protected with isopropylidene groups $(\rightarrow \mathbf{8 6})^{107}$ and the 6-position iodinated ${ }^{62}$ to readily afford isopropylidene-protected iodotagatoside 87 in $80 \%$ yield over the two-steps. 
<smiles>O=C(CO)C(O)[C@H](O)[C@H](O)CO</smiles>

D-tagatose (25)
$\mathrm{MeOH}, \mathrm{H}_{2} \mathrm{SO}_{4}$ 1 h, r.t., then

$\mathrm{NH}_{3}, 85 \% \mathrm{HO}$

HO"

83<smiles>CO[C@]1(CO)O[C@H](CO)[C@@H](O)[C@H]1O</smiles>

84

Acetone, $\mathrm{H}_{2} \mathrm{SO}_{4}$

$\mathrm{CuSO}_{4}$, r.t., $18 \mathrm{~h}$

$82 \%$

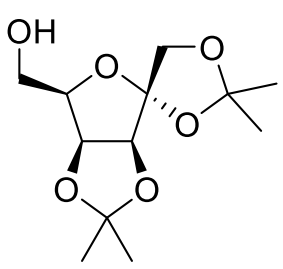

86

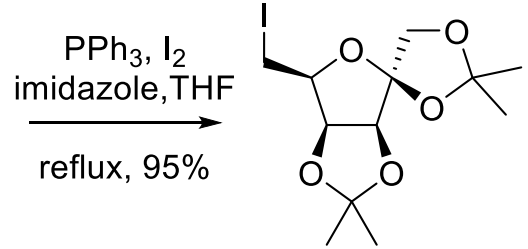

87<smiles>CO[C@]1(CO)O[C@H](CI)[C@@H](O)[C@H]1O</smiles>

85

Scheme 21: Synthesis of isopropylidene-protected iodotagatoside 86 from D-tagatose (25).

It was then anticipated that a one pot Vasella-reductive amination would give the desired alkenylamine. To this end, iodide 87 was subjected to $\mathrm{Zn}$ (10 equiv), AcOH (17 equiv.) and $\mathrm{NH}_{4} \mathrm{OAc}$ (10 equiv.) in EtOH under reflux for $18 \mathrm{~h}$ (Scheme 22). Following purification using Dowex- $\mathrm{H}^{+}$ion exchange resin and silica gel flash column chromatography it was determined that diastereomeric mixtures of protected alkenylamines $\mathbf{8 8}$ and deprotected alkenylamines 89, along with the dimer $\mathbf{9 0}$, were obtained in a 4:1:3 ratio, respectively, and in $85 \%$ combined yield. While the in situ deprotection of the isopropylidene PG was unsurprising, given the acidic aqueous conditions of the reductive amination, the formation of dimer $\mathbf{9 0}$, which is the result of a Wurtz-type coupling reaction, was unusual as hydrogenation is often difficult to prevent. ${ }^{108}$ 
<smiles>CC1(C)O[C@H]2[C@@H](O1)[C@@H](CI)O[C@]21COC(C)(C)O1</smiles>

87
$\mathrm{Zn}, \mathrm{AcONH}_{4}$

$\mathrm{AcOH}, \mathrm{EtOH}$

reflux, $18 \mathrm{~h}$

$87: 88: 89,4: 1: 3$

$85 \%$

THF: $\mathrm{H}_{2} \mathrm{O}, 9: 1, \mathrm{Zn}$

reflux, $18 \mathrm{~h}, 80 \%$<smiles>C=C[C@@H]1OC(C)(C)O[C@H]1C(=O)CO</smiles>

$\mathrm{NaCNBH}_{3} \mathrm{AcONH}_{4}$

$\mathrm{EtOH}$, r.t., $18 \mathrm{~h}$

$55 \%(87) ; 12 \%(88)$

1) $\mathrm{NaCNBH}_{3}, \mathrm{EtOH}$

$\mathrm{AcONH}_{4}$, r.t., $18 \mathrm{~h}$

2) Dowex- $\mathrm{H}^{+}, \mathrm{H}_{2} \mathrm{O}$

$2 \mathrm{~h}, 71 \%$<smiles>C=C[C@H](O)[C@@H](O)C(N)CO</smiles>

89

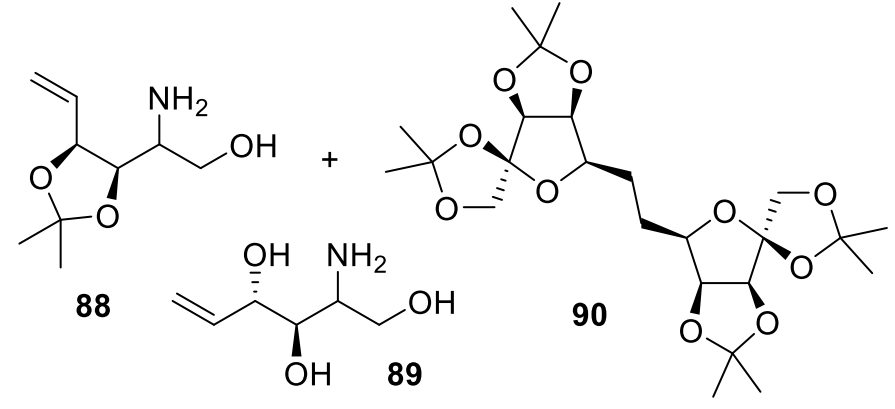

88<smiles>C=C[C@H](O)[C@@H](O)C(N)CO</smiles>

89
$\mathrm{NaHCO}_{3}$ (sat.)

$\times \mathrm{I}_{2}, 10$ days

r.t. $-100^{\circ} \mathrm{C}$<smiles>CC1(C)O[C@H]2C(CO)N3C(=O)OCC3[C@@H]2O1</smiles>

92

Scheme 22: Vasella-reductive-amination of protected iodide 87.

To eliminate the possibility of dimer formation, the Vasella ring opening and reductive amination were then performed sequentially (Scheme 22). Accordingly, iodide 87 was refluxed with zinc in a solution of THF: $\mathrm{H}_{2} \mathrm{O}(9: 1)$ to give ketone 91 in $80 \%$ yield following purification. Ketone $\mathbf{9 1}$ was then subjected to reductive amination using $\mathrm{AcONH}_{4}$ and $\mathrm{NaBH}_{3} \mathrm{CN}$ in ethanol, which resulted in a 1:1 diasteromeric mixture of isopropylidine protected alkenylamine $\mathbf{8 8}$ and the deprotected adduct $\mathbf{8 9}$. While the protected alkenylamine $\mathbf{8 8}$ could be isolated in 55\% yield following purification of the crude reaction mixture by silica gel flash column chromatography, this alkenylamine was not amenable to the previously optimised annulation conditions ( $\rightarrow \mathbf{9 2}$, see Chapter 2 ), with only starting material being isolated despite prolonged reaction times and heating the solution to $100{ }^{\circ} \mathrm{C}$. Given this result, there was no purpose in isolating $\mathbf{8 8}$ and following the reductive amination of ketone 91, the crude reaction mixture was treated with water and Dowex- $\mathrm{H}^{+}$for 2 hours to give the deprotected alkenylamine 89 as the sole product in $71 \%$ yield and in $1: 1$ diastereomeric mixture. Unfortunately, the 
diastereoisomers of $\mathbf{8 9}$ were inseparable via silica gel column flash chromatography, despite multiple attempts, and the material was further reacted as a mixture in the hope that the diasteromers could be separated at a later stage in the synthesis.

Next, alkenylamine 89 was subjected to $\mathrm{I}_{2}$ and $\mathrm{NaHCO}_{3}$ (sat. soln) for 18 hours at room temperature to induce the carbamate annulation (Scheme 23). The reaction mixture was lyophilised, extracted using methanol, and the residue columned over silica to give an inseparable mixture of carbamates 80:80a (19:1) in $60 \%$ overall yield. While the stereochemistry of $\mathbf{8 0}$ and $\mathbf{8 0 a}$ could not be ascertained at this stage, it was reasoned that the major carbamate would be $\mathbf{8 0}$, with the 2,5-trans, 4,5-cis configuration, which would result from the annulation of the $2 R$ isomer of the alkenylamine. Here, the transition state adopted by the $2 R$ isomer of alkenylamine $\mathbf{8 9}$ has both the electronically favourable $\mathrm{OH}$ in the plane of the double bond ( $\rightarrow 4,5$-cis configuration),${ }^{88}$ and the sterically favourable 2,5-trans relationship (Chapter 2), which leads to the preferential formation of carbamate 80. In contrast, cyclisation of the $2 S$ isomer of $\mathbf{8 9}$ could give carbamates with either the 2,5-trans, 4,5-trans configuration $(\rightarrow \mathbf{8 0 a})$ or the 2,5-cis, 4,5-trans configuration. As discussed in Chapter 2, it was determined that the 2,5-cis steric interaction showed greater influence on the transition state energy, and thus it was expected that carbamate 80a would be preferentially formed.

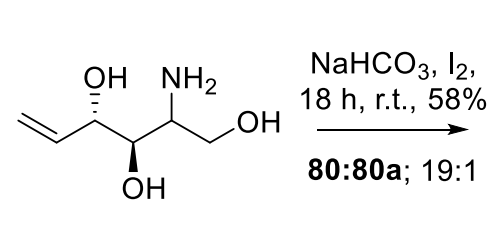

89

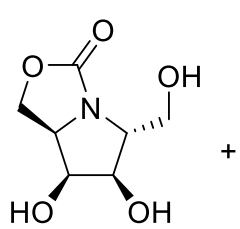

80

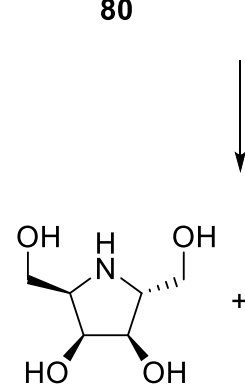

79

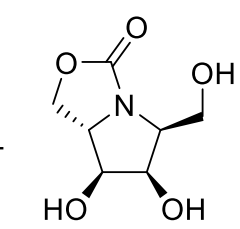

$80 a$

$\mathrm{NaOH}, \mathrm{EtOH}$ reflux, $4 \mathrm{~h}$, quant. 79:92; 19:1

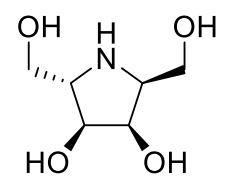

93

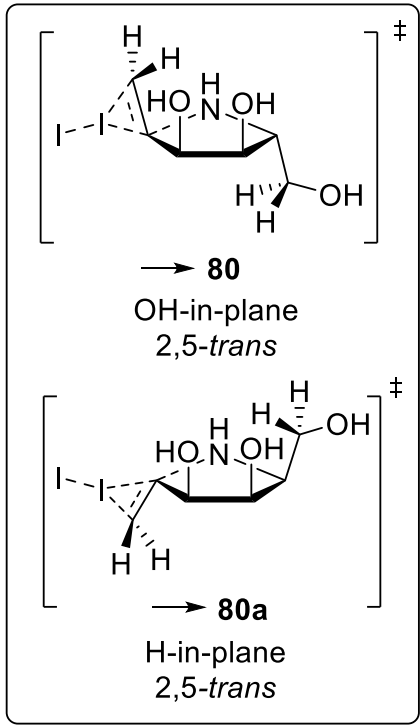

Scheme 23: Carbamate annulation of alkenylamines 89 and base-mediated hydrolysis to yield DIA 79 and 2,5-dideoxy-2,5-imino-L-altritol (93). 
To confirm the stereochemistry of the carbamates, the mixture of $\mathbf{8 0}$ and $\mathbf{8 0 a}$ was subjected to $\mathrm{NaOH}$ in ethanol at reflux for 4 hours. One product was observed by TLC $\left(\mathrm{R}_{f}=0.15 ; \mathrm{DCM} / \mathrm{EtOH} / \mathrm{MeOH} / 28 \%\right.$ aq. $\left.\mathrm{NH}_{3} 5 / 2 / 2 / 1 ; \mathrm{v} / \mathrm{v} / \mathrm{v} / \mathrm{v}\right)$, which was obtained in quantitative yield following purification using Dowex $-\mathrm{H}^{+}$resin. Analysis by NMR revealed the product to have six discrete environments in both the ${ }^{1} \mathrm{H}$ and ${ }^{13} \mathrm{C}$ spectra, revealing an asymmetrical product. The spectral data matches those of DIA (79), ${ }^{84,} 103$ however as 2,5-dideoxy-2,5-imino-L-altritol (93), ${ }^{109}$ the enantiomer of DIA (79), would have an identical NMR spectra, the optical rotation of the mixture was measured to establish that DIA was present in 89\% ee. Being enantiomers, DIA (79) and L-altritol (93) were inseparable by conventional chromatographic techniques, and this was problematic from a total synthesis point of view. Notwithstanding, the generation of these two hydroxy pyrrolidines, with only minor amounts of L-altritol (92), further supported our hypothesis that carbamate annulations with complementary electronic and steric effects give excellent yields of the 4,5-cis carbamate ( $2 R$ isomer of alkenylamine $\mathbf{8 9} \rightarrow \mathbf{8 0}$ ), while those annulation reactions with opposing steric and electronic factors give poorer yields of the corresponding carbamates ( $2 S$ isomer of alkenylamine $\mathbf{8 9} \rightarrow \mathbf{8 0 a}$ ).

\subsection{Asymmetric synthesis of 2,5-dideoxy-2,5-imino-D-altritol}

Having demonstrated the potential of the carbamate annulation en route to the formation of DIA (79), attention was then directed towards a strategy for the improved synthesis and isolation of required $2 R$ isomer of alkenylamine 89. It was observed previously that $N$-diphenylmethyl diastereomers of alkenylamines were more readily separable by silica gel flash column chromatography (Chapter 2). Moreover, when using diphenylmethylamine as the nucleophile for the reductive amination of ketone $\mathbf{9 1}$, it was possible that chelation control ${ }^{81}$ and the larger size of the amine nucleophile would favour formation of the $2 R$ isomer of alkenylamine $\mathbf{8 9}$ via intermediate VII. Gratifyingly, this proposition was correct, with the protected alkenylamine 94 being the only product observed following the treatment of ketone 91 with diphenylmethylamine and $\mathrm{NaCNBH}_{3}$ (Scheme 24). Alkenylamine 94 was then treated with TFA and triethylsilane at reflux for 2 hours to give $2 R$-alkenylamine $\mathbf{8 1}$ in $62 \%$ yield following purification using Dowex- $\mathrm{H}^{+}$ resin. The subsequent annulation of $\mathbf{8 1}$ and hydrolysis then gave DIA (79) in excellent yield. Taken together, this completed the synthesis of 2,5-dideoxy-2,5-imino-D-altritol (79) in seven steps and in a $22 \%$ overall yield. 


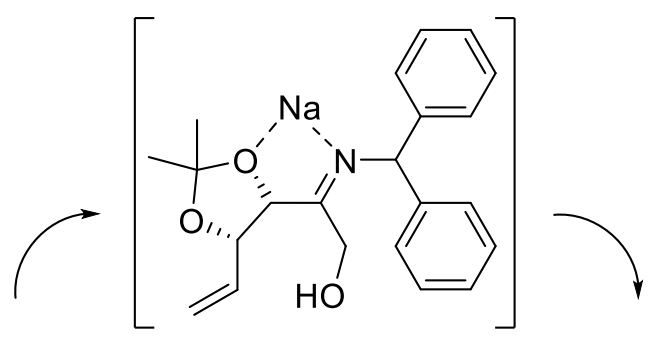

VII<smiles>C=C[C@H]1OC(C)(C)O[C@H]1C(=O)CO</smiles>

91<smiles>OC[C@H]1N[C@H](CO)[C@@H](O)[C@H]1O</smiles>

79<smiles>C=C[C@H]1OC(C)(C)O[C@H]1C(CO)NC(c1ccccc1)c1ccccc1</smiles>

TFA, $\mathrm{Et}_{3} \mathrm{SiH}$ $\downarrow$ Reflux, 2 h, 62\%

1) $\mathrm{NaHCO}_{3}$ (sat.) $\mathrm{I}_{2}$, r.t., $18 \mathrm{~h}, 96 \%$

2) $\mathrm{NaOH}, \mathrm{EtOH}$ Reflux, 4 h, 99\% $\underset{\mathrm{EtOH}, 90{ }^{\circ} \mathrm{C}}{\stackrel{\mathrm{NaCNBH}_{3}}{\longrightarrow}}$ $18 \mathrm{~h}, 61 \%$ $\mathrm{Ph}_{2} \mathrm{CHNH}_{2} \cdot \mathrm{HCl}$ 94

Scheme 24: Synthesis of DIA (79) from isopropylidine-protected ketone 91.

\subsection{Conclusion}

In conclusion, the total synthesis of 2,5-dideoxy-2,5-imino-D-altritol (DIA, 79) was successfully completed in 7 steps and $22 \%$ yield. This is not only the shortest synthesis of DIA from commercially available starting materials, but is also the highest yielding. It is envisioned that ready access to DIA will allow for more in-depth studies into the potential of this molecule as a pharmacological chaperone for the treatment of Fabry disease. Additionally, this work also further illustrates how electronic and steric influences can affect the diastereoselectivity of the $\mathrm{I}_{2}$-mediated carbamate annulation and show how these factors can be used as a predictive tool in the planning of efficient total syntheses. 


\section{Chapter 4}

\section{Novel DMJ synthesis}

\subsection{Introduction}

Minimalizing or eliminating the use of protecting groups requires a concise synthetic strategy, sometimes helped by the development of novel methodology. It was the development of the Vasella-reductive-amination and the $\mathrm{I}_{2}$-mediated carbamate annulation by Dangerfield et al. ${ }^{110}$ that led to the efficient synthesis of numerous iminosugars ${ }^{111-115}$, and alteration of this methodology leading to the efficient synthesis of DIA (79, Chapter 3). While new synthetic methodologies can be developed through the logical modification of existing chemistries, it is often an unexpected side-reaction that forms the starting point in the development of a new reaction. This chapter describes the exploration of a side reaction, which led to the discovery of a novel one-pot-two-step substitution/reduction reaction that, once optimised, was then used for the efficient synthesis of 1-deoxymannojirimycin (DMJ, 36).

\subsection{Acid mediated decomposition of 2-O-Methyl-6-deoxy-6- iodo-D-Fructofuranoside}

During the early stages of optimising the protecting group free Vasella-reductiveamination used in the synthesis of 2,5-dideoxy-2,5-imino-L-iditol (77, see chapter 2), methyl iodofructoside $\mathbf{7 4}$ was observed to be acid labile. Concentrating methyl 
iodofructoside $\mathbf{7 4}$ under slightly acidic conditions or leaving the material in a flask with trace iodine and atmospheric $\mathrm{H}_{2} \mathrm{O}$ would occasionally lead to the formation of a decomposition product. This product was isolated and examined using HRMS and NMR spectroscopy. Analysis by ${ }^{1} \mathrm{H}$ NMR showed all peaks present in methyl iodofructoside 74, with exception of the $O$-methyl peak, with HRMS further indicating the absence of a methyl group ( $m / z$ obsd: 290.9728; matching calcd. mass for $\left[\mathrm{C}_{6} \mathrm{H}_{11} \mathrm{IO} 5+\mathrm{H}\right]^{+}:$290.9724). Further examination using 2D NMR identified the decomposition product as 6-deoxy-6iodo-D-fructose $(\mathbf{9 5})$, with spectral data matching that previously reported in literature (Scheme 25). ${ }^{116,117}$

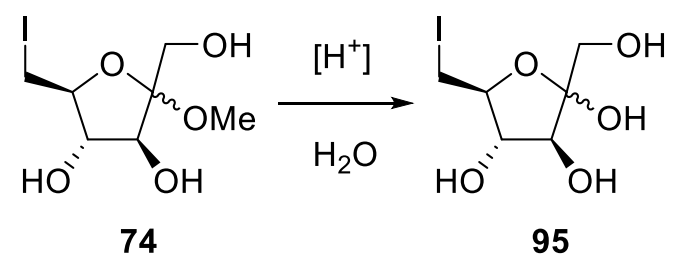

Scheme 25: Acid degradation of methyl iodofructoside 74.

Normally, methyl glycosides are very stable, with an $O$-methyl group considered difficult to remove. ${ }^{118}$ However, Fischer glycosidation is an equilibrium reaction that, in principle, is reversible. Thus, to understand why iodofructoside $\mathbf{9 5}$ formed, it is useful to examine the Fischer glycosidation of D-fructose in methanol (31, Scheme 26). Here, Fischer glycosidation begins with either furan 96 or pyran 97 undergoing acid catalysed dehydration to give the respective oxocarbenium intermediates VIII and $\mathbf{X}$ (respectively), with corresponding carbocation resonance structures IX and XI (respectively). ${ }^{118}$ Nucleophilic attack by methanol of VIII/IX gives the desired furan methyl glycoside $\mathbf{7 2}$ and similarly, attack by methanol of $\mathbf{X} / \mathbf{X I}$ gives pyran methyl glycoside $\mathbf{7 3}$. Note that until the reaction is neutralised, D-fructose (31) and methyl glycosides $\mathbf{7 2}$ and $\mathbf{7 3}$ remain in equilibrium. 


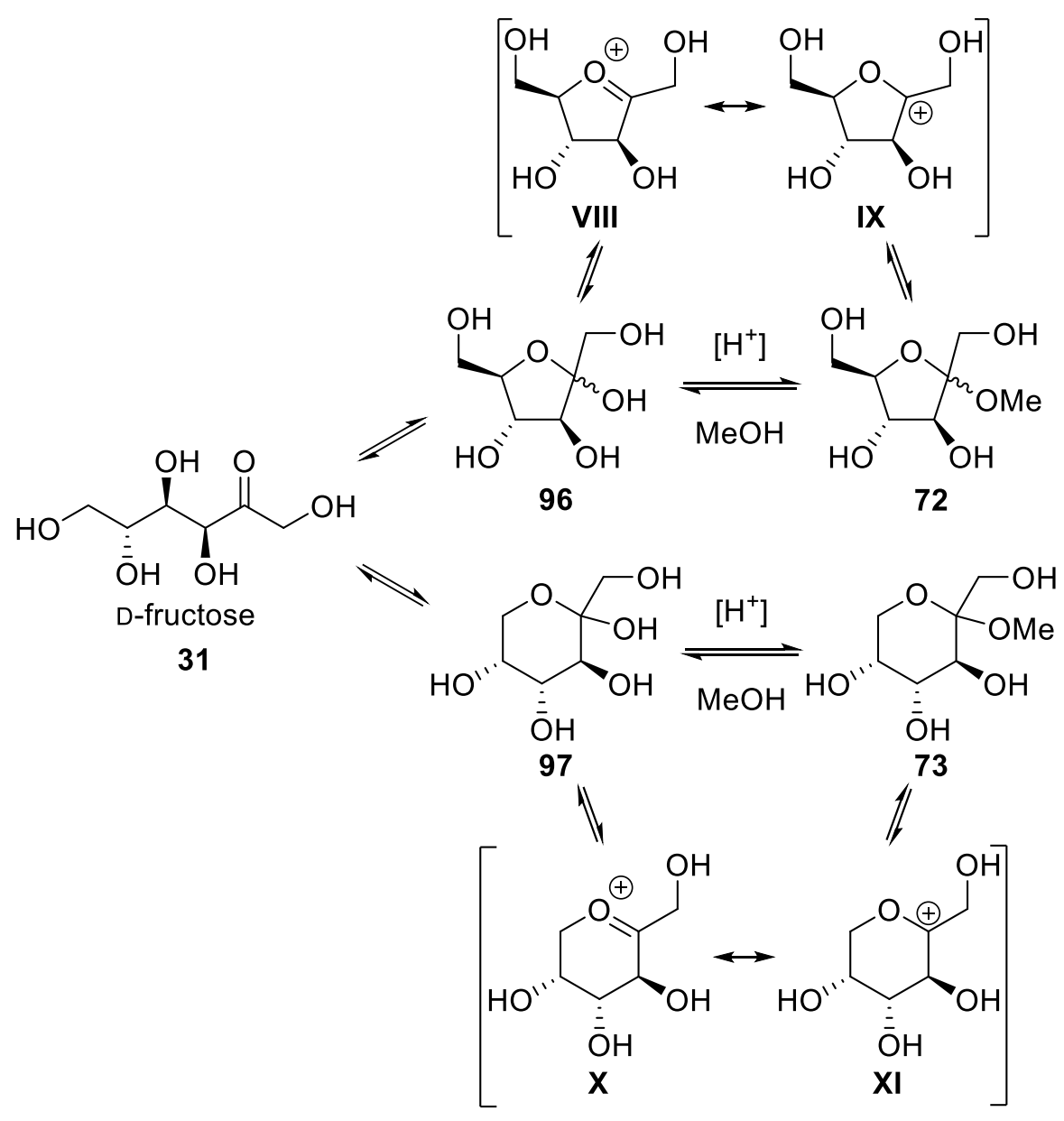

Scheme 26: Fischer glycosidation of D-fructose (31) to form methyl glycosides 72 and 73.

Under kinetic conditions the furan methyl glycoside $\mathbf{7 2}$ is formed preferentially, with thermodynamic conditions favouring formation of pyran methyl glycoside $\mathbf{7 3}$. Under kinetic conditions, the ratio of furan $\mathbf{7 2}$ and pyran $\mathbf{7 3}$ formed during glycosidation reflect the ratio of cyclic precursors 96 and 97 (respectively) that are present in solution at room temperature, where D-fructose is predominantly present as furan 96. Furthermore, intermediates VIII/IX are more stable than intermediates $\mathbf{X} / \mathbf{X I}$, with the geometry of the furan ring in VIII/IX better able to stabilise the positively charged $\mathrm{sp}^{2}$ carbon over a pyran ring. Conversely, thermodynamic conditions favour the formation of pyran methyl glycoside 73, with a pyran ring providing a final product of lower energy.

The Fischer glycosidation of D-fructose (31) is more facile than that of its aldose analogues, the latter of which used in the original work by Dangerfield et al. en route to the synthesis of pyrrolidines. ${ }^{62,65-67}$ As such, glycosidation of D-fructose (31) requires a lower concentration of acid and shorter reaction times. This increased reactivity of Dfructose (31) is due to the greater stability of the oxocarbenium intermediate VIII, as 
compared to the analogous oxocarbenium ion from the aldose sugars (XII, Figure 9). With D-fructose (31), as with any ketose sugar, the formation of the oxocarbenium intermediate is aided by the extra hydroxyl-methyl group at the anomeric carbon, which is better able to inductively stabilise the positive charge of the oxocarbenium intermediate than the hydrogen substituent present in aldoses. The steric and electronic factors that make formation of methyl glycoside $\mathbf{7 2}$ facile are also the same factors that make methyl iodofructoside $\mathbf{7 4}$ comparatively less stable. Thus, slightly acidic conditions in the presence of $\mathrm{H}_{2} \mathrm{O}$ are sufficient to cause decomposition of methyl iodofructoside $\mathbf{7 4}$ in to iodofructoside 95.

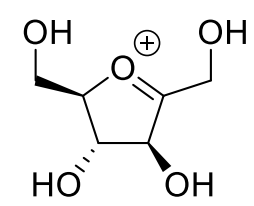

VIII

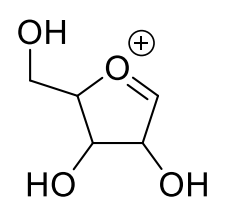

XII

Figure 9: The oxocarbenium intermediates VIII and XII resulting from D-fructose (31) and aldopentoses (respectively) during Fischer glycosidation.

\subsection{Attempted Vasella-reductive-amination of 6-deoxy-6-iodo-D- fructose (95)}

Having isolated and identified iodofructoside 95, the ability of this substrate to undergo Vasella-reductive-amination to yield alkenylamine 75 was explored. Thus, iodofructoside 95 was subjected to a Vasella-reductive-amination reaction (Scheme 27). ${ }^{62}$ Monitoring product formation by TLC proved difficult due to the presence of excess $\mathrm{AcONH}_{4}$, although starting material was observed to react completely within 30 minutes. After 18 hours at reflux, the reaction was concentrated in vacuo and purified using Dowex- $\mathrm{H}^{+}$ exchange resin. The resulting mixture was examined by NMR spectroscopy, and, despite the ${ }^{1} \mathrm{H}$ spectra of the crude reaction mixture being poorly resolved and indicating a mixture of products, it was apparent that a single major product had formed that was not the desired alkenylamine 75. This unknown product XIII $\left(\mathbf{R}_{f}=0.1\right.$ (DCM/EtOH/MeOH/30\% $\mathrm{NH}_{3}$ (aq.), 5/2/2/1, v/v/v/v) was subsequently purified by silica gel flash column chromatography (DCM/EtOH/MeOH/NH3(aq.) 20/2/2/1; v/v/v/v). 


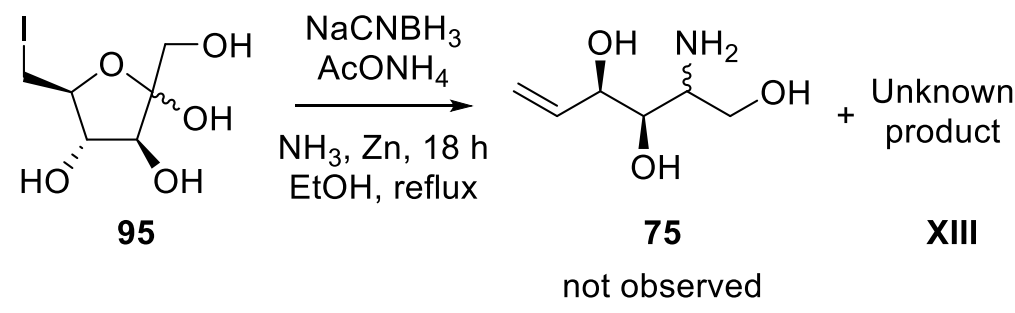

Scheme 27: attempted Vasella-reductive-amination of iodofructoside 95 resulting in unknown product XIII.

Following isolation, the structural elucidation of product XIII began with HRMS. Here, the mass of XIII was determined to be 164.0915 , corresponding to the chemical formula $\mathrm{C}_{6} \mathrm{H}_{13} \mathrm{NO}_{4}$ (calcd. $\left[\mathrm{C}_{6} \mathrm{H}_{13} \mathrm{NO}_{4}+\mathrm{H}\right]^{+}:$164.0917). This mass formula suggested the loss of iodine and, with a double bond equivalence of 1 , the presence of either an alkene, carbonyl, or ring within the structure. Furthermore, both the even mass ion peak and accuracy of the mass spectrometry peak suggest the presence of one nitrogen atom. Subsequent ${ }^{1} \mathrm{H}$ NMR spectroscopy revealed six distinct proton environments integrating for one proton, and a mulitplet (suspected as two overlapping proton environments) integrating for 2 protons, between 3.0 - 4.4 ppm (Figure 10). The ${ }^{13} \mathrm{C}$ NMR spectrum showed six signals between $45-75 \mathrm{ppm}$. Having all ${ }^{1} \mathrm{H}$ signals between 3.0-4.4 ppm eliminated the presence of an alkene, while the absence of ${ }^{13} \mathrm{C}$ signals below $10 \mathrm{ppm}$, or above $80 \mathrm{ppm}$, suggested that the molecule did not contain iodine or carbonyl groups, respectively. Taken together, the NMR data and HRMS suggested product XIII had an asymmetric poly-hydroxylated ring structure containing a nitrogen. 

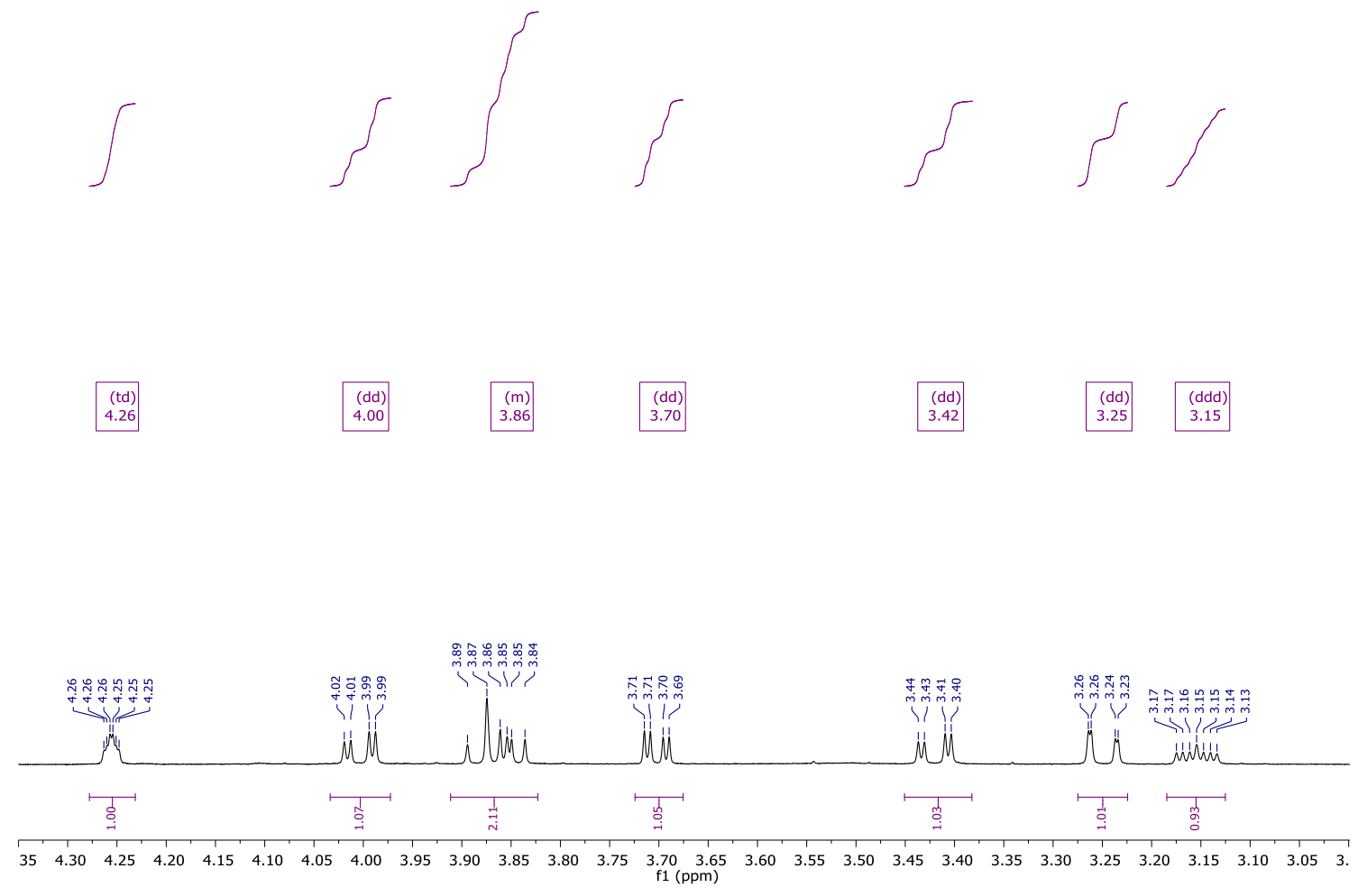

Figure 10: ${ }^{1} \mathrm{H}$ NMR spectrum of unknown product XIII.

Further structural elucidation was achieved by more closely examining the $1 \mathrm{D}$ and $2 \mathrm{D}$ NMR data (see Figure 10, and Table 2). Beginning with the apparent tenting doublet of doublets at $3.42 \mathrm{ppm}$ and $3.25 \mathrm{ppm}$ within the ${ }^{1} \mathrm{H}$ NMR spectrum, these environments both integrated for one and, as shown by HSQC, were bound to the same carbon at 47.4 ppm (assigned C1). As such, these two proton environments were assigned H1a and H1b (respectively). Analysis by COSY indicated that these two protons coupled with one another $(J=13.6 \mathrm{~Hz})$ and to a third proton $(J=3.1 \mathrm{~Hz}$ and $1.5 \mathrm{~Hz}$, for H1a and H1b respectively), establishing an easily recognisable $\mathrm{ABX}$ system. The third proton environment, a triplet of doublets at $4.26 \mathrm{ppm}$ (assigned H2), integrated for one proton and was bound to the carbon at $65.7 \mathrm{ppm}(\mathbf{C 2})$. As well as the ABX couplings, $\mathbf{H 2}$ also coupled to a doublet of doublets at $3.70 \mathrm{ppm}(\mathbf{H 3}, \mathbf{C 3}=72.2 \mathrm{ppm})$. The $J=3.1 \mathrm{~Hz}$ coupling constant between $\mathbf{H 2}$ and $\mathbf{H 3}$ suggested a syn stereochemical relationship. Moreover, COSY revealed that $\mathbf{H 3}$ coupled to a multiplet at $3.86 \mathrm{ppm}$, with HSQC indicating that this multiplet consisted of two overlapping proton resonances- one a methyne (attached to a carbon with $\delta 65.6 \mathrm{ppm}$ ), and the other one proton of a methylene (attached to a carbon with $\delta 57.9 \mathrm{ppm}$ ). Due to the multiplicity (i.e. doublet of doublets) 
of $\mathbf{H 3}$, it was clear $\mathbf{H 3}$ was not coupling to both protons in the multiplet at $3.86 \mathrm{ppm}$ or the other proton of the methylene. Thus, it was proposed that $\mathbf{C 4}$ is likely the methyne carbon at 65.6 ppm, where the relative stereochemistry between $\mathbf{H 3}$ and $\mathbf{H 4}$ would be trans $(J=9.5 \mathrm{~Hz})$. Further analysis by COSY then suggested that both protons at 3.86 ppm (H4 and the methylene proton attached to the carbon at $\delta 57.9 \mathrm{ppm})$ and the proton at $4.00 \mathrm{ppm}$ (also attached to the carbon at $\delta 57.9 \mathrm{ppm}$ ) coupled to a doublet of doublet of doublets (ddd) at $3.15 \mathrm{ppm}$, thereby indicating the presence of an ABNX system. As such, the ddd at $3.15 \mathrm{ppm}$ was assigned $\mathbf{H 5}(\mathbf{C 5}=60.0 \mathrm{ppm})$, with $\mathbf{H 5}$ coupling to both H6a $\left(\delta 4.00 \mathrm{ppm}, J_{5-6 \mathrm{a}}=3.3 \mathrm{~Hz}\right)$ and H6b $\left(\delta 3.86, J_{5-6 b}=6.8 \mathrm{~Hz}\right)$ forming the ABX system, with coupling between $\mathbf{H 5}$ and $\mathbf{H 4}\left(J_{5-4}=10.6 \mathrm{~Hz}\right)$ completing the observed ABNX system. The presence of a ring structure was confirmed via an HMBC of $\mathbf{H 5}$ with H1a and H1b. Though H5 was near C1 (HMBC), H1a and H1b only showed ABX coupling, suggesting that there is either an oxygen or nitrogen atom between $\mathbf{C 1}$ and $\mathbf{C 5}$.

Table 2: NMR data used in the structural elucidation of unknown product XIII.

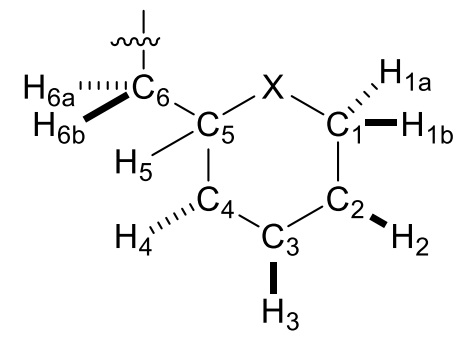

XIII

\begin{tabular}{|c|c|c|}
\hline Position & ${ }^{1} \mathrm{H}$ shift $(\delta$, ppm $)$ & $\begin{array}{l}{ }^{13} \mathrm{C} \\
(\mathrm{ppm})\end{array}$ \\
\hline $1 \mathbf{a}$ & $3.42\left(\mathrm{dd}, J_{1 \mathrm{a}, 1 \mathrm{~b}}=13.6 \mathrm{~Hz}, J_{1 \mathrm{a}, 2}=3.1 \mathrm{~Hz}, 1 \mathrm{H}\right)$ & \multirow{2}{*}{47.4} \\
\hline $\mathbf{1 b}$ & $3.25\left(\mathrm{dd}, J_{1 \mathrm{~b}, 1 \mathrm{a}}=13.6 \mathrm{~Hz}, J_{1 \mathrm{~b}, 2}=1.5 \mathrm{~Hz}, 1 \mathrm{H}\right)$ & \\
\hline 2 & $4.26\left(\mathrm{td}, J_{2,1 \mathrm{a}}=J_{2,3}=3.1 \mathrm{~Hz}, J_{2,1 \mathrm{~b}}=1.5 \mathrm{~Hz}, 1 \mathrm{H}\right)$ & 65.7 \\
\hline 3 & $3.70\left(\mathrm{dd}, J_{3,4}=9.5 \mathrm{~Hz}, J_{3,2}=3.1 \mathrm{~Hz}, 1 \mathrm{H}\right)$ & 72.2 \\
\hline 4 & $3.86(\mathrm{~m}, 2 \mathrm{H})\left[\mathrm{dd}, J_{4,5}=10.3 \mathrm{~Hz}, J_{3,4}=9.5 \mathrm{~Hz}, 1 \mathrm{H}\right]$ & 65.6 \\
\hline 5 & $\begin{array}{l}3.15\left(\mathrm{ddd}, J_{5,4}=10.3 \mathrm{~Hz}, J_{5,6 \mathrm{a}}=6.7 \mathrm{~Hz}, J_{5,6 \mathrm{~b}}=3.3 \mathrm{~Hz} \text {, }\right. \\
1 \mathrm{H})\end{array}$ & 60.0 \\
\hline $6 \mathbf{a}$ & $3.86(\mathrm{~m}, 2 \mathrm{H})\left[\mathrm{dd}, J_{6 \mathrm{a}, 6 \mathrm{~b}}=12.6 \mathrm{~Hz}, J_{6 \mathrm{a}, 5}=6.7 \mathrm{~Hz}, 1 \mathrm{H}\right]$ & \multirow{2}{*}{57.9} \\
\hline $6 \mathbf{b}$ & $4.00\left(\mathrm{dd}, J_{6 \mathrm{~b}, 6 \mathrm{a}}=12.6 \mathrm{~Hz}, J_{6 \mathrm{~b}, 5}=3.3 \mathrm{~Hz}, 1 \mathrm{H}\right)$ & \\
\hline
\end{tabular}

Relevant HMBC coupling: C5-H1; C1-H5; C4-H5 (strong), H6 (weak). 
The IR of this compound, however, did not show a clear doublet above $3200 \mathrm{~cm}^{-1}$, implying there is only one N-H stretch, which requires $\mathrm{X}$ to be nitrogen. Based on the HRMS data, four oxygen atoms and four hydrogen atoms were unaccounted for, thus suggesting that $\mathbf{C 2}, \mathbf{C 3}, \mathbf{C 4}$, and $\mathbf{C 6}$ were attached to a hydroxyl group. Whilst the stereochemistry about C5 remained unclear, it was quickly noted that the proposed structure of unknown product XIII (Figure 11) resembled the relative configuration of well-known iminosugars 1-deoxymannojirimycin (DMJ) and its 5-epimer. Examination of published spectral data ${ }^{119}$ and subsequent optical rotation measurements $\left([\alpha]_{D}^{20}-15.7\right.$ [c 1.6, $\mathrm{H}_{2} \mathrm{O}$ ]; lit. ${ }^{120}[\alpha]_{D}^{20}-15.0$ [c 2, $\left.\mathrm{H}_{2} \mathrm{O}\right]$ ) confirmed the structure of unknown product XIII as 1-deoxymannojirimycin (DMJ, 36). DMJ was first isolated in 1979 by Fellows and Bell from Lonchocarpus sericeus ${ }^{121}$, and found to be a moderate $\alpha$-mannosidase and strong mammalian $\alpha$-fucosidase inhibitor, ${ }^{122}$ several notable syntheses of DMJ were subsequently achieved. ${ }^{120,123,124}$<smiles>OC[C@H]1NC[C@@H](O)[C@@H](O)[C@H]1O[Si]</smiles><smiles>C#CC[C@H]1NC[C@@H](O)[C@@H](O)[C@H]1O</smiles>

36

Figure 11: Elucidation of unknown product XIII as DMJ (36) via comparing NMR spectra and optical rotation data to literature.

Having determined that the structure of the unknown product was DMJ, it remained to be determined how this product could be formed from iodofructoside $\mathbf{9 5}$ under Vasellareductive-amination reaction conditions (Scheme 28). The stereochemistry at C3, C4, and C5 in iodofructoside 95 matched that of $\mathrm{C} 4, \mathrm{C} 3$, and $\mathrm{C} 2$, respectively, in DMJ and suggested that a cascade of reactions was occurring, including a reductive amination, cyclisation, and iodide displacement, which would in turn dictate the stereochemistry at C5 in DMJ (36). However, before the details of the reaction mechanism were explored, efforts were made towards optimising the synthesis of DMJ, which required both an efficient synthesis of iodofructoside $\mathbf{9 5}$ and its subsequent conversion into DMJ. 


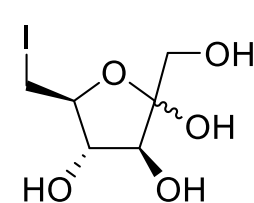

95

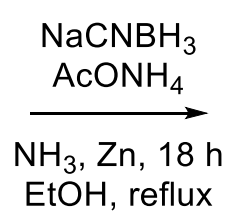

EtOH, reflux

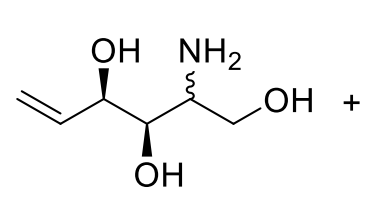

75

not observed<smiles>OCC1NCC(O)C(O)[C@@H]1O</smiles>

36

$>75 \%$

Scheme 28: The attempted Vasella-reductive-amination of iodofructoside 95 resulting in DMJ (36) formation.

\subsection{Optimising the synthesis of 1-deoxymannojirimycin (DMJ)}

The optimisation of converting methyl iodofructoside $\mathbf{7 4}$ to iodofructoside 95 began with subjecting methyl iodofructoside $\mathbf{7 4}$ to aqueous $\mathrm{HCl}$ at $0.09 \mathrm{M}$ (entry 1, Table 3). Here, it was thought that exposing methyl iodofructoside $\mathbf{7 4}$ to the same acid concentration used for the Fischer glycosidation of D-fructose (3) would be sufficient to re-establish the equilibrium between methyl iodofructoside $\mathbf{7 4}$ and iodofructoside $\mathbf{9 5}$, with the presence of excess of $\mathrm{H}_{2} \mathrm{O}$ favouring the formation of iodofructoside 95. Analysis of the reaction by TLC, however, revealed only partial demethylation occurred after stirring at r.t. for 3 hours (entry 1), with extending the reaction time to 18 hours (entry 2) also not improving product yields. Bringing the reaction mixture to reflux led to greater formation of iodofructoside 95, however after half an hour, all material had degraded (entry 3 ). Thus, rather than heating at reflux, the reaction was warmed to $50{ }^{\circ} \mathrm{C}$ under reduced pressure $(0.3 \mathrm{~atm})$ in an effort to remove the $\mathrm{MeOH}$ that formed during the reaction (entry 4$)$. This resulted in approximately $75 \%$ conversion to the desired iodofructoside 95 after 7 hours (entry 4). While this was encouraging, it was preferable to avoid the need for heat or reduced pressure and thus the acid concentration was increased to $0.15 \mathrm{M}$, thereby allowing for complete conversion of methyl iodofructoside $\mathbf{7 4}$ to iodofructoside 95 (via TLC) after 3 days (entry 5). This reaction time can be dramatically reduced via the use of reduced pressure and a $50{ }^{\circ} \mathrm{C}$ water bath (entry 6). All reactions were performed with the substrate at a dilute concentration of $10 \mathrm{~mL} / \mathrm{mmol}$ to further favour demethylation, with larger scale reactions (>0.5 g) requiring slightly longer reaction times. 


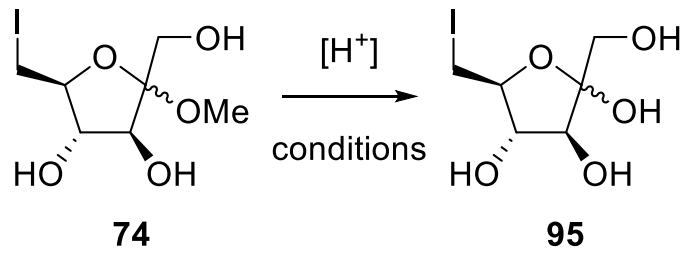

\begin{tabular}{ccccc}
\hline Entry & $\begin{array}{c}\text { HCl conc } \\
(\text { molar })^{\mathrm{a}}\end{array}$ & Temp. (time) & $\begin{array}{c}\text { Pressure } \\
(\text { atm })^{\mathrm{b}}\end{array}$ & Conversion $^{\mathrm{c}}$ \\
\hline 1 & 0.09 & r.t. $(3 \mathrm{~h})$ & 1 & $50 \%$ \\
2 & 0.09 & r.t. $(18 \mathrm{~h})$ & 1 & $50 \%$ \\
3 & 0.09 & reflux $(0.5 \mathrm{~h})$ & 1 & degraded \\
4 & 0.09 & $50(7 \mathrm{~h})$ & 0.3 & $75 \%$ \\
5 & 0.15 & r.t. $(3 \mathrm{~d})$ & 1 & completion \\
6 & 0.15 & $50(2-3 \mathrm{~h})$ & 0.3 & completion \\
\hline
\end{tabular}

a) All reactions done at a substrate concentration of $10 \mathrm{~mL} / \mathrm{mmol}$

b) reduced pressure achieved using a rotatory evaporator

c) All conversions approximated by TLC

With the conditions for demethylation optimised, the next step was to determine the optimal conditions for the formation of DMJ (36). Initially, the synthesis of DMJ (36) was achieved using a batch of iodofructoside 95 that had unintentionally formed from the long-term storage methyl iodofructoside 74. Thus, upon subjecting this batch of iodofructoside 95 to Vasella-reductive-amination conditions, DMJ (36) was formed in $\approx 80 \%$ yield (entry 1, Table 4). Whilst encouraging, it was important to develop a robust protocol that could be consistently repeated, therefore methyl iodofructoside $\mathbf{7 4}$ was demethylated using optimised conditions and subjected to further reaction conditions (entries 2-7). To assess the requirement of zinc in the reaction, freshly made iodofructoside 95 was subjected to $\mathrm{NH}_{3}$ and $\mathrm{NH}_{4} \mathrm{OAc}$ in the presence of $\mathrm{NaCNBH}_{3}$ at 80 ${ }^{\circ} \mathrm{C}$ for 18 hours (entry 2). The reaction mixture was then concentrated and purified via Dowex $-\mathrm{H}^{+}$resin and by silica flash column chromatography to give DMJ (36) in $88 \%$ yield. In proving that zinc was not required for the reaction, the need for the use of 
ammonium salts was explored. To this end, iodofructoside 95 was treated to the same reaction conditions but in the absence of $\mathrm{NH}_{4} \mathrm{OAc}$ (entry 3 ). Again, this led to the desired product in approximately the same yield (89\%). Next it was hoped that increasing the reaction concentration would allow the reaction to be performed at lower temperatures. As such, iodofructoside $\mathbf{9 5}$ was subjected to the same reagents at a reduced substrate concentration of $15 \mathrm{~mL} / \mathrm{mmol}$ and at room temperature for 18 hours (entry 4). Gratifyingly, this gave an isolated yield of DMJ (36) of 96\%. Next, the effect of reaction time on product yield was explored. Here, shorter reaction times $(9 \mathrm{~h}$, entry $6 ; 6 \mathrm{~h}$ entry 7) showed decreased yields of DMJ (36), while longer reaction times (3 days, entry 8) did not increase product yield. 
<smiles>OC[C@]1(O)O[C@H](CI)[C@@H](O)[C@H]1O</smiles>

95<smiles>O=C(O)O[Na]</smiles>

DMJ

36

\begin{tabular}{|c|c|c|c|c|}
\hline Entry & Reagents $^{\mathrm{a}, \mathrm{b}}$ & Solvent (conc) & Temp. (time) & Yield $^{c, c}$ \\
\hline $1^{\mathrm{e}}$ & $\begin{array}{c}\mathrm{Zn}\left(10 \text { equiv.), } \mathrm{NH}_{3} \text { (aq.) }\right. \\
\text { (144 equiv.), } \mathrm{NH}_{4} \mathrm{OAc} \\
\text { (130 equiv.) }\end{array}$ & $\begin{array}{c}\mathrm{EtOH} \\
(28 \mathrm{~mL} / \mathrm{mmol})\end{array}$ & Reflux (18 h) & $>80 \%$ \\
\hline $2^{\mathrm{f}}$ & $\begin{array}{l}\mathrm{NH}_{3} \text { (aq.) }(90 \text { equiv.), } \\
\mathrm{NH}_{4} \mathrm{OAc}(130 \text { equiv.) }\end{array}$ & $\begin{array}{c}\mathrm{H}_{2} \mathrm{O} \\
(28 \mathrm{~mL} / \mathrm{mmol})\end{array}$ & $80^{\circ} \mathrm{C}(18 \mathrm{~h})$ & $88 \%$ \\
\hline $3^{\mathrm{f}}$ & $\mathrm{NH}_{3}$ (aq.) (90 equiv.) & $\begin{array}{c}\mathrm{H}_{2} \mathrm{O} \\
(28 \mathrm{~mL} / \mathrm{mmol})\end{array}$ & $80{ }^{\circ} \mathrm{C}(18 \mathrm{~h})$ & $89 \%$ \\
\hline $4^{\mathrm{f}}$ & $\mathrm{NH}_{3}$ (aq.) (90 equiv.) & $\begin{array}{c}\mathrm{H}_{2} \mathrm{O} \\
(15 \mathrm{~mL} / \mathrm{mmol})\end{array}$ & r.t. $(18 \mathrm{~h})$ & $96 \%$ \\
\hline $6^{\mathrm{f}}$ & $\mathrm{NH}_{3}$ (aq.) (90 equiv.) & $\begin{array}{c}\mathrm{H}_{2} \mathrm{O} \\
(15 \mathrm{~mL} / \mathrm{mmol})\end{array}$ & r.t. $(9 \mathrm{~h})$ & $92 \%$ \\
\hline $7^{\mathrm{f}}$ & $\mathrm{NH}_{3}$ (aq.) (90 equiv.) & $\begin{array}{c}\mathrm{H}_{2} \mathrm{O} \\
(15 \mathrm{~mL} / \mathrm{mmol})\end{array}$ & r.t. $(6 \mathrm{~h})$ & $91 \%$ \\
\hline $7^{\mathrm{f}}$ & $\mathrm{NH}_{3}$ (aq.) (90 equiv.) & $\begin{array}{c}\mathrm{H}_{2} \mathrm{O} \\
(15 \mathrm{~mL} / \mathrm{mmol})\end{array}$ & r.t. $(72$ h) & $96 \%$ \\
\hline
\end{tabular}

a) All reactions used 4 equiv. of $\mathrm{NaCNBH}_{3}$

b) All reagents added in one step

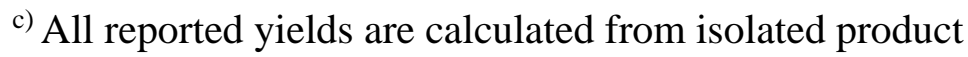

d) All reactions gave DMJ (36) stereoselectively

e) iodofructoside 95 was formed unintentionally, neat, in the presence of $\mathrm{I}_{2}$ and used without concentrating or purification

f) iodofructoside $\mathbf{9 5}$ formed using optimised conditions, all reagents were added to the crude reaction mixture 
In summary, the initially formed iodofructoside 95, prepared via an in situ acid mediated deprotection of methyl iodofructoside 74, can be converted to DMJ (36) over a two-stepone-pot reaction in $96 \%$ yield. As a result, the total synthesis of DMJ (36) is achieved over 3 steps in $62 \%$ overall yield from readily available D-fructose (31), representing the shortest and highest yielding total synthesis of DMJ (36) from readily available starting material. DMJ has been synthesised using various stratergies, the most comparable synthesis was published by Furneaux, Tyler, and Whitehouse, where their seminal synthesis gave DMJ (36) from D-fructose (31) in 5 steps and $25 \%$ overall yield. ${ }^{120}$ Similarly, Maier, Anderson, and Lundt reported on DMJ synthesis over 7 steps and 35\% overall yield from 1,5-anhydro-D-fructose. ${ }^{123}$ Whilst difficult to discern if the work reported here bests all known enzymatic processes developed for the synthesis of other norijirymicins that could be employed for the synthesis of DMJ (36), ${ }^{57,59}$ the work reported here does improve on published DMJ (36) syntheses utilising enzymatic catalysis. ${ }^{125,126}$

\subsection{The mechanism of DMJ formation from 6-deoxy-6-iodo-D- fructose (94)}

When examining how iodofructoside 95 can form DMJ (36) in the presence of only $\mathrm{NH}_{3}$ and $\mathrm{NaCNBH}_{3}$, it is important to note that there are three possible reaction pathways, each requiring a different sequence of imine formation, iodide substitution, and imine reduction (Scheme 29). Key in pathway A is the nucleophilic substitution of iodine in iodofructoside $\mathbf{9 5}$ (or linear ketone $\mathbf{9 8}$ ) in the presence of $\mathrm{NH}_{3}$ to form linear amine $\mathbf{9 9}$, which then undergoes intramolecular imine formation to give cyclic imine $\mathbf{1 0 0}$ and subsequent stereoselective reduction to give DMJ (36). Pathway B begins with formation of linear imine $\mathbf{1 0 1}$ followed by intramolecular iodide substitution to again give cyclic imine 100, which, following reduction, gives DMJ (36). Finally, pathway $\mathrm{C}$ also involves formation of linear amine 101, with stereoselective reduction giving linear amine $\mathbf{1 0 2}$ and subsequent intramolecular iodide substitution giving DMJ (36). 


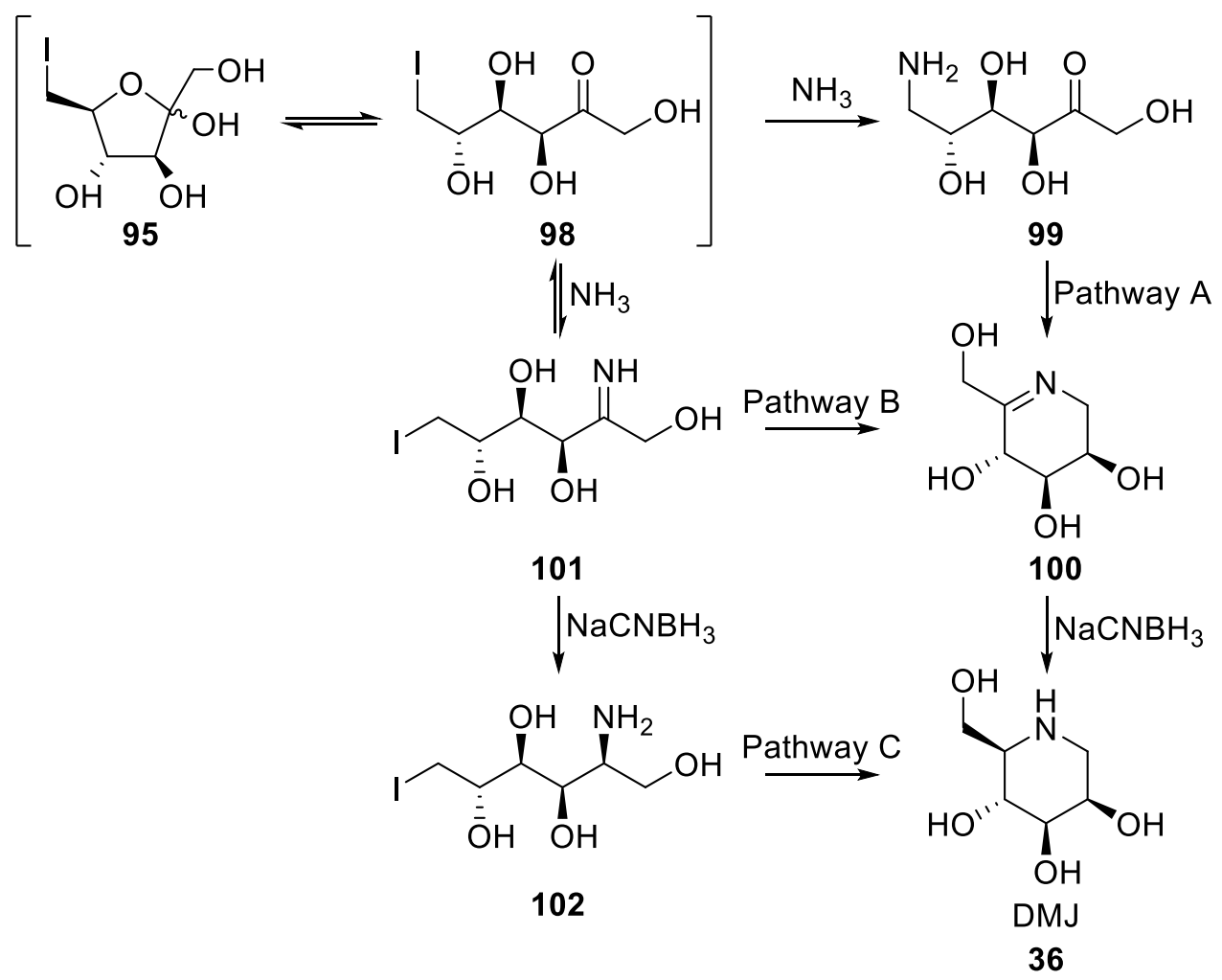

Scheme 29: The possible reaction pathways of DMJ (36) formation from 6-deoxy-6-iodoD-fructose (95).

Examination of the mechanism for the synthesis of DMJ (36) from iodofructoside 95 began with exploring the likelihood of pathway A. To test the feasibility of $\mathrm{NH}_{3}$ causing nucleophilic displacement of iodide, methyl iodofructoside $\mathbf{7 4}$ was subjected to concentrated aqueous $\mathrm{NH}_{3}$ (Scheme 30). Despite extended reaction times and eventually bringing the reaction to reflux, no formation of amine 103 was observed. Thus, pathway A was considered unlikely.

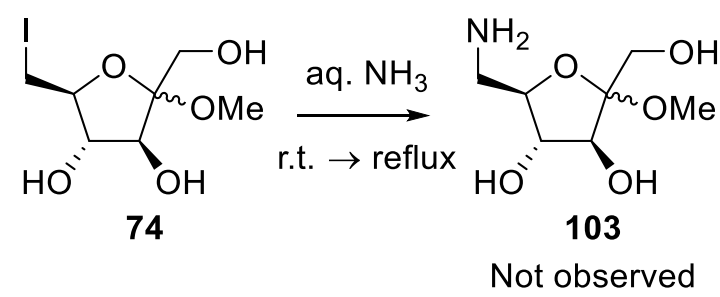

Scheme 30: The attempted synthesis of amine 103 via iodide displacement.

Next, the stereospecificity of pathway C was explored, whereby D-fructose (31) was exposed to the reductive amination conditions used to prepare DMJ (36) from iodofructoside 95 (Scheme 31). The resulting amine 104 was formed as a mixture of 
diastereomers, with no apparent diastereoselectivity. This result is in agreement with the reductive amination studies described earlier in Chapters 2 and 3, however, the lack of stereoselectivity observed en route to the synthesis of DMJ (36) indicates that pathway C is unlikely.

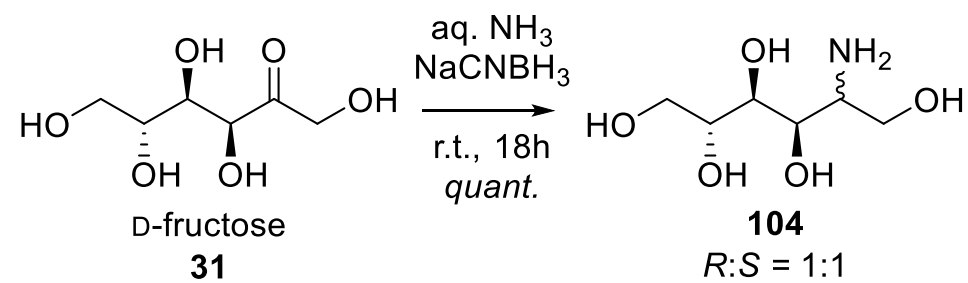

Scheme 31: Reductive amination of D-fructose (31).

To provide evidence to support the likelihood of Pathway B being the mechanism that leads to the synthesis of DMJ (36), the relevant literature was examined. The key piece of evidence for the reaction following pathway B can be found by considering the stereoselective formation of DMJ (36). Previous syntheses of DMJ (36) resulting from the reduction of cyclic imine $\mathbf{1 0 0}$, formed either in situ or through the use of protecting groups, demonstrated that reduction of cyclic imine $\mathbf{1 0 0}$ consistently favours the formation of DMJ (36, Scheme 32). Through amine instalation to generate ketone 99, ${ }^{120 \text {, }}$ 127 the in situ formation and subsequent reduction of cyclic imine 100 gave DMJ formation stereoselectively, with cyclic imine $\mathbf{1 0 0}$ being proposed as an intermediate during reduction. The use of a double reductive amination of di-carbonyl 105 to give DMJ is similarly postulated to pass through cyclic imine 100. ${ }^{128,129}$ Here, the more reactive aldehyde at the 6-position is proposed to undergo reductive amination first (giving 99), which after subsequent cyclisation, leads to the formation of cyclic imine 100. Note however, that synthesis of DMJ (36) via double reductive amination is not stereoselective, with the DMJ 5-epimer having been isolated as a minor product from the reaction. The formation of the DMJ 5-epimer was considered a result of minor amounts of the ketone in di-carbonyl 105 undergoing a non-stereoselective reductive amination first. Lastly, cyclic imine $\mathbf{1 0 0}$ has been synthesised through the reaction of ketone $\mathbf{1 0 6}$ (vide supra Scheme 5, page 9). Here, a protected imine equivalent of $\mathbf{1 0 6}$ was partially deprotected to undergo intramolecular displacement of a mesylate leaving group (LG) at the 6position to generate the oxy-imine equivalent of cyclic imine 100, which was actually isolated before being reduced. ${ }^{130}$ 
<smiles>O=C[C@H](O)[C@@H](O)C(O)C(=O)CO</smiles><smiles>C[Ge](C)(C[C@@H](O)[C@H](O)[C@@H](O)C(=N)CO)C(=O)O</smiles>

Scheme 32: Strategies leading to the formation of cyclic imine 100 towards the synthesis of DMJ (36).

All the publications that postulate or knowingly form, and subsequently reduce, cyclic imine 100 note that the preferential or selective formation of DMJ (36) is a result of conformation, where the lowest energy pathway of imine reduction occurs on a conformation with the maximum number substituents of cyclic imine $\mathbf{1 0 0}$ in a pseudoequatorial orientation. Examining both possible conformers of cyclic imine 100 (100a, 100b, Figure 12), conformer 100a can undergo reduction from the $R e$ or $S i$ face, resulting in formation of 107a and 36a (respectively) and conformer 100b can undergo Re or $S i$ facial reduction to give $\mathbf{1 0 7 b}$ and $36 \mathbf{b}$ (respectively). Whilst 107a,b and 36a,b are just conformers of each other, it is the conformation during reduction that determines the relative transition state energies. Here, the conformer 100a has the greatest number of substituents in pseudo-equatorial position, where reduction from the $S i$ face of this conformer puts the bulky hydroxy methyl group (denoted R) into pseudo-equatorial orientation during the transition state, thus favouring formation of 36a, and, in turn, DMJ (36). 


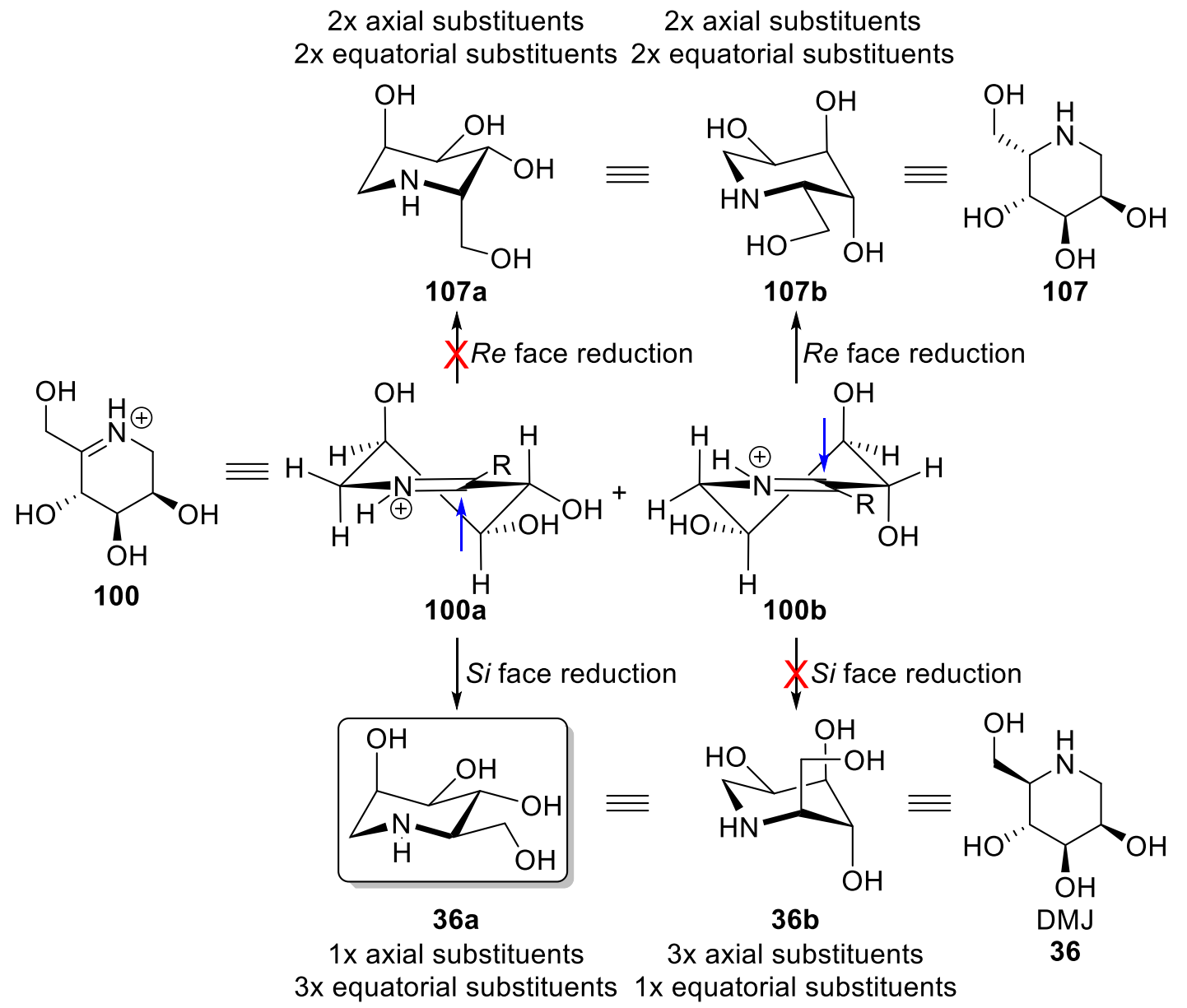

Figure 12: possible conformers of cylic imine 100 and the possible reductions leading to DMJ (36) and the 4-epimer 107.

Whilst preferential formation of DMJ from the reduction of cyclic imine $\mathbf{1 0 0}$ has been explained by the impact of conformation on transition state energies, minimal attention has been given to the steric effects of the neighbouring 4-hydroxyl. Cheng et al. explored the steric factors impacting the nucleophilic attack of the related cyclic imine $\mathbf{1 0 8}$ (Scheme 33). ${ }^{131}$ Here, the attack of a sterically bulky nucleophile (Nu, e.g. isopropylMgBr or $\mathrm{BnMgBr}$ ) occurs preferentially from the opposite face of the neighbouring benzyl protected hydroxyl (109). As the $\mathrm{Nu}$ becomes smaller (e.g. vinylMgBr) facial selectivity is reduced, with the 2,3-anti adduct remaining the major product 110 (anti:syn 95:5, respectively). In the reduction of cyclic imine 100, the major product DMJ (36) results from the attack of imine $\mathbf{1 0 0}$ from the more sterically hindered face, suggesting that conformation impacts the transition state energy greater than the minimal steric interactions between $\mathrm{NaCNBH}_{3}$ and neighbouring 4-hydroxyl of imine 100. 


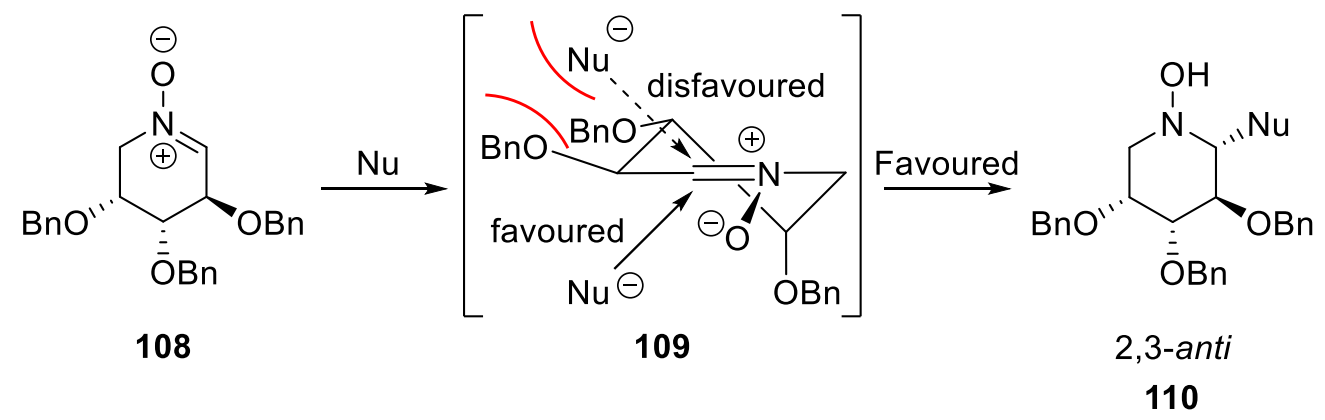

Scheme 33: Synthesis of iminosugar derivatives (110) via the nucleophilic attack of cyclic imine 108.

Through the examination of each possible pathway, both observed results and literature suggest that iodofructoside $\mathbf{9 5}$ undergoes imine formation, intramolecular substitution, and finally stereoselective imine reduction to give DMJ. The stereoselective formation of $\mathrm{DMJ}$ is rationalised through cyclic imine $\mathbf{1 0 0}$ forming the conformation with the most substituents in pseudo-equatorial positions to reduce the transition state energy of imine reduction, with the unfavourable steric interactions between $\mathrm{NaCNBH}_{3}$ and neighbouring 4-hydroxyl of imine $\mathbf{1 0 0}$ considered to have minimal effects. This theory implies that imine-mediated cyclisation of linear imine $\mathbf{1 0 1}$ to give cyclic imine $\mathbf{1 0 0}$ is faster than the reduction of $\mathbf{1 0 1}$ to give linear amine $\mathbf{1 0 2}$, thus also suggesting that imine reduction is the rate determining step.

\subsection{Conclusion}

In conclusion, the acid-mediated degradation of methyl iodofructoside $\mathbf{7 4}$ lead to the discovery that iodofructoside 95 can be converted into DMJ (36) stereoselectively in one step when treated with $\mathrm{NH}_{3}$ and $\mathrm{NaCNBH}_{3}$. Iodofructoside 95 is proposed to form $\mathrm{DMJ}$ (36) through rapid imine formation, followed by intramolecular iodide substitution and subsequent stereoselective imine reduction. Here, reduction of cyclic imine $\mathbf{1 0 0}$ occurs on the conformer with the greatest number of substituents in pseudo-equatorial position, with reduction preferentially occurring from the face that puts the bulky hydroxy methyl group into pseudo-equatorial orientation, minimalising the resulting transition state energy. The disfavoured steric interactions between $\mathrm{NaCNBH}_{3}$ and the neighbouring 4hydroxyl of imine $\mathbf{1 0 0}$ are considered to have minimal impact on the transition state energy. After optimisation, the total synthesis of DMJ (36) from D-fructose (31) was 
achieved over 3 steps in an impressive $62 \%$ overall yield. To date, this synthesis is the highest yielding and shortest synthesis of DMJ (36) from cheap, readily available starting materials. Moreover, the synthetic route is applicable to the synthesis of numerous other iminosugars and iminosugar derivatives. 


\section{Chapter 5}

\section{Novel synthesis of piperidines and an azepane}

\subsection{Introduction and retro synthesis}

During the synthesis of 2,5-dihydroxymethyl-3,4-dihydroxypyrrolidines from D-fructose (Chapter 2), it was discovered that methyl 6-deoxy-6-iodo-D-fructofuranoside was acid labile. Furthermore, it was discovered that exposing the product resulting from acidmediated degradation (6-deoxy-6-iodo-D-fructofuranoside) to reductive amination conditions gave DMJ selectively and in high yield (Chapter 4). As a result, a novel method of DMJ synthesis was developed, giving DMJ over 3 steps from D-fructose in $62 \%$ overall yield, and a mechanism was postulated that suggested the stereoselective formation of DMJ resulted from the selective reduction of a cyclic imine intermediate.

In this chapter, studies into the scope and limitations of this newly identified synthetic strategy will be presented. Thus, a general retrosynthetic strategy employing the aforementioned reductive amination methodology was proposed for the synthesis of a variety of iminosugars (Scheme 34). Here, the desired iminosugar XIV would be generated from the respective methyl iodoglycoside $\mathbf{X V}$ via demethylation and subsequent reductive amination, with methyl iodoglycoside $\mathbf{X V}$ being synthesised from a given naturally occurring carbohydrate XVI through Fischer glycosidation and subsequent iodination. Initially, it was desired to examine the effect of configuration on the efficiency and selectivity of imine reduction, thus syntheses beginning from various stereoisomers of D-fructose ( $n=1, \mathrm{R}=\mathrm{CH}_{2} \mathrm{OH}$ ) would be performed. Following this, the scope of this synthetic strategy would be explored using various aldose sugar starting materials $(n=1$ or $2, \mathrm{R}=\mathrm{H})$. 


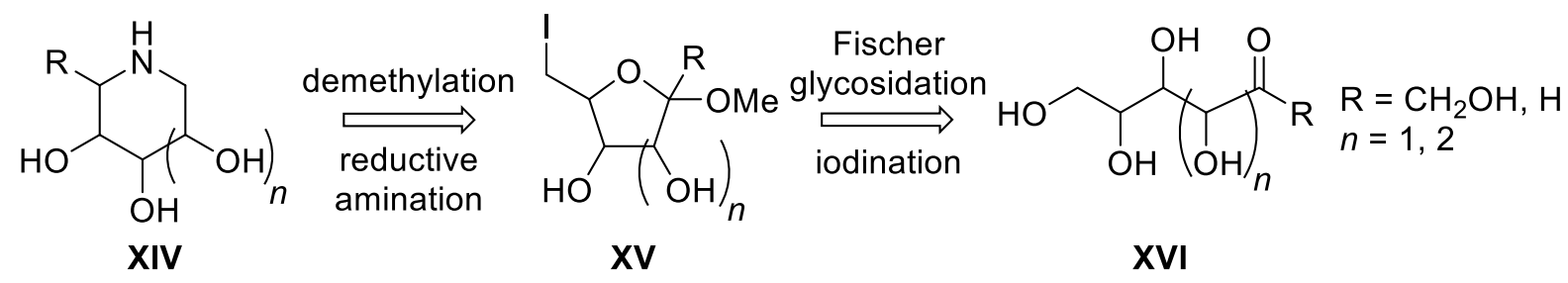

Scheme 34: The retrosynthesis of iminosugars utilising the synthetic strategy developed in Chapter 4.

\subsection{Synthesis of 6-deoxynojirimycin (DNJ)}

First, the synthesis of 1-deoxynojirimycin from L-sorbose (111) was studied. Accordingly, L-sorbose (111) was subjected to previously reported ${ }^{132}$ Fischer glycosidation conditions, which, after purification, gave $\alpha / \beta$-furan methyl glycosides 112 in 55\% yield (Scheme 35). Along with furans 112, the pyran methyl sorbosides 113 were also formed $(\mathbf{1 1 2 : 1 1 3}=3: 2)$.

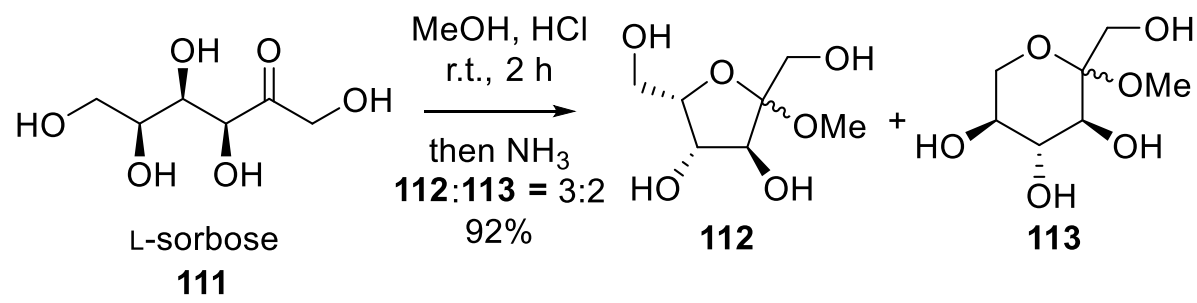

Scheme 35: Fischer glycosidation of L-sorbose (111).

Next, the iodination of methyl glycosides 112 was attempted. Initial attempts using previously optimised conditions on a mixture of impure methyl sorbosides $\mathbf{1 1 2}$ and $\mathbf{1 1 3}$ did not yield any desired methyl iodoglycoside 114. As such, methyl sorbofuranosides 112 were isolated and iodination of this material attempted, first using $\mathrm{PPh}_{3}, \mathrm{I}_{2}$, and imidazole at $150{ }^{\circ} \mathrm{C}$ (entry 1, Table 5). Here, no desired product was observed, although TLC analysis revealed that methyl sorboside 112 was being consumed during the reaction. It was thought that either the starting materials or desired products were decomposing at the high reaction temperature $\left(70{ }^{\circ} \mathrm{C}\right)$. Thus, iodination of methyl sorbosides 112 was attempted at the lower temperature of $55^{\circ} \mathrm{C}$ (entry 2), with the desired product being isolated in a modest $35 \%$ yield. Using a higher number of equivalents of 
iodine led to increased reaction yields to give methyl iodoglycoside 114 in an isolated yield of $78 \%$ (entry 3 ).

Table 5: lodination conditions for the formation of methyl iodosorbosides 114.

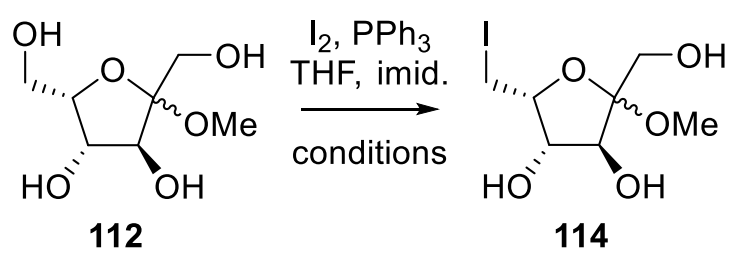

\begin{tabular}{cccc}
\hline Entry & Reagents $^{\mathrm{a}}$ & $\left.\operatorname{Temp}^{\circ} \mathrm{C}\right)$ & Yield \\
\hline 1 & $\mathrm{PPh}_{3}(2$ equiv. $)$ & 70 & $\mathrm{NA}$ \\
& $\mathrm{I}_{2}(1.5$ equiv. $)$ & & \\
2 & $\mathrm{PPh}_{3}(2$ equiv. $)$ & $55 \%$ & $35 \%$ \\
& $\mathrm{I}_{2}(1.5$ equiv. $)$ & & $78 \%$ \\
3 & $\mathrm{PPh}_{3}(2.5$ equiv. $)$ & 55 & \\
\hline
\end{tabular}

a) All reactions used 3 equiv. of imidazole, in THF, with $\mathrm{I}_{2}$ dissolve in THF and added dropwise to a heated solution of all other reagents.

With methyl iodosorboside 114 now in hand, the material was deprotected using previously optimised conditions to give full conversion to iodosorboside $\mathbf{1 1 5}$, as observed by TLC (Scheme 36). Exposure of the crude iodosorboside 115 to reductive amination conditions, followed by purification using Dowex $-\mathrm{H}^{+}$ion exchange resin and silica gel flash column chromatography gave DNJ (3) in 95\% yield from methyl iodosorboside 114. As observed during DMJ synthesis (Chapter 4), the lowest energy pathway of imine reduction seems to occur via the conformation of cyclic imine XVII. Here, the maximum number of substituents of cyclic imine XVII are in a pseudo-equatorial orientation, with reduction occurring selectively at the $S i$ face to put the bulky hydroxy methyl group (denoted R) also in a pseudo-equatorial orientation. As a result, the total synthesis of DNJ (3) was completed in 3 steps and $41 \%$ overall yield from cheap, readily available Lsorbose (111). 


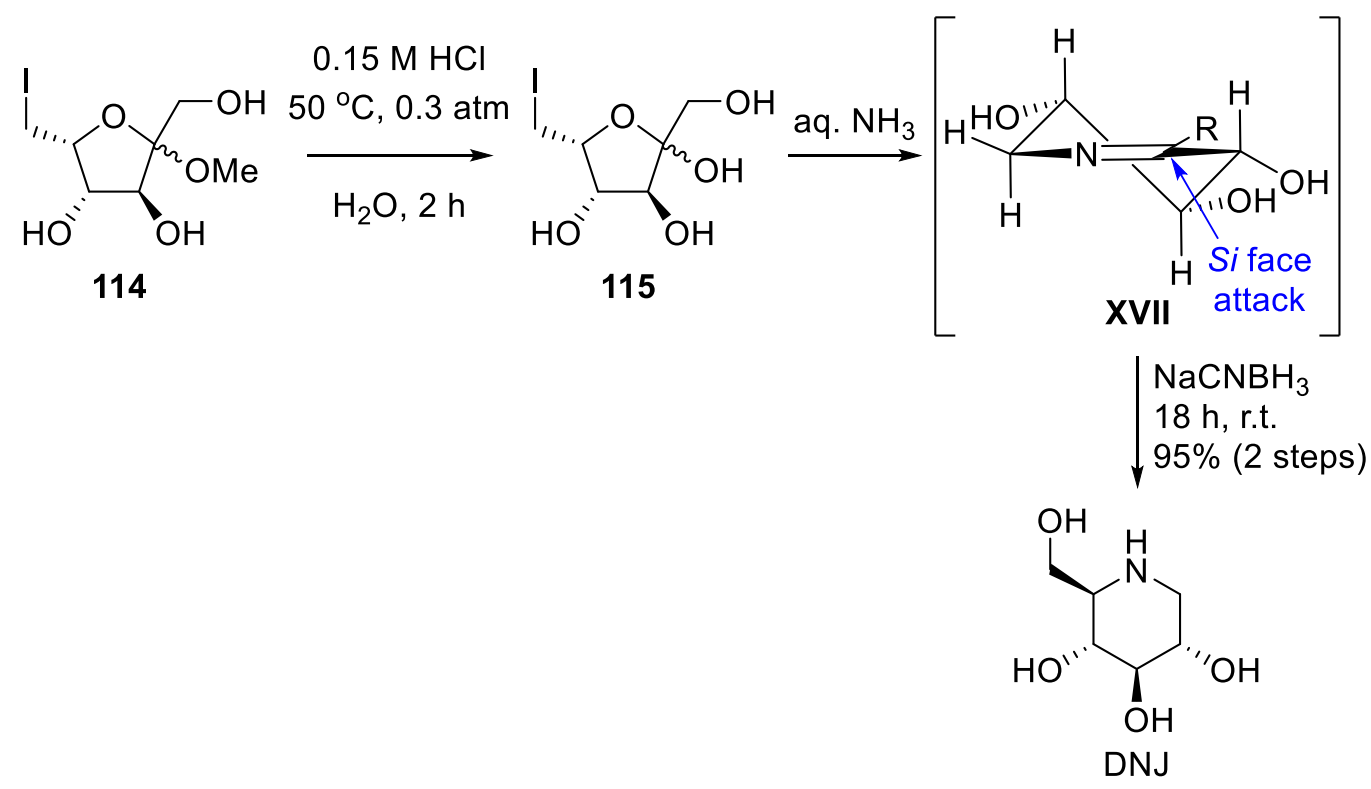

3

Scheme 36: The synthesis of DNJ (3) from methyl iodosorboside 114.

Due to the valuable biological activity of DNJ (3) and its $N$-functionalised derivatives (see Chapter 1), much attention has been given to its synthesis. The shortest and highest yielding syntheses of DNJ and its respective $N$-functionalised derivatives currently belongs to strategies utilising enzyme catalysis ( 3 steps, $55-65 \%$ overall yields), ${ }^{133-135}$ with Demailly reporting the most efficient synthesis of DNJ formation without the use of enzymes in $1989 .{ }^{136}$ Here, Demailly synthesised DNJ in 4 steps and $54 \%$ overall yield from L-sorbose through azide functionalisation of the 6-position, followed by global deprotection and subsequent reduction. Thus, the formation of DNJ reported herein is comparable stepwise to the synthetic strategies utilising enzymes, and in yields comparable to those achieved by Demailly.

\subsection{Synthesis of L-1-deoxygalactojirimycin (L-DGJ)}

The synthesis of L-1-deoxygalactojirimycin (L-DGJ) began with D-tagatose (25). As previously described (Chapter 3), Fischer glycosidation of D-tagatose (25) showed modest selectivity for the formation of furan methyl glycosides 84 (Scheme 37), however, the subsequent iodination of methyl glycosides 84 proved difficult. Accordingly, Dtagatose (25) was protected using isopropylidene groups to give the protected tagatoside 
86, which was then iodinated at the 6-position to give protected iodotagatoside $\mathbf{8 7}$ in $78 \%$ yield over 2 steps.

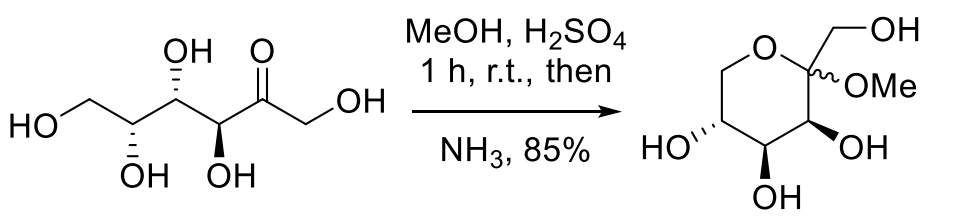

D-tagatose (25)

83<smiles>CO[C@@]1(CO)O[C@H](CO)[C@@H](O)[C@H]1O</smiles>

$2: 3$
84

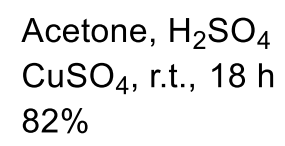

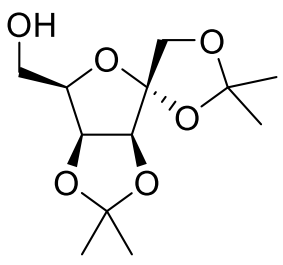

86

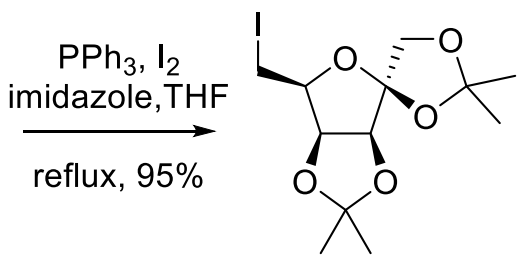

87<smiles>CO[C@]1(CO)O[C@H](CI)[C@@H](O)[C@H]1O</smiles>

85

Scheme 37: Synthesis of methyl tagatosides 83 and 84 and isopropylidene-protected iodotagatoside 87 from D-tagatose (25).

With protected iodotagatoside $\mathbf{8 7}$ in hand, subsequent acid-mediated deprotection was explored. Due to being water insoluble, protected iodotagatoside 87 was treated with 0.15 $\mathrm{M} \mathrm{HCl}$ at 0.3 atm in a $50{ }^{\circ} \mathrm{C}$ water bath, with $\mathrm{MeOH}$, rather than just $\mathrm{H}_{2} \mathrm{O}$, as the reaction solvent (Scheme 38). Monitoring the reaction by TLC indicated complete conversion of protected iodotagaside $\mathbf{8 7}$ to a mixture of partially deprotected iodoglycosides. Exposing this mixture to $0.15 \mathrm{M} \mathrm{HCl}$ in $\mathrm{H}_{2} \mathrm{O}$ at room temperature for 18 hours was required to give complete conversion to iodotagatoside 116, as observed by TLC. Following this, iodotagatoside $\mathbf{1 1 6}$ was subjected to the previously optimised reductive amination conditions involving treatment with $\mathrm{NH}_{3}$ (aq.) and $\mathrm{NaCNBH}_{3}$. Following purification of the resulting reaction mixture using Dowex $-\mathrm{H}^{+}$exchange resin and silica gel flash column chromatography, L-DGJ (30) was isolated in $86 \%$ yield (from protected iodotagatoside 87) with trace amounts of an inseparable minor product. As with DMJ and DNJ, the formation of the major product L-DGJ appears to result from the reduction of cyclic imine XVIII from the face of the conformer that gives the greatest number substituents in pseudo-equatorial orientation. Unfortunately, at the time of submission, the minor product could not be separated from L-DGJ, where it is envisioned that further 
optimisation may result in the total synthesis of L-DGJ (30) in 3 steps and approximately $67 \%$ overall yield from D-tagatose (25).

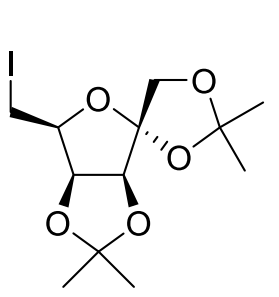

87

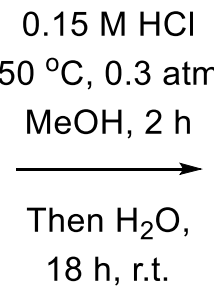

$18 \mathrm{~h}, \mathrm{r.t}$.
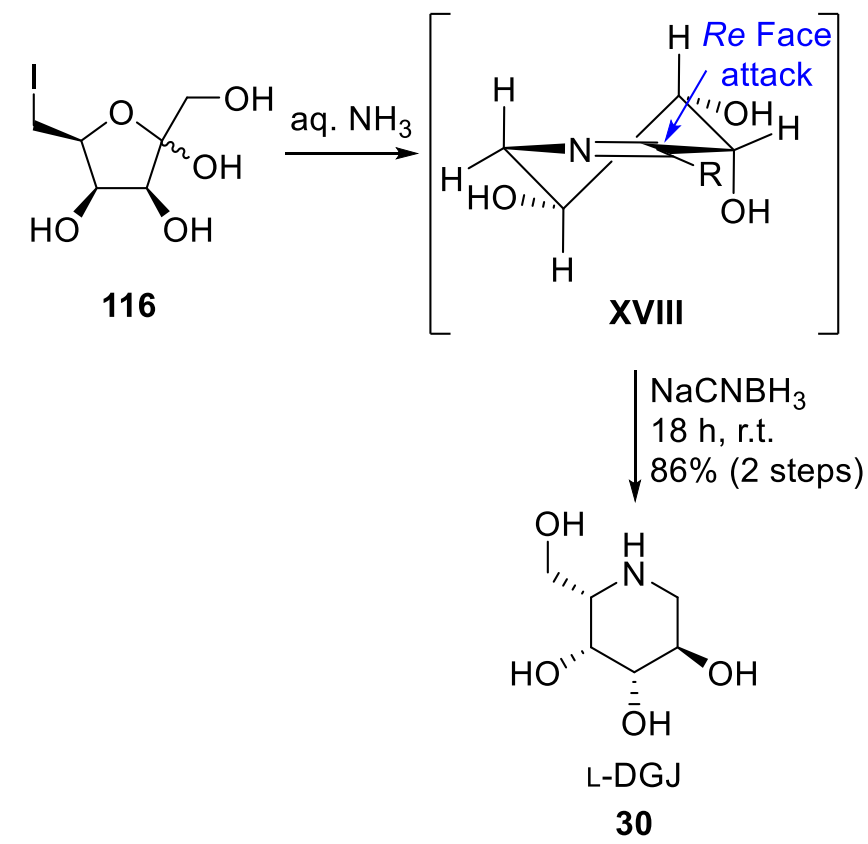

Scheme 38: The synthesis of L-DGJ (30) from protected iodoglycoside 87.

First synthesised in 1990, ${ }^{137}$ L-DGJ (30) has since been identified as an inhibitor and molecular chaperone of galactosidases and galactotranserases. ${ }^{138-141}$ Reports of L-DGJ (30) synthesis and biological testing are scarce, ${ }^{142-146}$ with the most comparable and efficient synthesis being reported by Fleet in 2011, ${ }^{147}$ with L-DGJ (30) being synthesised over 4 steps in $66 \%$ overall yield from D-tagatose (25). Thus, it is envisioned that further optimisation of the methods reported here may result in the total synthesis of L-DGJ (30) in 3 steps and an overall yield comparable to that reported in literature.

\subsection{Synthesis of $(3 R, 4 r, 5 S)$-piperidine-3,4,5-triol}

Following iminosugar synthesis from ketohexose sugars, the scope of this synthetic strategy using aldose carbohydrate starting materials was explored. To this end, it was proposed that $(3 R, 4 r, 5 S)$-piperidine-3,4,5-triol could be synthesised from D-xylose. As such, D-xylose (54) was subjected to $\mathrm{AcCl}$ in methanol to give methyl xylofuranoside which was subsequently iodinated using $\mathrm{PPh}_{3}$ and $\mathrm{I}_{2}$ in the presence of imidazole to give methyl iodoxyloside 55 in 60\% yield (2 steps, Scheme 39). 
<smiles>O=CC(O)C(O)C(O)CO</smiles>

D-xylose

54
1) $\mathrm{MeOH}$ $\mathrm{AcCl}, 24 \mathrm{~h}$

2) $\mathrm{PPh}_{3}, \mathrm{I}_{2}$ Imid., THF

reflux, $2 \mathrm{~h}$

$60 \%(2$ steps $)$

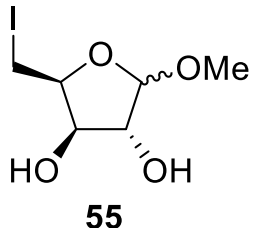

55

Scheme 39: Synthesis of methyl iodoglycoside 55 from D-xylose (54).

Following the isolation of methyl iodoxyloside 55, acid mediated demethylation was attempted. It was initially observed by TLC that exposing methyl iodoxyloside $\mathbf{5 5}$ to an aqueous $0.15 \mathrm{M} \mathrm{HCl}$ solution at a reduced pressure of $0.3 \mathrm{~atm}$ and $50{ }^{\circ} \mathrm{C}$ water bath gave minimal deprotection to iodoxyloside 117 (entry 1 Table 6). Next, methyl iodoxyloside 55 was exposed to the same reaction conditions but at double the $\mathrm{HCl}$ concentration (entry 2), which even after 7 hours showed minimal formation of iodoglycoside 117. In an attempt to drive the reaction to completion, methyl iodoxyloside $\mathbf{5 5}$ was refluxed in a 0.3 $\mathrm{M} \mathrm{HCl}$ solution (entry 4). Following the reaction by TLC showed complete conversion of methyl iodoxyloside $\mathbf{5 5}$ to iodoglycoside $\mathbf{1 1 7}$ after an hour.

Table 6: Optimisation of the demethylation of methyl iodoxyloside 55.<smiles>CO[C@H]1O[C@H](CI)[C@@H](O)[C@H]1O</smiles>

55<smiles>O[C@H]1O[C@H](CI)[C@@H](O)[C@H]1O</smiles>

117

\begin{tabular}{ccccc}
\hline Entry & $\begin{array}{c}\mathrm{HCl} \text { conc. }^{\text {a }} \\
(\mathrm{M})\end{array}$ & $\begin{array}{c}\text { Temp. } \\
(\text { time })\end{array}$ & $\begin{array}{c}\text { Pressure }^{\mathrm{b}} \\
(\mathrm{atm})\end{array}$ & Conversion $^{\mathrm{c}}$ \\
\hline 1 & 0.15 & $50^{\circ} \mathrm{C}(2 \mathrm{~h})$ & 0.3 & $<25 \%$ \\
2 & 0.3 & $50{ }^{\circ} \mathrm{C}(7 \mathrm{~h})$ & 0.3 & $50 \%$ \\
3 & 0.3 & reflux $(1 \mathrm{~h})$ & 1 & $100 \%$ \\
\hline
\end{tabular}

a) All reactions done at a substrate dilution of $10 \mathrm{~mL} / \mathrm{mmol}$

b) Reduced pressure achieved using a rotary evaporator

c) As indicated by complete consumption of $\mathbf{2 5}$ by TLC 
With the deprotection of methyl iodoxyloside $\mathbf{5 5}$ optimised, a solution of iodoxyloside 117 was exposed to $\mathrm{NH}_{3}$ (aq.) and $\mathrm{NaCNBH}_{3}$ at room temperature for 18 hours. Following purification via Dowex- $\mathrm{H}^{+}$and silica gel flash column chromatography, the $(3 R, 4 r, 5 S)$-piperidine-3,4,5-triol (118) was isolated in $88 \%$ yield (53\% overall yield).

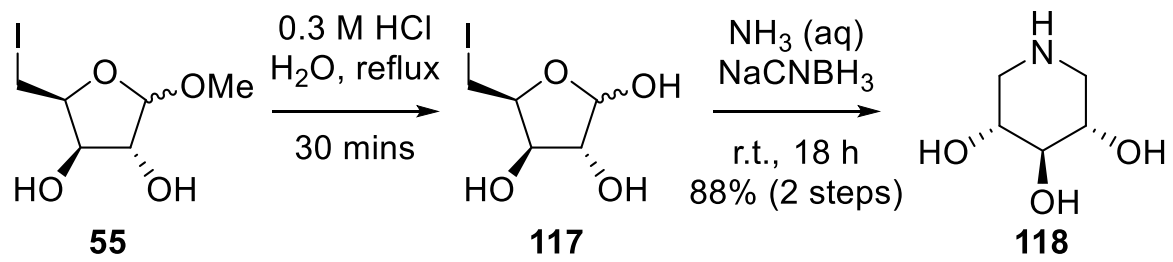

Scheme 40: The synthesis of $(3 R, 4 r, 5 S)$-piperidine-3,4,5-triol (118) from methyl iodoglycoside 55.

Here, triol 118 was identified as the major product using HRMS $(\mathrm{m} / \mathrm{z}$ calcd. for $\left[\mathrm{C}_{5} \mathrm{H}_{11} \mathrm{NO}_{3}+\mathrm{H}\right]^{+}:$134.0812, obsd.: 134.0808) and NMR spectroscopy. The ${ }^{1} \mathrm{H}$ NMR and ${ }^{13} \mathrm{C}$ NMR spectra of the highly symmetric $(3 R, 4 r, 5 S)$-piperidine-3,4,5-triol (118) contained only four and three environments (respectively). More specifically, the ${ }^{1} \mathrm{H}$ NMR spectrum (Figure 13) indicated the presence of an ABNX system, with a ddd at $3.64 \mathrm{ppm}$ coupling to the triplet at $3.40 \mathrm{ppm}$, which further couples to both of the remaining signals (dd) that were observed at 3.30 and $2.71 \mathrm{ppm}$. These proton environments all integrated for two protons except for the triplet at $3.40 \mathrm{ppm}$, which was assigned as the proton on the meso-chiral $4 r$ center. (3R,4r,5S)-Piperidine-3,4,5-triol (118) belongs to the class of iminosugars, and was first synthesised in the 1960s. ${ }^{1,3,4,148}$ Historically, the shortest and highest yielding synthesis of $(3 R, 4 r, 5 S)$-piperidine-3,4,5triol (118) was reported by Ganem, whereby the iminosugar was prepared in 5 steps and $40 \%$ overall yield from methyl 6-deoxyl-6-bromo- $\alpha$-D-glucopyranoside. ${ }^{149}$ Thus, the preparation of $(3 R, 4 r, 5 S)$-piperidine-3,4,5-triol described here is the shortest and highest yielding synthesis reported to date. 


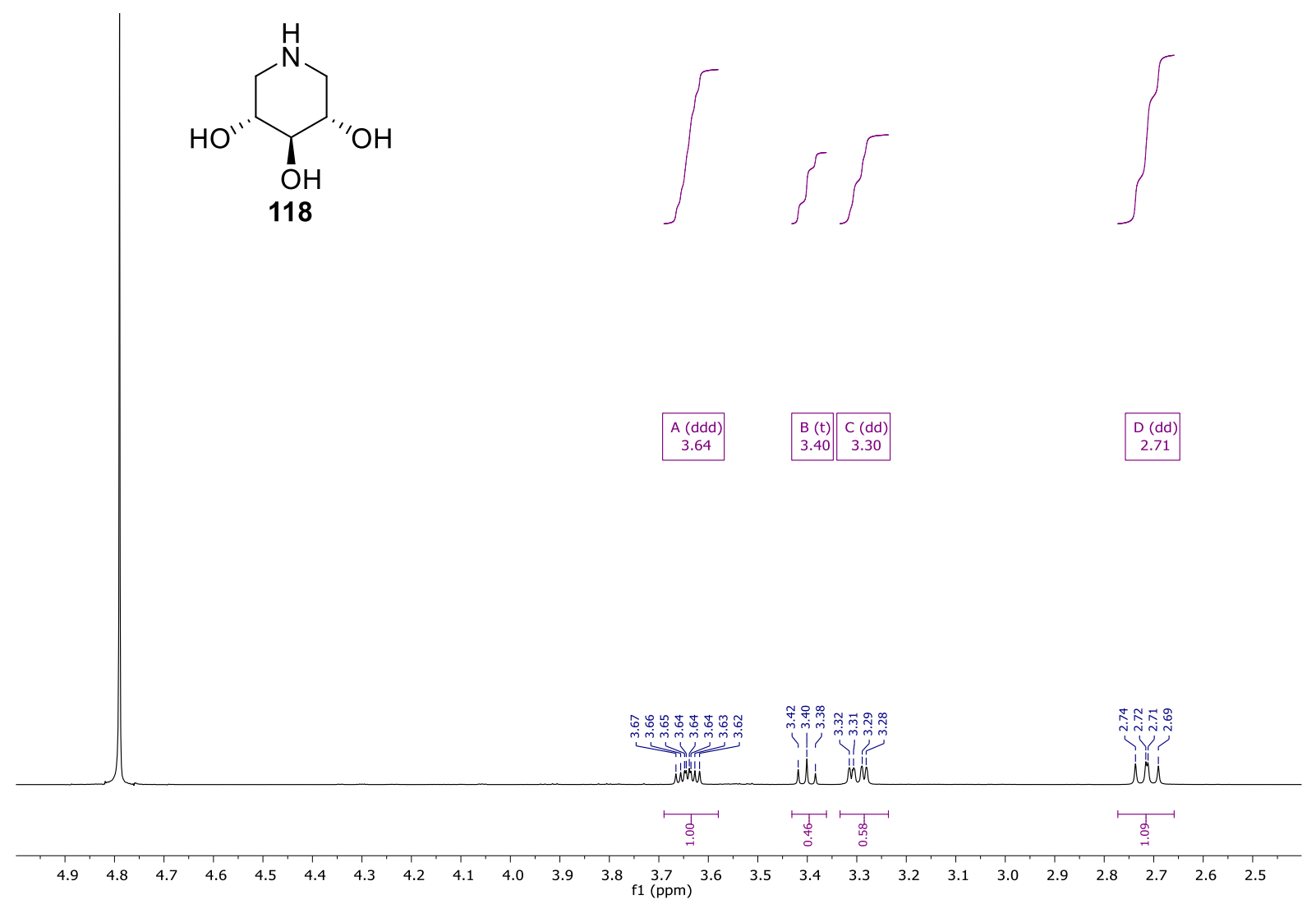

Figure 13: ${ }^{1} \mathrm{H}$ NMR spectrum of $(3 R, 4 r, 5 S)$-piperidine-3,4,5-triol (118)

\subsection{Synthesis of $(3 S, 4 R, 5 S, 6 R)$-azepane-3,4,5,6-tetraol}

Following the successful synthesis of $(3 R, 4 r, 5 S)$-piperidine-3,4,5-triol (118) from Dxylose (54), the synthesis of an azepane from an aldohexose carbohydrate was attempted. The difficulty associated with demethylation of aldohexoses has been well documented, ${ }^{118}$ thus, azepane synthesis was initially attempted via the use of an aldohexose with the more acid labile isopropylidene protecting group at the 1- and 2positions. Accordingly, D-galactose (59) was isopropylidene protected and iodinated at the 6 position to give protected iodogalactoside 119 in $78 \%$ yield (2 steps) using previously reported methods (Scheme 41). ${ }^{63}$ Exposing iodogalactoside 119 to a methanolic $0.5 \mathrm{M} \mathrm{HCl}$ solution in the presence of water at $0.3 \mathrm{~atm}$ in a $50{ }^{\circ} \mathrm{C}$ water bath for 7 hours resulted in a 1:1 mixture of the desired iodogalactoside $\mathbf{1 2 0}$ and stable methyl iodogalactcoside 121. Subsequent treatment of this mixture with $1.0 \mathrm{M} \mathrm{HCl}$ in $\mathrm{H}_{2} \mathrm{O}$ did not alter the ratio of $\mathbf{1 2 0}$ and $\mathbf{1 2 1}$, despite keeping the reaction at reflux for 7 days. 

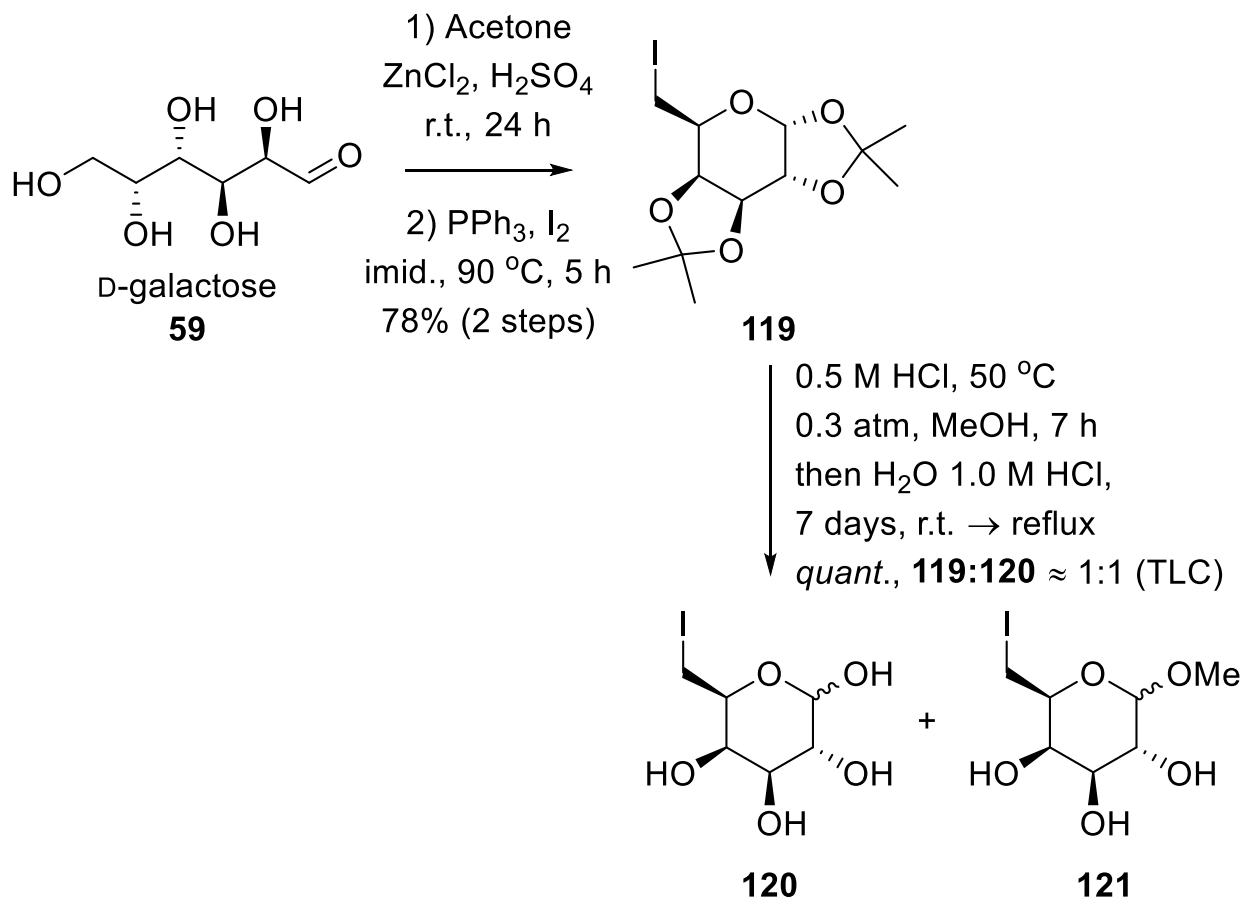

Scheme 41: The synthesis and subsequent acid mediated deprotection of isopropylidene protected iodogalactoside 119 from D-galactose (59).

As methyl iodogalactoside 121 was forming as a result from the use of methanol during deprotection of protected iodogalactoside 119, an alternative method for the removal of the isopropylidene groups was sought. It was reported previously that isopropylidene deprotection was viable by dissolving isopropylidene-protected glycosides in a 9:1 mixture of $\mathrm{AcOH}: \mathrm{H}_{2} \mathrm{O}$ and bringing the mixture to reflux for 2 days. As such, subjecting protected iodogalactoside 119 to these conditions showed full conversion (via TLC) to iodogalactoside 120 after 2 days (Scheme 42). Whilst successful, it was thought that the deprotection of iodogalactoside $\mathbf{1 1 9}$ could be achieved more rapidly using a stronger acid. To this end, protected iodogalactoside 119 was dissolved in a 9:1 mixture of TFA: $\mathrm{H}_{2} \mathrm{O}$ at $50{ }^{\circ} \mathrm{C}$ and 0.3 atm. ${ }^{150}$ Analysis by TLC revealed complete conversion of protected iodogalactoside 119 to iodogalactoside 120 after 30 minutes, with 120 being isolated following a $\mathrm{CH}_{2} \mathrm{Cl}_{2}: \mathrm{H}_{2} \mathrm{O}$ extraction and subsequent concentration in vacuo. This represents the first known isolation of iodogalactoside 120. Next, iodogalactoside 120 was exposed to the reductive amination conditions using $\mathrm{NH}_{3}$ (aq.) and $\mathrm{NaCNBH}_{3}$ at r.t. for 18 hours. Following purification by Dowex- $\mathrm{H}^{+}$, which required careful elution $(0.1 \%$ $\left.\mathrm{NH}_{3}\right)$, pure $(3 S, 4 R, 5 S, 6 R)$-azepane-3,4,5,6-tetraol (49) was isolated in $68 \%$ yield (in 2 steps from protected iodogalactcoside 119). As such, azepane 49 was synthesised over 4 steps and 55\% overall yield from readily available D-galactose (59). 


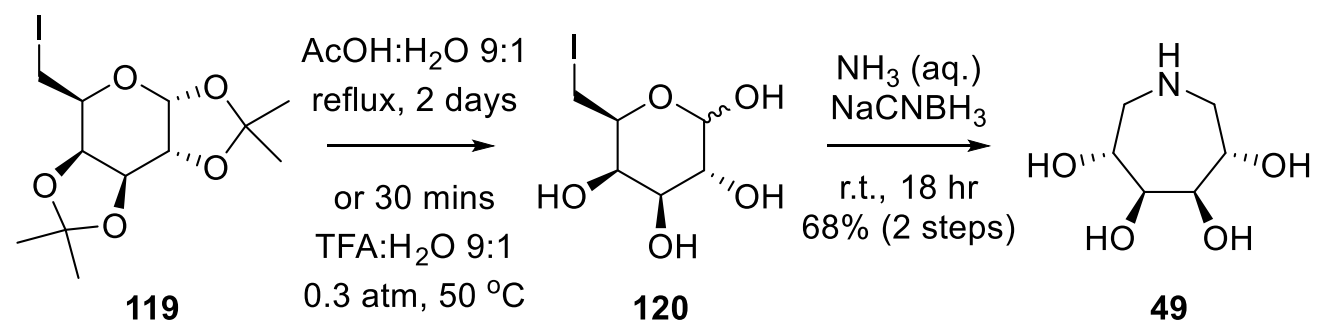

Scheme 42: Formation of (3S,4R,5S,6R)-azepane-3,4,5,6-tetraol (49) from protected iodoglycoside 119.

Key in the identification of $(3 S, 4 R, 5 S, 6 R)$-azepane-3,4,5,6-tetraol (49) as the major product was HRMS ( $\mathrm{m} / z$ calcd. for $\left[\mathrm{C}_{6} \mathrm{H}_{13} \mathrm{NO}_{4}+\mathrm{H}\right]^{+}:$164.0917, obsd.: 164.0921) coupled with NMR analysis, which suggested a highly symmetrical compound with four and three distinct environments observed in ${ }^{1} \mathrm{H}$ and ${ }^{13} \mathrm{C}$ NMR spectra, respectively. In the ${ }^{1} \mathrm{H}$ NMR spectrum (Figure 14), four environments that each integrated for one proton were observed, which was identified as an ABNX system. The synthesis of $(3 S, 4 R, 5 S, 6 R)$ azepane-3,4,5,6-tetraol (49) reported here is comparable to the most efficient synthesis of 49 that was reported by Wong and co-workers that was achieved in 4 steps and 63\% overall yield from D-galactose (59). ${ }^{151}$ In the same communication, azepane 49 was shown to inhibit numerous glycosidases, including $\alpha$-and $\beta$-galactosidase, $\beta$-glucosidase, and $\alpha$-fucosidase. 


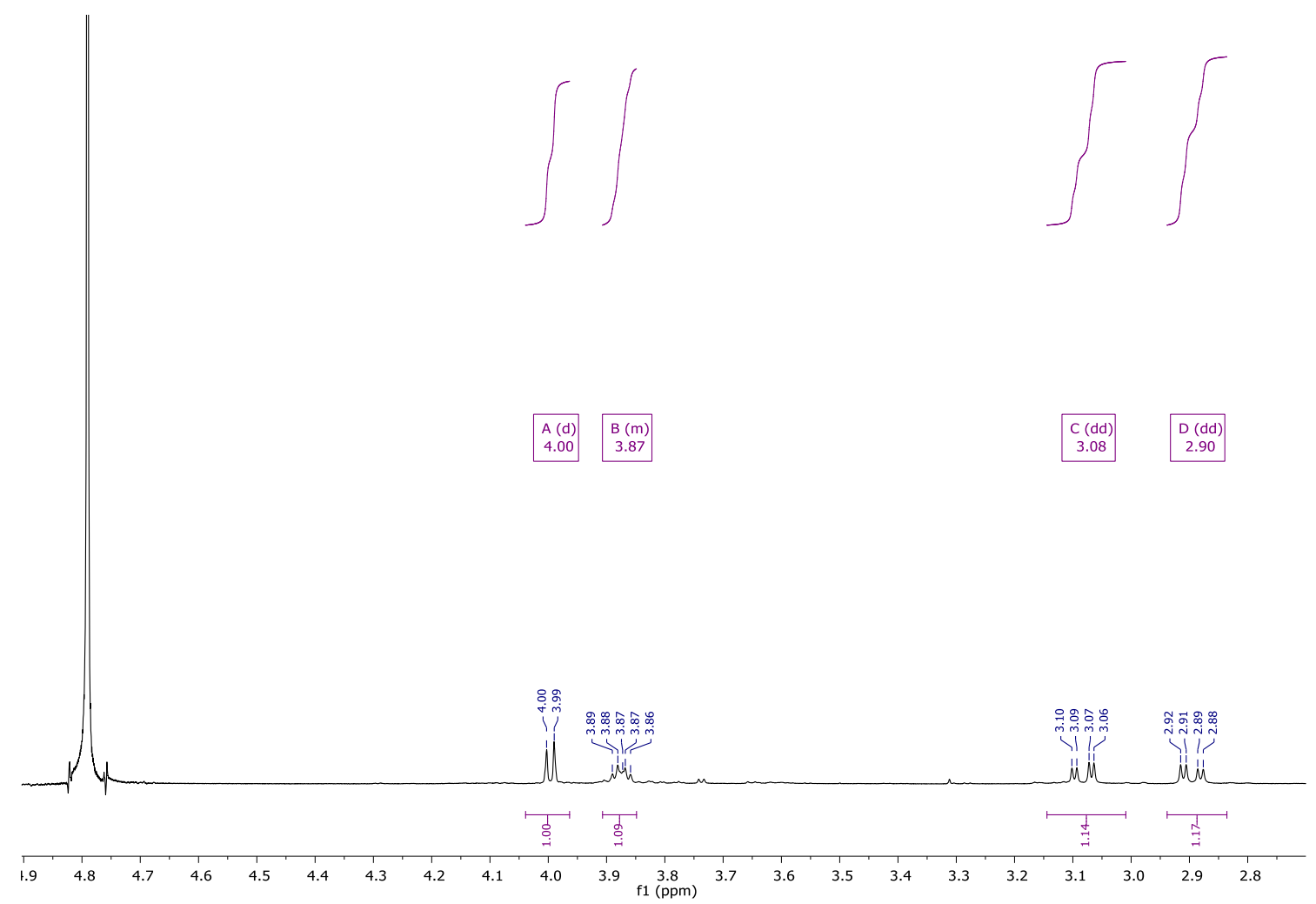

Figure 14: ${ }^{1} \mathrm{H}$ NMR spectrum of (3S,4R,5S,6R)-azepane-3,4,5,6-tetraol (49).

Following the successful synthesis of $(3 S, 4 R, 5 S, 6 R)$-azepane-3,4,5,6-tetraol (49), it was desired to achieve the synthesis of this compound via methyl iodogalactoside $\mathbf{1 2 0}$ in order to eliminate the need for isopropylidene protecting groups. First, methyl iodoglycoside 121 was synthesised from the respective methyl galactoside 122 via selective iodination of the 6-position using $\mathrm{PPh}_{3}$ and $\mathrm{I}_{2}$, which was achieved in $47 \%$ yield. Following isolation, methyl iodogalactoside $\mathbf{1 2 1}$ was exposed to a 9:1 mixture of TFA: $\mathrm{H}_{2} \mathrm{O}$ at 0.3 atm in a 50 ${ }^{\circ} \mathrm{C}$ water bath (Scheme 43). Pleasingly, exposure of methyl iodogalactoside 121 to these conditions gave complete conversion to iodogalactoside $\mathbf{1 2 0}$ after an hour (observed via TLC). Subsequent $\mathrm{CH}_{2} \mathrm{Cl}_{2} / \mathrm{H}_{2} \mathrm{O}$ extraction and treatment of iodoglycoside 120 to reductive amination conditions once again gave $(3 S, 4 R, 5 S, 6 R)$-azepane-3,4,5,6-tetraol (49) in a 69\% yield (2 steps), and 32\% overall yield from methyl galactoside 122. 
<smiles>CO[C@H]1OC(CO)[C@@H](O)[C@H](O)[C@H]1O</smiles>

122

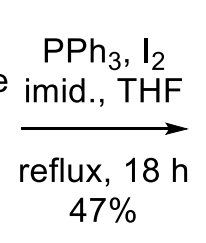

$47 \%$

121<smiles>CO[C@H]1OC(CI)[C@@H](O)[C@H](O)[C@H]1O</smiles>

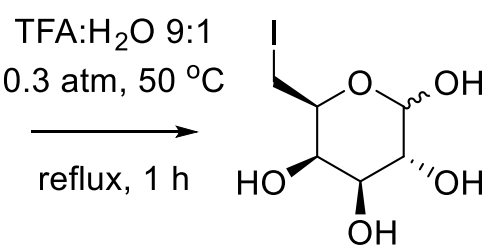

120

$\mathrm{NH}_{3}(\mathrm{aq})$

$\mathrm{NaCNBH}_{3}$

r.t., $18 \mathrm{~h}$

$68 \%$ (2 steps)

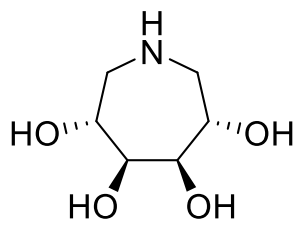

49

Scheme 43: The synthesis of $(3 S, 4 R, 5 S, 6 R)$-azepane-3,4,5,6-tetraol (49) via methyl iodogalactoside 121.

Gratifyingly, this result confirmed that azepane synthesis via aldohexose-derived methyl iodoglycosides was possible. However, comparing the two routes developed for the synthesis of $(3 S, 4 R, 5 S, 6 R)$-azepane-3,4,5,6-tetraol (49) revealed that the use of isopropylidene protecting groups was more efficient. Here, it was the yield of iodinating methyl galactoside 122 that made the synthesis of iodogalactoside 121 lower than that of protected iodogalactcoside 119, an observation that has been previously reported by the Stocker-Timmer group. ${ }^{112}$ Thus, it is foreseeable that where iodination of the respective methyl glycoside is high yielding, efficient azepane synthesis would be achievable.

\subsection{Conclusion}

In summary, DNJ (3) and L-DGJ (30) were synthesised from cheap, readily available carbohydrates in a 4 step-3 pot fashion and $44 \%$ and $67 \%$ overall yield (respectively) using the synthetic strategy developed in Chapter 4. Examining the major product resulting from reductive amination of each synthesised iodoglycoside, in combination with the result observed during DMJ synthesis described in chapter 4, further suggested that reduction occurs with the most substituents in pseudo-equatorial position, where the steric effects of the neighbouring 4-hydroxyl appeared to be minimal. Following this, iminosugar synthesis beginning from aldose sugars was successfully achieved, with 
$(3 R, 4 r, 5 S)$-piperidine-3,4,5-triol (118) and $(3 S, 4 R, 5 S, 6 R)$-azepane-3,4,5,6-tetraol (49) having been synthesised in 3 steps and both in $53 \%$ overall yield and of which are the most step efficent and highest yielding. Additionally, the isolation of the potentially useful synthon 6-dexoy-6-iodo-galactose was achieved for the first time. However, it is most notable that all of the total syntheses reported here are in comparable or greater yields and step efficientcy than that of current literature, validating the power and scope of the explored synthetic strategy. 


\section{Chapter 6}

\section{Conclusions and future prospects}

\subsection{Conclusion}

The overall objective of this thesis was to develop synthetic methodology that would allow for the rapid synthesis of iminosugars through minimalising the use of protecting groups. Initially, the PGF Vasella-reductive-amination and carbamate annulation methodologies developed in the Stocker-Timmer research group were exemplified and applied to the efficient synthesis of 2,5-dideoxy-2,5-imino-L-iditol and 2,5-dideoxy-2,5imino-D-altritol. From this work came the discovery and development of a novel iminering-closing methodology, which was subsequently used for the efficient synthesis of 1deoxymannojirimycin (DMJ), 1-deoxynojirimycin (DNJ), L-1-deoxygalactojirimycin (LDGJ), $(3 R, 4 r, 5 S)$-piperidine-3,4,5-triol, and (3S,4R,5S,6R)-azepane-3,4,5,6-tetraol.

In Chapter 2 a synthetic strategy was developed for the synthesis of 2,5-dideoxy-2,5imino-L-iditol from D-fructose utilising PGF Vasella-reductive-amination and carbamate annulation methodologies. Key in the development of the Vasella-reductive-amination of ketones (as compared to aldehydes) was the use of acidic conditions ( $\mathrm{pH}=6)$. Moreover, diphenylmethylamine, rather than $\mathrm{NH}_{3}$, was required to generate alkenylamine diastereoisomers that could be subsequently separated by silica gel flash column chromatography. Following this, the carbamate annulation of each alkenylamine was explored. It was demonstrated that the $\mathrm{I}_{2}$-mediated carbamate annulation favours the formation of pyrrolidines with a 2,5-trans, 3,4-cis relationship, and when in competition, 
the 2,5-steric interaction overrides the electronic 3,4-cis effect of the allylic alcohol. In summary, 2,5-dideoxy-2,5-imino-L-iditol was synthesised in 6-steps and in 18\% overall yield from D-fructose, utilising minimal protecting groups.

The synthetic strategy developed for the synthesis of 2,5-dideoxy-2,5-imino-L-iditol was applied to the synthesis of 2,5-dideoxy-2,5-imino-D-altritol in Chapter 3. Beginning from D-tagatose, the application of the PGF Vasella-reductive-amination to 6-deoxy-6iodo-1,2:3,4-di- $O$-isopropylidene- $\alpha$-D-tagatose resulted in dimerisation via a Wurtz-type coupling reaction, thereby requiring the Vasella and reductive amination reactions to be performed sequentially. The reductive amination of the intermediate isopropylideneprotected alkenylketone, however, was stereoselective, which can be attributed to chelation control and the use of a bulky nucleophile such as diphenylmethylamine. The subsequent carbamate annulation again favoured the 2,5-trans, 3,4-cis relationship, allowing for the total synthesis of 2,5-dideoxy-2,5-imino-D-altritol in 7 steps and 22\% yield, the shortest and highest yielding synthesis of this iminosugar to date.

Chapter 4 describes the identification and attempted Vasella-reductive-amination of a decomposition product isolated from a synthetic intermediate used in the synthesis of 2,5dideoxy-2,5-imino-L-iditol. The product resulting from the attempted Vasella-reductiveamination of 6-deoxy-6-iodo-D-fructose led to the discovery of novel imine-ring-closing methodology, which allowed for the shortest and highest yielding synthesis of DMJ to date (3 steps, $62 \%$ overall yield). Further investigation of this imine-ring-closing methodology suggested that the reaction occurs via imine formation, and intramolecular substitution, followed by stereoselective reduction. Here, stereoselective reduction occurs from the lowest energy transition state, which has the imine adopting a conformation with the greatest number of substituents in pseudo-equatorial position. Reduction with a small reducing agent, such as $\mathrm{NaCNBH}_{3}$, then occurs from the face that will result in the bulky hydroxy methyl group being in the equatorial orientation.

Lastly, Chapter 5 explores the scope and application of the imine-ring-closing methodology through the use of numerous carbohydrate starting materials. First, DNJ and L-DGJ were synthesised from inexpensive, readily available carbohydrates in 3 steps and in $44 \%$ and $67 \%$ overall yield, respectively. Once again, reduction of the respective cyclic imines preferentially occurred from the transition state which had the most substituents in pseudo-equatorial positions, and where the resulting hydroxymethyl substituent would be in the equatorial orientation. Following this, $(3 R, 4 r, 5 S)$-piperidine-3,4,5-triol and 
$(3 S, 4 R, 5 S, 6 R)$-azepane-3,4,5,6-tetraol were synthesised from D-xylose and D-galactose, respectively, both in 3 steps and in $53 \%$ overall yield. The total syntheses of these two iminosugars reported herein are the most step efficient and highest yielding reported to date. Additionally, isolation of the useful synthon 6-dexoy-6-iodo-D-galactose was achieved for the first time.

\subsection{Future prospects}

The scope of the imine-ring-closing methodology is not limited to the synthesis of the iminosugars described above. For example, a similar synthetic strategy commencing with D-psicose would be expected to yield L-1-deoxyallonojirimicin (L-DAJ, Scheme 44). Preliminary results indicated that D-psicose $\mathbf{( 1 2 3 )}$ can be isopropylidene protected $(\rightarrow \mathbf{1 2 4})$, followed by iodination to give protected iodopsicoside $\mathbf{1 2 5}$ in $85 \%$ yield (2 steps). While the acid mediated deprotection $(\rightarrow \mathbf{1 2 6})$ and subsequent reductive amination of protected iodopsicoside $\mathbf{1 2 5}$ has yet to be optimised, the major product from this reaction is expected to be L-DAJ (127), which would result from reduction from the $R e$ face of the cyclic imine containing the most substituents in pseudo-equatorial position.
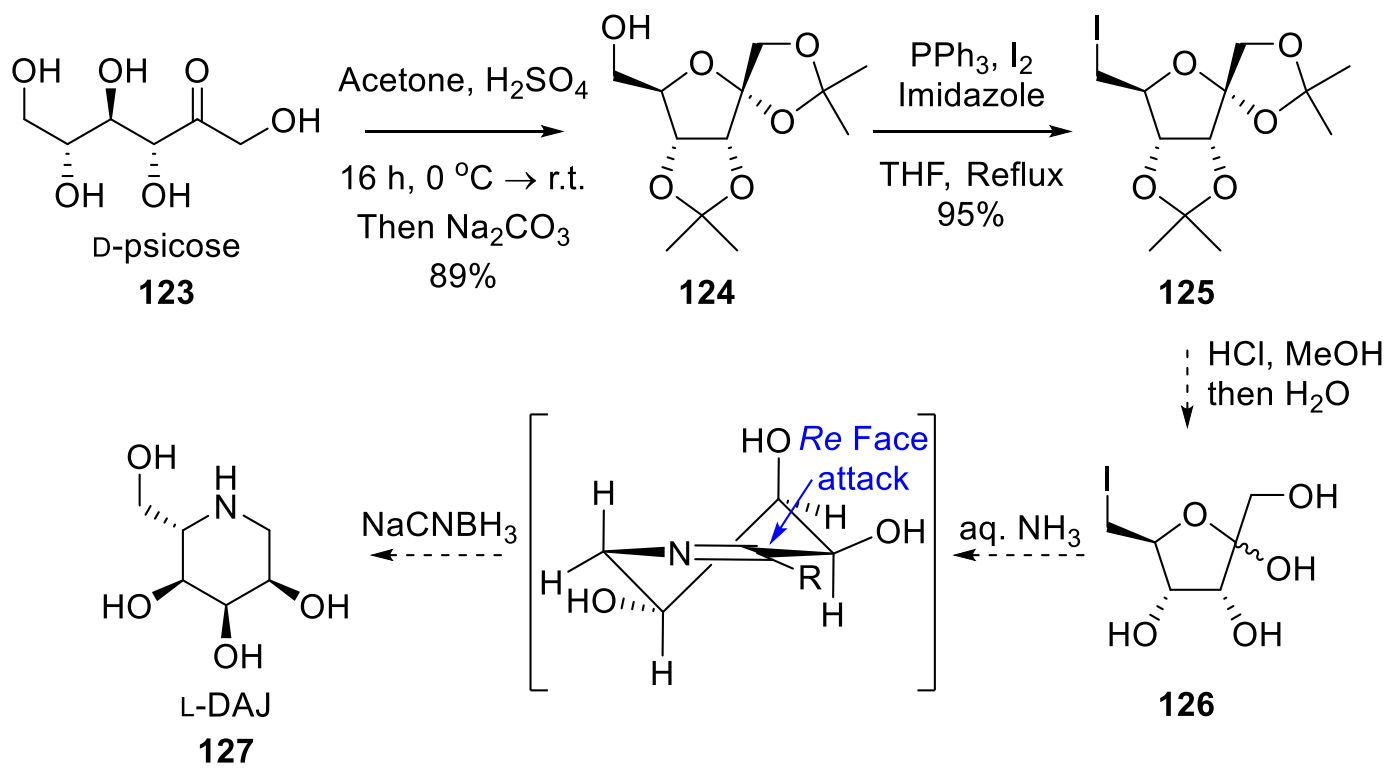

Scheme 44: Proposed synthesis of L-1-deoxyallonojirimicin (L-DAJ, 127) from D-psicose (123).

Similarly, it is it is conceivable that additional azepanes could be synthesised using analogous methodology. For example, the commercially available methyl $\alpha$-D- 
glucopyranoside (128, Scheme 45) can be iodinated selectively at the 6-position followed by TFA-mediated demethylation to give 6-deoxy-6-iodo-D-glucose (129) as a white crystalline solid in excellent overall yield. At the time of submission, the reductive amination of 6-deoxy-6-iodo-D-glucose 129 to give the expected product $(3 S, 4 R, 5 R, 6 R)$ azepane-3,4,5,6-tetraol (130) remains unoptimised, however it is envisioned that this route could give azepane $\mathbf{1 3 0}$ in very high overall yields in only 3 steps. It is also viable that other iminosugars such as $(3 R, 5 R)$-piperidine-3,4,5-triol, $(3 R, 4 s, 5 S)$-piperidine3,4,5-triol, or 1-deoxygalactojirimycin (DGJ) could be prepared from D-arabinose, Dribose, and L-tagatose, respectively, by applying the aforementioned synthetic strategy utilising the imine-ring-closing methodology.

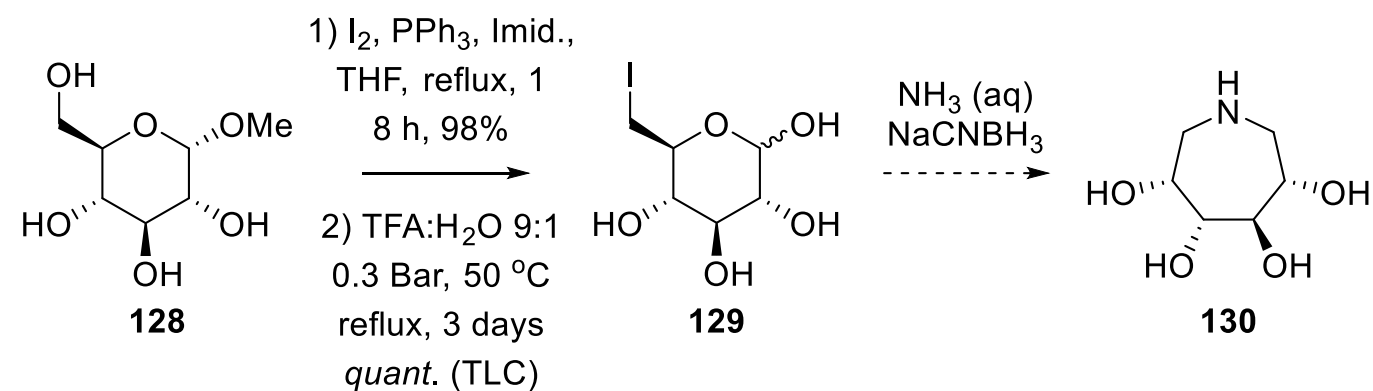

Scheme 45: Proposed synthesis of $(3 S, 4 R, 5 R, 6 R)$-azepane-3,4,5,6-tetraol (130) from commercially available methyl $\alpha$-D-glucopyranoside 128.

In addition to applying the imine-ring-closing methodology to the synthesis of additional iminosugars, it is envisioned that the use of various of primary amines in place of $\mathrm{NH}_{3}$ during the reductive amination could directly lead to a series of $N$-functionalised iminosugars, without the need for additional steps. For example, using $\mathrm{N}$ phenylethylamine, $n$-butylamine, and methylamine during the reductive amination of 6 deoxy-6-iodo-D-fructose (98) should allow for the synthesis of $N$-phenylethyl, $N$-butyl, and $N$-methyl derivatives of DMJ (131, Scheme 46). Given the importance of DMJ and related analogues for the inhibition of mannosidase enzymes associated with viral and fungal infection ${ }^{152}$, the efficient synthesis of such derivatives could find wide application. 


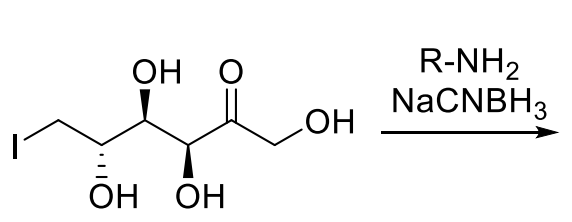

98<smiles>[R]N1C[C@H](O)[C@@H](O)[C@H](O)[C@H]1CO</smiles>

131

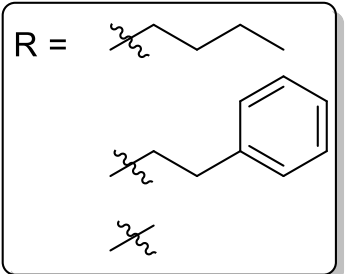

Scheme 46: Proposed synthesis of $N$-functionalised derivatives of DMJ (131) directly from 6-deoxy-6-iodo-D-fructose (98)

Finally, building on the studies by Cheng et al., ${ }^{131}$ it is possible that a variety of iminosugar derivatives could be prepared by reacting different nucleophiles, in place of $\mathrm{NaCNBH}_{3}$, with an in situ formed cyclic imine. For example, exposing 5-deoxy-5-iodoD-xylose (54) to $\mathrm{NH}_{3}$ and $\mathrm{KCN}$ in a stepwise fashion should result in the synthesis of (3S,4S,5R)-3,4,5-trihydroxypiperidine-2-carbonitrile (132), which after exposure to acid would give (3S,4S,5R)-3,4,5-trihydroxypiperidine-2-carboxylic acid (133, Scheme 47). While the biological applications of such compounds are relatively unexplored, with only two papers having been published on the biological testing of carboxylic acids $\mathbf{1 3 3}$ thus far, ${ }^{153,} 154$ the efficient synthesis of such derivatives would greatly facilitate further biological investigations into these and other novel compounds.

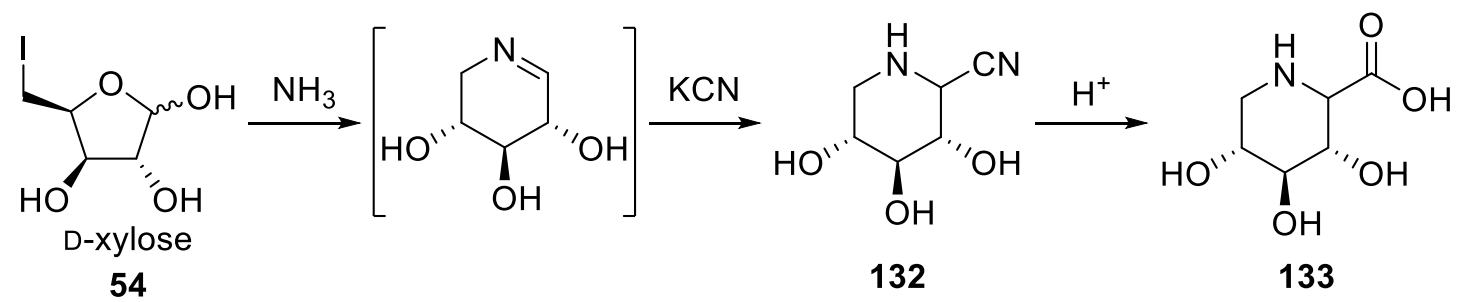

Scheme 47: Proposed synthesis of (3S,4S,5R)-3,4,5-trihydroxypiperidine-2-carboxylic acid (133) from 5-deoxy-5-iodo-D-xylose (54). 


\section{Chapter 7}

\section{Experimental}

\subsection{Experimental details:}

Unless otherwise stated all reactions were performed under atmospheric air. THF (LabScan) was distilled from activated zinc prior to use. MeOH (Pure Science), EtOH (absolute, Pure Science), AcOH (Lab Scam), $\mathrm{CH}_{2} \mathrm{Cl}_{2}$ (LabServ), 30\% aqueous $\mathrm{NH}_{3}$ (Fisher Science), isopropanol (BDH), triethylsilane (Fluka), D-fructose (carbosynth), Dxylose (carbosynth), D-galactose (carbosynth), $\mathrm{NaCNBH}_{3}$ (Aldrich), imidazole (Aldrich), $\mathrm{I}_{2}(\mathrm{BDH})$, Triphenyl phosphine (Acros), $\mathrm{AcONH}_{4}$ (Aldrich), aqueous $35 \% \mathrm{HCl}$ (Univar), and $98 \% \mathrm{H}_{2} \mathrm{SO}_{4}$ (Panreac) were used as received. D-tagatose (carbosynth), $\mathrm{NaOH}$ (Pure Science), $\mathrm{Ti}\left(\mathrm{O}^{\mathrm{i}} \mathrm{Pr}\right)_{4}$ (Aldrich), anhydrous $\mathrm{Cu}^{\mathrm{II}} \mathrm{SO}_{4}$ (Scientific \& chemical supplies), TFA (Aldrich), aminodiphenylmethane (Aldrich), were used as received. Drum Pretrolium ether, and ethyl acetate were distilled before use. Distilled $\mathrm{H}_{2} \mathrm{O}$ was generated using a Millipore RiOs 8 purifier. $\mathrm{Zn}$ dust was activated by the careful addition of conc. $\mathrm{H}_{2} \mathrm{SO}_{4}$ to $\mathrm{Zn}$ powder in the presence of ethanol, the solid decanted, washed with ethanol, diethyl ether, and then finally washed (and stored) in petroleum ether. All solvents were removed by evaporation under reduced pressure (in vacuo). Reactions were monitored by TLCanalysis on Macherey-Nagel silica gel coated plastic sheets $(0.20 \mathrm{~mm}$, with fluorescent indicator UV254) with detection by UV-absorption ( $254 \mathrm{~nm}$ ), by dipping in $10 \% \mathrm{H}_{2} \mathrm{SO}_{4}$ in $\mathrm{MeOH}$ or $3 \%$ ninhydrin in $\mathrm{EtOH}$ followed by charring at $\sim 150{ }^{\circ} \mathrm{C}$. Column chromatography was performed on Pure Science silica gel (40-63 micron). DOWEX® 
$\mathrm{H}^{+}$50wx8-100 ion exchange resin was activated by 1-hour exposure to $1 \mathrm{M} \mathrm{HCl}$. Highresolution mass spectra were recorded on a Waters Q-TOF PremierTM Tandem Mass Spectrometer using positive electro-spray ionisation. Optical rotations were recorded using a Perkin-Elmer 241 polarimeter at the sodium D-line. Infrared spectra were recorded as thin films using a Bruker Tensor 27 FTIR spectrometer, equipped with an Attenuated Total Reflectance (ATR) sampling accessory, and are reported in wave numbers $\left(\mathrm{cm}^{-1}\right)$. Nuclear magnetic resonance spectra were recorded at $20{ }^{\circ} \mathrm{C}$ in $\mathrm{CDCl}_{3}$ or $\mathrm{D}_{2} \mathrm{O}$ using either a Varian Unity-INOVA operating at $300 \mathrm{MHz}$ or a Varian Unity operating at $500 \mathrm{MHz}$. Chemical shifts are given in $\mathrm{ppm}(\delta)$ and are relative to chloroform or water, all given ${ }^{13} \mathrm{C}$ spectra are proton decoupled. NMR peak assignments were made using COSY, HSQC, and HMBC experiments.

\subsection{Chapter 2 experimental}<smiles>C[C@]1(CO)OC(CO)[C@H](O)C1O</smiles>

Methyl D-Fructofuranoside (72). D-Fructose (31) (3.6 g, $20 \mathrm{mmol}$ ) and $\mathrm{H}_{2} \mathrm{SO}_{4}(1.0 \mathrm{~mL}, 18 \mathrm{mmol})$ were added to $200 \mathrm{~mL}$ of $\mathrm{MeOH}$. After the solution was stirred for $15 \mathrm{~min}$, aq. $\mathrm{NH}_{3}$ (4 mL, 30\%) was added, the reaction concentrated to $\sim 50 \mathrm{~mL}$ in vacuo, cooled over ice, filtered, and finally concentrated in vacuo. The remaining oil was purified over by silica gel flash column chromatography (EtOAc $\backslash \mathrm{MeOH} 99 \backslash 1$ to $95 \backslash 5 \mathrm{vlv}$ ) to afford 72 in an anomeric mixture (3.43 g, 87\%). $\alpha$-anomer, $\mathrm{R}_{f}=0.57, \beta$-anomer, $\mathrm{R}_{f}=0.70\left(\right.$ EtOAc $\backslash i \mathrm{PrOH} \backslash \mathrm{H}_{2} \mathrm{O}$ $6 \backslash 4 \backslash 1 \mathrm{v} \backslash \mathrm{v} \backslash \mathrm{v})$. IR and NMR spectral data matched those previously reported. ${ }^{72} \mathrm{HRMS}: \mathrm{m} / z$ calcd for $\left[\mathrm{C}_{7} \mathrm{H}_{14} \mathrm{O}_{6}+\mathrm{Na}\right]^{+}:$217.0682, obsd.: 217.0690 .<smiles>CO[C@@]1(CO)O[C@H](I)[C@@H](O)[C@H]1O</smiles>
Methyl 6-deoxy-6-iodo-D-Fructofuranoside (74). Methyl glycoside 72 (2.02 g, $10.5 \mathrm{mmol}), \mathrm{PPh}_{3}(4.12 \mathrm{~g}, 15.7 \mathrm{mmol})$, and imidazole (1.54 $\mathrm{g}, 20.9 \mathrm{mmol})$ were dissolved in dry THF $(84 \mathrm{~mL})$ and brought to reflux. A solution of $\mathrm{I}_{2}(3.99 \mathrm{~g}, 15.7 \mathrm{mmol})$ in THF $(42 \mathrm{~mL})$ was added drop wise ( 1 drop every 4 seconds) to the refluxing solution. The resulting solution was refluxed for a further 10 mins, cooled to room temperature, filtered over celite (washing with THF), and concentrated in vacuo. The remaining orange oil was purified via normal (Petroleum etherlEtOAc $4 \backslash 1$ to $1 \backslash 2 \mathrm{vlv}$ ) and reverse $\left(\mathrm{H}_{2} \mathrm{O} \backslash \mathrm{MeOH} 100 \backslash 0\right.$ to $9 \backslash 1 \mathrm{vlv}$ ) phase column chromatography, affording an anomeric mixture of iodo glycoside 74 (2.37 g, 75\% yield), $\alpha-74, \mathrm{R}_{f}=0.34, \beta-74, \mathrm{R}_{f}=0.29$ (DCM $\backslash \mathrm{MeOH} 5 \backslash 1 \mathrm{v} \backslash \mathrm{v}$ ). Spectral data matched those previously reported. ${ }^{73}$ IR (film) $3350,2895,1462,1039,1031 \mathrm{~cm}^{-1} \cdot \alpha-74{ }^{1} \mathrm{H}-\mathrm{NMR}$ 
(500 MHz, D $2 \mathrm{O}) \delta 4.16$ (d, J3,4 = $2 \mathrm{~Hz}, 1 \mathrm{H}, \mathrm{H}-3), 3.93-3.89$ (m, 2H, H-4, H-5), 3.79 (d, $\left.J_{1 \mathrm{a}, 1 \mathrm{~b}}=12.5 \mathrm{~Hz}, 1 \mathrm{H}, \mathrm{H}-1 \mathrm{a}\right), 3.68\left(\mathrm{~d}, J_{1 \mathrm{~b}, 1 \mathrm{a}}=12.5 \mathrm{~Hz}, 1 \mathrm{H}, \mathrm{H}-1 \mathrm{~b}\right), 3.49\left(\mathrm{dd}, J_{6 \mathrm{a}, 6 \mathrm{~b}}=4.5 \mathrm{~Hz}\right.$, $\left.J_{6 \mathrm{~b}, 5}=10.5 \mathrm{~Hz}, 1 \mathrm{H}, \mathrm{H}-6 \mathrm{a}\right), 3.41-3.41(\mathrm{~m}, 1 \mathrm{H}, \mathrm{H}-6 \mathrm{~b}), 3.32$ (s, 3H, OMe). ${ }^{13} \mathrm{C}-\mathrm{NMR}(125$ $\left.\mathrm{MHz}, \mathrm{D}_{2} \mathrm{O}\right) \delta 108.1$ (C-2), 81.7 (C-5), 80.7 (C-4), 80.4 (C-3), 57.7 (C-1), $48.2(\mathrm{OMe}), 5.2$ (C-6). $\beta-74{ }^{1} \mathrm{H}-\mathrm{NMR}\left(500 \mathrm{MHz}, \mathrm{D}_{2} \mathrm{O}\right) \delta 4.20\left(\mathrm{~d}, J_{3,4}=8 \mathrm{~Hz}, 1 \mathrm{H}, \mathrm{H}-3\right), 4.06\left(\mathrm{t}, J_{4,3}=8\right.$ $\mathrm{Hz}, 1 \mathrm{H}, \mathrm{H}-4), 3.88-3.84(\mathrm{~m}, 1 \mathrm{H}, \mathrm{H}-5), 3.71$ (d, $\left.J_{1 \mathrm{a}, 1 \mathrm{~b}}=12.5 \mathrm{~Hz}, \mathrm{H}-1 \mathrm{a}\right), 3.66$ (d, J $J_{1 \mathrm{~b}, 1 \mathrm{a}}=$ $12.5 \mathrm{~Hz}, \mathrm{H}-1 \mathrm{~b}$ ), 3.49 (dd, J6a,6b $\left.=4.5 \mathrm{~Hz}, J_{6 \mathrm{~b}, 5}=10.5 \mathrm{~Hz}, 1 \mathrm{H}, \mathrm{H}-6 \mathrm{a}\right), 3.41-3.41$ (m, 1H, H6b), 3.36 (s, 3H, OMe). ${ }^{13} \mathrm{C}-\mathrm{NMR}\left(125 \mathrm{MHz}, \mathrm{D}_{2} \mathrm{O}\right) \delta 103.7$ (C-2), 80.1 (C-5), 78.6 (C4), 77.0 (C-3), 59.4 (C-1), 49.3 (OMe), 6.9 (C-6). HRMS: m/z calcd. for $\left[\mathrm{C}_{7} \mathrm{H}_{13} \mathrm{IO}_{5}+\mathrm{Na}\right]^{+}$: 326.9699, obsd.: 326.9704 .
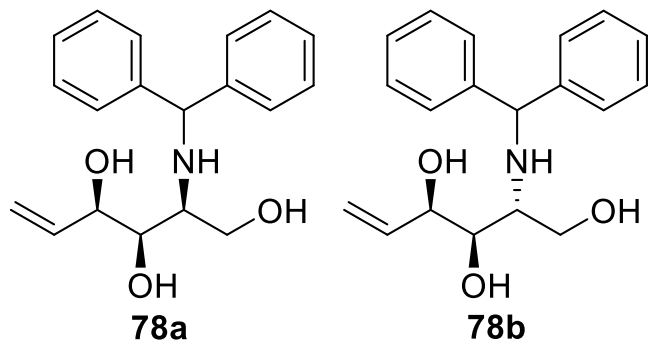

$(2 S, 3 R, 4 R)-2$-(Diphenylmethyl)amino-hex-5-ene-1,3,4-triol (78a) and (2R,3R,4R)-2(Diphenylmethyl)amino-hex-5-ene-1,3,4-triol (78b). A solution of methyl iodofructosides 74 (0.514 g, $1.69 \mathrm{mmol})$, activated $\mathrm{Zn}(1.108 \mathrm{~g}, 16.9 \mathrm{mmol})$, $\mathrm{Ph}_{2} \mathrm{CHNH}_{2} . \mathrm{HCl}(1.862,8.45 \mathrm{mmol})$, and $\mathrm{NaCNBH}_{3}(0.425 \mathrm{~g}, 6.76 \mathrm{mmol})$ in EtOH (34 $\mathrm{mL}$ ) was refluxed for 18 hours, cooled, filtered over celite, then concentrated in vacuo. The remaining mixture was dissolved in DCM $(50 \mathrm{~mL})$ and washed with a saturated solution of $\mathrm{Na}_{2} \mathrm{CO}_{3} \backslash \mathrm{Na}_{2} \mathrm{SO}_{3} \backslash \mathrm{NaCl}, 1 \backslash 1 \backslash 1$, v $\backslash v \backslash v(3 \times 50 \mathrm{~mL}$ ). The organic layer was dried over $\mathrm{MgSO}_{4}$, filtered, and concentrated in vacuo. The resulting colourless oil was purified via silia gel flash column chromatography to give $\mathbf{7 8 a}(0.269 \mathrm{~g}, 0.85 \mathrm{mmol})$ and $\mathbf{7 8 b}$ $(0.183 \mathrm{~g}, 5.86 \mathrm{mmol})$ in $51 \%$ and $35 \%$ yield, respectively. $78 \mathrm{a} \mathrm{R}_{f}=0.4$

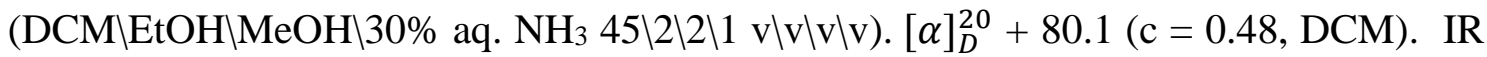
(film) 3552, 3113, 3052, 2891, 1636, 1547, $1088 \mathrm{~cm}^{-1} .{ }^{1} \mathrm{H}-\mathrm{NMR}\left(500 \mathrm{MHz}, \mathrm{CDCl}_{3}\right) \delta$ 7.54-7.13 (m, 10H, Ph-H), 5.81 (ddd, $J_{5,4}=4.4 \mathrm{~Hz}, J_{5,6 \mathrm{~b}}=10.6 \mathrm{~Hz}, J_{5,6 \mathrm{a}}=17.0 \mathrm{~Hz}, 1 \mathrm{H}$, H-5), 5.45 (d, $\left.J_{6 \mathrm{a}, 5}=17.2 \mathrm{~Hz}, 1 \mathrm{H}, \mathrm{H}-6 \mathrm{a}\right), 5.27$ (d, J6b,5 $\left.=10.6 \mathrm{~Hz}, 1 \mathrm{H}, \mathrm{H}-6 \mathrm{~b}\right), 5.05(\mathrm{~s}, 1 \mathrm{H}$, H7), $4.31\left(\mathrm{t}, J_{4,5}=J_{4,3}=4.6 \mathrm{~Hz}, 1 \mathrm{H}, \mathrm{H}-4\right), 3.97\left(\mathrm{dd}, J_{1 \mathrm{a}, 2}=4.3 \mathrm{~Hz}, J_{1 \mathrm{a}, 1 \mathrm{~b}}=11.8 \mathrm{~Hz}, 1 \mathrm{H}\right.$, H-1a), 3.77 (dd, $\left.J_{1 \mathrm{~b}, 2}=1.7 \mathrm{~Hz}, J_{1 \mathrm{~b}, 1 \mathrm{a}}=11.8 \mathrm{~Hz}, 1 \mathrm{H}, \mathrm{H}-1 \mathrm{~b}\right), 3.71$ (bs, $1 \mathrm{H}, \mathrm{H}-3$ ), 2.78-2.76 (m, 1H, H-2). ${ }^{13} \mathrm{C}-\mathrm{NMR}\left(125 \mathrm{MHz}, \mathrm{CDCl}_{3}\right) \delta 143.3$ (C-Ph), 141.8 (C-Ph), $136.8(\mathrm{C}-5)$, 128.9-126.9 (C-Ph), 116.6 (C-6), 75.1 (C-3), 74.3 (C-4), 64.0 (C-7), 61.7 (C-1), 57.8 (C2). $78 \mathrm{~b} \mathrm{R}_{f}=0.39$ (DCM\EtOH\MeOH\30\% aq. $\left.\mathrm{NH}_{3} 45 \backslash 2 \backslash 2 \backslash 1 \mathrm{v} \backslash \mathrm{v} \backslash \mathrm{v} \backslash \mathrm{v}\right) .[\alpha]_{D}^{20}-6.1$ (c $=$ 
0.65, DCM). IR (film) 3537, 3098, 3052, 2898, 1636, 1544, $1075 \mathrm{~cm}^{-1} .{ }^{1} \mathrm{H}-\mathrm{NMR}$ (500 $\left.\mathrm{MHz} \mathrm{CDCl}_{3}\right) \delta 7.50-7.22(\mathrm{~m}, 10 \mathrm{H}, \mathrm{Ph}-\mathrm{H}), 5.74\left(\mathrm{ddd}, J_{5,4}=5.9 \mathrm{~Hz}, J_{5,6 \mathrm{~b}}=10.5 \mathrm{~Hz}, J_{5,6 \mathrm{a}}\right.$ $=16.8 \mathrm{~Hz}, 1 \mathrm{H}, \mathrm{H}-5), 5.29$ (d, J6a,5 $=17.0 \mathrm{~Hz}, 1 \mathrm{H}, \mathrm{H}-6 \mathrm{a}), 5.16$ (d, J6b,5 $=10.5 \mathrm{~Hz}, 1 \mathrm{H}, \mathrm{H}-$ 6b), 5.00 (s, 1H, H-7), 4.24 (t, $\left.J_{4,5}=J_{4,3}=5.4 \mathrm{~Hz}, 1 \mathrm{H}, \mathrm{H}-4\right), 3.78-3.61(\mathrm{~m}, 3 \mathrm{H}, \mathrm{H}-3, \mathrm{H}-$ 1a, H-1b), 2.70-2.68 (m, 1H, H-2). ${ }^{13} \mathrm{C}-\mathrm{NMR}\left(125 \mathrm{MHz}, \mathrm{CDCl}_{3}\right) \delta 143.4$ (C-Ph), 143.0 (C-Ph), 137.0 (C-5), 128.6-127.2 (C-Ph), 117.3 (C-6), 73.4 (C-3), 73.4 (C-4), 64.1 (C-7), 60.2 (C-1), 56.7 (C-2). HRMS: $m / z$ calcd for $\left[\mathrm{C}_{19} \mathrm{H}_{23} \mathrm{NO}_{3}+\mathrm{H}\right]^{+}$: 314.3982, obsd.: 314.3985.

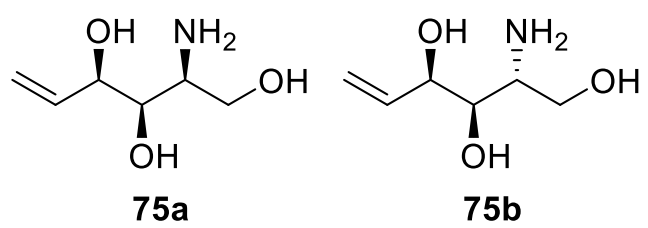

$(2 S, 3 R, 4 R)$-2-amino-hex-5-ene-1,3,4-triol (75a) and $(2 R, 3 R, 4 R)$-2-amino-hex-5-ene1,3,4-triol (75b). Method 1: A solution of methyl iodofructosides 74 (0.264 g, 0.87 mmol), Zn (0.295 g, 4.5 mmol), $\mathrm{AcONH}_{4}(0.678$ g, $8.8 \mathrm{mmol}), \mathrm{NaCNBH}_{3}(0.188 \mathrm{~g}, 3$ $\mathrm{mmol})$, in $\mathrm{AcOH}(0.87 \mathrm{~mL})$ and ethanol $(3.47 \mathrm{~mL})$ was stirred at reflux for 7 days, after which time the reaction was purified over Dowex $-\mathrm{H}^{+}$resin followed by silica-gel column chromatography to give the title products $\mathbf{7 5 a}$ and $\mathbf{7 5 b}$ as a 1:1 diastereomeric mixture (0.085 g, 67\% yield).

Method 2: A solution of 78a (or 78b) (0.58 g, $1.858 \mathrm{mmol}$ ) and $\mathrm{Et}_{3} \mathrm{SiH}(0.6 \mathrm{~mL}, 3.23$ mmol) in TFA (15 mL) was refluxed for 2 hours, concentrated in vacuo, and purified using Dowex $-\mathrm{H}^{+}$, with the product being eluted using a $35 \%$ ammonia solution, to give the respective alkenylamine 75a (or 75b, 55\%) $(0.147 \mathrm{~g}, 54 \%)$. 75a $\mathrm{R}_{f}=0.30$ (DCM\EtOH\MeOH\30\% aq. $\left.\mathrm{NH}_{3} 25 \backslash 2 \backslash 2 \backslash 1 \mathrm{v} \backslash \mathrm{v} \backslash \mathrm{v} \backslash \mathrm{v}\right) .[\alpha]_{D}^{20}+23.5(\mathrm{c}=0.89, \mathrm{MeOH}) . \mathrm{IR}$ (film) 3475, 3150, 2905, 2847, 1672, 1609, 1472, $1046 \mathrm{~cm}^{-1} .{ }^{1} \mathrm{H}-\mathrm{NMR}\left(500 \mathrm{MHz}, \mathrm{D}_{2} \mathrm{O}\right)$ $\delta 5.91\left(\mathrm{ddd}, J_{5,4}=6.2 \mathrm{~Hz}, J_{5,6 \mathrm{~b}}=10.6 \mathrm{~Hz}, J_{5,6 \mathrm{a}}=17.0 \mathrm{~Hz}, 1 \mathrm{H}, \mathrm{H}-5\right), 5.37\left(\mathrm{~d}, J_{6 \mathrm{a}, 5}=17.4\right.$ Hz, 1H, H-6a), 5.29 (d, J6b,5 $=10.6 \mathrm{~Hz}, 1 \mathrm{H}, \mathrm{H}-6 \mathrm{~b}), 4.24$ (dd, $J_{4,3}=5.4 \mathrm{~Hz}, J_{4,5}=6.6 \mathrm{~Hz}$, $1 \mathrm{H}, \mathrm{H}-4), 3.67$, (dd, $\left.J_{1 \mathrm{a}, 1 \mathrm{~b}}=11.3 \mathrm{~Hz}, J_{1 \mathrm{a}, 2}=5.6 \mathrm{~Hz}, 1 \mathrm{H}, \mathrm{H}-1 \mathrm{a}\right), 3.63-3.54$ (m, 2H, H-3, H1b), 3.08-2.98 (m, 1H, H-2). ${ }^{13} \mathrm{C}-\mathrm{NMR}\left(125 \mathrm{MHz}, \mathrm{D}_{2} \mathrm{O}\right) \delta 136.5$ (C-5), 117.9 (C-6), 73.3 (C-4), 72.3 (C-3), 62.5 (C-1), 53.0 (C-2). 75b R $\mathrm{R}_{f}=0.30$ (DCM\EtOH\MeOH\30\% aq. $\left.\mathrm{NH}_{3} 25 \backslash 2 \backslash 2 \backslash 1 \mathrm{v} \backslash \mathrm{v} \backslash \mathrm{v} \backslash \mathrm{v}\right) .[\alpha]_{D}^{20}+12.6(\mathrm{c}=1.50, \mathrm{MeOH})$. IR (film) 3395, 3112, 2893, 1621, 1498, $1056 \mathrm{~cm}^{-11} \mathrm{H}-\mathrm{NMR}\left(500 \mathrm{MHz}, \mathrm{D}_{2} \mathrm{O}\right) \delta 5.95\left(\mathrm{ddd}, J_{5,4}=6.2 \mathrm{~Hz}, J_{5,6 \mathrm{~b}}=10.6 \mathrm{~Hz}, J_{5,6 \mathrm{a}}\right.$ $=17.0 \mathrm{~Hz}, 1 \mathrm{H}, \mathrm{H} 5), 5.38$ (d, J6a,5 $=17.3 \mathrm{~Hz}, 1 \mathrm{H}, \mathrm{H6a}), 5.30$ (d, J6b,5 = $10.8 \mathrm{~Hz}, 1 \mathrm{H}, \mathrm{H} 6 \mathrm{~b})$, 4.33-4.27 (m, 1H, H4), $3.80\left(\mathrm{dd}, J_{1 \mathrm{a}, 2}=3.9 \mathrm{~Hz}, J_{1 \mathrm{a}, 1 \mathrm{~b}}=11.4 \mathrm{~Hz}, 1 \mathrm{H}, \mathrm{H} 1 \mathrm{a}\right), 3.58\left(\mathrm{dd}, J_{1 \mathrm{~b}, 2}\right.$ 
$\left.=7.1 \mathrm{~Hz}, J_{1 \mathrm{~b}, 1 \mathrm{a}}=11.4 \mathrm{~Hz}, 1 \mathrm{H}, \mathrm{H} 1 \mathrm{~b}\right), 2.79\left(\mathrm{td}, J_{2,1 \mathrm{a}}=3.8 \mathrm{~Hz}, J_{2,1 \mathrm{~b}}=J_{2,3}=7.0 \mathrm{~Hz}, 1 \mathrm{H}, \mathrm{H} 2\right)$.

${ }^{13} \mathrm{C}-\mathrm{NMR}\left(125 \mathrm{MHz}, \mathrm{D}_{2} \mathrm{O}\right) \delta 136.8$ (C-5), 117.1 (C-6), 74.3 (C-4), 72.5 (C-3), 62.5 (C1), 52.8 (C-2). HRMS: m/z calcd. for $\left[\mathrm{C}_{6} \mathrm{H}_{13} \mathrm{NO}_{3}+\mathrm{H}\right]^{+}:$148.0968, obsd.: 148.0967 .

\section{Carbamate annulation general procedure:}

A solution of alkenylamine $(1 \mathrm{mmol})$ and $\mathrm{I}_{2}(1.5 \mathrm{mmol})$ were dissolved in a sat. aq. $\mathrm{NaHCO}_{3}$ solution $(10 \mathrm{~mL})$ and stirred at room temperature for 18 hours. The resulting reaction mixture was lyophilised, dissolved in $\mathrm{MeOH}$, decanted, and purified via silica gel flash column chromatography (Petroleum ether/EtOAc $1 \backslash 1 \mathrm{v} \backslash \mathrm{v}$ to EtOAclMeOH 95\5 $\mathrm{v}(\mathrm{v})$, affording the desired product as a white amorphus solid which was reacted further without recording yield.

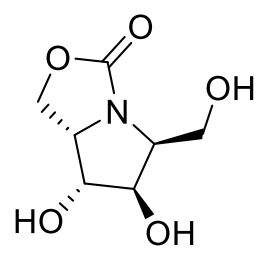

(5S,6R,7R,7aS)-6,7-dihydroxy-5-(hydroxymethyl)tetrahydro1H,3H-pyrrolo[1,2-c]oxazol-3-one (76a). By subjecting alkenylamine 75a $(0.046 \mathrm{~g}, 0.32 \mathrm{mmol})$ to the general procedure gave carbamate 76a. $[\alpha]_{D}^{20}+42.8\left(\mathrm{c}=0.86, \mathrm{H}_{2} \mathrm{O}\right)$. IR (film) $3365,2941,1702,1678,1422$, 1247, 1130, 1034, 794, $705 \mathrm{~cm}^{-1} .{ }^{1} \mathrm{H}-\mathrm{NMR}\left(500 \mathrm{MHz}, \mathrm{D}_{2} \mathrm{O}\right) \delta 4.64\left(\mathrm{t}, J_{6 \mathrm{a}, 6}=J_{6 \mathrm{a}, 5}=9 \mathrm{~Hz}\right.$, $1 \mathrm{H}, \mathrm{H}-6 \mathrm{a}), 4.51\left(\mathrm{dd}, J_{6 \mathrm{~b}, 5}=3.4 \mathrm{~Hz}, J_{6 \mathrm{~b}, 6 \mathrm{a}}=9.3 \mathrm{~Hz}, 1 \mathrm{H}, \mathrm{H}-6 \mathrm{~b}\right), 4.48$ (d, $J_{3,2}=5 \mathrm{~Hz}, 1 \mathrm{H}, \mathrm{H}-$ 3), 4.36-4.30 (m, 1H, H-5), 4.08 (s, 1H, H-4), 3.94-3.88 (m, 1H, H-2), 3.83 (dd, $J_{1 \mathrm{a}, 2}=$ $\left.5.8 \mathrm{~Hz}, J_{1 \mathrm{a}, 1 \mathrm{~b}}=11.5 \mathrm{~Hz}, 1 \mathrm{H}, \mathrm{H}-1 \mathrm{a}\right), 3.76\left(\mathrm{dd}, J_{1 \mathrm{~b}, 2}=7.3 \mathrm{~Hz}, J_{1 \mathrm{~b}, 1 \mathrm{a}}=11.5 \mathrm{~Hz}, 1 \mathrm{H}, \mathrm{H}-1 \mathrm{~b}\right)$. ${ }^{13} \mathrm{C}-\mathrm{NMR}\left(125 \mathrm{MHz}, \mathrm{D}_{2} \mathrm{O}\right) \delta 164.7$ (C-7), 77.2 (C-3), 75.4 (C-4), 63.9 (C-6), 61.7 (C-2), 62.0 (C-5), 59.7 (C-1) HRMS: m/z calcd. for $\left[\mathrm{C}_{7} \mathrm{H}_{11} \mathrm{NO}_{5}+\mathrm{Na}\right]^{+}:$212.0529, obsd.: 212.0530 .

\section{Base hydrolysis general procedure:}

A solution of a carbamate $(1 \mathrm{mmol})$ and $\mathrm{NaOH}(10 \mathrm{mmol})$ in $20 \mathrm{~mL}$ of EtOH was stirred at reflux for 4 hours. The reaction mixture was cooled to room temperature and neutralised with Dowex $-\mathrm{H}^{+}$. The resulting product was eluted from the resin using $35 \%$ ammonia solution, and concentrated in vacuo, to afford the desired product.<smiles>OC[C@H]1N[C@H](CO)[C@@H](O)[C@H]1O</smiles>

2,5-dideoxy-2,5-imino-l-iditol (77). Subjecting carbamate 76a to the general procedure gave desired product imino-iditol 4 in $98 \%$ yield (from alkenylamine 75a), $\mathrm{R}_{f}=0.15\left(\mathrm{DCM} / \mathrm{EtOH} / \mathrm{MeOH} / 30 \%\right.$ aq. $\mathrm{NH}_{3}$ $5 / 2 / 2 / 1 \mathrm{v} / \mathrm{v} / \mathrm{v} / \mathrm{v}) \cdot[\alpha]_{D}^{20}+16.7$ (c 1.4, $\mathrm{H}_{2} \mathrm{O}$ ). IR (film) 3347, 2899, 1329, 
$1070 \mathrm{~cm}^{-1}$. Free base ${ }^{1} \mathrm{H}-\mathrm{NMR}\left(500 \mathrm{MHz}, \mathrm{D}_{2} \mathrm{O}\right) \delta 4.14(\mathrm{~d}, \mathrm{~J} 3,2=3.9 \mathrm{~Hz}, 2 \mathrm{H}, \mathrm{H}-3), 3.75$ $\left(\mathrm{dd}, J_{1 \mathrm{a}, 2}=6.6 \mathrm{~Hz}, J_{1 \mathrm{a}, 1 \mathrm{~b}}=11.1 \mathrm{~Hz}, 2 \mathrm{H}, \mathrm{H}-1 \mathrm{a}\right), 3.65\left(\mathrm{dd}, J_{1 \mathrm{~b}, 2}=6.5 \mathrm{~Hz}, J_{1 \mathrm{~b}, 1 \mathrm{a}}=11.1 \mathrm{~Hz}\right.$, $2 \mathrm{H}, \mathrm{H}-1 \mathrm{~b}), 3.40\left(\mathrm{td}, J_{2,3}=4.0 \mathrm{~Hz}, J_{2,1 \mathrm{a}}=J_{2,1 \mathrm{~b}}=6.5 \mathrm{~Hz}, 2 \mathrm{H}, \mathrm{H}-2\right) .{ }^{13} \mathrm{C}-\mathrm{NMR}(125 \mathrm{MHz}$, $\left.\mathrm{D}_{2} \mathrm{O}\right) \delta 77.0(\mathrm{C}-3), 60.3(\mathrm{C}-1), 59.9(\mathrm{C}-2)$. HCl salt ${ }^{1} \mathrm{H}-\mathrm{NMR}\left(500 \mathrm{MHz}, \mathrm{D}_{2} \mathrm{O}\right) \delta 4.32(\mathrm{~d}$, $\left.J_{3,2}=2.8 \mathrm{~Hz}, 2 \mathrm{H}, \mathrm{H}-3\right), 4.00-3.91(\mathrm{~m}, 4 \mathrm{H}, \mathrm{H}-1 \mathrm{a} \& \mathrm{H}-2), 3.87$ (dd, $J_{1 \mathrm{~b}, 2}=7.0 \mathrm{~Hz}, J_{1 \mathrm{a}, 1 \mathrm{~b}}=$ 10.2, 2H, H-1b). ${ }^{13} \mathrm{C}-\mathrm{NMR}:\left(125 \mathrm{MHz}, \mathrm{D}_{2} \mathrm{O}\right) \delta 74.4$ (C-3), 62.7 (C-2), 57.3 (C-1). HRMS: $\mathrm{m} / \mathrm{z}$ calcd. for $\left[\mathrm{C}_{6} \mathrm{H}_{13} \mathrm{NO}_{4}+\mathrm{H}\right]^{+}: 164.0917$, obsd.: 164.0921

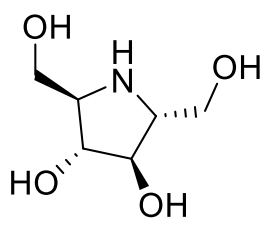

DMDP.HCl (4). Subjecting carbamate $\mathbf{7 6 b}$ to the general procedure gave a mixture that was purified using silica gel column chromatography (DCM/EtOH/MeOH/30\% aq. $\mathrm{NH}_{3}, 95 \backslash 2 \backslash 2 \backslash 1$ to $62.5 / 15 / 15 / 7.5, \mathrm{v} / \mathrm{v} / \mathrm{v} / \mathrm{v})$ to give desired product DMDP (4) as it's $\mathrm{HCl}$ salt in $16 \%$ yield (from alkenylamine $\mathbf{7 5 b}$ ), $\mathrm{R}_{f}=0.15\left(\mathrm{DCM} / \mathrm{EtOH} / \mathrm{MeOH} / \mathrm{aq} . \mathrm{NH}_{3}\right.$, 5/2/2/1, v/v/v/v). $[\alpha]_{D}^{20}+52.9\left(\mathrm{c}=0.74, \mathrm{H}_{2} \mathrm{O}\right.$ ). IR (film) 3293, 2947, 1290, 1104, $921 \mathrm{~cm}^{-}$ 1. ${ }^{1} \mathrm{H}-\mathrm{NMR}\left(500 \mathrm{MHz}, \mathrm{D}_{2} \mathrm{O}\right) \delta$ 4.00-3.93 (m, 2H, H-3), 3.91-3.68 (m, 4H, H-1a,b), 3.513.40 (m, 2H, H-2). ${ }^{13} \mathrm{C}-\mathrm{NMR}:\left(125 \mathrm{MHz}, \mathrm{D}_{2} \mathrm{O}\right) \delta 74.1$ (C-3), 62.2 (C-2), 57.7 (C-1). HRMS: m/z calcd. for $\left[\mathrm{C}_{6} \mathrm{H}_{13} \mathrm{NO}_{4}+\mathrm{H}\right]^{+}:$164.0917, obsd.: 164.0920

\subsection{Chapter 3 experimental}<smiles>C[C@]1(CO)O[C@H](CO)[C@@H](O)[C@H]1O</smiles>

Methyl D-tagatofuranoside (84). A solution of D-tagatose $(1.33 \mathrm{~g}$, $7.38 \mathrm{mmol})$ and $\mathrm{H}_{2} \mathrm{SO}_{4}(11.8 \mu \mathrm{L}, 98 \%)$ in $\mathrm{MeOH}(67 \mathrm{~mL})$ was stirred at room temperature for $1 \mathrm{~h}$. The reaction was quenched with aq. $35 \% \mathrm{NH}_{3}(2 \mathrm{~mL})$, concentrated to $1 / 4$ the volume and filtered over celite (MeOH wash). The mother liquor was concentrated and purified via silica gel flash column chromatography (Petroleum ether/EtOAc, $100 / 0$ to $0 / 100, \mathrm{v} / \mathrm{v}$ ) to give $\alpha$-methyl D-tagatofuranoside 84 in $47 \%$ yield. Spectral data matched those previously reported. ${ }^{8}$ 106

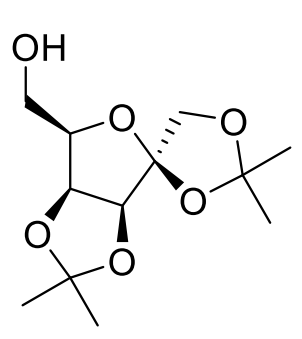

1,2:3,4-Di- $O$-isopropylidene-D-tagatose (86). Anhydrous $\mathrm{Cu}(\mathrm{II}) \mathrm{SO}_{4}(4.17 \mathrm{~g}, 26 \mathrm{mmol})$ and D-tagatose $(1.17 \mathrm{~g}, 6.5 \mathrm{mmol})$ were added to a flask under argon atmospheres. To this flask, $\mathrm{H}_{2} \mathrm{SO}_{4}(36$ $\mathrm{mM}$ ) in acetone (distilled and degassed, $22 \mathrm{~mL}$ ) was added and the resulting mixture stirred at room temperature for 18 hours. The reaction was quenched with sodium carbonate, filtered over celite, concentrated, and 
purified via silica gel flash column chromatography (Petroleum ether/EtOAc, 100/0 to 4/1, v/v) to give 85 as a colourless oil (1.47 g, 87\% yield), $\mathrm{R}_{f}=0.3$ (petroleum ether/EtOAc, $1 / 1, \mathrm{v} / \mathrm{v})$. Spectral data matched those previously reported. ${ }^{49}$

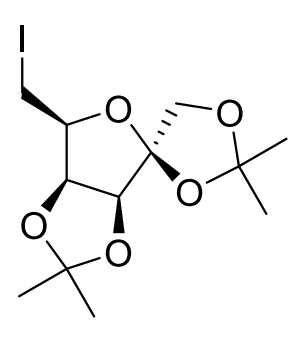

\section{1,2:3,4-Di- $O$-isopropylidene-6-deoxy-6-iodo-D-tagatose}

Diisopropylidene-protected sugar 86 (2.31 g, 8.9 mmol), $\mathrm{PPh}_{3}$ (6.75 $\mathrm{g}, 25.8 \mathrm{mmol})$, and imidazole $(1.81 \mathrm{~g}, 26.6 \mathrm{mmol})$ were added to freshly distilled THF ( $89 \mathrm{~mL})$ and the solution brought to reflux. To this, $\mathrm{I}_{2}(4.56 \mathrm{~g}, 18 \mathrm{mmol})$ in THF (44 mL) was added dropwise over 1.5 hours. The resulting mixture was refluxed for a further 12 hours then quenched with methanol and concentrated. The residue was subjected to silica gel flash column chromatography (Petroleum ether/EtOAc, 100/0 to 4/1, v/v) to give iodide 87 as a white crystalline solid (2.84 g, 87\% yield), $\mathrm{R}_{f}=0.8$ (petroleum ether/EtOAc, 1/1, v/v). Spectral data matched those previously reported. ${ }^{62}[\alpha]_{D}^{20}=+46.1\left(\mathrm{c}=1.1, \mathrm{CDCl}_{3}\right)$. IR (film) 2989, 2391, 1376, 1209, 1028, $851 \mathrm{~cm}^{-1} .{ }^{1} \mathrm{H}-\mathrm{NMR}\left(500 \mathrm{MHz}, \mathrm{CDCl}_{3}\right) \delta 4.82$ (m, 1H, H-4), 4.63 $\left(\mathrm{d}, J_{3,4}=5.5 \mathrm{~Hz}, 1 \mathrm{H}, \mathrm{H}-3\right), 4.23\left(\mathrm{dd}, J_{1 \mathrm{a}, 1 \mathrm{~b}}=9.5 \mathrm{~Hz}, J_{1 \mathrm{a}, 3}=1 \mathrm{~Hz}, 1 \mathrm{H}, \mathrm{H}-1 \mathrm{a}\right), 4.20$ (dd, $\left.J_{1 \mathrm{a}, 1 \mathrm{~b}}=9.5 \mathrm{~Hz}, J_{1 \mathrm{~b}, 3}=1 \mathrm{~Hz}, 1 \mathrm{H}, \mathrm{H}-1 \mathrm{~b}\right), 4.20$ (m, 1H, H-5), 3.28 (m, 2H, H-6a,b), 1.41 (s, 3H, H-8), 1.32 (s, 3H, H-9), 1.47 (s, 3H, H-11), 1.39 (s, 3H, H-12); ${ }^{13} \mathrm{C}-\mathrm{NMR}$ (125 MHz, $\left.\mathrm{CDCl}_{3}\right) \delta 112.9(\mathrm{C}-2), 111.8(\mathrm{C}-10), 111.8$ (C-7), 85.4 (C-3), 79.8 (C-5), $79.7(\mathrm{C}-4), 69.3$ (C-1), 26.4 (C-11), 26.4 (C-12), 26.0 (C-8), 25.0 (C-9), -0.9 (C-6). HRMS: m/z calcd. for $\left[\mathrm{C}_{12} \mathrm{H}_{20} \mathrm{IO}{ }_{5}+\mathrm{H}\right]^{+}$: 371.0350, obsd.: 371.0347. Spectral data matched that previously reported. $^{155}$

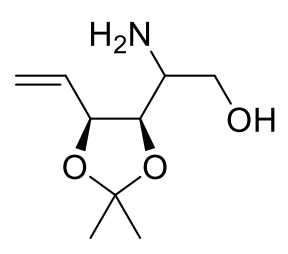

(S)-2-amino-2-((4R,5S)-2,2-dimethyl-5-vinyl-1,3-dioxolan-4yl)ethan-1-ol and $(R)$-2-amino-2-((4R,5S)-2,2-dimethyl-5-vinyl1,3-dioxolan-4-yl)ethan-1-ol (88). Ketone 90 (0.20 g, $1.10 \mathrm{mmol})$, $\mathrm{AcONH}_{4}(0.86 \mathrm{~g}, 11.0 \mathrm{mmol})$, and $\mathrm{NaCNBH}_{3}(0.27 \mathrm{~g}, 5.5 \mathrm{mmol})$ were added to distilled ethanol $(11 \mathrm{~mL})$ and the solution stirred at reflux for 18 hours. The resulting mixture was concentrated in vacuo then purified by silica gel flash column chromatography (DCM/EtOH/MeOH/30\% aq. $\mathrm{NH}_{3}, 105 / 2 / 2 / 1$ to 10/2/2/1, v/v/v/v), to give 12 as a 1:1 mixture of diastereomers (0.11 g, 55\%). $\mathrm{R} f=0.4$ and 0.39 , (DCM/EtOH/MeOH/ $30 \%$ aq. $\mathrm{NH}_{3}, 55 / 2 / 2 / 1$, v/v/v/v) for the $2 S$ and $2 R$ diastereomers, respectively. IR (film) 3321, 3093, 2972, 1634, 1356, $1128 \mathrm{~cm}^{-1}$. (S)-2-amino-2-((4R,5S)2,2-dimethyl-5-vinyl-1,3-dioxolan-4-yl)ethan-1-ol: ${ }^{1} \mathrm{H}-\mathrm{NMR}\left(500 \mathrm{MHz}, \mathrm{CDCl}_{3}\right) \delta 6.01$ $\left(\mathrm{ddd}, J_{2,3}=7.5 \mathrm{~Hz}, J_{2,1 \mathrm{~b}}=10.3 \mathrm{~Hz}, J_{2,1 \mathrm{a}}=17.5 \mathrm{~Hz}, 1 \mathrm{H}, \mathrm{H}-2\right), 5.39$ (d, $J_{1 \mathrm{a}, 2}=17.3 \mathrm{~Hz}, 1 \mathrm{H}$, H-1a), 5.34 (d, $\left.J_{1 b, 2}=10.0 \mathrm{~Hz}, 1 \mathrm{H}, \mathrm{H}-1 \mathrm{~b}\right), 4.64$ (t, $\left.J_{3,2}=J_{3,4}=7.5 \mathrm{~Hz}, 1 \mathrm{H}, \mathrm{H}-3\right), 4.20$ (dd, 
$\left.J_{4,5}=4.3 \mathrm{~Hz}, J_{4,3}=7.0 \mathrm{~Hz}, 1 \mathrm{H}, \mathrm{H}-4\right), 3.83-3.62(\mathrm{~m}, 3 \mathrm{H}, \mathrm{H}-5, \mathrm{H}-6 \mathrm{a}, \mathrm{H}-6 \mathrm{~b}), 1.47$ (s, 3H, $\left.\mathrm{CH}_{3}\right), 1.37$ (s, 3H, $\left.\mathrm{CH}_{3}\right) .{ }^{13} \mathrm{C}-\mathrm{NMR}\left(125 \mathrm{MHz}, \mathrm{CDCl}_{3}\right) \delta 133.5(\mathrm{C}-2), 118.6(\mathrm{C}-1), 108.9$ (C-7), 78.9 (C-3), 77.7 (C-4), $69.7(\mathrm{C}-5), 64.2(\mathrm{C}-6), 27.7\left(\mathrm{CH}_{3}\right), 25.2\left(\mathrm{CH}_{3}\right) .(R)-2-$ amino-2-((4R,5S)-2,2-dimethyl-5-vinyl-1,3-dioxolan-4-yl)ethan-1-ol: $\quad{ }^{1} \mathrm{H}-\mathrm{NMR} \quad(500$ $\left.\mathrm{MHz}, \mathrm{CDCl}_{3}\right) \delta 6.01\left(\mathrm{ddd}, J_{2,3}=7.5 \mathrm{~Hz}, J_{2,1 \mathrm{~b}}=10.3 \mathrm{~Hz}, J_{2,1 \mathrm{a}}=17.5 \mathrm{~Hz}, 1 \mathrm{H}, \mathrm{H}-2\right), 5.47$ $\left(\mathrm{d}, J_{1 \mathrm{a}, 2}=17.2 \mathrm{~Hz}, 1 \mathrm{H}, \mathrm{H}-1 \mathrm{a}\right), 5.33$ (d, $\left.J_{1 \mathrm{~b}, 2}=10.5 \mathrm{~Hz}, 1 \mathrm{H}, \mathrm{H}-1 \mathrm{~b}\right), 4.71$ (t, $J_{3,2}=J_{3,4}=6.8$ $\mathrm{Hz}, 1 \mathrm{H}, \mathrm{H}-3$ ), 4.11 (dd, $\left.J_{4,3}=6.5 \mathrm{~Hz}, J_{4,5}=8.5 \mathrm{~Hz}, 1 \mathrm{H}, \mathrm{H}-4\right), 3.83-3.62$ (m, 3H, H-5, H6a, H-6b), 1.54 (s, 3H, CH3), $1.40\left(\mathrm{~s}, 3 \mathrm{H}, \mathrm{CH}_{3}\right) .{ }^{13} \mathrm{C}-\mathrm{NMR}\left(125 \mathrm{MHz}, \mathrm{CDCl}_{3}\right) \delta 133.7(\mathrm{C}-$ 2), 119.9 (C-1), 109.0 (C-7), 78.48 (C-3), 78.1 (C-4), 69.7 (C-5), 64.3 (C-6), $27.2\left(\mathrm{CH}_{3}\right)$, $24.9\left(\mathrm{CH}_{3}\right)$. HRMS $m / z$ calcd. for $\left[\mathrm{C}_{9} \mathrm{H}_{16} \mathrm{NO}_{3}+\mathrm{H}\right]^{+}:$186.1125, obsd.: 186.1130 .<smiles>C=CC(O)C(O)C(N)CO</smiles>

\section{$(2 R, 3 R, 4 S)$-2-aminohex-5-ene-1,3,4-triol and $(2 S, 3 R, 4 S)-2-$} aminohex-5-ene-1,3,4-triol (89). Ketone 91 (0.17 g, 0.96 mmol), $\mathrm{AcONH}_{4}(0.71 \mathrm{~g}, 9.3 \mathrm{mmol})$, and $\mathrm{NaCNBH}_{3}(0.32 \mathrm{~g}, 5.0 \mathrm{mmol})$ were added to distilled ethanol $(9.4 \mathrm{~mL})$ and the solution was stirred at room temperature for 18 hours. To the resulting mixture were added distilled $\mathrm{H}_{2} \mathrm{O}$ and Dowex- $\mathrm{H}^{+}$and the reaction occasionally stirred over 2 hours, after which time the product was removed from Dowex- $\mathrm{H}^{+}\left(25 \%\right.$ aq. $\left.\mathrm{NH}_{3}\right)$, concentrated in vacuo, and purified by silica gel flash column chromatography (DCM/EtOH/MeOH/30\% aq. $\mathrm{NH}_{3}, 105 / 2 / 2 / 1$ to $10 / 2 / 2 / 1$, v/v/v/v) to give a 1:1 diastereomeric mixture of $\mathbf{8 9}$ as a colourless oil $(0.095 \mathrm{~g}, 71 \%)$. R $f=0.25$ (DCM/EtOH/MeOH/30\% aq. $\mathrm{NH}_{3}$ 35/6/6/3 v/v/v/v). IR (film) 3389, 3092, 2982, 2912 , 1669, 1615, 1452, $1052 \mathrm{~cm}^{-1}$ (2R,3R,4S)-2-aminohex-5-ene-1,3,4-triol: ${ }^{1} \mathrm{H}-\mathrm{NMR}(500$ $\left.\mathrm{MHz}, \mathrm{D}_{2} \mathrm{O}\right) \delta 5.93\left(\mathrm{ddd}, J_{2,3}=7.0 \mathrm{~Hz}, J_{2,1 \mathrm{~b}}=10.5 \mathrm{~Hz}, J_{2,1 \mathrm{a}}=17.3 \mathrm{~Hz}, 1 \mathrm{H}, \mathrm{H}-2\right), 5.37$ (d, $\left.J_{1 \mathrm{a}, 2}=17.3 \mathrm{~Hz}, 1 \mathrm{H}, \mathrm{H}-1 \mathrm{a}\right), 5.31$ (d, $\left.J_{1 \mathrm{~b}, 2}=10.5 \mathrm{~Hz}, 1 \mathrm{H}, \mathrm{H}-1 \mathrm{~b}\right), 4.20$ (t, $J_{3,2}=J_{3,4}=7.0$ $\mathrm{Hz}, 1 \mathrm{H}, \mathrm{H}-3), 3.83$ (dd, $\left.J_{6 \mathrm{a}, 6 \mathrm{~b}}=11.6 \mathrm{~Hz}, J_{6 \mathrm{a}, 5}=3.7 \mathrm{~Hz}, 1 \mathrm{H}, \mathrm{H}-6 \mathrm{a}\right), 3.66-3.57$ (m, 2H, H4, H-6b). ${ }^{13} \mathrm{C}-\mathrm{NMR}\left(125 \mathrm{MHz}, \mathrm{D}_{2} \mathrm{O}\right) \delta 135.7$ (C2), 118.3 (C-1), 73.3 (C-4), 73.1 (C-3), 61.3 (C-6), 53.3 (C-5). (2S,3R,4S)-2-aminohex-5-ene-1,3,4-triol: ${ }^{1} \mathrm{H}-\mathrm{NMR}\left(500 \mathrm{MHz}, \mathrm{D}_{2} \mathrm{O}\right)$ $\delta 5.91(\mathrm{~m}, 1 \mathrm{H}, \mathrm{H}-2), 5.32$ (m,2H, H-1a,b), 4.15 (t, $\left.J_{2,3}=6.5 \mathrm{~Hz}, 1 \mathrm{H}, \mathrm{H}-3\right), 3.56(\mathrm{~m}, 1 \mathrm{H}$, H-4, H6a,b), 2.90 (m, 1H, H-5); ${ }^{13} \mathrm{C}-\mathrm{NMR}\left(125 \mathrm{MHz}, \mathrm{D}_{2} \mathrm{O}\right) \delta 136.3$ (C-2), 118.1 (C-1), 72.8 (C-3), 72.4 (C-4), 62.7 (C-6), 52.1 (C-5). HRMS: $m / z$ calcd. for $\left[\mathrm{C}_{6} \mathrm{H}_{13} \mathrm{NO}_{3}+\mathrm{H}\right]^{+}$: 148.0968, obsd.: 148.0972 .

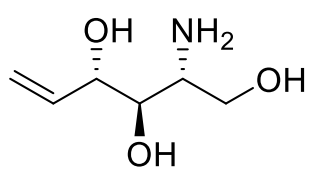

Method for the synthesis of pure $(2 R, 3 R, 4 S)$-2-aminohex-5-ene-

1,3,4-triol (81). A solution of diphenylmethyl amine protected alkenylamine $94(135 \mathrm{mg}, 0.38 \mathrm{mmol})$ and $\mathrm{Et}_{3} \mathrm{SiH}(0.12 \mathrm{~mL}, 0.76$ mmol) in TFA (1.9 mL) was refluxed for 2 hours. The solution was then concentrated in 
vacuo and the residue purified using Dowex- $\mathrm{H}^{+}$, with alkenylamine 13a (34.8 $\mathrm{mg}, 62 \%$ ) being eluted using a $35 \%$ ammonia solution. $[\alpha]_{D}^{20}+40.1$ (c $\left.0.6, \mathrm{MeOH}\right)$.

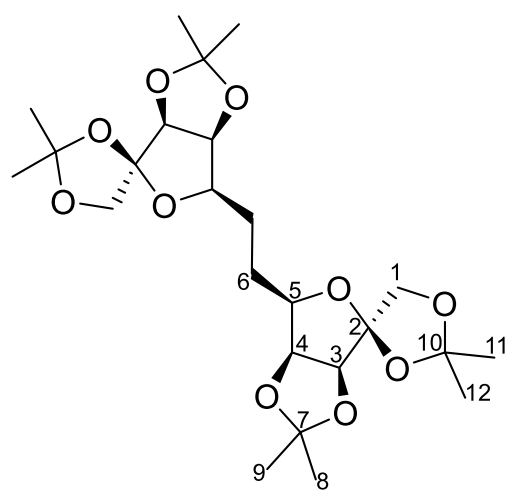

1,2-bis((3aS,4S,6R,6aS)-2,2,2',2'tetramethyldihydro-6H-spiro[furo[3,4d] $[1,3]$ dioxole-4,4'-[1,3]dioxolan]-6-yl)ethane $(90)$. Isopropylidine-protected iodide $87(0.11 \mathrm{~g}, 0.31 \mathrm{mmol})$, activated zinc $(0.10 \mathrm{~g}, 1.55 \mathrm{mmol})$, and $\mathrm{AcOH}(0.31 \mathrm{~mL})$ were added to ethanol $(1.25 \mathrm{~mL})$ and the resulting solution refluxed for 12 hours. The mixture was then cyclic loaded onto Dowex- $\mathrm{H}^{+}$, from which dimer 90 $\left(\mathrm{H}_{2} \mathrm{O}\right)$, and alkenylamines 12 and $\mathbf{1 3}\left(35 \%\right.$ aq. $\left.\mathrm{NH}_{3}\right)$ were eluted. The title compound was isolated as a white solid $(35.3 \mathrm{mg}, 0.072 \mathrm{mmol}, 12 \%)$ without further purification, with 88 and 89 then being separated via silica gel column chromatography (DCM/EtOH/MeOH, 30\% aq. $\mathrm{NH}_{3}, 105 / 2 / 2 / 1$ to 10/2/2/1, v/v/v/v) to give 88 (18.1 mg, $0.096 \mathrm{mmol})$ and $\mathbf{8 9}(3.5 \mathrm{mg}, 0.023 \mathrm{mmol})$ as a $1: 1$ mixture of diastereoisomers. Dimer 90, $\mathrm{R}_{f}=0.8$ (petroleum ether/EtOAc, 1/1, v/v). $[\alpha]_{D}^{20}+60.2$ (c 1.1, DCM). IR (film) 2982, 1479, 1355, 1224, $1041 \mathrm{~cm}^{-1} .{ }^{1} \mathrm{H}-\mathrm{NMR}\left(500 \mathrm{MHz}, \mathrm{CDCl}_{3}\right) \delta 4.69$ (dd, $J_{4,5}=3.6 \mathrm{~Hz}, J_{3,4}$ $=5.8 \mathrm{~Hz}, 1 \mathrm{H}, \mathrm{H}-4), 4.60\left(\mathrm{~d}, J_{3,4}=5.8 \mathrm{~Hz}, 1 \mathrm{H}, \mathrm{H}-3\right), 4.24\left(J_{1 \mathrm{a}, 1 \mathrm{~b}}=9.7 \mathrm{~Hz}, 1 \mathrm{H}, \mathrm{H}-1 \mathrm{a}\right), 4.02$ $\left(J_{1 \mathrm{~b}, 1 \mathrm{a}}=9.7 \mathrm{~Hz}, 1 \mathrm{H}, \mathrm{H}-1 \mathrm{~b}\right), 3.96$ (m, 1H, H-5), 1.95-1.73 (m, 2H, H-6a,6b), 1.45 (s, 3H, H-11), 1.41 (s, 3H, H-8), 1.39 (s, 3H, H-12), 1.31 (s, 3H, H-9). ${ }^{13} \mathrm{C}-\mathrm{NMR}(125 \mathrm{MHz}$, $\left.\mathrm{CDCl}_{3}\right) \delta 112.4(\mathrm{C}-7), 111.7$ (C-2), 111.6 (C-10), 85.4 (C-3), 80.5 (C-4), 79.0 (C-5), 69.3 (C-1), 25.0 (C-6), 26.5 (C-11), 26.4 (C-12), 26.0 (C-8), 24.9 (C-9). HRMS: m/z calcd. for $\left[\mathrm{C}_{24} \mathrm{H}_{38} \mathrm{O}_{10}+\mathrm{H}\right]^{+}:$487.2538, obsd.: 487.2542 .

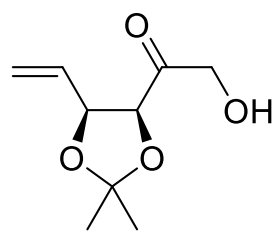

1-((4S,5S)-2,2-dimethyl-5-vinyl-1,3-dioxolan-4-yl)-2-

hydroxyethan-1-one (91). Iodide 87 (1.03 g, $2.8 \mathrm{mmol})$, activated zinc $(1.96 \mathrm{~g}, 29 \mathrm{mmol})$, and $\mathrm{H}_{2} \mathrm{O}(7 \mathrm{~mL})$ were added to $63 \mathrm{~mL}$ of distilled THF. The solution was brought to reflux and stirred at room temperature for 12 hours. The reaction mixture was then cooled to room temperature and decanted into a separating funnel, in which ether $(80 \mathrm{~mL})$ and water $(15 \mathrm{~mL})$ were added. The organic layer was collected and the aq. layer washed with ether $(20 \mathrm{~mL}$ x 3$)$. The organic fractions were combined, dried over $\mathrm{MgSO}_{4}$, filtered over celite, concentrated in vacuo, and the residue purified by silica gel flash column chromatography (Petroleum ether/EtOAc, $100 / 0$ to $1 / 1, \mathrm{v} / \mathrm{v})$ to yield the title compound $(0.41 \mathrm{~g}, 80 \%$ yield $)$ as a colourless oil. $\mathrm{R} f=0.5$ (petroleum ether/EtOAc, $1 / 1, \mathrm{v} / \mathrm{v}) .[\alpha]_{D}^{20}+9.4$ (c 1.38, DCM). IR 
(film) 3523, 3098, 2899, 1710, 1632, 1226, $1052 \mathrm{~cm}^{-1} .{ }^{1} \mathrm{H}-\mathrm{NMR}\left(500 \mathrm{MHz}, \mathrm{CDCl}_{3}\right) \delta$ $5.59(\mathrm{~m}, 1 \mathrm{H}, \mathrm{H}-1), 5.42$ (d, $\left.J_{1 \mathrm{a}, 2}=17 \mathrm{~Hz}, 1 \mathrm{H}, \mathrm{H}-1 \mathrm{a}\right), 5.24$ (d, $\left.J_{1 \mathrm{~b}, 2}=10.5 \mathrm{~Hz}, 1 \mathrm{H}, \mathrm{H}-1 \mathrm{~b}\right)$, $4.875 .42\left(\mathrm{t}, J_{3,4}=8 \mathrm{~Hz}, 1 \mathrm{H}, \mathrm{H}-3\right), 4.69\left(\mathrm{~d}, J_{3,4}=8.5 \mathrm{~Hz}, 1 \mathrm{H}, \mathrm{H}-4\right) .4 .49$ (d, $J_{6 \mathrm{a}, \mathrm{b}}=20.5$ Hz, 1H, H-6a), 4.19 (d, J6a,b = 20.5 Hz, 1H, H-6b), 1.58 (s, 3H, H-8), 1.38 (s, 3H, H-9). ${ }^{13} \mathrm{C}-\mathrm{NMR}\left(125 \mathrm{MHz}, \mathrm{CDCl}_{3}\right) \delta 209.2$ (C-5), 131.2 (C-2), 119.0 (C-1), 110.8 (C-7), 81.7 (C-4), 78.4 (C-3), 67.8 (C6), 26.5 (C-8), 24.4 (C-9). HRMS m/z calcd. for [ $\left.\mathrm{C}_{9} \mathrm{H}_{14} \mathrm{O}_{4}+\mathrm{Na}\right]^{+}$: 209.0784, obsd.: 209.0780.

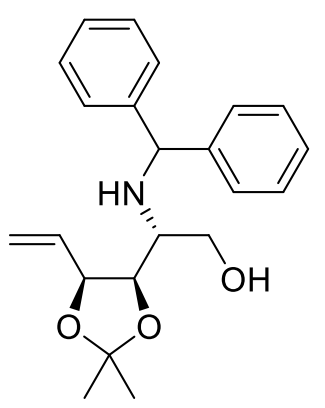

(R)-2-(benzhydrylamino)-2-((4R,5S)-2,2-dimethyl-5-vinyl-1,3dioxolan-4-yl)ethan-1-ol (94). Ketone 91 (0.20, 1.08 mmol), $\mathrm{Ph}_{2} \mathrm{CHNH}_{2} . \mathrm{HCl}$ (1.43 g, 1.48mmol), and NaCNBH3 (0.27 g, 1.24 mmol) were added to $\mathrm{EtOH}(21 \mathrm{~mL})$ and the resulting solution refluxed for 18 hours. The mixture was then concentrated in vacuo, dissolved in EtOAc $(20 \mathrm{~mL})$, washed with brine $(3 \times 50 \mathrm{~mL})$, dried over $\mathrm{MgSO}_{4}$, and concentrated in vacuo. The remaining oil was purified via silica gel flash column chromatography (Petroleum ether/EtOAc, 100/0 to 9/1, v/v) to give the protected alkenylamine $94(0.23 \mathrm{~g}, 61 \%)$ as a colourless oil, $\mathrm{R}_{f}=0.31$ (petroleum ether/EtOAc, 1/1, v/v). [ $\alpha]_{D}^{20}-19.2$ (c 0.9, DCM). IR (film) 3598, 3480, 3087, 2925, $1671,1564,1288,1028 \mathrm{~cm}^{-1}{ }^{1} \mathrm{H}-\mathrm{NMR}\left(500 \mathrm{MHz}, \mathrm{CDCl}_{3}\right) \delta$ 7.39-7.21 (m, 10H, phenylH) $5.73\left(\mathrm{ddd}, J_{5,4}=7.3 \mathrm{~Hz}, J_{5,6 \mathrm{~b}}=10.5 \mathrm{~Hz}, J_{5,6 \mathrm{a}}=17.4 \mathrm{~Hz}, 1 \mathrm{H}, \mathrm{H}-5\right), 5.28\left(\mathrm{~d}, J_{6 \mathrm{a}, 5}=17.1\right.$ $\mathrm{Hz}, 1 \mathrm{H}, \mathrm{H}-6 \mathrm{a}), 5.11$ (d, J6b,5 = $10.3 \mathrm{~Hz}, 1 \mathrm{H}, \mathrm{H}-6 \mathrm{~b}), 4.96$ (s, 1H, H-7), 4.66 (t, $J_{4,5}=J_{4,3}=$ $7.0 \mathrm{~Hz}, 1 \mathrm{H}, \mathrm{H}-4), 4.29$ (t, $\left.J_{3,4}=J_{3,2}=6.9 \mathrm{~Hz}, 1 \mathrm{H}, \mathrm{H}-3\right), 3.78-3.50$ (m, 2H, H-1a,1b), 2.73 $\left(\mathrm{dt}, J_{2,1 \mathrm{a}}=J_{2,1 \mathrm{~b}}=3.7 \mathrm{~Hz}, J_{2,3}=7.1 \mathrm{~Hz}, 1 \mathrm{H}, \mathrm{H}-2\right), 1.46\left(\mathrm{~s}, 3 \mathrm{H}, \mathrm{CH}_{3}\right), 1.36\left(\mathrm{~s}, 3 \mathrm{H}, \mathrm{CH}_{3}\right)$. ${ }^{13} \mathrm{C}-\mathrm{NMR}\left(125 \mathrm{MHz}, \mathrm{CDCl}_{3}\right) \delta 144.1$ (C-Ph), 143.3 (C-Ph), 133.8 (C-6), 128.5-127.1 (CPh), 118.6 (C-2), 108.4 (C-Hemiacetal), 78.8 (C-4), 78.7 (C-3), 64.22 (C-7), 60.6 (C-1), $55.8(\mathrm{C}-2), 27.5\left(\mathrm{CH}_{3}\right), 25.1\left(\mathrm{CH}_{3}\right)$. HRMS: $m / z$ calcd. for $\left[\mathrm{C}_{22} \mathrm{H}_{27} \mathrm{NO}_{3}+\mathrm{H}\right]^{+}$: 354.2064, obsd.: 354.2059 .

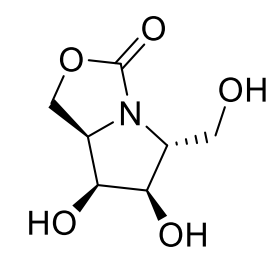

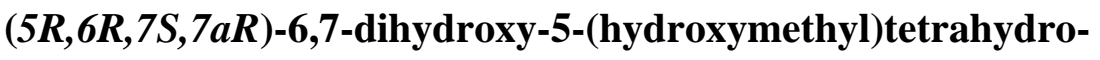
1H,3H-pyrrolo[1,2-c]oxazol-3-one (80) By subjecting alkenylamine $\mathbf{8 1}(0.046 \mathrm{~g}, 0.32 \mathrm{mmol})$ to the general procedure gave carbamate $\mathbf{8 0}$. $[\alpha]_{D}^{20}-6.4$ (c 0.8, MeOH). IR (film) 3601, 2989, 1715, 1648, 1193, 1031, $725 \mathrm{~cm}^{-1}$. ${ }^{1} \mathrm{H}-\mathrm{NMR}\left(500 \mathrm{MHz}, \mathrm{D}_{2} \mathrm{O}\right)$ 4.62-4.53 (m, 2H, H-1a, H-1b), 4.34 (dd, J3,4 $\left.=3.6 \mathrm{~Hz}, J_{2,3}=7.7 \mathrm{~Hz}, 1 \mathrm{H}, \mathrm{H}-3\right), 4.21-4.15(\mathrm{~m}, 1 \mathrm{H}, \mathrm{H}-5), 4.08$ (d, J3,4 $=3.6 \mathrm{~Hz}, 1 \mathrm{H}, \mathrm{H}-$ 4), $3.89\left(\mathrm{dd}, J_{6 \mathrm{a}, 5}=3.6 \mathrm{~Hz}, J_{6 \mathrm{a}, 6 \mathrm{~b}}=12.1 \mathrm{~Hz}, 1 \mathrm{H}, \mathrm{H}-6 \mathrm{a}\right), 3.71\left(\mathrm{dd}, J_{6 \mathrm{~b}, 5}=5.5 \mathrm{~Hz}, J_{6 \mathrm{~b}, 6 \mathrm{a}}=\right.$ 12.1 Hz, 1H, H-6b). ${ }^{13} \mathrm{C}-\mathrm{NMR}\left(125 \mathrm{MHz}, \mathrm{D}_{2} \mathrm{O}\right) \delta 74.6$ (C-3), 71.5 (C-4), 64.1 (C-6), 63.0 
(C-2), 61.4 (C-5), 61.02 (C-1). HRMS: m/z calcd. for $\left[\mathrm{C}_{7} \mathrm{H}_{11} \mathrm{NO}_{5}+\mathrm{Na}\right]^{+}: 212.0529$, obsd.: 212.0530 .

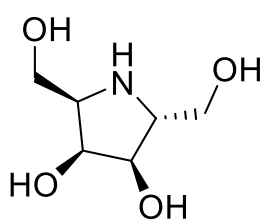

$1280 \mathrm{~cm}^{-1}$. Free Base ${ }^{1} \mathrm{H}-\mathrm{NMR}\left(500 \mathrm{MHz}, \mathrm{D}_{2} \mathrm{O}\right) \delta 4.19\left(\mathrm{t}, J_{4,3}=J_{4,5}=4.1 \mathrm{~Hz}, 1 \mathrm{H}, \mathrm{H}-4\right)$, $4.01\left(\mathrm{dd}, J_{3,4}=4.3 \mathrm{~Hz}, J_{3,2}=8.5 \mathrm{~Hz}, 1 \mathrm{H}, \mathrm{H}-3\right), 3.83-3.72$ (m, 2H, H-1a, H-6a), 3.69-3.61 (m, 2H, H-1b, H-6b), 3.33 (dt, $J_{5,4}=3.8 \mathrm{~Hz}, J_{5,6 \mathrm{a}}=J_{5,6 \mathrm{~b}}=6.7 \mathrm{~Hz}, 1 \mathrm{H}, \mathrm{H}-5$ ), 3.15 (ddd, $\left.J_{2,1 \mathrm{a}}=3.9 \mathrm{~Hz}, J_{2,1 \mathrm{~b}}=5.9 \mathrm{~Hz}, J_{2,3}=8.5 \mathrm{~Hz}, 1 \mathrm{H}, \mathrm{H}-2\right) .{ }^{13} \mathrm{C}-\mathrm{NMR}\left(125 \mathrm{MHz}, \mathrm{D}_{2} \mathrm{O}\right) \delta 73.4$ (C-4), 71.8 (C-3), 61.7 (C-1), 61.2 (C-2), 60.3 (C-6), 59.7 (C-5). HCl salt ${ }^{1} \mathrm{H}-\mathrm{NMR}$ (500 $\left.\mathrm{MHz}, \mathrm{D}_{2} \mathrm{O}\right) \delta 4.35\left(\mathrm{t}, J_{4,3}=J_{4,5}=3.5 \mathrm{~Hz}, 1 \mathrm{H}, \mathrm{H}-4\right), 4.28\left(\mathrm{dd}, J_{3,4}=3.9 \mathrm{~Hz}, J_{3,2}=9.2 \mathrm{~Hz}\right.$, 1H, H-3), 4.04-3.83 (m, 4H, H-1a,b, H-6a,6b), 3.77 (ddd, $J_{5,4}=3.2 \mathrm{~Hz}, J_{5,6 \mathrm{a}}=5.2 \mathrm{~Hz}$, $\left.J_{5,6 \mathrm{~b}}=8.3 \mathrm{~Hz}, 1 \mathrm{H}, \mathrm{H}-5\right), 3.65\left(\mathrm{ddd}, J_{2,1 \mathrm{a}}=3.3 \mathrm{~Hz}, J_{2,1 \mathrm{~b}}=5.9 \mathrm{~Hz}, J_{2,3}=9.3 \mathrm{~Hz}, 1 \mathrm{H}, \mathrm{H}-2\right)$. ${ }^{13} \mathrm{C}-\mathrm{NMR}\left(125 \mathrm{MHz}, \mathrm{D}_{2} \mathrm{O}\right) \delta 71.1$ (C-3), 70.0 (C-4), 62.1 (C-5), 61.6 (C-2), $58.0(\mathrm{C}-6)$, 57.4 (C-1). HRMS: $\mathrm{m} / \mathrm{z}$ calcd. for $\left[\mathrm{C}_{6} \mathrm{H}_{13} \mathrm{NO}_{4}+\mathrm{H}\right]^{+}:$164.0917, obsd.: 164.0915

\subsection{Chapter 4 experimental}<smiles>OCC1NCC(O)[C@H](O)[C@@H]1O</smiles>

1-Deoxymannojirimycin (36): Methyl iodofructoside 74 (0.48 g, 1.56 mmol) was dissolved in $16 \mathrm{~mL}$ of a $0.15 \mathrm{M} \mathrm{HCl}$ solution and stirred at room temperature until TLC confirmed full conversion to iodofructoside 95 (ca. 3 days). [ $\mathrm{R}_{f}=0.25(\mathrm{DCM} / \mathrm{MeOH}, 5 / 1, \mathrm{v} / \mathrm{v}),{ }^{1} \mathrm{H}-$ NMR (500 MHz, D $2 \mathrm{O}) \delta 4.20\left(\mathrm{~d}, J_{3,4}=8.4 \mathrm{~Hz}, 1 \mathrm{H}, \mathrm{H}-3\right), 4.13\left(\mathrm{t}, J_{4,3}=J_{4,5}=7.7 \mathrm{~Hz}, 1 \mathrm{H}\right.$, H-4), 3.85 (m, 1H, H-5), 3.65 (d, $\left.J_{1 \mathrm{a}, 1 \mathrm{~b}}=12.3 \mathrm{~Hz}, 1 \mathrm{H}, \mathrm{H}-1 \mathrm{a}\right), 3.60$ (d, $J_{1 \mathrm{~b}, 1 \mathrm{a}}=12.3 \mathrm{~Hz}$, $1 \mathrm{H}, \mathrm{H}-1 \mathrm{~b}), 3.56$ (dd, $\left.J_{6 \mathrm{a}, 6 \mathrm{~b}}=10.8 \mathrm{~Hz}, J_{6 \mathrm{a}, 5}=5.2 \mathrm{~Hz}, 1 \mathrm{H}, \mathrm{H}-6 \mathrm{a}\right), 3.45$ (dd, $J_{6 \mathrm{~b}, 6 \mathrm{a}}=10.8 \mathrm{~Hz}$, $\left.J_{6 \mathrm{~b}, 5}=6.3 \mathrm{~Hz}, 1 \mathrm{H}, \mathrm{H}-6 \mathrm{~b}\right) .{ }^{13} \mathrm{C}-\mathrm{NMR}\left(125 \mathrm{MHz}, \mathrm{D}_{2} \mathrm{O}\right) \delta 101.5$ (C-2), 79.5 (C-5), 78.4 (C4), 75.5 (C-3), 62.7 (C-1), 7.3 (C-6). HRMS: m/z calcd. for $\left[\mathrm{C}_{6} \mathrm{H}_{11} \mathrm{IO}_{5}+\mathrm{H}\right]^{+}:$: 290.9724 , obsd.: 290.9728] Next, aq. $\mathrm{NH}_{3}(8 \mathrm{~mL}, 144 \mathrm{mmol})$ and $\mathrm{NaCNBH}_{3}(0.40 \mathrm{~g}, 6.4 \mathrm{mmol})$ were then added to the reaction flask and stirred for a further 18 hours. The resulting reaction mixture was concentrated in vacuo and purified using Dowex- $\mathrm{H}^{+}\left(1 \%\right.$ aq. $\left.\mathrm{NH}_{3}\right)$ and silica gel flash column chromatography (DCM/EtOH/MeOH/aq. $\mathrm{NH}_{3}, 20 / 2 / 2 / 1$, $\mathrm{v} / \mathrm{v} / \mathrm{v} / \mathrm{v})$ to give pure DMJ $(36)$ as a white solid in $96 \%$ yield $(0.24 \mathrm{~g}, 1.50 \mathrm{mmol}) . \mathrm{R}_{f}=$ 0.10 (DCM/EtOH/MeOH/aq. $\left.\mathrm{NH}_{3}, 5 / 2 / 2 / 1, \mathrm{v} / \mathrm{v} / \mathrm{v} / \mathrm{v}\right) .[\alpha]_{D}^{20}-15.7$ [c 1.6, $\left.\mathrm{H}_{2} \mathrm{O}\right] ;$ lit. $^{120}[\alpha]_{D}^{20}$ 
-15.0 [c 2, $\mathrm{H}_{2} \mathrm{O}$ ]. IR (film) 3420, 3305, 2992, $2883 \mathrm{~cm}^{-1} .{ }^{1} \mathrm{H}-\mathrm{NMR}\left(500 \mathrm{MHz}, \mathrm{D}_{2} \mathrm{O}\right) \delta$ $4.26\left(\mathrm{td}, J_{2,1 \mathrm{a}}=J_{2,3}=3.1 \mathrm{~Hz}, J_{2,1 \mathrm{~b}}=1.5 \mathrm{~Hz}, 1 \mathrm{H}, \mathrm{H}-2\right), 4.00\left(\mathrm{dd}, J_{6 \mathrm{~b}, 6 \mathrm{a}}=12.6 \mathrm{~Hz}, J_{6 \mathrm{~b}, 5}=3.3\right.$ Hz, 1H, H-6b), 3.86 (m, 2H, H6a, H-4), 3.70 (dd, $J_{3,4}=9.5$ Hz, $J_{3,2}=3.1 \mathrm{~Hz}, 1 \mathrm{H}$ ), 3.42 $\left(\mathrm{dd}, J_{1 \mathrm{a}, 1 \mathrm{~b}}=13.6 \mathrm{~Hz}, J_{1 \mathrm{a}, 2}=3.1 \mathrm{~Hz}, 1 \mathrm{H}, \mathrm{H}-1 \mathrm{a}\right), 3.25\left(\mathrm{dd}, J_{1 \mathrm{~b}, 1 \mathrm{a}}=13.6 \mathrm{~Hz}, J_{1 \mathrm{~b}, 2}=1.5 \mathrm{~Hz}\right.$, $1 \mathrm{H}, \mathrm{H}-1 \mathrm{~b}), 3.15$ (ddd, $\left.J_{5,4}=10.3 \mathrm{~Hz}, J_{5,6 \mathrm{a}}=6.7 \mathrm{~Hz}, J_{5,6 \mathrm{~b}}=3.3 \mathrm{~Hz}, 1 \mathrm{H}, \mathrm{H}-5\right) .{ }^{13} \mathrm{C}-\mathrm{NMR}$ (125 MHz, D2O) $\delta 72.2$ (C-3), 65.7 (C-2), 65.6 (C-4), 60.0 (C-5), 57.9 (C-6), 47.4 (C-1). HRMS: $m / z$ calcd. for $\left[\mathrm{C}_{6} \mathrm{H}_{13} \mathrm{NO}_{4}+\mathrm{H}\right]^{+}:$164.0917, obsd.: 164.0915. Spectral data matched that previously reported. ${ }^{119}$

\subsection{Chapter 5 experimental}

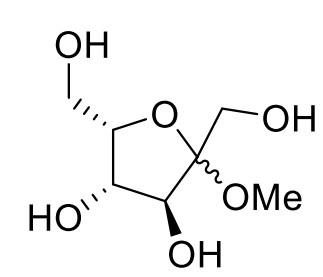

Methyl L-sorbofuranoside (112). To a flask containing $\mathrm{H}_{2} \mathrm{SO}_{4}$ in $\mathrm{MeOH}(0.03 \mathrm{M}, 400 \mathrm{~mL})$ was added L-sorbose $(2.00 \mathrm{~g}, 11.1 \mathrm{mmol})$ and stirred at room temperature. After $2 \mathrm{~h}$, aq. $35 \% \mathrm{NH}_{3}$ was added $(3 \mathrm{~mL})$, the reaction concentrated in vacuo to $1 / 4$ the volume and filtered over celite (cold $\mathrm{MeOH}$ wash). The mother liquor was collected, concentrated, and purified using silica gel flash column chromatography (EtOAc to EtOAc/MeOH 9/1) to give an $\alpha, \beta$ mixture of methyl-D-sorbofuranoside (1.19 $\mathrm{g}, 55 \%)$, which was subsequently used as a mixture. A: $\mathrm{R}_{f}=0.32\left(\right.$ EtOAc/i-PrOH/H$\left./ \mathrm{H}_{2} \mathrm{O}, 6 / 4 / 1, \mathrm{v} / \mathrm{v} / \mathrm{v}\right), \beta: \mathrm{R}_{f}=$ $0.30\left(\right.$ EtOAc/i-PrOH/ $/ \mathrm{H}_{2} \mathrm{O}$ 6/4/1, v/v/v). Spectral data matched those previously reported. ${ }^{132}$<smiles>CO[C@@]1(CO)O[C@H](I)[C@@H](O)[C@@H]1O</smiles>

Methyl 6-deoxy-6-iodo-L-sorbofuranoside (114). To a $\alpha, \beta$-mixture of methyl L-sorbofuranoside $(0.55 \mathrm{~g}, 2.8 \mathrm{mmol})$ in THF $(28 \mathrm{~mL})$ was added $\mathrm{PPh}_{3}(1.85 \mathrm{~g}, 70 \mathrm{mmol})$ and imidazole $(0.57 \mathrm{~g}, 84 \mathrm{mmol})$. The reaction was brought to $70{ }^{\circ} \mathrm{C}$ and a solution of $\mathrm{I}_{2}(1.43 \mathrm{~g}, 56 \mathrm{mmol})$ in THF (14 mL) was added portion wise over 5 mins. The reaction mixture was stirred at $70{ }^{\circ} \mathrm{C}$ until TLC showed complete conversion of starting material to desired product $\approx 7$ h), after which $\mathrm{MeOH}$ was added and the reaction concentrated in vacuo. The resulting mixture was purified using silica gel flash column chromatography (Petroleum ether/EtOAc 4/1 to $1 / 1$, v/v) and $\mathrm{HP} 20\left(\mathrm{H}_{2} \mathrm{O}\right.$ to $\mathrm{H}_{2} \mathrm{O} / \mathrm{MeOH}, 9 / 1$, v/v) to give an $\alpha, \beta$ mixture (predominately $\beta$ ) of methyl 6-deoxy-6-iodo-L-sorbofuranoside (0.67 g $78 \%$ ), which was subsequently used as a mixture. $\alpha \mathrm{R}_{f}=\beta \mathrm{R}_{f}=0.35(\mathrm{DCM} / \mathrm{MeOH}, 5 / 1, \mathrm{v} / \mathrm{v})$. IR (film) 3401, 2980, 2880, 1462, 1039, $1031 \mathrm{~cm}^{-1}$. $\beta-113{ }^{1} \mathrm{H}-\mathrm{NMR}\left(500 \mathrm{MHz}, \mathrm{D}_{2} \mathrm{O}\right) \delta 4.41$ (m, 2H, H-4, H-5), 4.36 (m, 1H, H-3), 3.76 (d, Ja, 1b = 12.2 Hz, 1H, H-1a), 3.66 (d, J Jb,1a $=12.2 \mathrm{~Hz}, 1 \mathrm{H}, \mathrm{H}-1 \mathrm{~b}), 3.35\left(\mathrm{dd}, J_{6 \mathrm{a}, 6 \mathrm{~b}}=9.3 \mathrm{~Hz}, J_{6 \mathrm{a}, 5}=5.4 \mathrm{~Hz}, 1 \mathrm{H}, \mathrm{H}-6 \mathrm{a}\right), 3.29-3.23(\mathrm{~m}$, 
1H, H-6b), 3.31 (s, 3H, OMe). ${ }^{13} \mathrm{C}-\mathrm{NMR}\left(125 \mathrm{MHz}, \mathrm{D}_{2} \mathrm{O}\right) \delta 108.2$ (C-2), 80.6 (C-4), 75.2 (C-3), 71.5 (C-5), 58.5 (C-1), 48.8 (OMe), -0.4 (C-6). HRMS: m/z calcd. for $\left[\mathrm{C}_{7} \mathrm{H}_{13} \mathrm{IO}_{5}+\mathrm{Na}\right]^{+}:$326.9699, obsd.: 326.9694 .

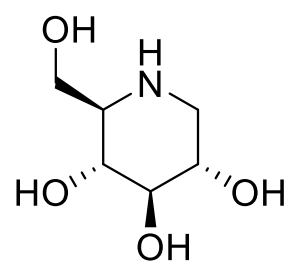

1-Deoxynojirimycin (3). To a solution of aq. $\mathrm{HCl}(0.15 \mathrm{M}, 13 \mathrm{~mL})$ was added methyl 6-deoxy-6-iodo-L-sorbofuranoside (0.42 g, 1.3 $\mathrm{mmol})$ and the solution put under reduced pressure $(0.3 \mathrm{~atm})$ in a 50

${ }^{\circ} \mathrm{C}$ water bath until TLC analysis showed full conversion to 6-deoxy6-iodo-L-sorbose $(\approx 2 \mathrm{~h})$. Following this, aq. $35 \% \mathrm{NH}_{3}(6.5 \mathrm{~mL}, 120 \mathrm{mmol})$ and $\mathrm{NaCNBH}_{3}(0.35 \mathrm{~g}, 5.2 \mathrm{mmol})$ were added sequentially to the reaction, which was stirred at room temperature for $18 \mathrm{~h}$. The resulting mixture was concentrated in vacuo and purified using Dowex- $\mathrm{H}^{+}\left(5 \% \mathrm{NH}_{3}\right)$ and silica gel flash column chromatography (DCM/EtOH/MeOH/aq. $\left.\mathrm{NH}_{3}, 20 / 2 / 2 / 1, \mathrm{v} / \mathrm{v} / \mathrm{v} / \mathrm{v}\right)$ to give 1-deoxynojirimycin $(0.21 \mathrm{~g}$, 95\%). $\mathrm{R}_{f}=0.10$ (DCM/EtOH/MeOH/aq. $\left.\mathrm{NH}_{3}, 5 / 2 / 2 / 1, \mathrm{v} / \mathrm{v} / \mathrm{v} / \mathrm{v}\right) .[\alpha]_{D}^{20} 46$ [c 0.8, $\left.\mathrm{H}_{2} \mathrm{O}\right]$; lit. ${ }^{136}[\alpha]_{D}^{20} 44$ [c 0.2, $\left.\mathrm{H}_{2} \mathrm{O}\right]$. IR (film) 3420, $3305 \mathrm{~cm}^{-1} .{ }^{1} \mathrm{H}-\mathrm{NMR}\left(500 \mathrm{MHz}, \mathrm{D}_{2} \mathrm{O}\right) \delta 3.93$ $\left(\mathrm{dd}, J_{6 \mathrm{a}, 6 \mathrm{~b}}=12.8 \mathrm{~Hz}, J_{6 \mathrm{a}, 5}=3.1 \mathrm{~Hz}, 1 \mathrm{H}, \mathrm{H}-6 \mathrm{a}\right), 3.86\left(\mathrm{dd}, J_{6 \mathrm{~b}, 6 \mathrm{a}}=12.7 \mathrm{~Hz}, J_{6 \mathrm{~b}, 5}=5.3 \mathrm{~Hz}\right.$, $1 \mathrm{H}, \mathrm{H}-6 \mathrm{~b}$ ), 3.77 (ddd, $\left.J_{2,1 \mathrm{~b}}=11.6 \mathrm{~Hz}, J_{2,3}=9.2 \mathrm{~Hz}, J_{2,1 \mathrm{a}}=5.1 \mathrm{~Hz}, 1 \mathrm{H}, \mathrm{H}-2\right), 3.58$ (dd, $J_{4,5}$ $\left.=10.5 \mathrm{~Hz}, J_{4,3}=9.3 \mathrm{~Hz}, 1 \mathrm{H}, \mathrm{H}-4\right), 3.52-3.44$ (m, $2 \mathrm{H}, \mathrm{H}-1 \mathrm{a}, \mathrm{H}-3$ ), 3.18 (ddd, $J_{5,4}=10.6$ $\left.\mathrm{Hz}, J_{5,6 \mathrm{~b}}=5.3 \mathrm{~Hz}, J_{5,6 \mathrm{a}}=3.1 \mathrm{~Hz}, 1 \mathrm{H}, \mathrm{H}-5\right), 2.95\left(\mathrm{dd}, J_{1 \mathrm{~b}, 1 \mathrm{a}}=12.5 \mathrm{~Hz}, J_{1 \mathrm{~b}, 2}=11.6 \mathrm{~Hz}, 1 \mathrm{H}\right.$, H-1b). ${ }^{13} \mathrm{C}-\mathrm{NMR}\left(125 \mathrm{MHz}, \mathrm{D}_{2} \mathrm{O}\right) \delta 76.0$ (C-3), 67.6 (C-4), 66.8 (C-2), 59.8 (C-5), 57.5 (C-6), 45.7 (C-1). HRMS: $m / z$ calcd. for $\left[\mathrm{C}_{6} \mathrm{H}_{13} \mathrm{NO}_{4}+\mathrm{H}\right]^{+}:$164.0917, obsd.: 164.0918. Spectral data matched those previously reported. ${ }^{156}$<smiles>OC[C@H]1NC[C@@H](O)[C@H](O)[C@@H]1O</smiles>

L-1-Deoxygalactonojirimycin (30). To a solution of $\mathrm{HCl}$ in $\mathrm{MeOH}$ $(0.15 \mathrm{M}, 12 \mathrm{~mL})$ was added 1,2:3,4-di- $O$-isopropylidene-6-deoxy-6iodo-D-tagatose $(\mathbf{8 7}, 0.45 \mathrm{~g}, 1.21 \mathrm{mmol})$ and the solution put under reduced pressure $(0.3 \mathrm{~atm})$ and heated in a $50{ }^{\circ} \mathrm{C}$ water bath until the starting material had completely reacted (observed via TLC analysis, 2 hours), following which $\mathrm{H}_{2} \mathrm{O}(12 \mathrm{~mL})$ was added, the $\mathrm{MeOH}$ removed in vacuo, and the remaining solution stirred at room temperature for 18 hours to give complete conversion to 6-deoxy-6-iodoD-tagatoside (observed via TLC analysis). Following this, $35 \%$ aq. $\mathrm{NH}_{3}(6.0 \mathrm{~mL}, 111$ mmol $)$ and $\mathrm{NaCNBH}_{3}(0.30 \mathrm{~g}, 4.84 \mathrm{mmol})$ were added sequentially to the reaction, which was stirred at room temperature for a further 18 hours. The resulting mixture was concentrated in vacuo and purified using Dowex- $\mathrm{H}^{+}\left(5 \%\right.$ aq. $\left.\mathrm{NH}_{3}\right)$ and silica gel flash column chromatography (DCM/EtOH/MeOH/ aq. $\mathrm{NH}_{3}, 20 / 2 / 2 / 1$, v/v/v/v) to give 1 deoxygalactojirimycin $(0.17 \mathrm{~g}, 86 \%)$ with trace amounts of an unidentified minor 
product. $\mathrm{R}_{f}=0.10\left(\mathrm{DCM} / \mathrm{EtOH} / \mathrm{MeOH} /\right.$ aq. $\mathrm{NH}_{3}, 5 / 2 / 2 / 1$, v/v/v/v). IR (film) $3380 \mathrm{~cm}^{-1}$. ${ }^{1} \mathrm{H}-\mathrm{NMR}\left(500 \mathrm{MHz}, \mathrm{D}_{2} \mathrm{O}\right) \delta 4.19\left(\mathrm{dd}, J_{4,3}=3.0 \mathrm{~Hz}, J_{4,5}=1.4 \mathrm{~Hz}, 1 \mathrm{H}, \mathrm{H}-4\right), 4.09$ (ddd, $\left.J_{2,1 \mathrm{~b}}=11.4 \mathrm{~Hz}, J_{2,3}=9.6 \mathrm{~Hz}, J_{2,1 \mathrm{a}}=5.3 \mathrm{~Hz}, 1 \mathrm{H}, \mathrm{H}-2\right), 3.90\left(\mathrm{dd}, J_{6 \mathrm{a}, 6 \mathrm{~b}}=12.3 \mathrm{~Hz}, J_{6 \mathrm{a}, 5}=\right.$ $4.9 \mathrm{~Hz}, 1 \mathrm{H}, \mathrm{H}-6 \mathrm{a}), 3.82$ (dd, $\left.J_{6 \mathrm{~b}, 6 \mathrm{a}}=12.2 \mathrm{~Hz}, J_{6 \mathrm{~b}, 5}=8.8 \mathrm{~Hz}, 1 \mathrm{H}, \mathrm{H}-6 \mathrm{~b}\right), 3.66$ (dd, $J_{3,2}=$ $\left.9.7 \mathrm{~Hz}, J_{3,4}=3.0 \mathrm{~Hz}, 1 \mathrm{H}, \mathrm{H}-3\right), 3.53\left(\mathrm{dd}, J_{1 \mathrm{a}, 1 \mathrm{~b}}=12.5 \mathrm{~Hz}, J_{1 \mathrm{a}, 2}=5.4 \mathrm{~Hz}, 1 \mathrm{H}, \mathrm{H}-1 \mathrm{a}\right), 3.44$ $\left(\mathrm{ddd}, J_{5,6 \mathrm{~b}}=8.9 \mathrm{~Hz}, J_{5,6 \mathrm{a}}=4.8 \mathrm{~Hz}, J_{5,4}=1.4 \mathrm{~Hz}, 1 \mathrm{H}, \mathrm{H}-5\right), 2.90\left(\mathrm{dd}, J_{1 \mathrm{~b}, 1 \mathrm{a}}=12.5 \mathrm{~Hz}, J_{1 \mathrm{~b}, 2}\right.$ $=11.5 \mathrm{~Hz}, 1 \mathrm{H}, \mathrm{H}-1 \mathrm{~b}) .{ }^{13} \mathrm{C}-\mathrm{NMR}\left(125 \mathrm{MHz}, \mathrm{D}_{2} \mathrm{O}\right) \delta 72.8(\mathrm{C}-3), 66.8(\mathrm{C}-4), 64.6(\mathrm{C}-2)$, 60.0 (C-5), 59.0 (C-6), 46.0 (C-1). HRMS: m/z calcd. for $\left[\mathrm{C}_{6} \mathrm{H}_{13} \mathrm{NO}_{4}+\mathrm{H}\right]^{+}: 164.0917$, obsd.: 164.0912. Spectral data matched those previously reported. ${ }^{147}$

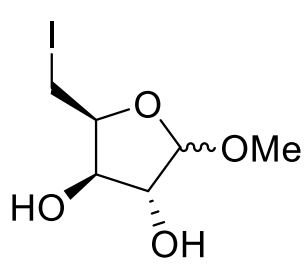

Methyl 5-deoxy-5-iodo- $\alpha / \beta$-D-xyloside (55). To a solution of Dxylose (4.16 g, $27.7 \mathrm{mmol})$ in $\mathrm{MeOH}(138 \mathrm{~mL}), \mathrm{AcCl}(0.42 \mathrm{~mL})$ was added and the reaction was stirred at room temperature for $24 \mathrm{~h}$. The reaction was neutralised by the addition of Dowex- $\mathrm{OH}^{-}$, filtered and concentrated. The resulting oil was purified by flash chromatography (MeOH/EtOAc, $1 / 9, \mathrm{v} / \mathrm{v})$ to give the pure methyl xylofuranosides. To a solution of the methyl xylofuranosides $(27.7 \mathrm{mmol})$ in dry THF $(152 \mathrm{~mL})$ under an argon atmosphere, $\mathrm{PPh}_{3}$ $(10.9 \mathrm{~g}, 41.5 \mathrm{mmol})$ and imidazole $(3.71 \mathrm{~g}, 55.4 \mathrm{mmol})$ were added. $\mathrm{I}_{2}(10.4 \mathrm{~g}, 41.5 \mathrm{mmol})$ in dry THF (42 mL) was cannulated into the reaction vessel. The reaction was refluxed for $2 \mathrm{~h}$, then cooled, filtered, and concentrated. The product was dissolved in Petroleum ether/EtOAc (3/1, v/v), filtered, then purified by reverse phase $\mathrm{HP} 20\left(\mathrm{MeOH} / \mathrm{H}_{2} \mathrm{O}, 5 / 1\right.$, $\mathrm{v} / \mathrm{v})$ to give methyl 5-deoxy-5-iodo- $\alpha / \beta$-D-xyloside (55) as a colourless oil (4.63 g, 61\%). $\mathrm{R}_{f}=0.65\left(\right.$ EtOAc/MeOH, 9/1, v/v); $[\alpha]_{D}^{20}=-19.7\left(\mathrm{c}=1.5, \mathrm{CHCl}_{3}\right) ; \mathrm{IR}($ film) 3446, 1216, $770 \mathrm{~cm}^{-1}$. $\boldsymbol{\alpha - 5 5}{ }^{1} \mathrm{H}$ NMR $\left(500 \mathrm{MHz}, \mathrm{CDCl}_{3}\right) \delta 5.06\left(\mathrm{~d}, J_{1,2}=4.4,1 \mathrm{H}, \mathrm{H}-1\right), 4.40(\mathrm{~m}, 1 \mathrm{H}$, $\mathrm{H}-4), 4.29$ (dd, $\left.J_{2,3}=3.3 \mathrm{~Hz}, J_{3,4}=4.6 \mathrm{~Hz}, 1 \mathrm{H}, \mathrm{H}-3\right), 4.17$ (dd, $J_{1,2}=4.4 \mathrm{~Hz}, J_{2,3}=3.3 \mathrm{~Hz}$, 1H, H-2), 3.51 (s, 3H, OMe), 3.31 (dd, $\left.J_{4,5 \mathrm{a}}=7.6 \mathrm{~Hz}, J_{5 \mathrm{a}, 5 \mathrm{~b}}=9.8 \mathrm{~Hz}, 1 \mathrm{H}, \mathrm{H}-5 \mathrm{a}\right), 3.25$ (dd, $\left.J_{4,5 \mathrm{~b}}=6.1 \mathrm{~Hz}, J_{5 \mathrm{a}, 5 \mathrm{~b}}=9.8 \mathrm{~Hz}, 1 \mathrm{H}, \mathrm{H}-5 \mathrm{~b}\right) .{ }^{13} \mathrm{C} \mathrm{NMR}\left(125 \mathrm{MHz}, \mathrm{CDCl}_{3}\right) 102.2(\mathrm{C}-1), 79.1$ (C-4), 78.4 (C-2), 76.9 (C-3), 56.2 (OMe), 1.6 (C-5); $\boldsymbol{\beta}-554.93$ (s, 1H, H-1), 4.60 (dt, J3,4 $\left.=3.9 \mathrm{~Hz}, J_{4,5 \mathrm{a}}=J_{4,5 \mathrm{~b}}=7.7 \mathrm{~Hz}, 1 \mathrm{H}, \mathrm{H}-4\right), 4.28(\mathrm{~s}, 1 \mathrm{H}, \mathrm{H}-2), 4.14\left(\mathrm{~d}, J_{3,4}=3.9 \mathrm{~Hz}, 1 \mathrm{H}, \mathrm{H}-\right.$ 3), 3.40 (s, 3H, OMe), 3.32 (d, $\left.J_{4,5}=7.7 \mathrm{~Hz}, 2 \mathrm{H}, \mathrm{H}-5 \mathrm{a}, \mathrm{b}\right) ;{ }^{13} \mathrm{C}$ NMR $(125 \mathrm{MHz}$, $\mathrm{CDCl}_{3}$ )109.0 (C-1), 83.7 (C-4), 79.7 (C-2), 76.0 (C-3), 55.5 (OMe), 1.9 (C-5); HRMS: $\mathrm{m} / \mathrm{z}$ calcd. for $\left[\mathrm{C}_{6} \mathrm{H}_{11} \mathrm{O}_{4} \mathrm{I}+\mathrm{Na}\right]^{+}:$296.9594, obsd.: 296.9601 . 
"

$(3 R, 4 r, 5 S)$-piperidine-3,4,5-triol (118). A solution of methyl 5deoxy-5-iodo- $\alpha / \beta$-D-xyloside (0.39 $\mathrm{g}, 1.42 \mathrm{mmol})$ in aqueous $\mathrm{HCl}$ $(0.3 \mathrm{M}, 14 \mathrm{~mL})$ was refluxed until full conversion of starting material was observed via TLC (ca. 1 h). Following this, $35 \%$ aq. $\mathrm{NH}_{3}(7 \mathrm{~mL}$,

$130 \mathrm{mmol})$ and $\mathrm{NaCNBH}_{3}(0.36 \mathrm{~g}, 5.68 \mathrm{mmol})$ were added sequentially to the reaction, which was stirred at room temperature for a further 18 hours. The resulting mixture was concentrated in vacuo and purified using Dowex- $\mathrm{H}^{+}\left(5 \%\right.$ aq. $\left.\mathrm{NH}_{3}\right)$ and silica gel flash column chromatography (DCM/EtOH/MeOH/aq. $\mathrm{NH}_{3}, 20 / 2 / 2 / 1, \mathrm{v} / \mathrm{v} / \mathrm{v} / \mathrm{v}$ ) to give $(3 R, 4 r, 5 S)$-piperidine-3,4,5-triol $(0.16 \mathrm{~g}, 88 \%) . \mathrm{R}_{f}=0.10\left(\mathrm{DCM} / \mathrm{EtOH} / \mathrm{MeOH} / \mathrm{aq} . \mathrm{NH}_{3}\right.$ 5/2/2/1 v/v/v/v). IR (film) 3420, 3350, 2902, $2887 \mathrm{~cm}^{-1} .{ }^{1} \mathrm{H}-\mathrm{NMR}\left(500 \mathrm{MHz}, \mathrm{D}_{2} \mathrm{O}\right) \delta 3.64$ $\left(\mathrm{ddd}, J_{2,1 \mathrm{~b}}=10.4 \mathrm{~Hz}, J_{2,3}=8.7 \mathrm{~Hz}, J_{2,1 \mathrm{a}}=4.8 \mathrm{~Hz}, 1 \mathrm{H}, \mathrm{H}-2\right), 3.40\left(\mathrm{t}, J_{3,2}=8.7 \mathrm{~Hz}, 1 \mathrm{H}, \mathrm{H}-\right.$ 3), $3.30\left(\mathrm{dd}, J_{1 \mathrm{a}, 1 \mathrm{~b}}=12.7 \mathrm{~Hz}, J_{1 \mathrm{a}, 2}=4.8 \mathrm{~Hz}, 1 \mathrm{H}, \mathrm{H}-1 \mathrm{a}\right), 2.71\left(\mathrm{dd}, J_{1 \mathrm{~b}, 1 \mathrm{a}}=12.7 \mathrm{~Hz}, J_{1 \mathrm{~b}, 2}=\right.$ $10.4 \mathrm{~Hz}, 1 \mathrm{H}, \mathrm{H}-1 \mathrm{~b}) .{ }^{13} \mathrm{C}-\mathrm{NMR}\left(125 \mathrm{MHz}, \mathrm{D}_{2} \mathrm{O}\right) \delta 76.1$ (C-3), 68.5 (C-2), 47.4 (C-1). HRMS: $m / z$ calcd. for $\left[\mathrm{C}_{6} \mathrm{H}_{12} \mathrm{NO}_{3}+\mathrm{H}\right]^{+}: 135.0812$, obsd.: 135.0817. Spectral data matched those previously reported. ${ }^{157}$

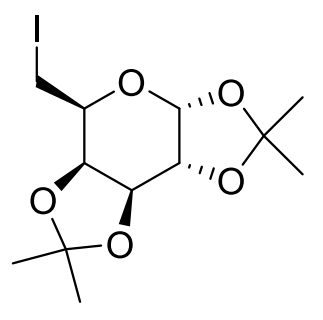

6-Deoxy-6-iodo-1,2:3,4-di- $O$-isopropylidene- $\alpha$-Dgalactopyranose (119). To a mixture of 1,2:3,4-di- $O$ isopropylidene- $\alpha$-D-galactopyranose ${ }^{63}(2.6 \mathrm{~g}, 10 \mathrm{mmol}), \mathrm{PPh}_{3}(3.93$ $\mathrm{g}, 15 \mathrm{mmol})$ and imidazole $(1.36 \mathrm{~g}, 20 \mathrm{mmol})$ in dry THF $(100 \mathrm{~mL})$, was added $\mathrm{I}_{2}(3.81 \mathrm{~g}, 15 \mathrm{mmol})$ in small portions. After refluxing for $1 \mathrm{~h}$, the reaction mixture was cooled to room temperature, and quenched by the addition of $10 \%$ aq. $\mathrm{Na}_{2} \mathrm{~S}_{2} \mathrm{O}_{4}$. The product was extracted with EtOAc, and the combined organic layers were washed with brine, dried $\left(\mathrm{MgSO}_{4}\right)$, filtered and concentrated. Distillation of the residue gave 6-deoxy-6-iodo-1,2:3,4- $O$-di-isopropyl- $\alpha$-D-galactopyranose as a yellow oil (3.14 g, 85\%). $\mathrm{R}_{f}=0.55$ (Petroleum ether/EtOAc, 4/1, v/v); $[\alpha]_{D}^{20}-52.1$ [c 1, DCM]; lit. ${ }^{158}[\alpha]_{D}^{20}-57.3[\mathrm{c} 1, \mathrm{DCM}] .{ }^{1} \mathrm{H}-\mathrm{NMR}\left(500 \mathrm{MHz}, \mathrm{CDCl}_{3}\right) \delta 5.52\left(\mathrm{~d}, J_{1,2}=5.0 \mathrm{~Hz}, 1 \mathrm{H}\right.$, $\mathrm{H}-1), 4.59\left(\mathrm{dd}, J_{3,4}=7.9 \mathrm{~Hz}, J_{3,2}=2.5 \mathrm{~Hz}, 1 \mathrm{H}, \mathrm{H}-3\right), 4.38\left(\mathrm{dd}, J_{4,3}=7.9 \mathrm{~Hz}, J_{4,5}=1.9 \mathrm{~Hz}\right.$, $1 \mathrm{H}, \mathrm{H}-4), 4.28\left(\mathrm{dd}, J_{2,1}=5.0 \mathrm{~Hz}, J_{2,3}=2.5 \mathrm{~Hz}, 1 \mathrm{H}, \mathrm{H}-2\right), 3.92\left(\mathrm{ddd}, J_{5,6 \mathrm{~b}}=7.2 \mathrm{~Hz}, J_{5,6 \mathrm{a}}=\right.$ $\left.6.8 \mathrm{~Hz}, J_{5,4}=1.9 \mathrm{~Hz}, 1 \mathrm{H}, \mathrm{H}-5\right), 3.29\left(\mathrm{dd}, J_{6 \mathrm{a}, \mathrm{b}}=10 \mathrm{~Hz}, J_{6 \mathrm{a}, 5}=6.8 \mathrm{~Hz}, 1 \mathrm{H}, \mathrm{H}-6 \mathrm{a}\right), 3.19$ $\left(\mathrm{dd}, J_{6 \mathrm{~b}, \mathrm{a}}=10 \mathrm{~Hz}, J_{6 \mathrm{~b}, 5}=7.2 \mathrm{~Hz}, 1 \mathrm{H}, \mathrm{H}-6 \mathrm{~b}\right), 1.52\left(\mathrm{~s}, 3 \mathrm{H}, \mathrm{CH}_{3}\right), 1.42\left(\mathrm{~s}, 3 \mathrm{H}, \mathrm{CH}_{3}\right), 1.33$ (s, $\left.3 \mathrm{H}, \mathrm{CH}_{3}\right), 1.31$ (s, 3H, CH3). ${ }^{13} \mathrm{C}-\mathrm{NMR}\left(125 \mathrm{MHz}, \mathrm{CDCl}_{3}\right) \delta 109.7$ (C-7), $109.0(\mathrm{C}-10)$, 96.8 (C-1), 71.5 (C-4), 71.1 (C-3), 70.5 (C-2), 68.9 (C-5), 26.2 (C-8), 26.1 (C-11), 25.0 (C-9), 24.6 (C-12), 2.5 (C-6). HRMS: $\mathrm{m} / z$ calcd. for $\left[\mathrm{C}_{12} \mathrm{H}_{20} \mathrm{IO}+\mathrm{H}+\mathrm{H}\right]^{+}: 371.0350$, obsd.: 371.0355 . 


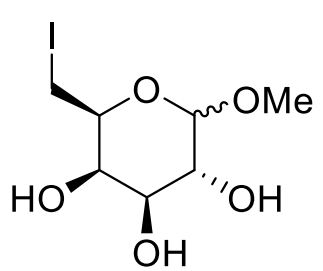

Methyl 6-deoxy-6-iodo- $\alpha / \beta$-D-galactopyranoside (121). To a solution of methyl $\alpha / \beta$-galactopyranoside $(1.24 \mathrm{~g}, 6.38 \mathrm{mmol})$ in dry THF (35 mL) under an atmosphere of $\mathrm{N}_{2}, \mathrm{PPh}_{3}(2.51 \mathrm{~g}, 9.58 \mathrm{mmol})$ and imidazole $(0.87 \mathrm{~g}, 12.7 \mathrm{mmol})$ were added. $\mathrm{I}_{2}(2.42 \mathrm{~g}, 9.58$ $\mathrm{mmol})$ in dry THF $(9.5 \mathrm{~mL})$ was cannulated into the reaction vessel. The reaction was refluxed for $2 \mathrm{~h}$, then cooled, filtered and concentrated. The product was taken up in Petroleum ether/EtOAc, 3/1, v/v, and filtered through a silica plug to removed excess iodine, then purified by column chromatography on reverse phase HP20 beads $(\mathrm{MeOH} /$ water, 5/1, v/v) to give methyl 6-deoxy-6-iodo- $\alpha / \beta$-D-galactopyranose. The mixture was concentrated in vacuo and the residue crystallised from $\mathrm{MeOH}$, giving the title compound $(1.78 \mathrm{~g}, 47 \%)$ as white crystals. Mp 175.0-175.6 ${ }^{\circ} \mathrm{C} ; \mathrm{R}_{f}=0.43$ (MeOH/EtOAc, 1/9, v/v); IR (film) 3354, 2953, 2906, 1454, 1360, 1297, 1132, 1102, 1078, $691 \mathrm{~cm}-1$; ${ }^{1} \mathrm{H}$ NMR (500 MHz, D $\left.2 \mathrm{O}\right) \delta 4.69$ (d, $J_{1,2}=3.6 \mathrm{~Hz}, 1 \mathrm{H}, \mathrm{H}-1$ ), 3.97 (dd, $\left.J_{3,4}=3.3, J_{4,5}=1.2 \mathrm{~Hz}, 1 \mathrm{H}, \mathrm{H}-4\right), 3.90\left(\mathrm{ddd}, J_{4,5}=1.2 \mathrm{~Hz}, J_{5,6 \mathrm{a}}=5.3, J_{5,6 \mathrm{~b}}=8.0 \mathrm{~Hz} 1 \mathrm{H}\right.$, H-5), 3.75 (dd, $\left.J_{1,2}=3.6, J_{2,3}=10.2 \mathrm{~Hz}, 1 \mathrm{H}, \mathrm{H}-2\right), 3.69$ (dd, $J_{2,3}=10.2, J_{3,4}=3.3 \mathrm{~Hz}, 1 \mathrm{H}$, H-3), 3.46 (s, 3H, OMe), 3.37 (dd, J5,6a $\left.=5.3, J_{6 \mathrm{a}, 6 \mathrm{~b}}=10.2 \mathrm{~Hz}, 1 \mathrm{H}, \mathrm{H}-6 \mathrm{a}\right), 3.33\left(\mathrm{dd}, J_{5,6 \mathrm{~b}}\right.$ $\left.=8.0, J_{6 \mathrm{a}, 6 \mathrm{~b}}=10.2 \mathrm{~Hz}, 1 \mathrm{H}, \mathrm{H}-6 \mathrm{~b}\right) ;{ }^{13} \mathrm{C} \mathrm{NMR}\left(125 \mathrm{MHz}, \mathrm{D}_{2} \mathrm{O}\right) \delta 100.2(\mathrm{C} 1), 71.4(\mathrm{C} 5)$, 70.4 (C4), 69.9 (C2), 68.4 (C3), 54.6 (OMe), 2.3 (C6). HRMS: m/z calcd. for [C7H13IO5+Na $]^{+}:$326.9700, obsd.: 326.9709 .

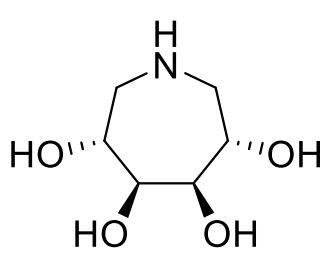

$(3 S, 4 R, 5 S, 6 R)$-azepane-3,4,5,6-tetraol (49). A 9:1 mixture of TFA: $\mathrm{H}_{2} \mathrm{O} \quad(4.3 \mathrm{~mL})$ and 6-deoxy-6-iodo-1,2:3,4-di- $O$ isopropylidene- $\alpha$-D-galactopyranose $(0.32 \mathrm{~g}, 0.86 \mathrm{mmol})$ was put under reduced pressure $(0.3 \mathrm{~atm})$ and heated in a $50{ }^{\circ} \mathrm{C}$ water bath for 30 minutes, when complete consumption of starting material was observed by TLC. The resulting mixture was concentrated in vacuo and redissolved in a mixture of DCM and $\mathrm{H}_{2} \mathrm{O}$, from which the product was extracted with $\mathrm{H}_{2} \mathrm{O}$ and concentrated to give 6deoxy-6-iodo-D-galactose (120) as a brown oil that was used without further purification. $\left[\mathrm{R}_{f}=0.35\left(\mathrm{DCM} / \mathrm{MeOH}, 5 / 1, \mathrm{v} / \mathrm{v}, \boldsymbol{\alpha}:{ }^{1} \mathrm{H} \mathrm{NMR}\left(500 \mathrm{MHz}, \mathrm{D}_{2} \mathrm{O}\right) \delta 5.19\left(\mathrm{~d}, J_{1,2}=3.8 \mathrm{~Hz}\right.\right.\right.$, $1 \mathrm{H}, \mathrm{H}-1$ ), 4.20-4.14 (m, 1H, H-5), 4.10 (dd, J4,3 = 3.3 Hz, J4,5 = 1.1 Hz, 1H, H-4), 3.81 (m, 1H, H-3), 3.79 (dd, $\left.J_{2,3}=10.3 \mathrm{~Hz}, J_{2,1}=3.9 \mathrm{~Hz}, 1 \mathrm{H}, \mathrm{H}-2\right), 3.35-3.16$ (m, 2H, H6a,6b); ${ }^{13} \mathrm{C}$ NMR (125 MHz, D $\left.2 \mathrm{O}\right) \delta 92.2$ (C-1), 70.7 (C-5), 69.9 (C-4), 69.0 (C-3), 67.8 (C-5), 2.3 (C-6). $\beta$ : ${ }^{1} \mathrm{H}$ NMR $\left(500 \mathrm{MHz}, \mathrm{D}_{2} \mathrm{O}\right) \delta 4.54\left(\mathrm{~d}, J_{1,2}=7.9 \mathrm{~Hz}, 1 \mathrm{H}, \mathrm{H}-1\right), 4.06\left(\mathrm{dd}, J_{4,3}=\right.$ $\left.3.5 \mathrm{~Hz}, J_{4,5}=1.0 \mathrm{~Hz}, 1 \mathrm{H}, \mathrm{H}-4\right), 3.81(\mathrm{~m}, 1 \mathrm{H}, \mathrm{H}-5), 3.59$ (dd, $J_{3,2}=10 \mathrm{~Hz}, J_{3,4}=3.5 \mathrm{~Hz}$, $1 \mathrm{H}, \mathrm{H}-3), 3.43\left(\mathrm{dd}, J_{2,3}=10 \mathrm{~Hz}, J_{2,1}=7.9 \mathrm{~Hz}, 1 \mathrm{H}, \mathrm{H}-2\right), 3.35-3.16$ (m, 2H, H-6a,6b); ${ }^{13} \mathrm{C}$ 
NMR (125 MHz, D 20 ) $\delta 92.2$ (C-1), 70.7 (C-5), 69.9 (C-4), 69.0 (C-3), 67.8 (C-5), 2.3 (C-6) HRMS: $m / z$ calcd. for $\left[\mathrm{C}_{6} \mathrm{H}_{11} \mathrm{IO}_{5}+\mathrm{H}\right]^{+}:$290.9724, obsd.: 290.9730]. Next, 6-deoxy6-iodo-D-galactopyranose (120) was dissolved in $\mathrm{H}_{2} \mathrm{O}(8.6 \mathrm{~mL})$, after which aq. $\mathrm{NH}_{3}(4.3$ $\mathrm{mL}, 80 \mathrm{mmol})$ and $\mathrm{NaCNBH}_{3}(0.22 \mathrm{~g}, 3.45 \mathrm{mmol})$ were added and the reaction stirred at room temperature for 2 days. The resulting mixture was concentrated in vacuo and purified using Dowex $-\mathrm{H}^{+}$exchange resin $\left(0.1 \% \mathrm{NH}_{3}\right)$ to give the title compound as an off white solid (95.4 mg, 68\% 2 steps). $\mathrm{R}_{f}=0.10$ (DCM/EtOH/MeOH/aq. $\mathrm{NH}_{3}, 5 / 2 / 2 / 1$, v/v/v/v). IR (film) 3401, 2988, $2896 \mathrm{~cm}^{-1} ;{ }^{1} \mathrm{H}-\mathrm{NMR}\left(500 \mathrm{MHz}, \mathrm{D}_{2} \mathrm{O}\right) \delta 4.00$ (d, J3,2 $=6.5$ $\mathrm{Hz}, 1 \mathrm{H}, \mathrm{H}-3$ ), 3.87 (ddd, $\left.J_{2,3}=6.5 \mathrm{~Hz}, J_{2,1 \mathrm{~b}}=4.8 \mathrm{~Hz}, J_{2,1 \mathrm{a}}=4.2 \mathrm{~Hz}, 1 \mathrm{H}, \mathrm{H}-2\right), 3.08$ (dd, $\left.J_{1 \mathrm{a}, 1 \mathrm{~b}}=14.7 \mathrm{~Hz}, J_{1 \mathrm{a}, 2}=4.2 \mathrm{~Hz}, 1 \mathrm{H}, \mathrm{H}-1 \mathrm{a}\right), 2.90\left(\mathrm{dd}, J_{1 \mathrm{~b}, 1 \mathrm{a}}=14.7 \mathrm{~Hz}, J_{1 \mathrm{~b}, 2}=4.8 \mathrm{~Hz}, 1 \mathrm{H}\right.$, H-1b). ${ }^{13} \mathrm{C}-\mathrm{NMR}\left(125 \mathrm{MHz}, \mathrm{D}_{2} \mathrm{O}\right) \delta 73.9$ (C-3), 70.0 (C-2), 51.0 (C-1). HRMS: $m / z$ calcd. for $\left[\mathrm{C}_{6} \mathrm{H}_{13} \mathrm{NO}_{4}+\mathrm{H}\right]^{+}:$164.0917, obsd.: 164.0923 . Spectral data matched those previously reported. ${ }^{151}$ 


\section{References}

1. J. K. N. Jones and W. A. Szarek, Canadian Journal of Chemistry, 1963, 41, 636640.

2. J. K. N. Jones and J. C. Turner, Journal of the Chemical Society (Resumed), 1962, 4699-4703.

3. H. Paulsen, Angewandte Chemie International Edition in English, 1962, 1, 454454.

4. S. Hanessian and T. H. Haskell, The Journal of Organic Chemistry, 1963, 28, 26042610.

5. S. Inouye, T. Tsuruoka and T. Niida, Journal of Antibiotics, 1966, 19, 288-\&.

6. H. Paulsen, I. Sangster and K. Heyns, Chemische Berichte-Recueil, 1967, 100, 802$\&$.

7. D. D. Schmidt, W. Frommer, B. Junge, L. Muller, W. Wingender, E. Truscheit and D. Schafer, Naturwissenschaften, 1977, 64, 535-536.

8. A. Welter, J. Jadot, G. Dardenne, M. Marlier and J. Casimir, Phytochemistry, 1976, 15, 747-749.

9. A. D. Elbein, M. Mitchell, B. A. Sanford, L. E. Fellows and S. V. Evans, Journal of Biological Chemistry, 1984, 259, 2409-2413.

10. R. J. Nash, P. I. Thomas, R. D. Waigh, G. W. J. Fleet, M. R. Wormald, P. M. D. Lilley and D. J. Watkin, Tetrahedron Letters, 1994, 35, 7849-7852.

11. P. E. Shaheen, W. Stadler, P. Elson, J. Knox, E. Winquist and R. M. Bukowski, Investigational New Drugs, 2005, 23, 577-581.

12. D. Tepfer, A. Goldmann, N. Pamboukdjian, M. Maille, A. Lepingle, D. Chevalier, J. Denarie and C. Rosenberg, Journal of Bacteriology, 1988, 170, 1153-1161.

13. E. Borges de Melo, A. da Silveira Gomes and I. Carvalho, Tetrahedron, 2006, 62, 10277-10302.

14. G. Legler, in Iminosugars as Glycosidase Inhibitors, Wiley-VCH Verlag GmbH \& Co. KGaA, 2004, DOI: 10.1002/3527601740.ch3, pp. 31-67.

15. J. H. Chang, T. M. Block and J. T. Guo, Antiviral Research, 2013, 99, 251-260.

16. C. S. Rye and S. G. Withers, Current Opinion in Chemical Biology, 2000, 4, 573580.

17. Q. P. Wang, R. W. Graham, D. Trimbur, R. A. J. Warren and S. G. Withers, Journal of the American Chemical Society, 1994, 116, 11594-11595.

18. L. J. Scott and C. M. Spencer, Drugs, 2000, 59, 521-549.

19. M. G. Szczepina, B. D. Johnston, Y. Yuan, B. Svensson and B. M. Pinto, Journal of the American Chemical Society, 2004, 126, 12458-12469.

20. F. M. Platt, G. R. Neises, R. A. Dwek and T. D. Butters, Journal of Biological Chemistry, 1994, 269, 8362-8365.

21. J. Aerts, W. E. Donkerkoopman, M. Koot, J. A. Barranger, J. M. Tager and A. W. Schram, Clinica Chimica Acta, 1986, 158, 155-163.

22. J. Aerts, W. E. Donkerkoopman, M. K. Vandervliet, L. M. V. Jonsson, E. I. Ginns, G. J. Murray, J. A. Barranger, J. M. Tager and A. W. Schram, European Journal of Biochemistry, 1985, 150, 565-574.

23. T. Wennekes, R. van den Berg, R. G. Boot, G. A. van der Marel, H. S. Overkleeft and J. Aerts, Angewandte Chemie-International Edition, 2009, 48, 8848-8869. 
24. T. Cox, R. Lachmann, C. Hollak, J. Aerts, S. van Weely, M. Hrebicek, F. Platt, T. Butters, R. Dwek, C. Moyses, I. Gow, D. Elstein and A. Zimran, Lancet, 2000, 355, 1481-1485.

25. T. M. Cox, J. Aerts, G. Andria, M. Beck, N. Belmatoug, B. Bembi, R. Chertkoff, S. Vom Dahl, D. Elstein, A. Erikson, M. Giralt, R. Heitner, C. Hollak, M. Hrebicek, S. Lewis, A. Mehta, G. M. Pastores, A. Rolfs, M. C. S. Miranda, A. Zimran and Ewggd, Journal of Inherited Metabolic Disease, 2003, 26, 513-526.

26. J. M. Benito, J. M. G. Fernandez and C. O. Mellet, Expert Opinion on Therapeutic Patents, 2011, 21, 885-903.

27. Z. Q. Yu, A. R. Sawkar and J. W. Kelly, Febs Journal, 2007, 274, 4944-4950.

28. D. Ringe and G. A. Petsko, Journal of Biology, 2009, 8, 80-80.

29. K. Nicholls, D. P. Germain, C. Feliciani, S. Shankar, F. Ezgu, S. G. Janmohamed, S. M. Laing, R. O. Schroyer, A. C. Bragat, S. Sitaraman and P. F. Boudes, Molecular Genetics and Metabolism, 2013, 108, S70-S70.

30. D. June, European Heart Journal, 2013, 34, 1387-1388.

31. M. F. Coutinho, J. I. Santos and S. Alves, International Journal of Molecular Sciences, 2016, 17, 1065.

32. J. Q. Fan, Biol Chem, 2008, 389, 1-11.

33. C. Porto, M. Cardone, F. Fontana, B. Rossi, M. R. Tuzzi, A. Tarallo, M. V. Barone, G. Andria and G. Parenti, Molecular Therapy: the Journal of the American Society of Gene Therapy, 2009, 17, 964-971.

34. P. B. Fischer, G. B. Karlsson, T. D. Butters, R. A. Dwek and F. M. Platt, Journal of Virology, 1996, 70, 7143-7152.

35. P. B. Fischer, G. B. Karlsson, R. A. Dwek and F. M. Platt, Journal of Virology, 1996, 70, 7153-7160.

36. C. Chapel, C. Garcia, P. Roingeard, N. Zitzmann, J. Dubuisson, R. A. Dwek, C. Trepo, F. Zoulim and D. Durantel, Journal of General Virology, 2006, 87, 861-871.

37. C. G. Bridges, S. P. Ahmed, M. S. Kang, R. J. Nash, E. A. Porter and A. S. Tyms, Glycobiology, 1995, 5, 249-253.

38. C. Sung, Y. Wei, S. Watanabe, H. S. Lee, Y. M. Khoo, L. Fan, A. P. S. Rathore, K. W. K. Chan, M. M. Choy, U. S. Kamaraj, O. M. Sessions, P. Aw, P. F. de Sessions, B. Lee, J. E. Connolly, M. L. Hibberd, D. Vijaykrishna, L. Wijaya, E. E. Ooi, J. G. H. Low and S. G. Vasudevan, Plos Neglected Tropical Diseases, 2016, 10, 1-23.

39. S. F. Wu, C. J. Lee, C. L. Liao, R. A. Dwek, N. Zitzmann and Y. L. Lin, Journal of Virology, 2002, 76, 3596-3604.

40. P. A. Norton, B. Gu and T. M. Block, in Iminosugars, John Wiley \& Sons, Ltd, 2008, DOI: 10.1002/9780470517437.ch9, pp. 209-224.

41. N. Asano, in Iminosugars, John Wiley \& Sons, Ltd, 2008, DOI: 10.1002/9780470517437.ch2, pp. 7-24.

42. B. E. Tyrrell, A. C. Sayce, K. L. Warfield, J. L. Miller and N. Zitzmann, Critical Reviews in Microbiology, 2017, 43, 521-545.

43. U. Andersson, T. D. Butters, R. A. Dwek and F. M. Platt, Biochemical Pharmacology, 2000, 59, 821-829.

44. P. Compain, V. Chagnault and O. R. Martin, Tetrahedron: Asymmetry, 2009, 20, 672-711.

45. P. Compain, in Iminosugars, John Wiley \& Sons, Ltd, 2008, DOI: 10.1002/9780470517437.ch4, pp. 63-86.

46. B. L. Ferla, L. Cipolla and F. Nicotra, in Iminosugars, John Wiley \& Sons, Ltd, 2008, DOI: 10.1002/9780470517437.ch3, pp. 25-61. 
47. P. Vogel, S. Gerber-Lemaire and L. Juillerat-Jeanneret, in Iminosugars, John Wiley \& Sons, Ltd, 2008, DOI: 10.1002/9780470517437.ch5, pp. 87-130.

48. J. B. Behr and G. Guillerm, Tetrahedron Letters, 2007, 48, 2369-2372.

49. S. F. Jenkinson, G. W. J. Fleet, R. J. Nash, Y. Koike, I. Adachi, A. Yoshihara, K. Morimoto, K. Izumori and A. Kato, Organic Letters, 2011, 13, 4064-4067.

50. P. J. Card and W. D. Hitz, Journal of Organic Chemistry, 1985, 50, 891-893.

51. E. Racine, C. Bello, S. Gerber-Lemaire, P. Vogel and S. Py, Journal of Organic Chemistry, 2009, 74, 1766-1769.

52. C. Matassini, S. Mirabella, X. Ferhati, C. Faggi, I. Robina, A. Goti, E. MorenoClavijo, A. J. Moreno-Vargas and F. Cardona, European Journal of Organic Chemistry, 2014, 5419-5432.

53. E. Roulland, Angewandte Chemie International Edition, 2011, 50, 1226-1227.

54. I. S. Young and P. S. Baran, Nat Chem, 2009, 1, 193-205.

55. K. J. M. Matus, W. C. Clark, P. T. Anastas and J. B. Zimmerman, Environmental Science \& Technology, 2012, 46, 10892-10899.

56. M. Schurmann and G. A. Sprenger, Journal of Biological Chemistry, 2001, 276, 11055-11061.

57. P. Clapes Saborit, J. Joglar Tamargo, J. A. Castillo Exposito and C. Lozano Perez, WO2008025826A1, 2008.

58. L. Espelt, T. Parella, J. Bujons, C. Solans, J. Joglar, A. Delgado and P. Clapes, Chemistry-a European Journal, 2003, 9, 4887-4899.

59. M. K. Sethi, S. R. Bhandya, N. Maddur, R. Shukla and A. Kumar, IN2011CH01443A, 2013.

60. P. R. Andreana, T. Sanders, A. Janczuk, J. I. Warrick and P. G. Wang, Tetrahedron Letters, 2002, 43, 6525-6528.

61. U. M. Lindstrom, R. Ding and O. Hidestal, Chemical Communications, 2005, DOI: 10.1039/B500190K, 1773-1774.

62. E. M. Dangerfield, M. S. M. Timmer and B. L. Stocker, Organic Letters, 2009, 11, 535-538.

63. M. S. M. Timmer, E. M. Dangerfield, J. M. H. Cheng, S. A. Gulab and B. L. Stocker, Tetrahedron Letters, 2011, 52, 4803-4805.

64. H. M. Corkran, S. Munneke, E. M. Dangerfield, B. L. Stocker and M. S. M. Timmer, Journal of Organic Chemistry, 2013, 78, 9791-9802.

65. B. L. Stocker, S. A. K. Jongkees, A. L. Win-Mason, E. M. Dangerfield, S. G. Withers and M. S. M. Timmer, Carbohydrate Research, 2013, 367, 29-32.

66. A. L. Win-Mason, E. M. Dangerfield, P. C. Tyler, B. L. Stocker and M. S. M. Timmer, European Journal of Organic Chemistry, 2011, DOI: 10.1002/ejoc.201100523, 4008-4014.

67. A. L. Win-Mason, S. A. K. Jongkees, S. G. Withers, P. C. Tyler, M. S. M. Timmer and B. L. Stocker, Journal of Organic Chemistry, 2011, 76, 9611-9621.

68. B. L. Stocker, A. L. Win-Mason and M. S. M. Timmer, Carbohydrate Research, 2012, 356, 163-171.

69. E. M. Dangerfield, C. H. Plunkett, B. L. Stocker and M. S. M. Timmer, Molecules, 2009, 14, 5298-5307.

70. E. M. Dangerfield, S. A. Gulab, C. H. Plunkett, M. S. M. Timmer and B. L. Stocker, Carbohydrate Research, 2010, 345, 1360-1365.

71. E. M. Dangerfield, C. H. Plunkett, A. L. Win-Mason, B. L. Stocker and M. S. M. Timmer, Journal of Organic Chemistry, 2010, 75, 5470-5477. 
72. S. J. Angyal and G. S. Bethell, Australian Journal of Chemistry, 1976, 29, 12491265.

73. A. Lauritsen and R. Madsen, Organic \& Biomolecular Chemistry, 2006, 4, 28982905.

74. B. Miriyala, S. Bhattacharyya and J. S. Williamson, Tetrahedron, 2004, 60, 14631471.

75. H. C. Brown and P. V. Ramachandran, Accounts of Chemical Research, 1992, 25, 16-24.

76. A. F. AbdelMagid, K. G. Carson, B. D. Harris, C. A. Maryanoff and R. D. Shah, Journal of Organic Chemistry, 1996, 61, 3849-3862.

77. D. Berkes, A. Kolarovic and F. Povazanec, Tetrahedron Letters, 2000, 41, 52575260.

78. W. Zou and W. A. Szarek, Carbohydrate Research, 1993, 242, 311-314.

79. Z. Y. Hong, L. Liu, M. Sugiyama, Y. Fu and C. H. Wong, Journal of the American Chemical Society, 2009, 131, 8352-+.

80. P. Merino, I. Delso, T. Tejero, F. Cardona, M. Marradi, E. Faggi, C. Parmeggiani and A. Goti, European Journal of Organic Chemistry, 2008, DOI: 10.1002/ejoc.200800098, 2929-2947.

81. M. T. Reetz, M. Hullmann and T. Seitz, Angewandte Chemie-International Edition in English, 1987, 26, 477-479.

82. Y. LeMerrer, L. Poitout, J. C. Depezay, I. Dosbaa, S. Geoffroy and M. J. Foglietti, Bioorganic \& Medicinal Chemistry, 1997, 5, 519-533.

83. V. Kumar and N. G. Ramesh, Tetrahedron, 2006, 62, 1877-1885.

84. B. J. Ayers, N. Ngo, S. F. Jenkinson, R. F. Martinez, Y. Shimada, I. Adachi, A. C. Weymouth-Wilson, A. Kato and G. W. J. Fleet, Journal of Organic Chemistry, 2012, 77, 7777-7792.

85. A. A. Ansari and Y. D. Vankar, Journal of Organic Chemistry, 2013, 78, 9383-9395.

86. T. K. M. Shing, Journal of the Chemical Society-Chemical Communications, 1987, 262-263.

87. T. K. M. Shing, Tetrahedron, 1988, 44, 7261-7264.

88. M. Tredwell, J. A. R. Luft, M. Schuler, K. Tenza, K. N. Houk and V. Gouverneur, Angewandte Chemie-International Edition, 2008, 47, 357-360.

89. A. R. Chamberlin, M. Dezube, P. Dussault and M. C. McMills, Journal of the American Chemical Society, 1983, 105, 5819-5825.

90. A. R. Chamberlin and R. L. Mulholland, Tetrahedron, 1984, 40, 2297-2302.

91. A. R. Chamberlin, R. L. Mulholland, S. D. Kahn and W. J. Hehre, Journal of the American Chemical Society, 1987, 109, 672-677.

92. C. Bouix, P. Bisseret and J. Eustache, Tetrahedron Letters, 1998, 39, 825-828.

93. S. G. Davies, R. L. Nicholson, P. D. Price, P. M. Roberts, A. J. Russell, E. D. Savory, A. D. Smith and J. E. Thomson, Tetrahedron-Asymmetry, 2009, 20, 758-772.

94. O. Lidove, M. L. West, G. Pintos-Morell, R. Reisin, K. Nicholls, L. E. Figuera, R. Parini, L. R. Carvalho, C. Kampmann, G. M. Pastores and A. Mehta, Genetics in Medicine, 2010, 12, 668-679.

95. H. Schulze and K. Sandhoff, Cold Spring Harbor Perspectives in Biology, 2011, 3.

96. G. Parenti, Embo Molecular Medicine, 2009, 1, 268-279.

97. J. Q. Fan, S. Ishii, N. Asano and Y. Suzuki, Nature Medicine, 1999, 5, 112-115.

98. R. Hamanaka, T. Shinohara, S. Yano, M. Nakamura, A. Yasuda, S. Yokoyama, J. Q. Fan, K. Kawasaki, M. Watanabe and S. Ishii, Biochimica Et Biophysica ActaMolecular Basis of Disease, 2008, 1782, 408-413. 
99. S. Ishii, Proc Jpn Acad Ser B Phys Biol Sci, 2012, 88, 18-30.

100. N. J. Leidenheimer and K. G. Ryder, Pharmacological Research, 2014, 83, 10-19.

101. A. Trapero and A. Llebaria, Future Medicinal Chemistry, 2013, 5, 573-590.

102. Y. Suzuki, Proceedings of the Japan Academy, Series B, 2014, 90, 145-162.

103. A. Kato, Y. Yamashita, S. Nakagawa, Y. Koike, I. Adachi, J. Hollinshead, R. J. Nash, K. Ikeda and N. Asano, Bioorganic \& Medicinal Chemistry, 2010, 18, 3790-3794.

104. S. Singh and H. Han, Tetrahedron Letters, 2004, 45, 6349-6352.

105. A. A. Hunt-Painter, G. J. Moggre, P. C. Tyler, B. L. Stocker and M. S. M. Timmer, Chemistryselect, 2017, 2, 8028-8032.

106. G. S. Bethell and R. J. Ferrier, Carbohydrate Research, 1973, 31, 69-80.

107. A. Yoshihara, S. Haraguchi, P. Gullapalli, D. Rao, K. Morimoto, G. Takata, N. Jones, S. F. Jenkinson, M. R. Wormald, R. A. Dwek, G. W. J. Fleet and K. Izumori, Tetrahedron-Asymmetry, 2008, 19, 739-745.

108. A. de Sa, G. M. A. Pontes, J. A. L. dos Anjos, S. R. Santana, L. W. Bieber and I. Malvestiti, Journal of the Brazilian Chemical Society, 2003, 14, 429-434.

109. M. H. Fechter and A. E. Stutz, Carbohydrate Research, 1999, 319, 55-62.

110. E. M. Dangerfield, M. S. M. Timmer and B. L. Stocker, Organic Letters, 2009, 11, 535-538.

111. H. M. Corkran, S. Munneke, E. M. Dangerfield, B. L. Stocker and M. S. M. Timmer, The Journal of Organic Chemistry, 2013, 78, 9791-9802.

112. M. S. M. Timmer, E. M. Dangerfield, J. M. H. Cheng, S. A. Gulab and B. L. Stocker, Tetrahedron Letters, 2011, 52, 4803-4805.

113. A. L. Win-Mason, E. M. Dangerfield, P. C. Tyler, B. L. Stocker and M. S. M. Timmer, European Journal of Organic Chemistry, 2011, 4008-4014.

114. B. L. Stocker, S. A. K. Jongkees, A. L. Win-Mason, E. M. Dangerfield, S. G. Withers and M. S. M. Timmer, Carbohydrate Research, 2013, 367, 29-32.

115. A. L. Win-Mason, S. A. K. Jongkees, S. G. Withers, P. C. Tyler, M. S. M. Timmer and B. L. Stocker, The Journal of Organic Chemistry, 2011, 76, 9611-9621.

116. M. Fellahi and C. Morin, Carbohydrate Research, 1999, 322, 142-146.

117. P. Page, C. Blonski and J. Périé, Tetrahedron, 1996, 52, 1557-1572.

118. T. K. Lindhorst, Essentials of Carbahydrate Chemistry and Biochemistry, WileyVch, ch. Chapter.

119. A. Singh, K. Bongchan, W. Koo Lee and H.-J. Ha, Organic \& Biomolecular Chemistry, 2011, 9, 1372-1380.

120. R. H. Furneaux, P. C. Tyler and L. A. Whitehouse, Tetrahedron Letters, 1993, 34, 3613-3616.

121. L. E. Fellows, A. E. Bell, D. G. Lynn, F. Pilkiewicz, I. Miura and K. Nakanishi, Journal of the Chemical Society, Chemical Communications, 1979, 22, 977-978.

122. A. kato, N. Kato, E. Kano, I. Adachi, K. Ikeda, L. Yu, T. Okamoto, Y. Banba, H. Ouchi, H. Takahata and N. Asano, Journal of Medical Chemistry, 2005, 48, 2036-2044.

123. P. Maier, S. M. Anderson and I. Lundt, Synthesis, 2006, 5, 827-830.

124. M.-C. Lamas, M. Malacria and S. Thorimbert, European Journal of Chemistry, 2011, 2777-2780.

125. M. Wei, Z. Li, T. Li, B. Wu, Y. Liu, J. Qu, X. Li, L. Li, L. Cai and P. G. Wang, ACS Catalysis, 2015, 5, 4060-4065.

126. A. Deraadt and A. E. Stutz, Tetrahedron Letters, 1992, 33, 189-192.

127. W. Zou and W. A. Szarek, Carbohydrate Research, 1994, 254, 25-33.

128. C. McDonnell, L. Cronin, J. L. O'Brien and P. V. Murphy, Journal of Organic Chemistry, 2004, 69, 3565-3568. 
129. C. R. Johnson, A. Golebiowski, E. Schoffers, H. Sundram and M. P. Brraun, Synlett, 1995, 313-314.

130. E. Racine, C. Bello, S. Gerber-Lemaire, P. Vogel and S. Py, Journal of Organic Chemistry, 2009, 74, 1766-1769.

131. T.-H. Chan, Y.-F. Chang, J.-J. Hsu and W.-C. Cheng, European Journal of Organic Chemistry, 2010, 5555-5559.

132. G. S. Bethell and R. J. Ferrier, Carbohydrate Research, 1973, 31, 69-80.

133. M. K. Sethi, S. Mahajan, S. R. Bhandya and K. Anish, IN2013CH03275A, 2016.

134. Z. Xu, K. Chen, G. Li and J. Yang, CN102702079A, 2012.

135. Y. Wang and Z. Tao, CN101270378A, 2008.

136. D. Beaupere, B. Stasik, R. Uzan and G. Demailly, Carbohydrate Research, 1989, 191, 163-166.

137. H. Paulsen, M. Matzke, B. Orthen, R. Nuck and W. Reutter, Liebigs Ann. Chem., 1990, 953-963.

138. F. X. Wilson, R. J. Nash, G. Horne and R. Storer, WO2010029313A1, 2010.

139. F. X. Wilson, R. J. Nash, G. Horne, R. Storer, J. M. Tinsley and A. G. Roach, WO2010049678A2, 2010.

140. F. X. Wilson, R. J. Nash, G. Horne, R. Storer, J. M. Tinsley and A. G. Roach, WO2010015815A2, 2010.

141. F. X. Wilson, R. J. Nash, G. Horne, R. Storer, J. M. Tinsley and A. G. Roach, WO2010015816A2, 2010.

142. O. K. Karjalainen, M. Passiniemi and A. M. P. Koskinen, Org. Lett., 2010, 12, $1145-$ 1147.

143. A. Kato, N. Kato, E. Kano, I. Adachi, K. Ikeda, L. Yu, T. Okamoto, Y. Banba, H. Ouchi, H. Takahata and N. Asano, J. Med. Chem., 2005, 48, 2036-2044.

144. T. B. Mercer, S. F. Jenkinson, B. Bartholomew, R. J. Nash, S. Miyauchi, A. Kato and G. W. J. Fleet, Tetrahedron: Asymmetry, 2009, 20, 2368-2373.

145. M. K. Sethi, A. Kumar, N. Maddur, R. Shukla and L. N. Vemula, J. Mol. Catal. B: Enzym., 2015, 112, 54-58.

146. A. M. C. H. van den Nieuwendijk, R. J. B. H. N. van den Berg, M. Ruben, M. D. Witte, J. Brussee, R. G. Boot, G. A. van der Marel, J. M. F. G. Aerts and H. S. Overkleeft, Eur. J. Org. Chem., 2012, 2012, 3437-3446.

147. S. F. Jenkinson, G. W. J. Fleet, R. J. Nash, Y. Koike, I. Adachi, A. Yoshihara, K. Morimoto, K. Izumori and A. Kato, Org. Lett., 2011, 13, 4064-4067.

148. J. K. N. Jones and J. C. Turner, Journal of the Chemical Society, 1962, DOI: 10.1039/JR9620004699, 4699-4703.

149. R. C. Bernotas, G. Papandreou, J. Urbach and B. Ganem, Tetrahedron Letters, 1990, 31, 3393-3396.

150. J. Mravljak and A. Obreza, Tetrahedron Lett., 2012, 53, 2234-2235.

151. F. MorisVaras, X. H. Qian and C. H. Wong, Journal of the American Chemical Society, 1996, 118, 7647-7652.

152. T. Hurtaux, G. Sfihi-Loualia, Y. Brissonnet, J. Bouckaert, J.-M. Mallet, B. Sendid, F. Delplace, E. Fabre, S. G. Gouin and Y. Guerardel, Carbohydr. Res., 2016, 429, 123127.

153. Y. Yoshimura, C. Ohara, T. Imahori, Y. Saito, A. Kato, S. Miyauchi, I. Adachi and H. Takahata, Bioorg. Med. Chem., 2008, 16, 8273-8286.

154. Y. Natori, T. Imahor and Y. Yoshimura, Yuki Gosei Kagaku Kyokaishi, 2016, 74, 335-349.

155. Y. Bechor and A. Albeck, Tetrahedron, 2008, 64, 2080-2089. 
156. Z.-X. Zhang, B. Wu, B. Wang, T.-H. Li, P.-F. Zhang, L.-N. Guo, W.-j. Wang, W. Zhao and P. G. Wang, Tetrahedron Letters, 2011, 52, 3802-3804.

157. H. Ouchi, Y. Mihara and H. Takahata, The Journal of Organic Chemistry, 2005, 70, 5207-5214.

158. Y. Zhao, Y.-P. Lu and L. Zhu, J. Carbohydr. Chem., 2008, 27, 113-119. 


\section{Appendix}

Chapter 2 spectra 
${ }^{1} \mathrm{H}$ NMR, $\mathrm{D}_{2} \mathrm{O}, 500 \mathrm{MHz}$

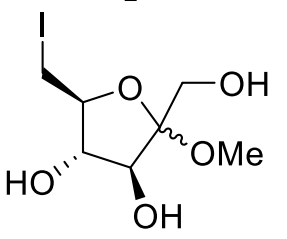

Methyl 6-deoxy-6-iodo-D-fructofuranoside

$$
\text { (74) }
$$

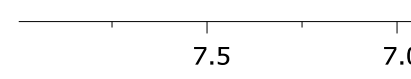

7.0

6.5

6.0

5.5

5.0
$\mathrm{f} 1(\mathrm{ppm})$

4.5 4.0

3.5

2.5 
${ }^{13} \mathrm{C} \mathrm{NMR}, \mathrm{D}_{2} \mathrm{O}, 125 \mathrm{MHz}$

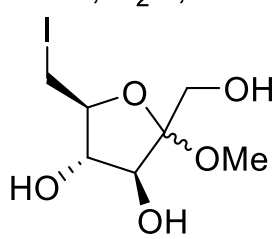

Methyl 6-deoxy-6-iodo-D-fructofuranoside

(74)

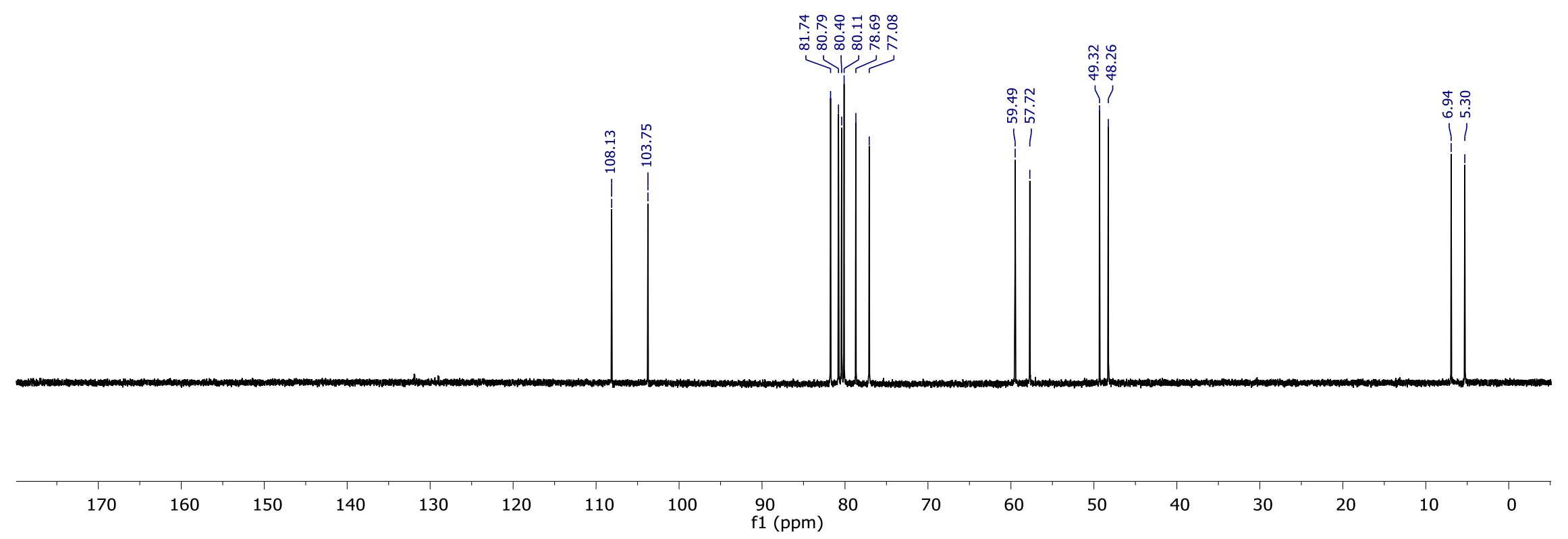


${ }^{1} \mathrm{H}$ NMR, $\mathrm{D}_{2} \mathrm{O}, 500 \mathrm{MHz}$

$\overbrace{\mathrm{OH}}^{\mathrm{NH}_{2}} \mathrm{OH}$

$(2 S, 3 R, 4 R)$-2-aminohex-5-ene-1,3,4-triol

$75 a$

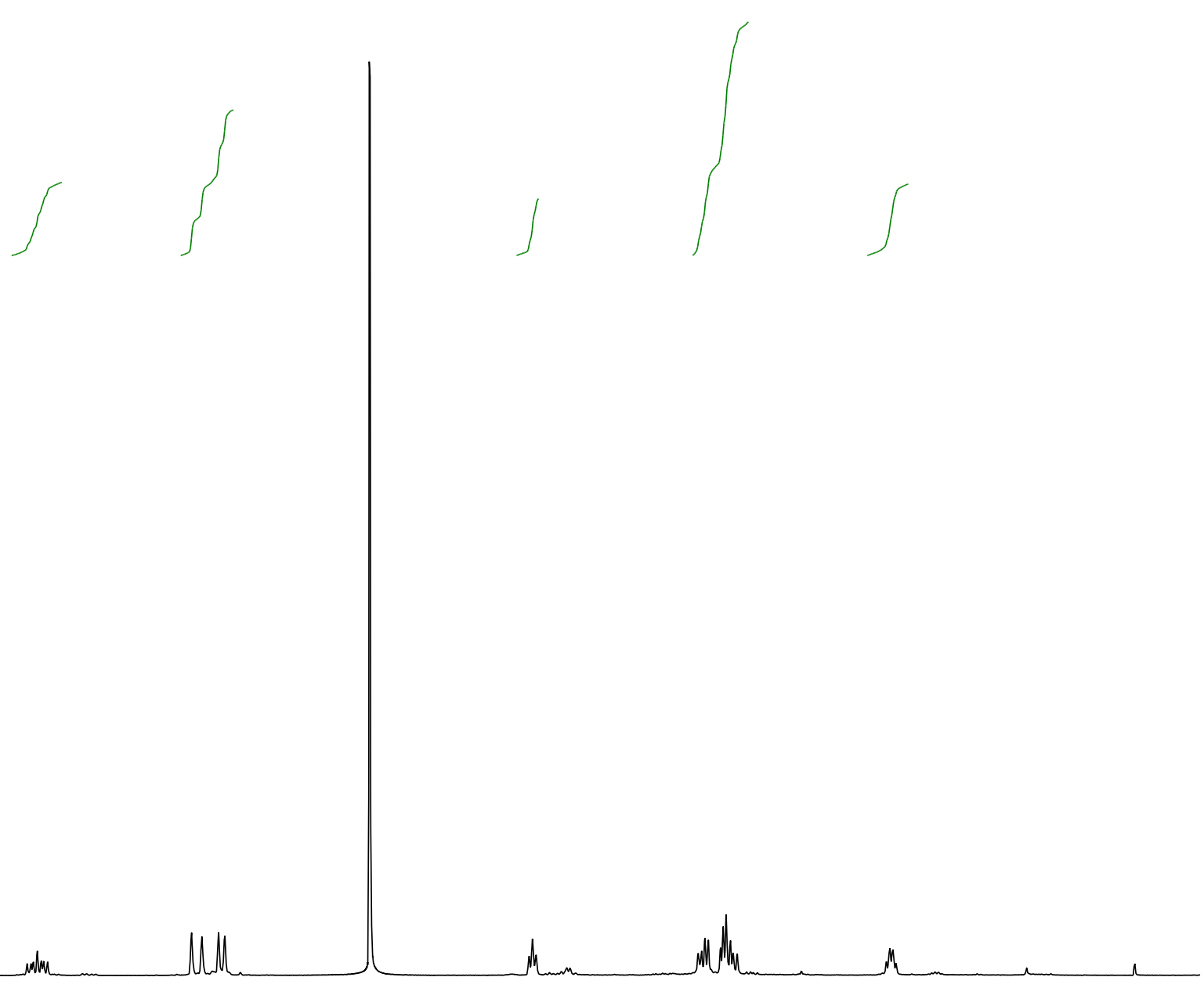

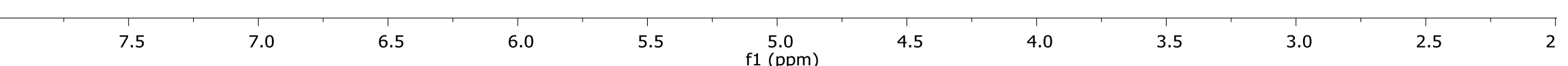


${ }^{13} \mathrm{C} N M R, \mathrm{D}_{2} \mathrm{O}, 125 \mathrm{MHz}$

$\overbrace{\mathrm{OH}}^{\mathrm{OH}} \mathrm{OH}$

$(2 S, 3 R, 4 R)-2$-aminohex-5-ene-1,3,4-triol

$75 a$

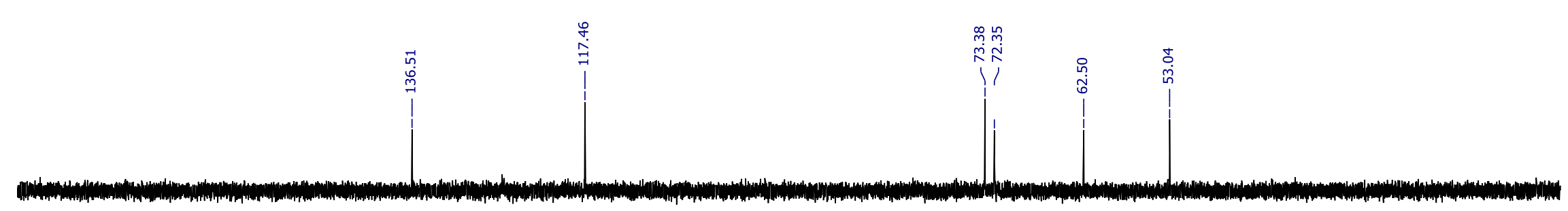

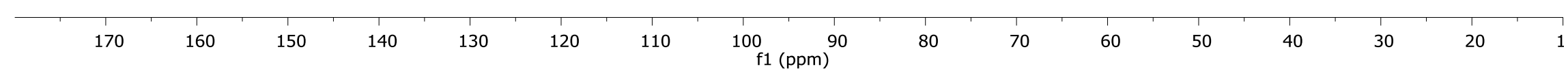




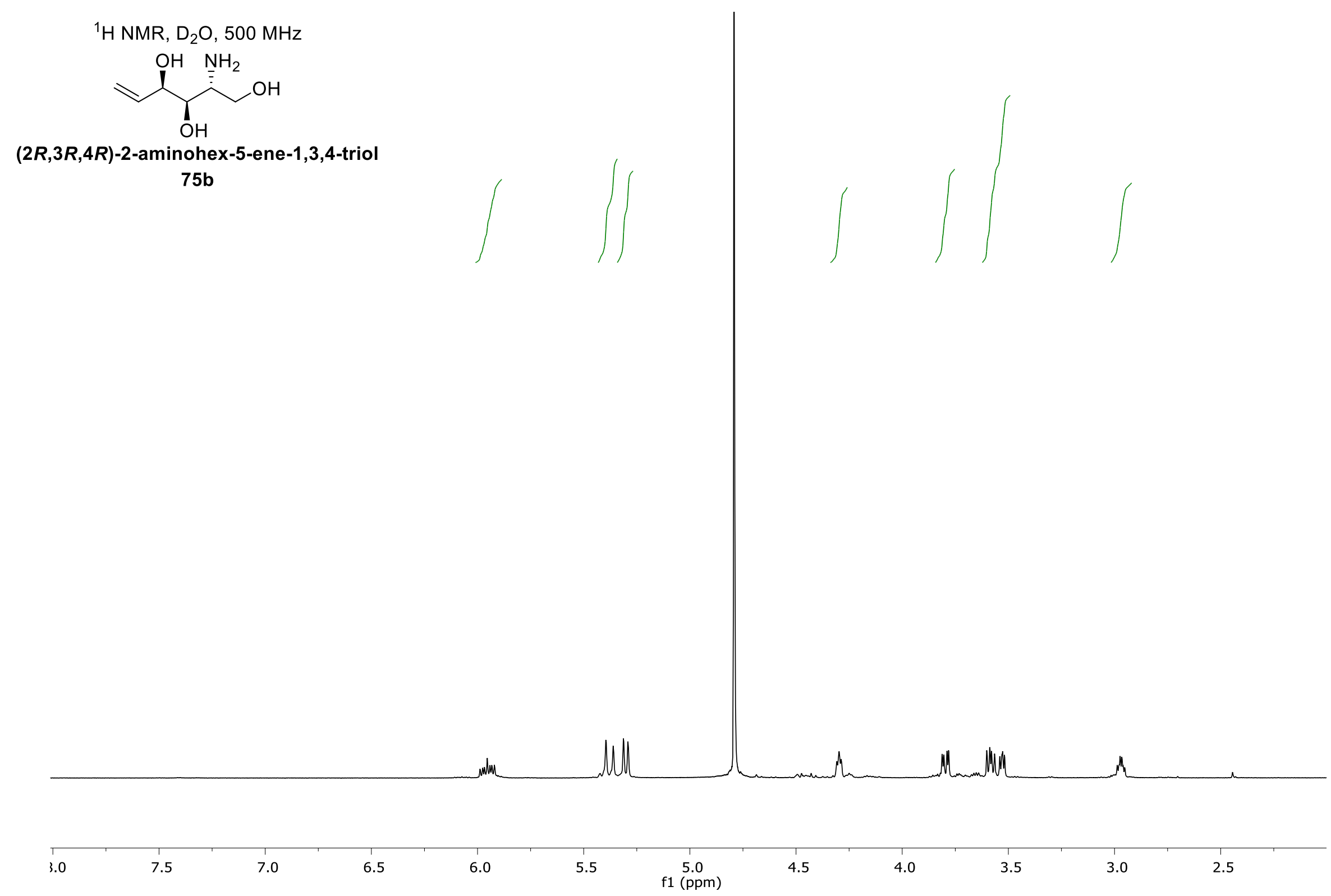


${ }^{1} \mathrm{H}$ NMR, $\mathrm{D}_{2} \mathrm{O}, 500 \mathrm{MHz}$

$\overbrace{\mathrm{OH}}^{\mathrm{OH}} \mathrm{OH}$

$(2 R, 3 R, 4 R)$-2-aminohex-5-ene-1,3,4-triol

75b

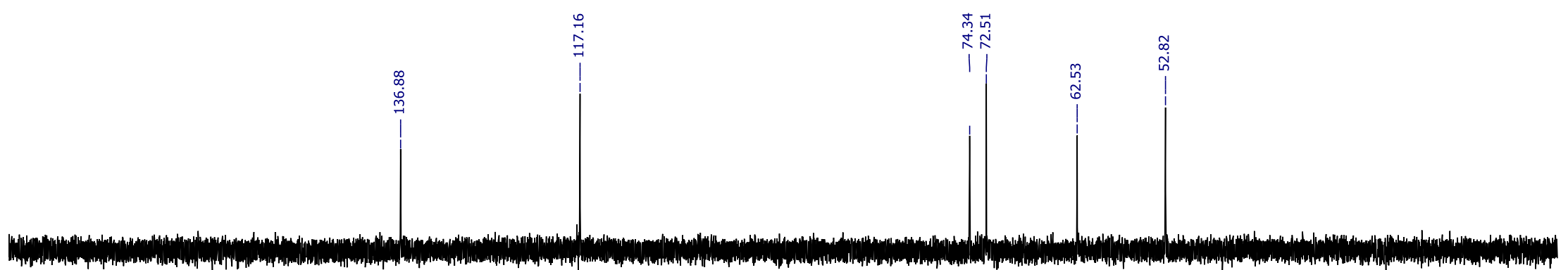

$170 \quad 160$

150

140

130

120

110

$100 \quad 90$

80

70

60

50

40

30

20 
${ }^{1} \mathrm{H} N M R, \mathrm{D}_{2} \mathrm{O}, 500 \mathrm{MHz}$

$\overbrace{1}^{\mathrm{OH}}$

$(3 R, 4 R)$-2-aminohex-5-ene-1,3,4-triol

75

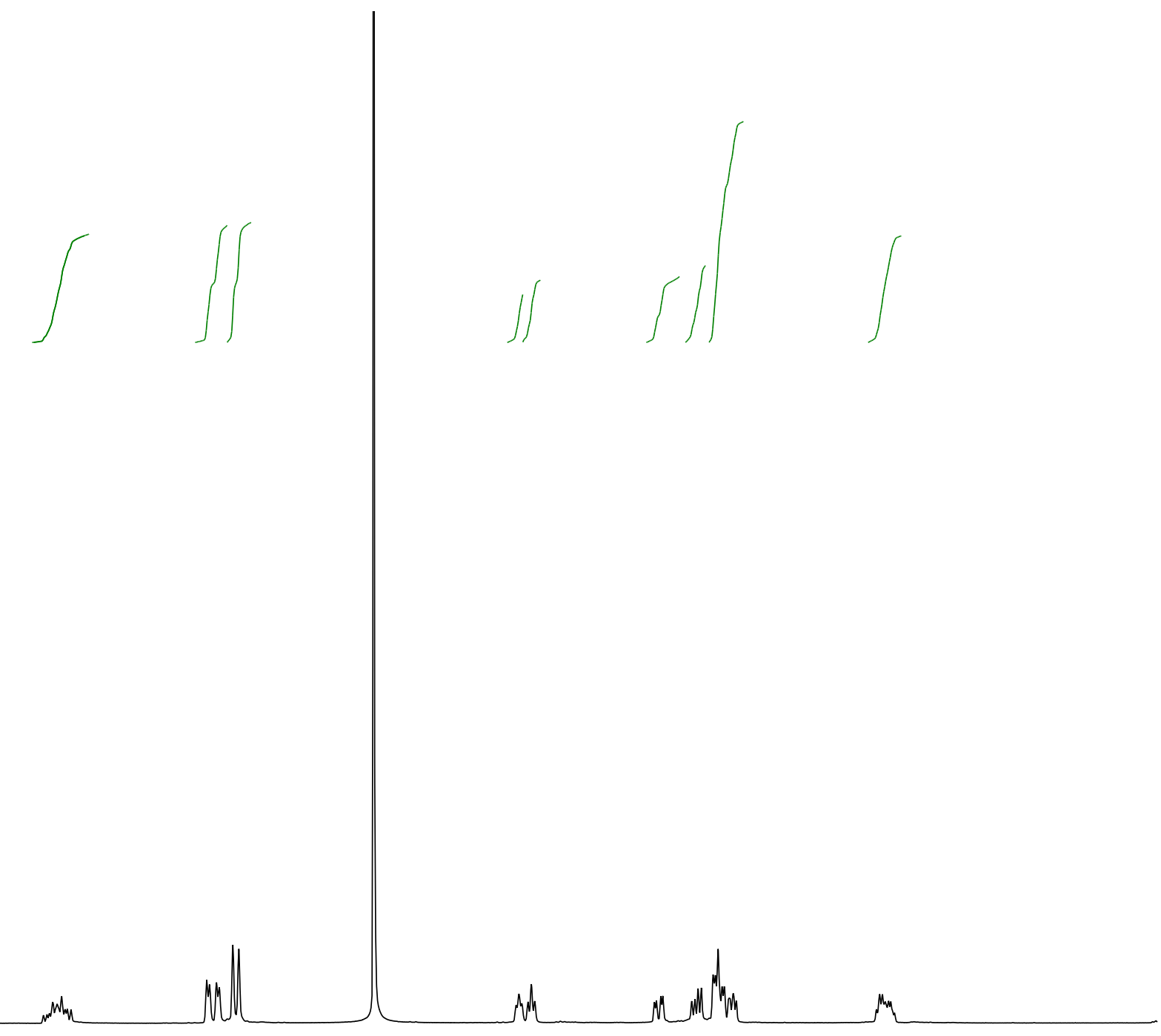

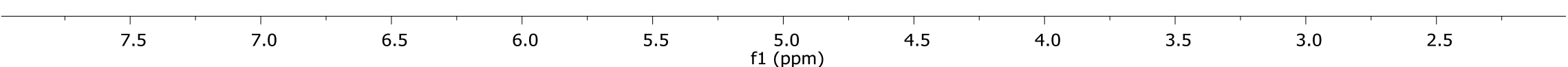


${ }^{13} \mathrm{C}$ NMR, $\mathrm{D}_{2} \mathrm{O}, 125 \mathrm{MHz}$

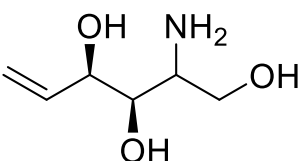

(3R,4R)-2-aminohex-5-ene-1,3,4-triol

75

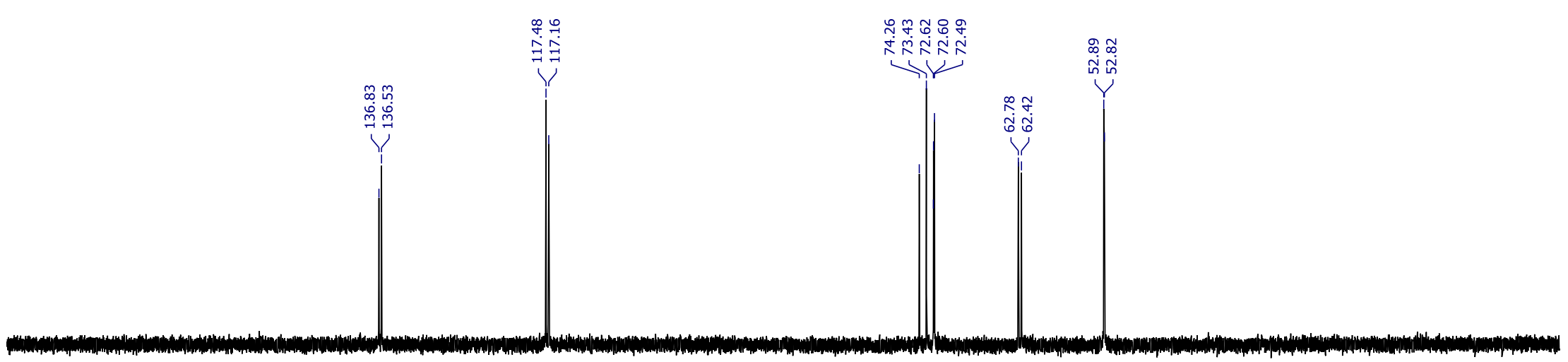


${ }^{1} \mathrm{H}$ NMR, $\mathrm{D}_{2} \mathrm{O}, 500 \mathrm{MHz}$

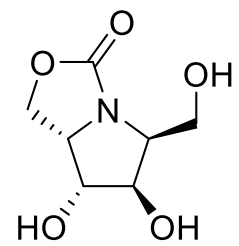

(5S,6R,7R,7aS)-6,7-dihydroxy-5-(hydroxymethyl)tetrahydro-

$1 \mathrm{H}, 3 \mathrm{H}$-pyrrolo[1,2-c]oxazol-3-one

(76a)

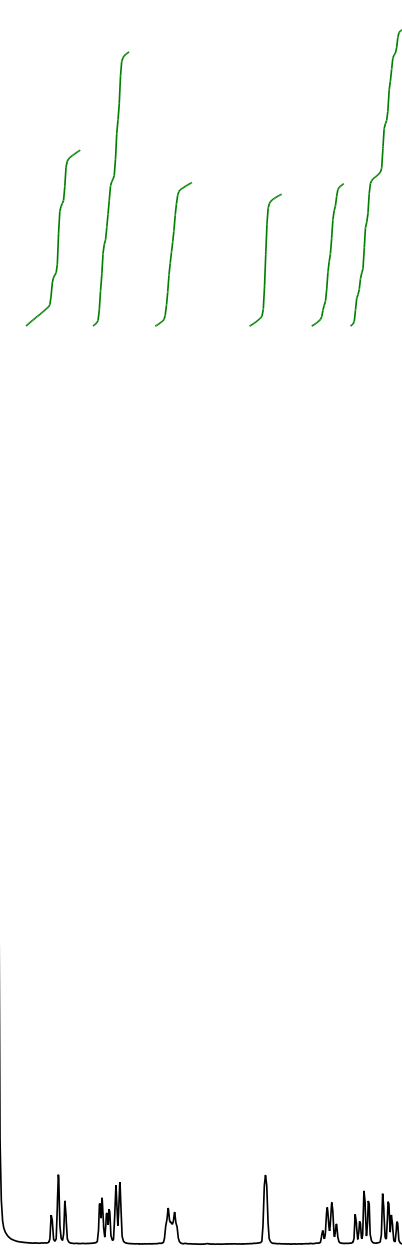

$: 0$

7.5

7.0

6.5

6.0

5.5

5.0
$\mathrm{f} 1(\mathrm{ppm})$

4.5

4.0

3.5

3.0

2.5 
${ }^{13} \mathrm{C}$ NMR, $\mathrm{D}_{2} \mathrm{O}, 125 \mathrm{MHz}$

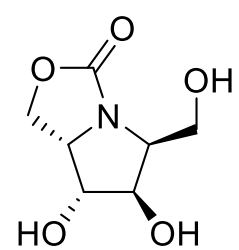

(5S,6R,7R,7aS)-6,7-dihydroxy-5-(hydroxymethyl)tetrahydro-

$1 H, 3 H$-pyrrolo[1,2-c]oxazol-3-one

$76 a$

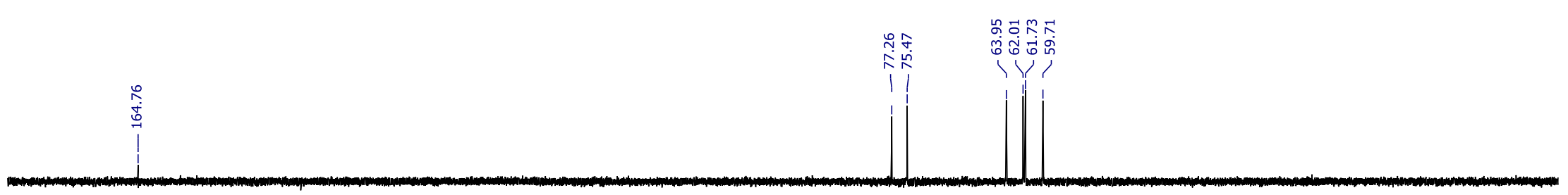

170 


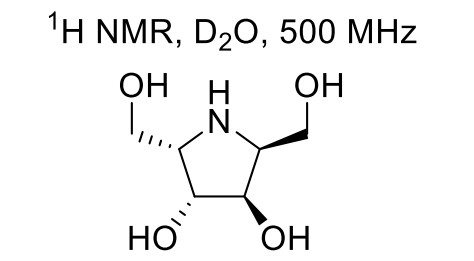

2,5-dideoxy-2,5-imino-L-iditol

77
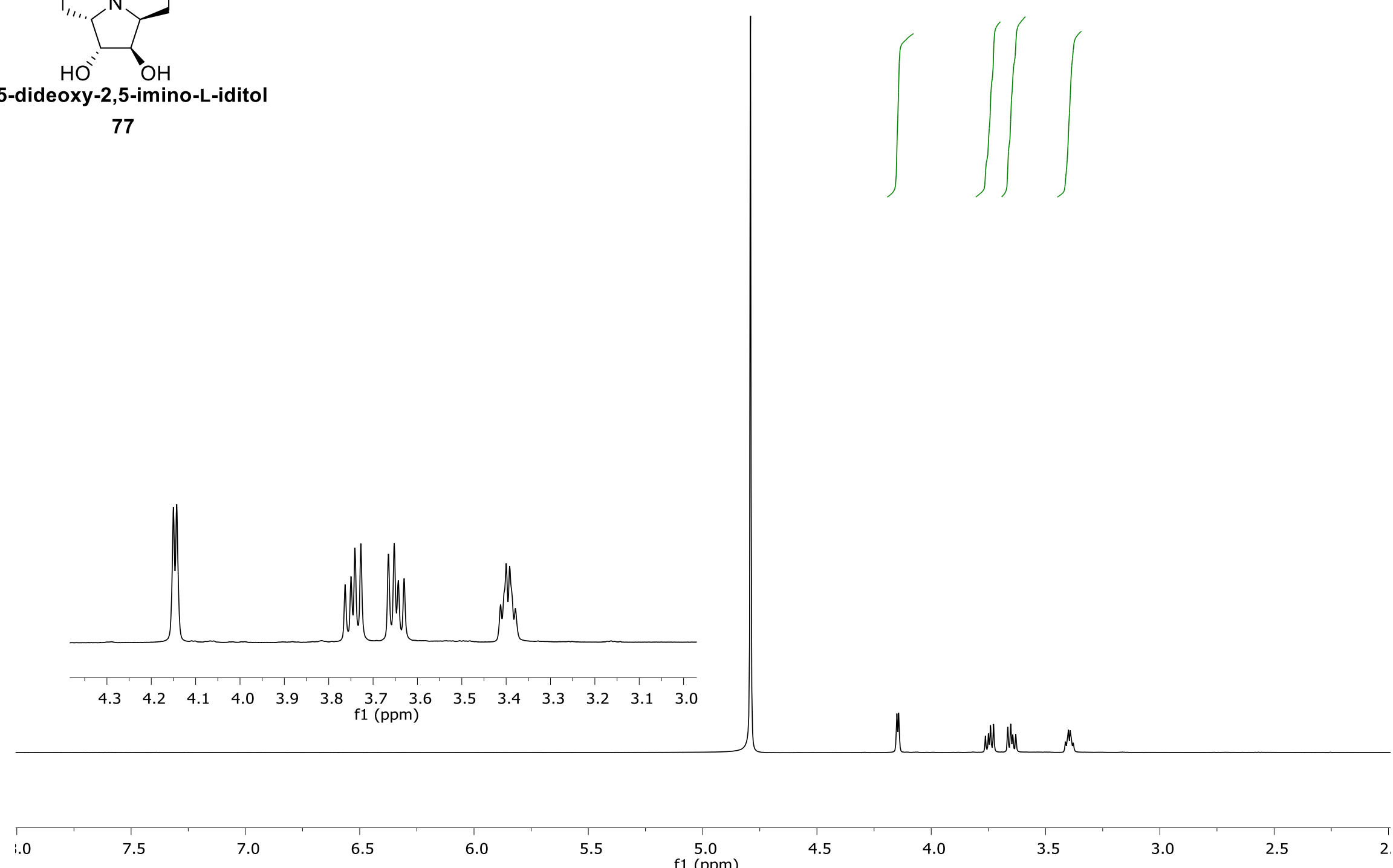
${ }^{13} \mathrm{C} N M R, \mathrm{D}_{2} \mathrm{O}, 125 \mathrm{MHz}$

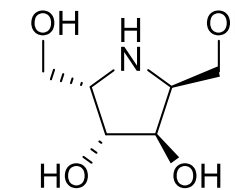

2,5-dideoxy-2,5-imino-L-iditol

77

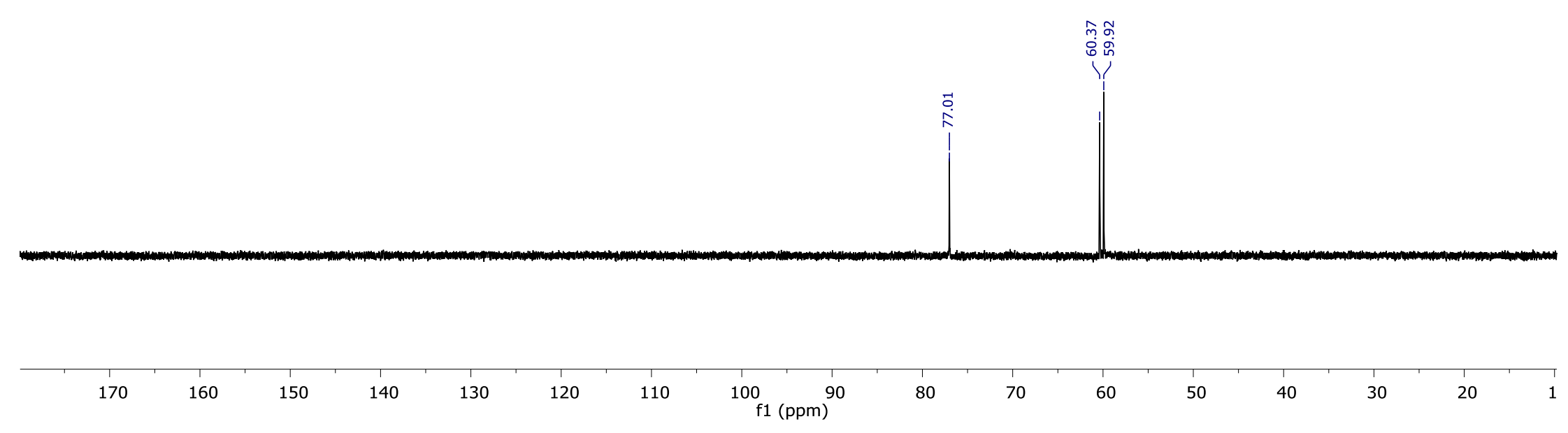


${ }^{1} \mathrm{H}$ NMR, $\mathrm{D}_{2} \mathrm{O}, 500 \mathrm{MHz}$

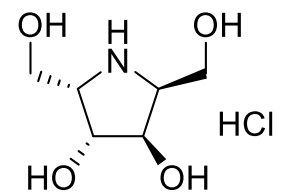

2,5-dideoxy-2,5-imino-L-iditol.HCI

77
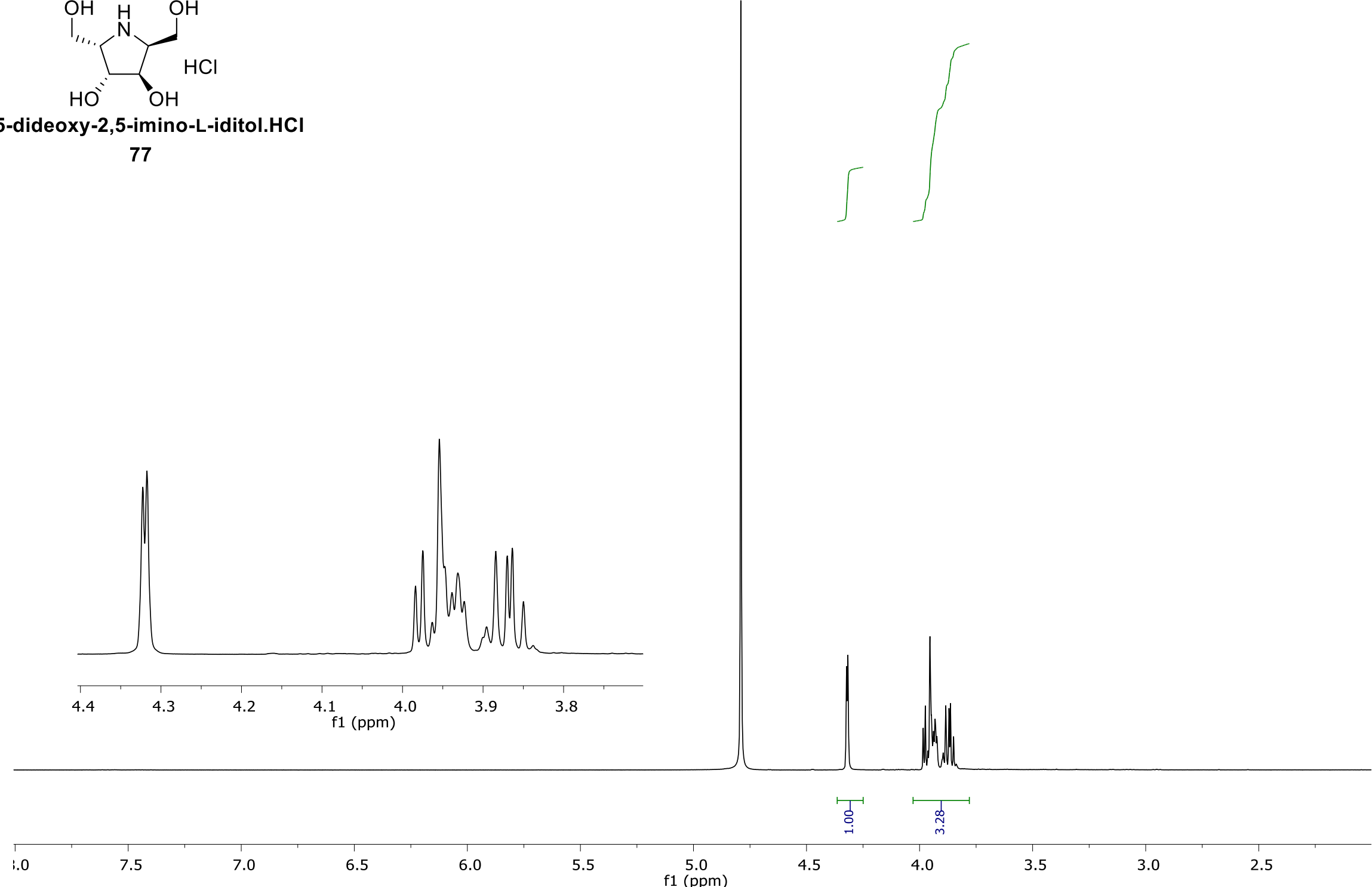
${ }^{13} \mathrm{C}$ NMR, $\mathrm{D}_{2} \mathrm{O}, 125 \mathrm{MHz}$

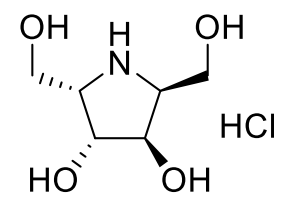

2,5-dideoxy-2,5-imino-L-iditol.HCI

77

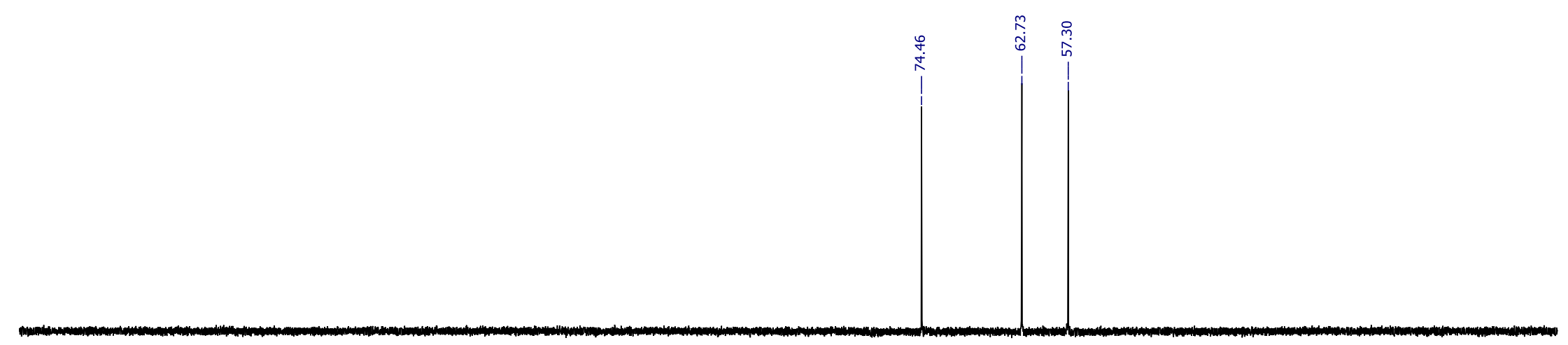

170 


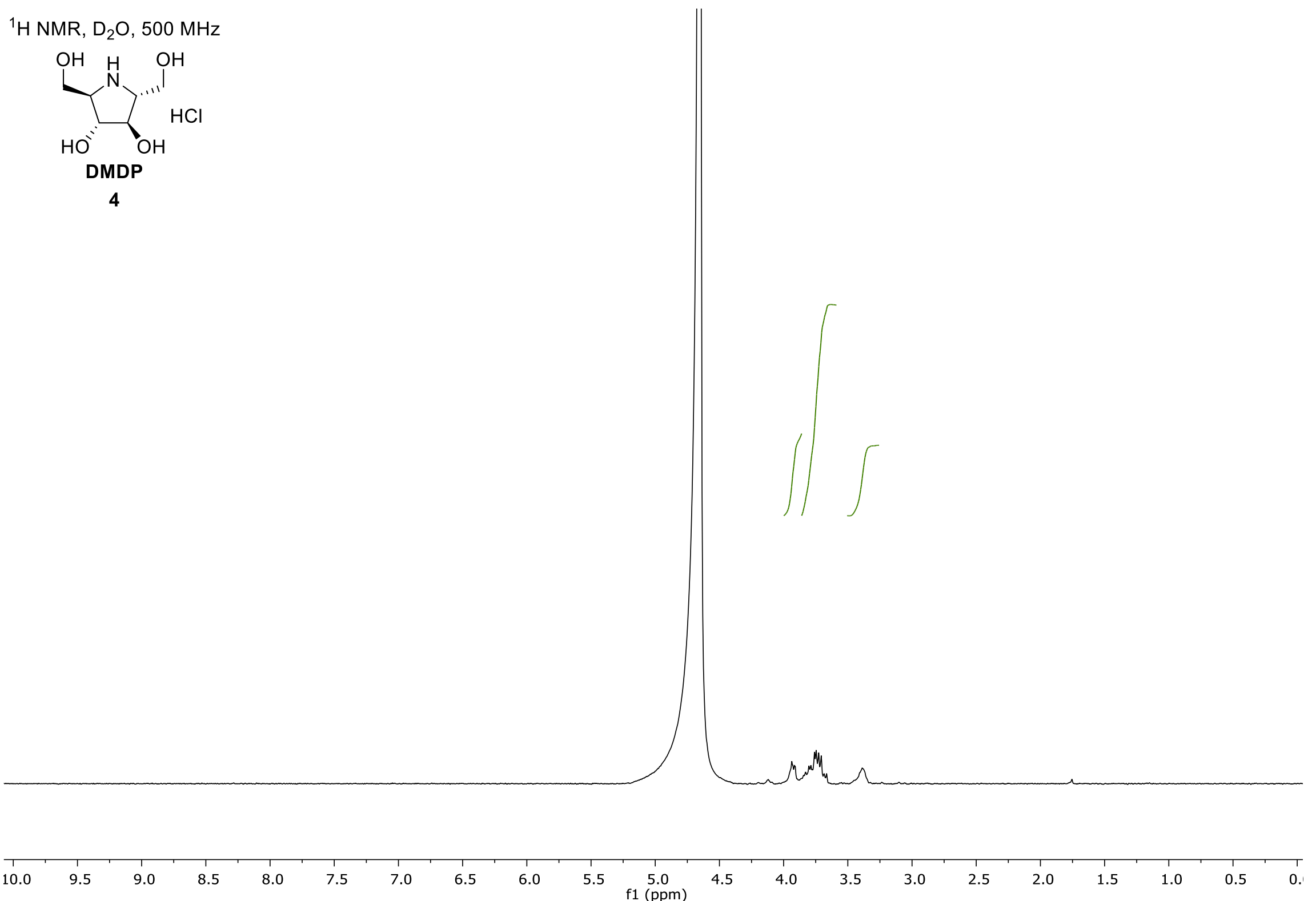


${ }^{1} \mathrm{H} \mathrm{NMR}, \mathrm{CDCl}_{3}, 500 \mathrm{MHz}$

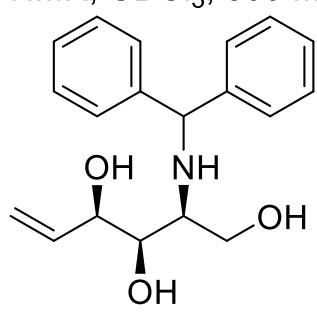

(2S,3R,4R)-2-(benzhydrylamino)hex-5-ene-1,3,4-triol

$78 a$

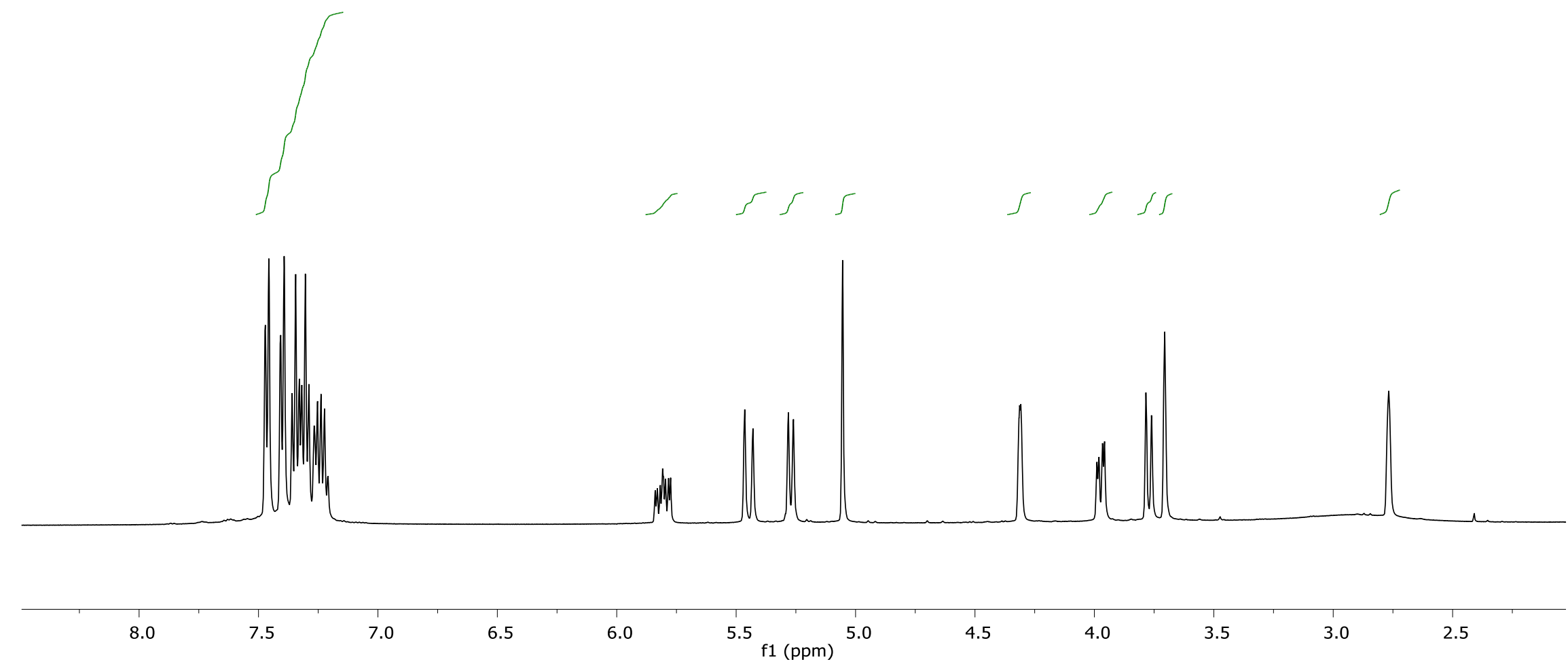


${ }^{13} \mathrm{C} \mathrm{NMR}, \mathrm{CDCl}_{3}, 125 \mathrm{MHz}$

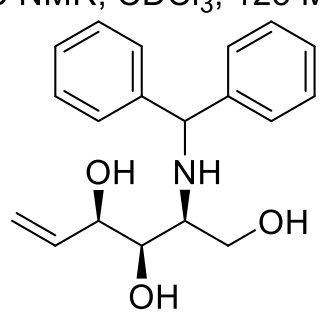

(2S,3R,4R)-2-(benzhydrylamino)hex-5-ene-1,3,4-triol

$78 a$

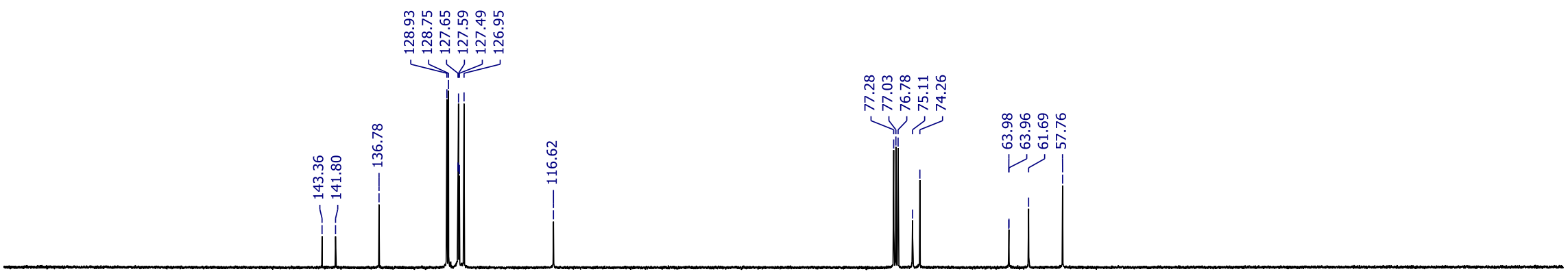


${ }^{1} \mathrm{H} \mathrm{NMR}, \mathrm{CDCl}_{3}, 500 \mathrm{MHz}$

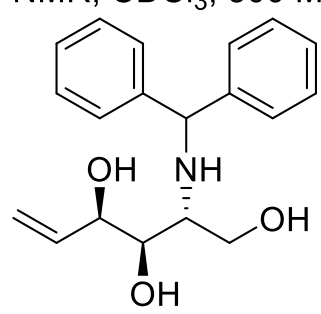

(2R,3R,4R)-2-(benzhydrylamino)hex-5-ene-1,3,4-triol

$78 b$
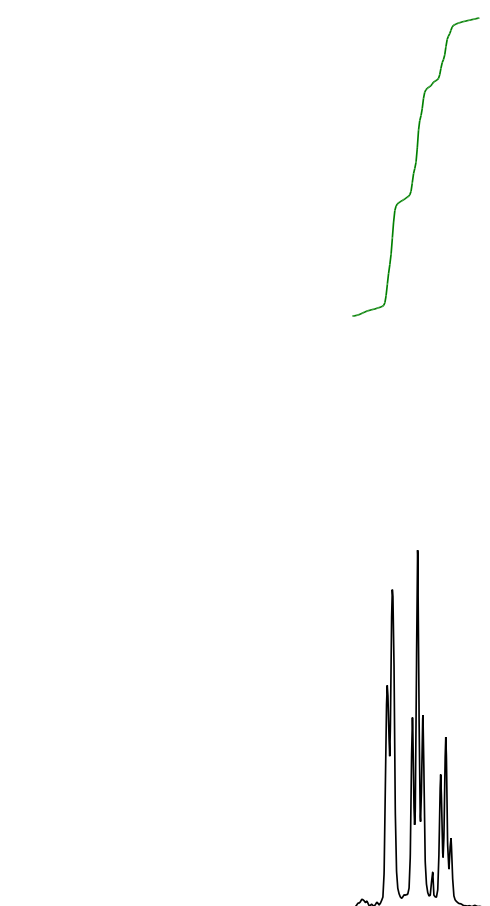

8.0

7.5

7.0

6.5

6.0

5.5

4.5

4.0

3.5 3.0

2.5 
${ }^{13} \mathrm{C} \mathrm{NMR,} \mathrm{CDCl}_{3}, 125 \mathrm{MHz}$<smiles>c1ccc(Cc2ccccc2)cc1</smiles><smiles>C=C[C@@H](O)[C@@H](O)[C@H](N)CO</smiles>

$(2 R, 3 R, 4 R)$-2-(benzhydrylamino)hex-5-ene-1,3,4-triol

$78 b$

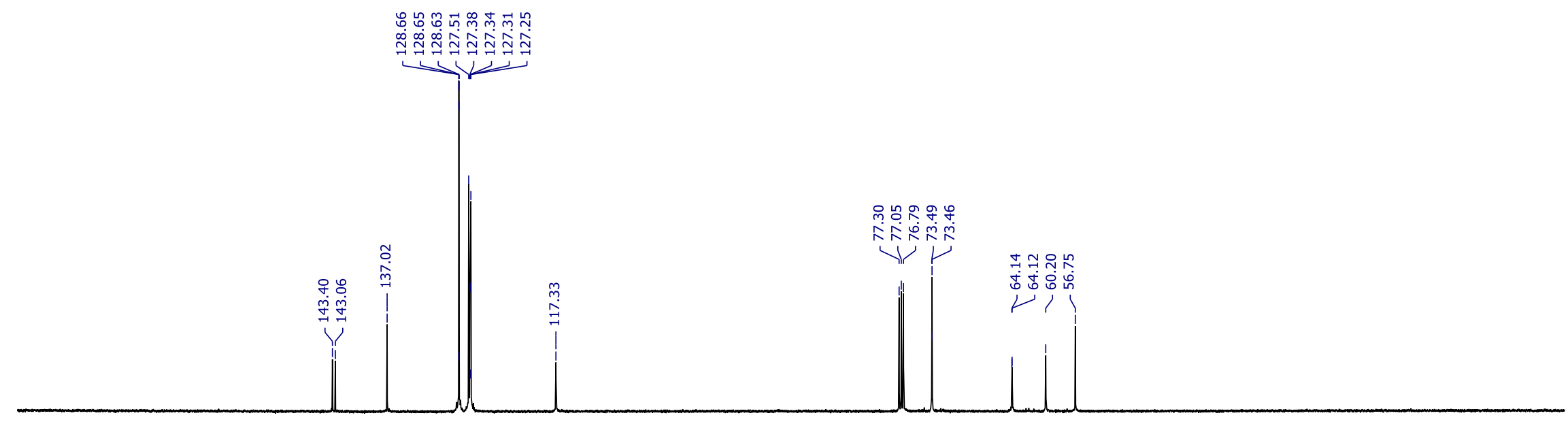


${ }^{1} \mathrm{H}$ NMR, $\mathrm{D}_{2} \mathrm{O}, 500 \mathrm{MHz}$

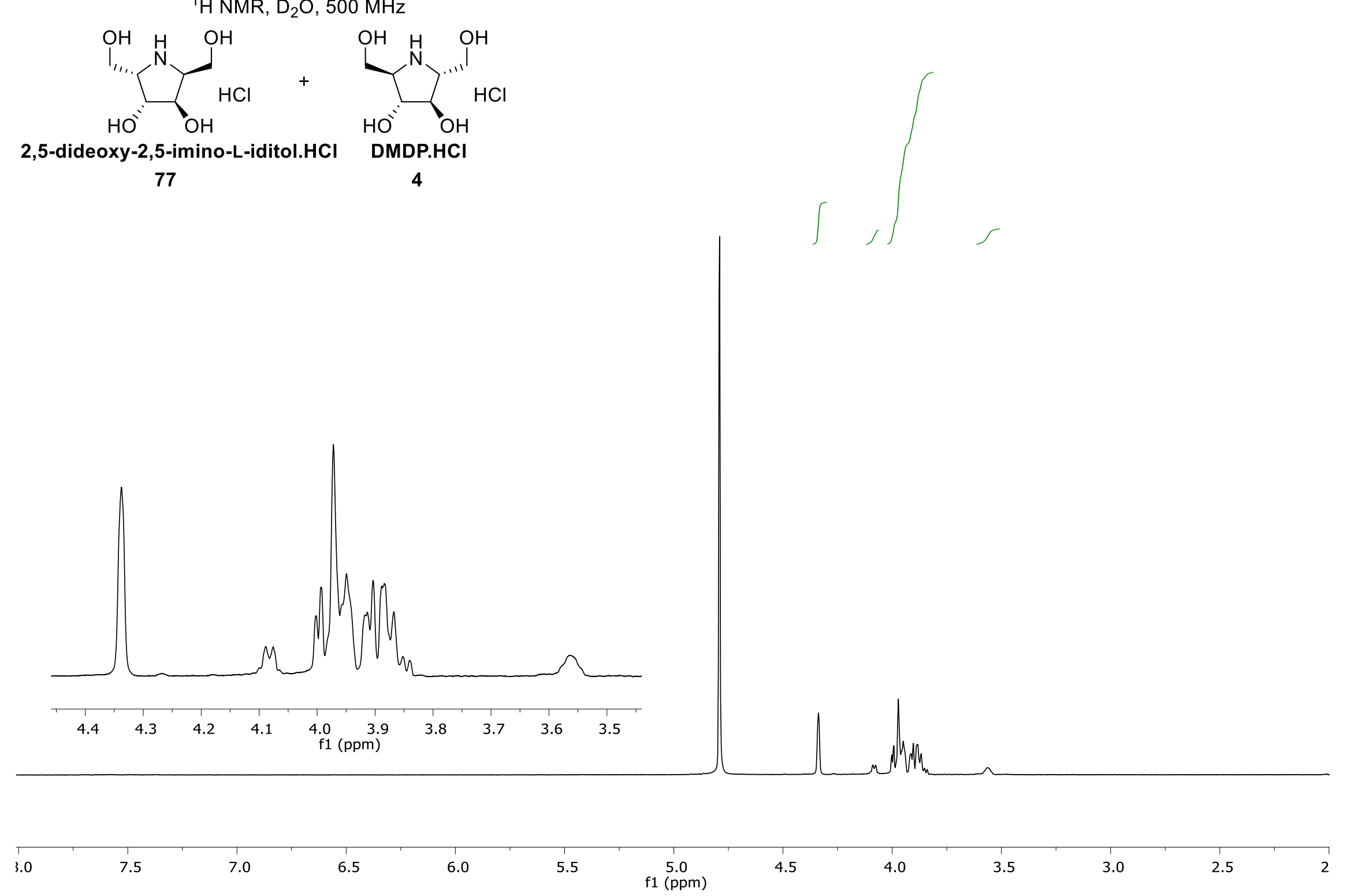


${ }^{13} \mathrm{C} \mathrm{NMR}, \mathrm{D}_{2} \mathrm{O}, 125 \mathrm{MHz}$

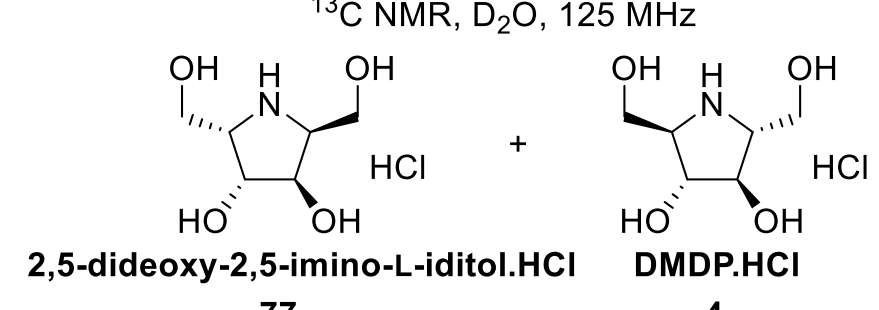
4

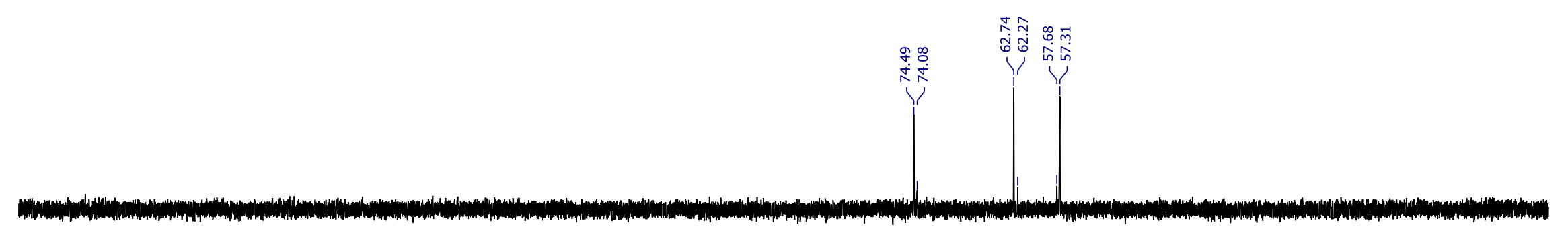

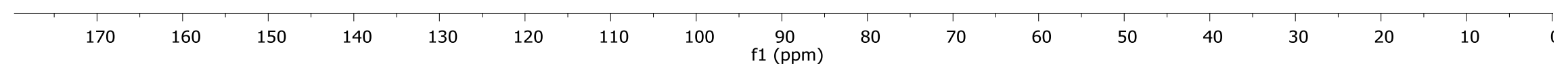


${ }^{1} \mathrm{H}$ NMR, $\mathrm{D}_{2} \mathrm{O}, 500 \mathrm{MHz}$

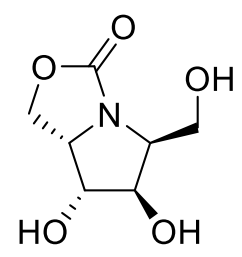

(5S,6R,7R,7aS)-6,7-dihydroxy

5-(hydroxymethyl)tetrahydro-

1H,3H-pyrrolo[1,2-c]oxazol-3-one

$76 a$

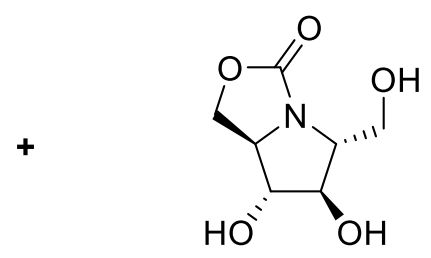

$(5 R, 6 R, 7 R, 7 \mathrm{a} R)$-6,7-dihydroxy-

5-(hydroxymethyl)tetrahydro-

$1 H, 3 H$-pyrrolo[1,2-c]oxazol-3-one

$76 b$

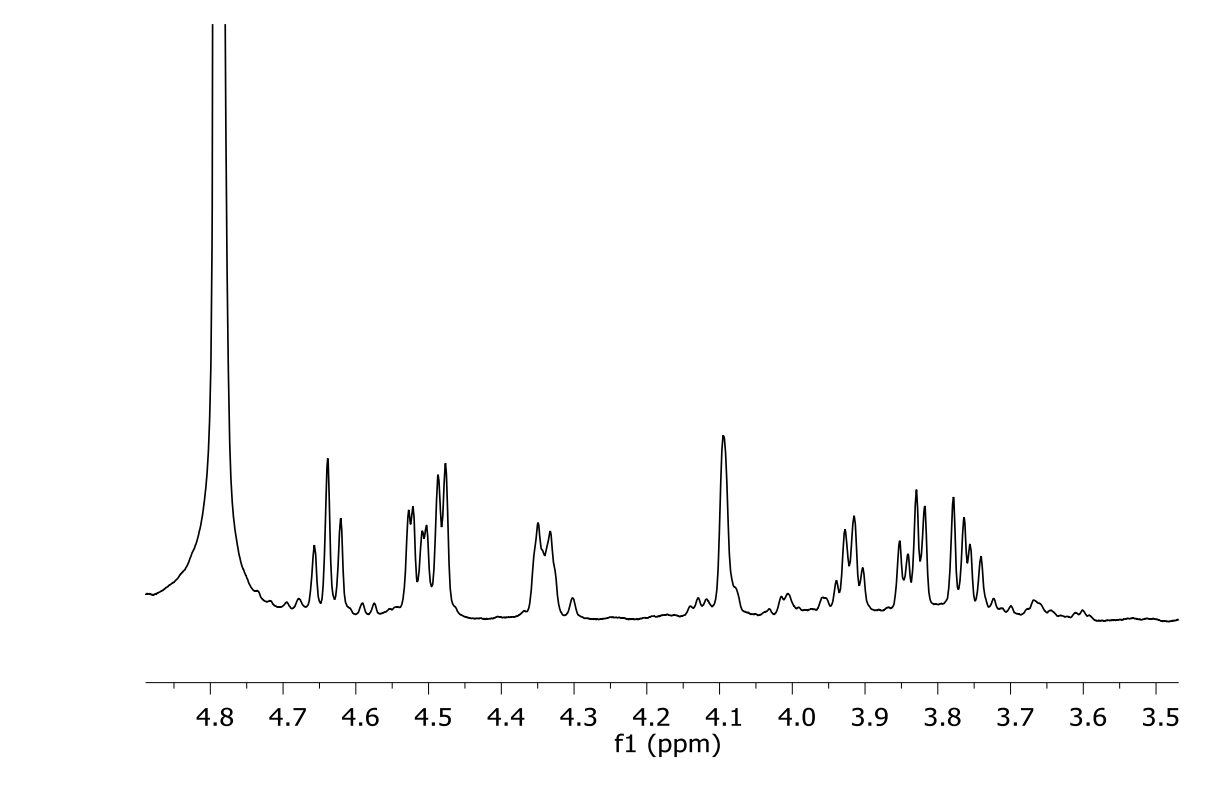

4.2
$f 1(p p m)$

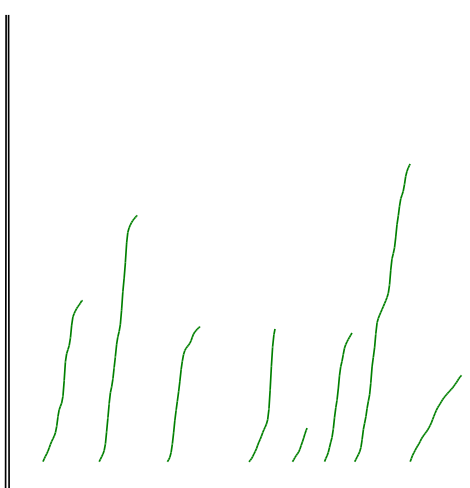

Cum nedamm

\section{i. 0}

7.5

7.0 6.5 6.0

5.5 5.0
f1 $(\mathrm{ppm})$

4.5

4.0

3.5

3.0

2.5 
${ }^{13} \mathrm{C}$ NMR, $\mathrm{D}_{2} \mathrm{O}, 500 \mathrm{MHz}$

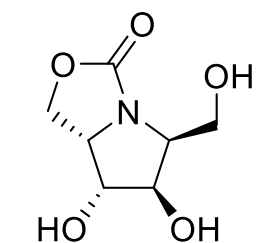

(5S,6R,7R,7aS)-6,7-dihydroxy-

5-(hydroxymethyl)tetrahydro-

$1 H, 3 H$-pyrrolo[1,2-c]oxazol-3-one

$76 a$

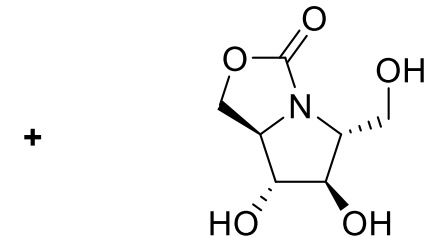

(5R,6R,7R,7aR)-6,7-dihydroxy-

5-(hydroxymethyl)tetrahydro-

1H,3H-pyrrolo[1,2-c]oxazol-3-one

$76 b$

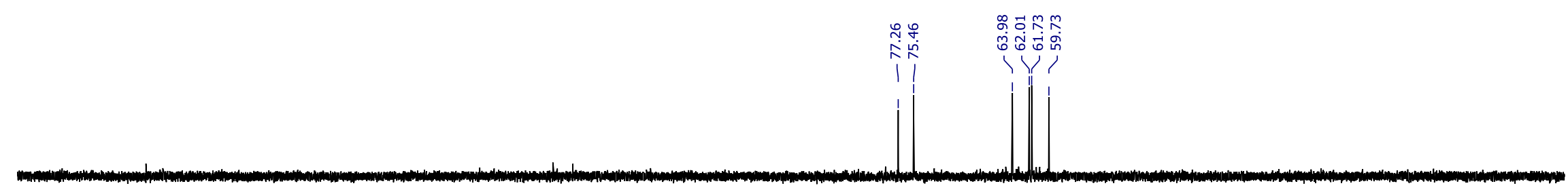

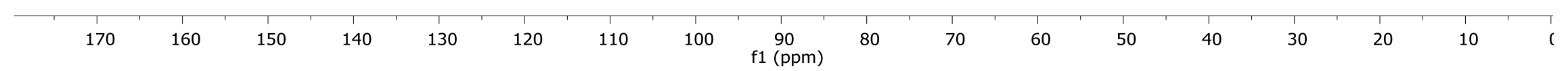


Chapter 3 spectra 


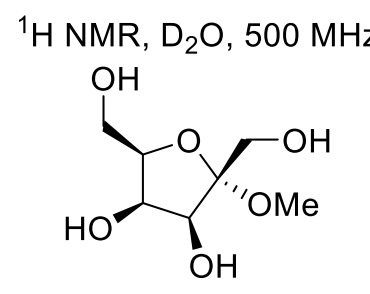

methyl $\alpha$-D-tagatofuranoside

83

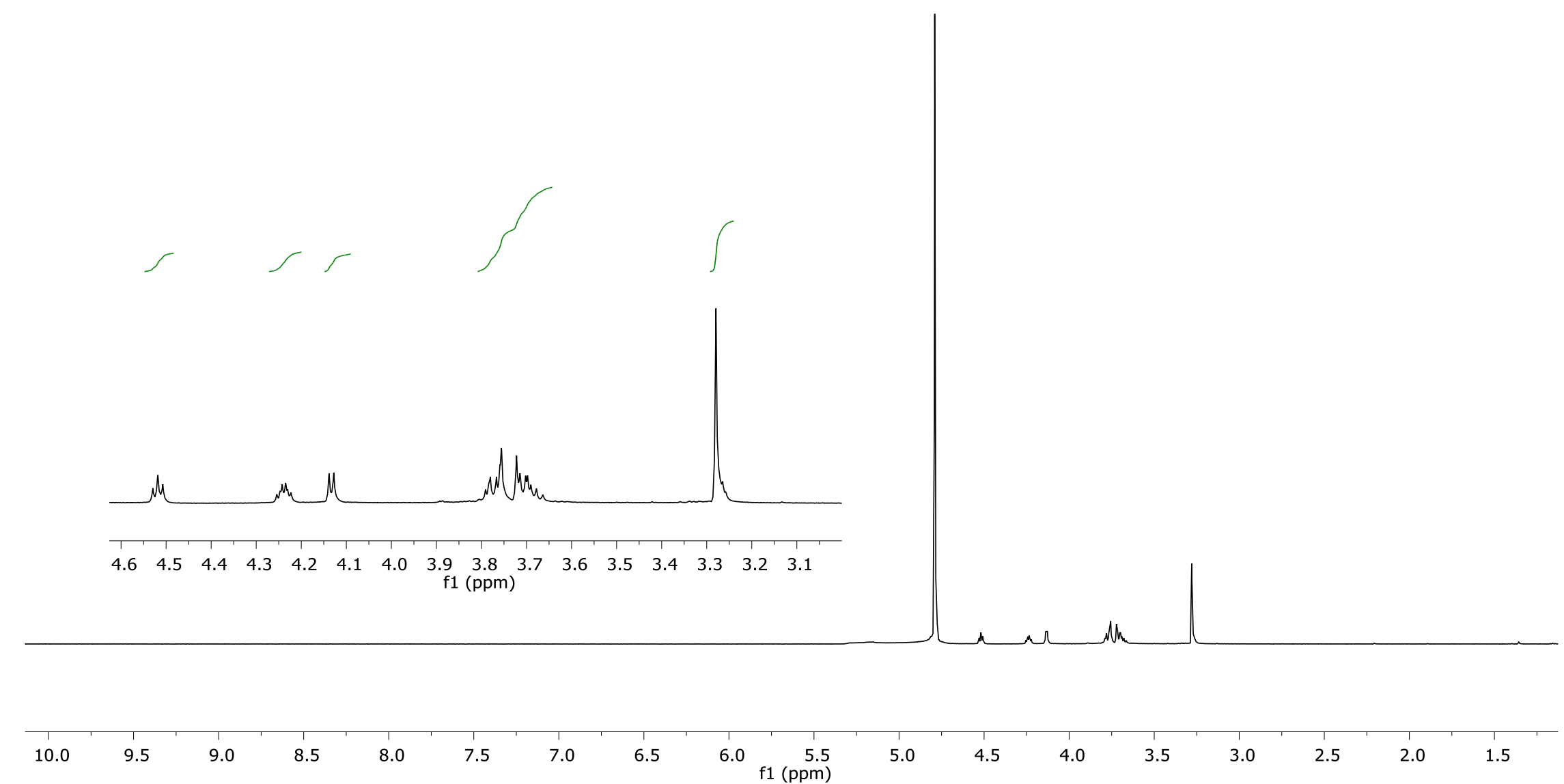


${ }^{13} \mathrm{C}$ NMR, $\mathrm{D}_{2} \mathrm{O}, 125 \mathrm{MHz}$

$\mathrm{OH}$

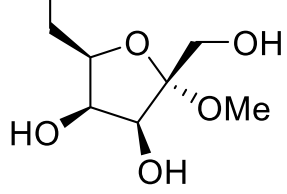

methyl $\alpha$-D-tagatofuranoside 83

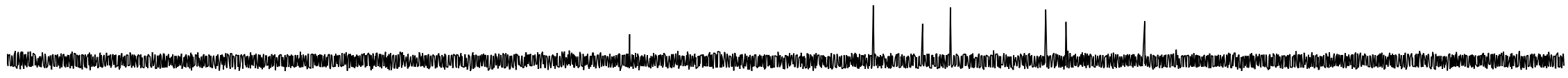

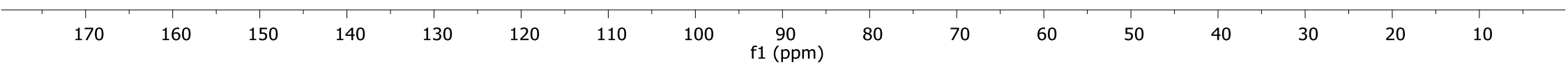


${ }^{1} \mathrm{H} \mathrm{NMR}, \mathrm{CDCl}_{3}, 500 \mathrm{MHz}$

$\mathrm{OH}$

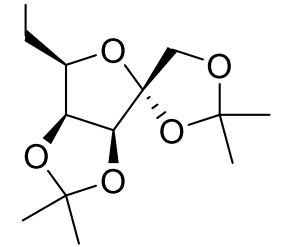

1,2:3,4-di-O-isopropylidene- $\alpha$-D-tagatofuranoside

85

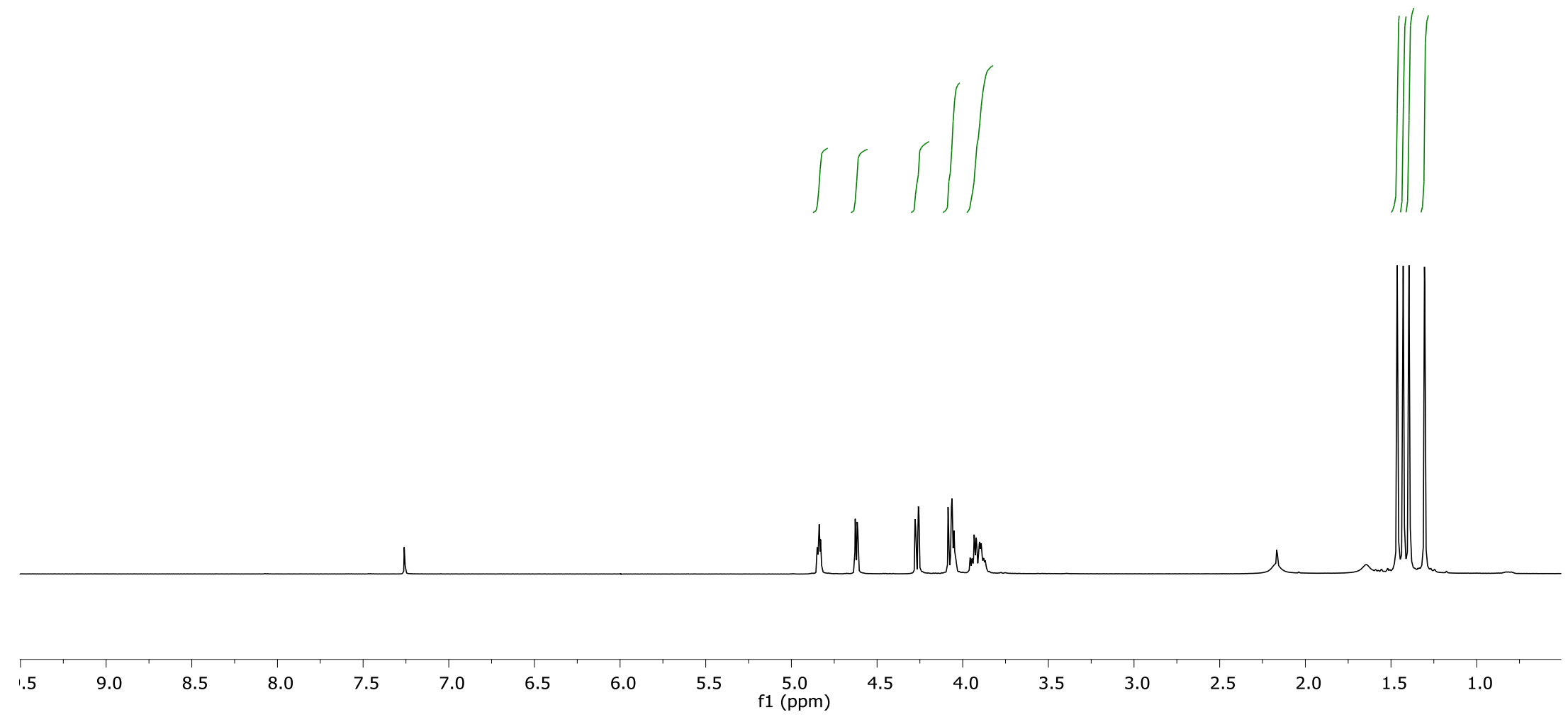


${ }^{13} \mathrm{C} \mathrm{NMR}, \mathrm{CDCl}_{3}, 125 \mathrm{MHz}$

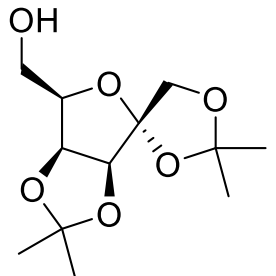

1,2:3,4-di-O-isopropylidene- $\alpha$-D-tagatofuranoside

85

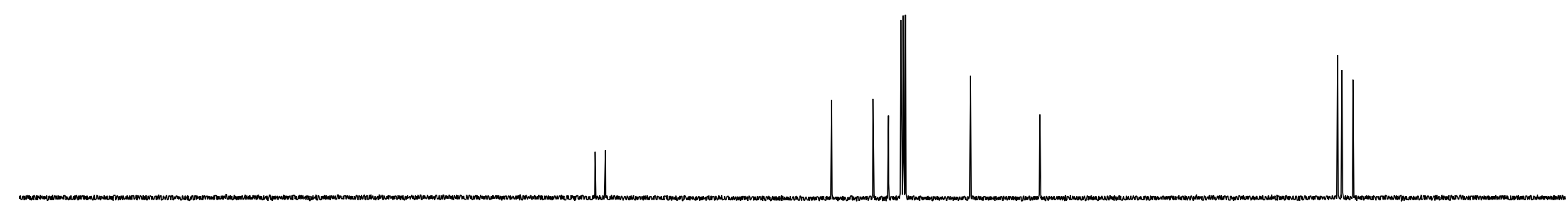

170 
${ }^{1} \mathrm{H} \mathrm{NMR}, \mathrm{CDCl}_{3}, 500 \mathrm{MHz}$

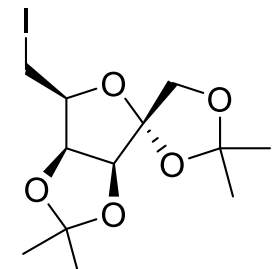

6-Deoxy-6-iodo-1,2:3,4-di-O-isopropylidene- $\alpha$-D-tagatofuranoside

86
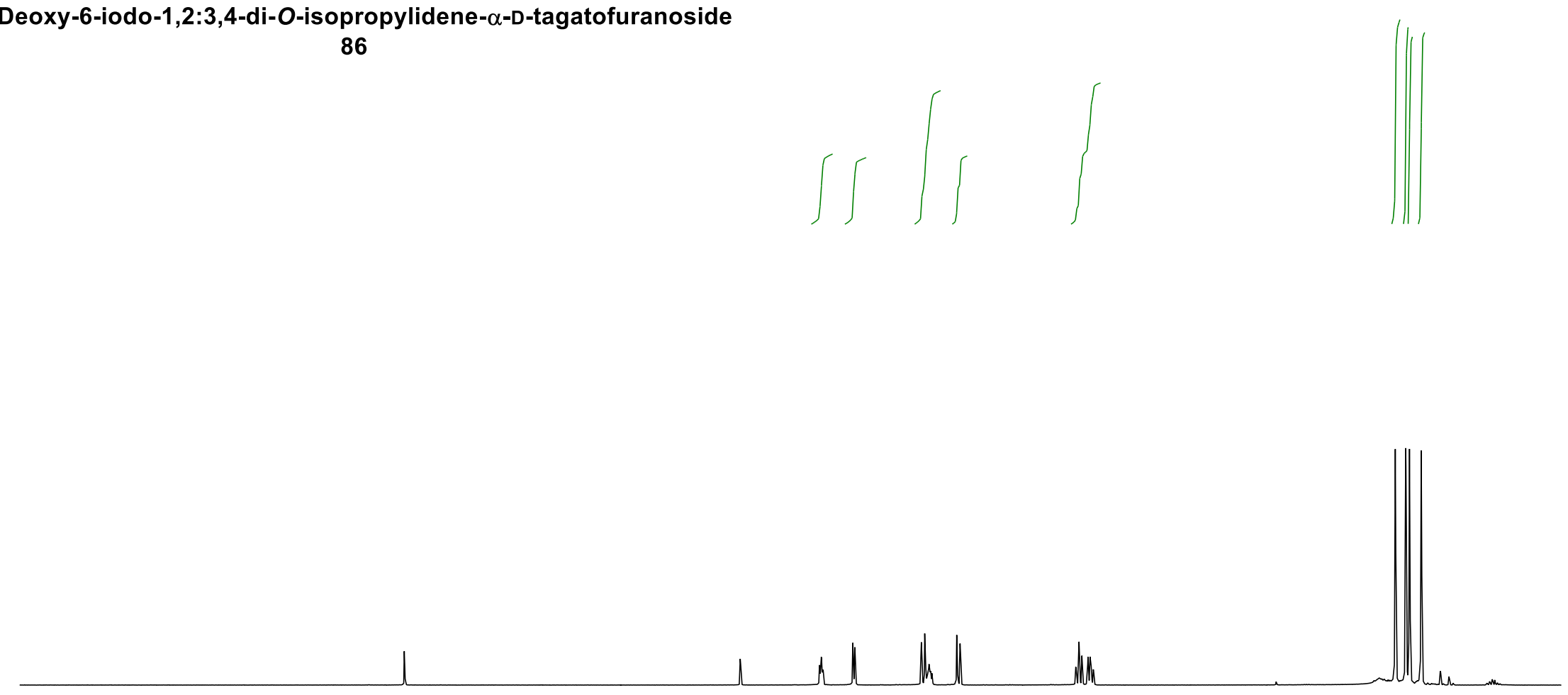

$.5 \quad 9$ 8.5 8.0

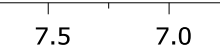
6.5 6.0 $5.5 \quad 5.0$ f1 (ppm) $4.5 \quad 4.0$ 3.5 
${ }^{13} \mathrm{C} \mathrm{NMR}, \mathrm{CDCl}_{3}, 125 \mathrm{MHz}$

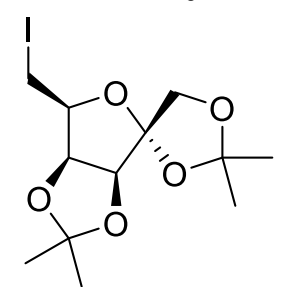

6-Deoxy-6-iodo-1,2:3,4-di-O-isopropylidene- $\alpha$-D-tagatofuranoside

86

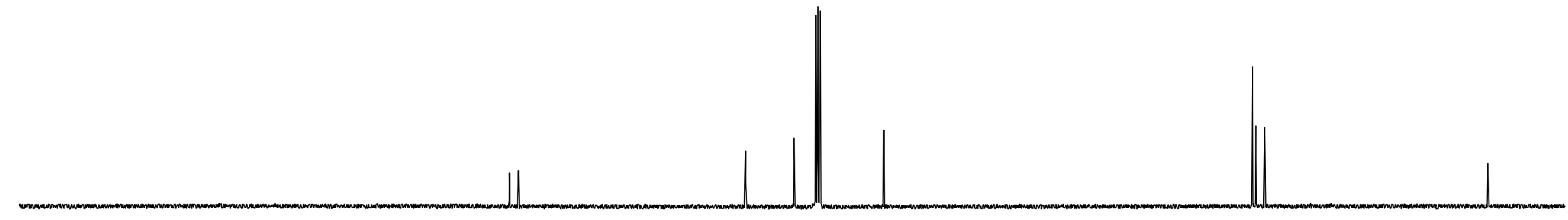

160

150

140

130

$120 \quad 110$

$110 \quad 100$

90

80
$\mathrm{f} 1(\mathrm{ppm})$ 
${ }^{1} \mathrm{H} \mathrm{NMR}, \mathrm{CDCl}_{3}, 500 \mathrm{MHz}$

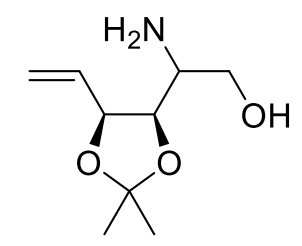

2-amino-2-((4R,5S)-2,2-dimethyl-5-vinyl-1,3-dioxolan-4-yl)ethan-1-ol

87

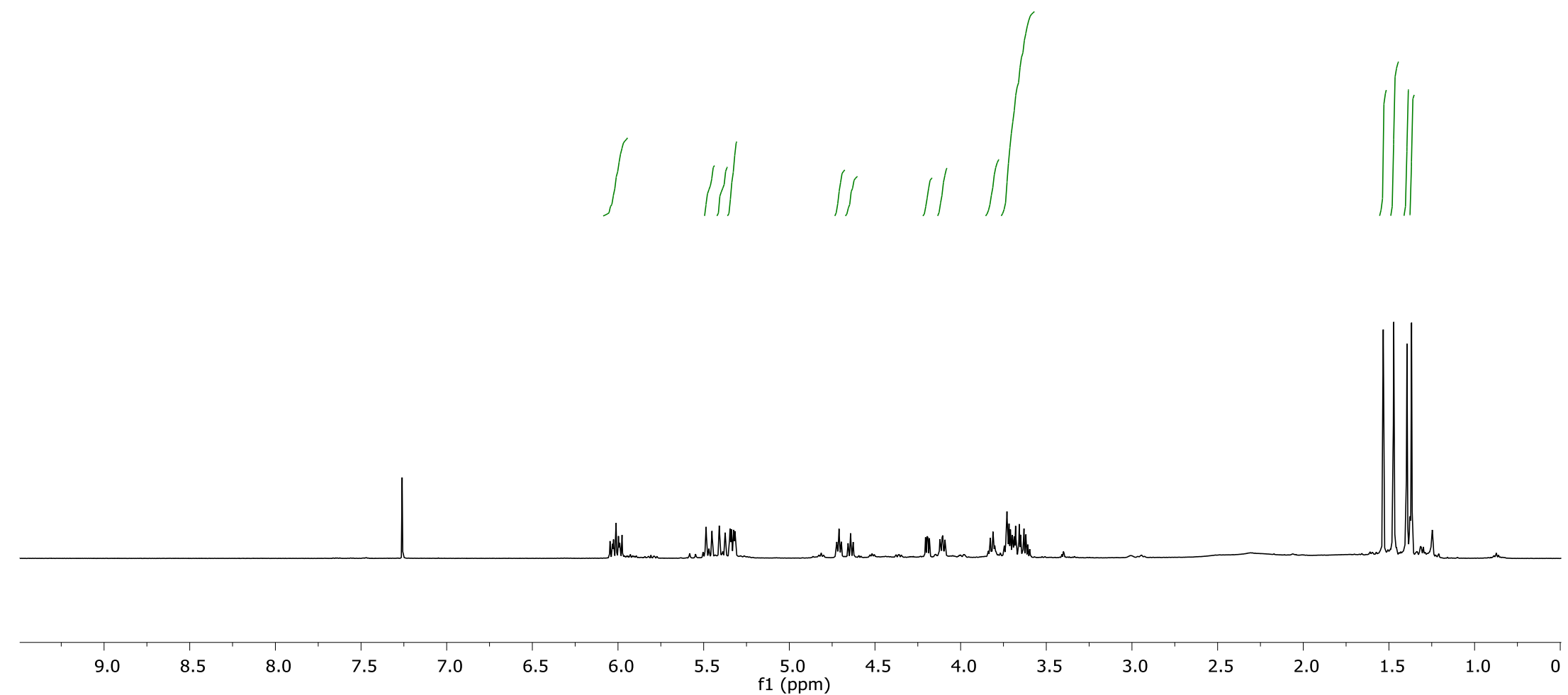


${ }^{13} \mathrm{C} \mathrm{NMR}, \mathrm{CDCl}_{3}, 125 \mathrm{MHz}$

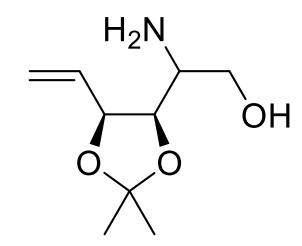

2-amino-2-((4R,5S)-2,2-dimethyl-5-vinyl-1,3-dioxolan-4-yl)ethan-1-ol

87

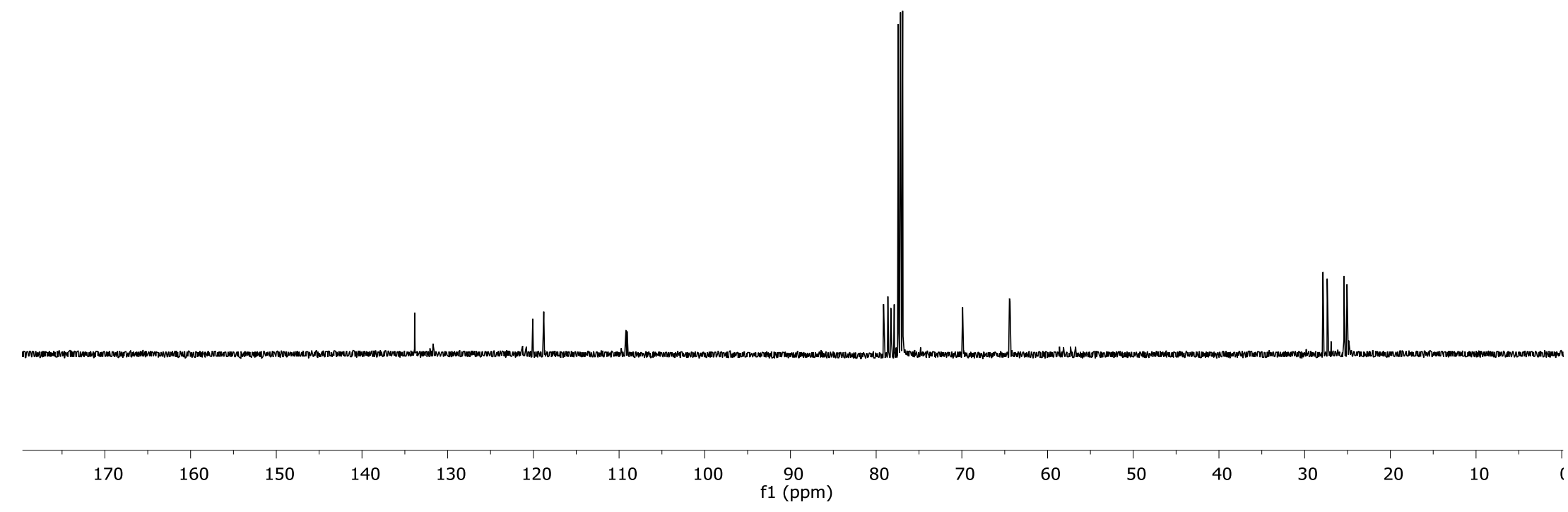


${ }^{1} \mathrm{H}$ NMR, $\mathrm{D}_{2} \mathrm{O}, 500 \mathrm{MHz}$

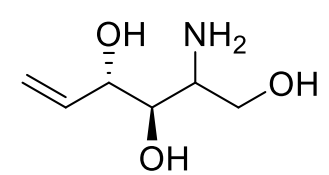

$(3 R, 4 S)$-2-aminohex-5-ene-1,3,4-triol 88 
${ }^{13} \mathrm{C}$ NMR, $\mathrm{D}_{2} \mathrm{O}, 125 \mathrm{MHz}$

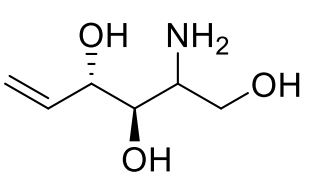

$(3 R, 4 S)$-2-aminohex-5-ene-1,3,4-triol

$$
88
$$

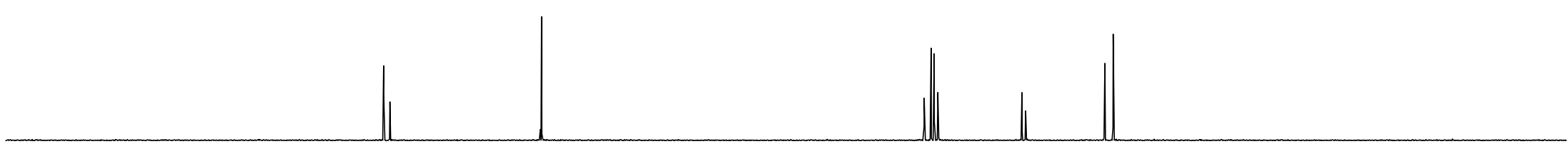




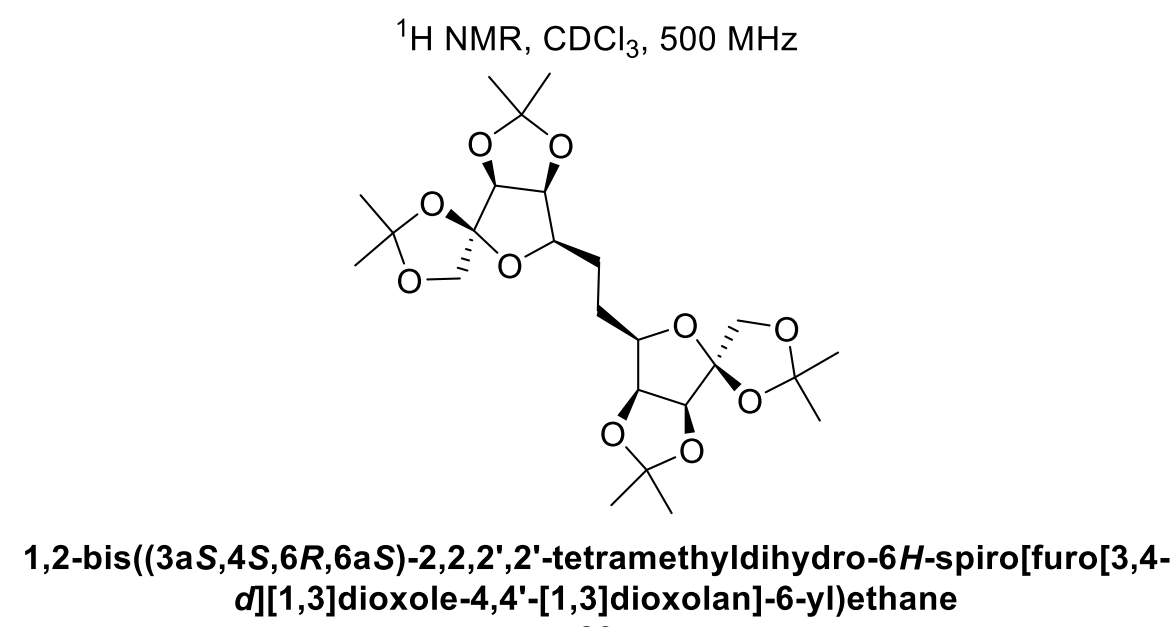

d] [1,3]dioxole-4,4'-[1,3]dioxolan]-6-yl)ethane

89
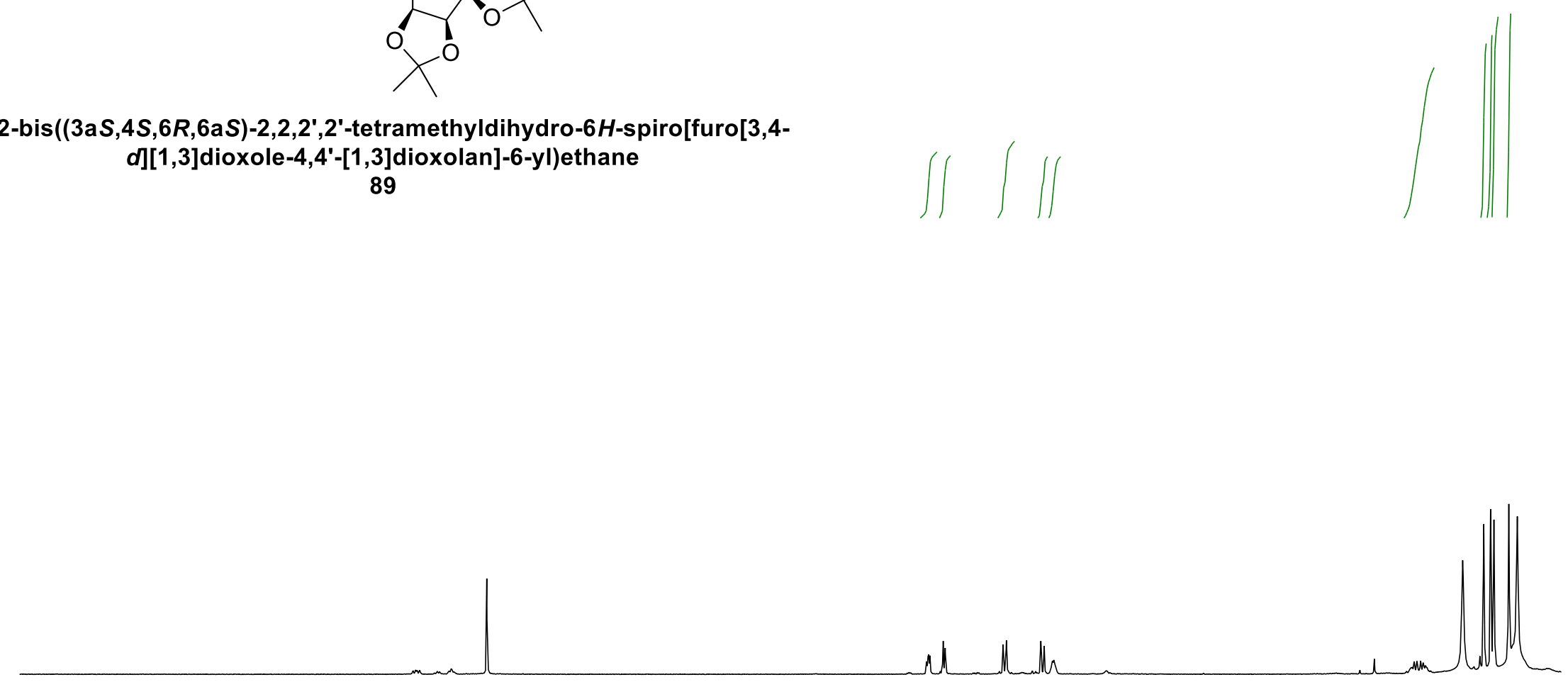

5.0

4.5

4.0 
${ }^{13} \mathrm{C} \mathrm{NMR}, \mathrm{CDCl}_{3}, 125 \mathrm{MHz}$

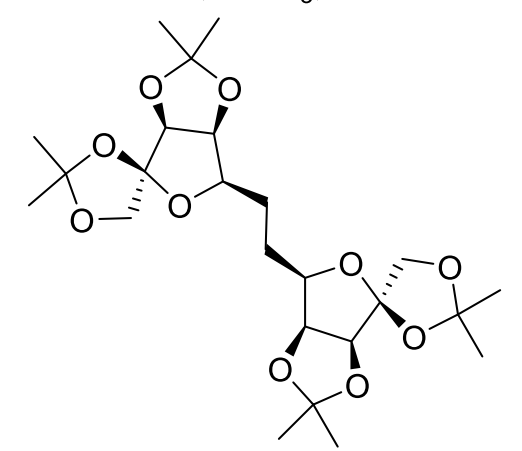

1,2-bis((3aS,4S,6R,6aS)-2,2,2',2'-tetramethyldihydro-6H-spiro[furo[3,4d] $[1,3]$ dioxole-4,4'-[1,3]dioxolan]-6-yl)ethane

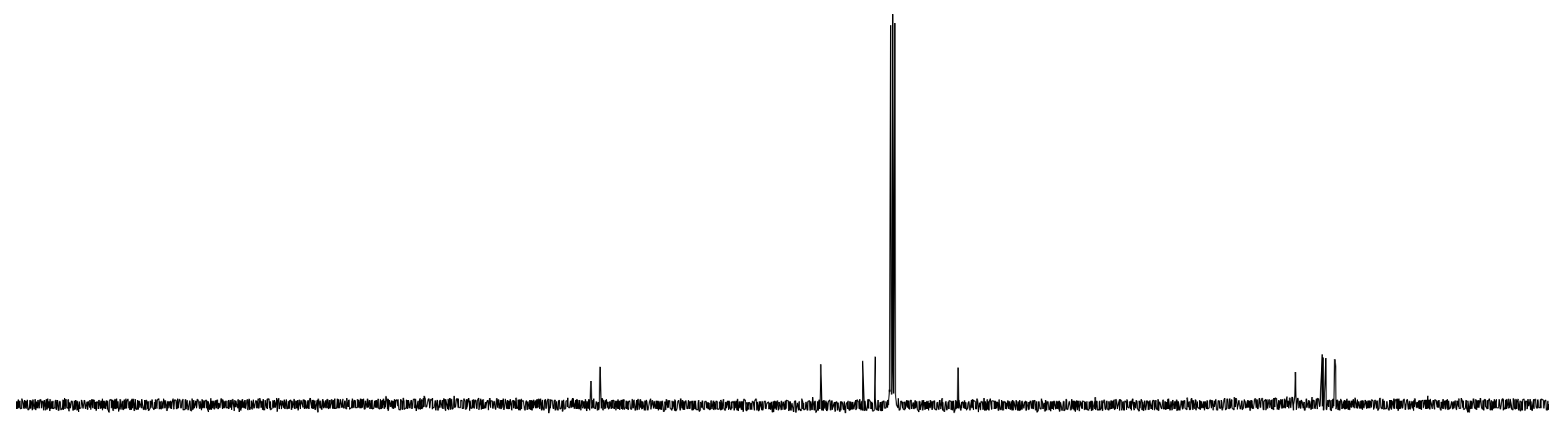

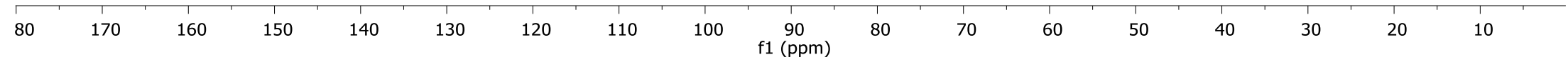


${ }^{1} \mathrm{H}$ NMR, $\mathrm{CDCl}_{3}, 500 \mathrm{MHz}$

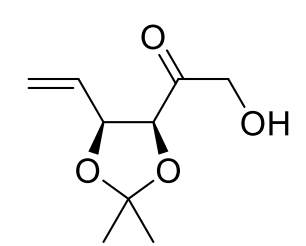

1-((4S,5S)-2,2-dimethyl-5-vinyl-1,3-dioxolan-4-yl)-2-hydroxyethan-1-one

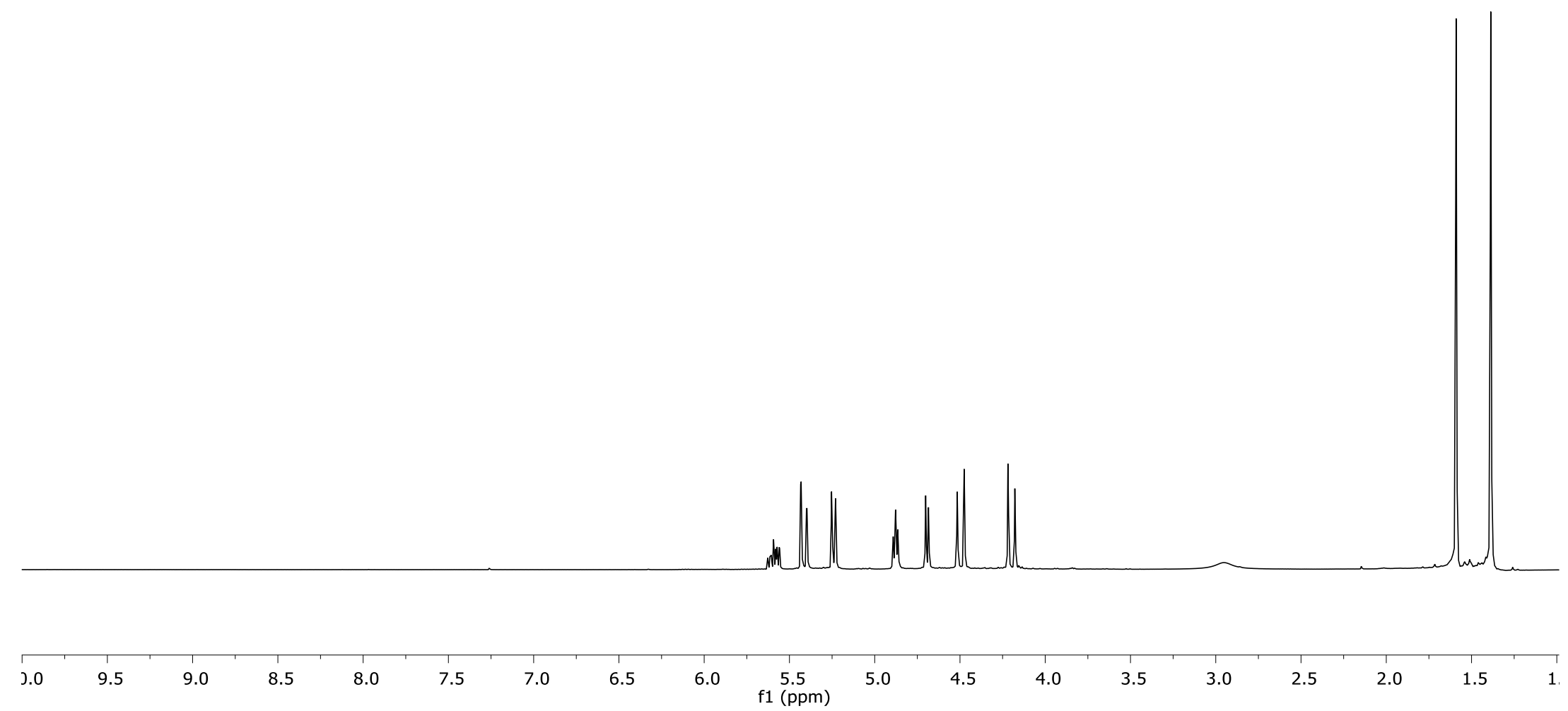


${ }^{13} \mathrm{C} \mathrm{NMR}, \mathrm{CDCl}_{3}, 125 \mathrm{MHz}$

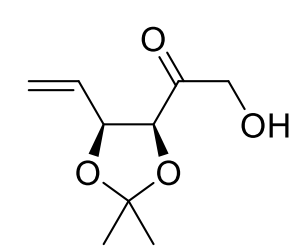

1-((4S,5S)-2,2-dimethyl-5-vinyl-1,3-dioxolan-4-yl)-2-hydroxyethan-1-one

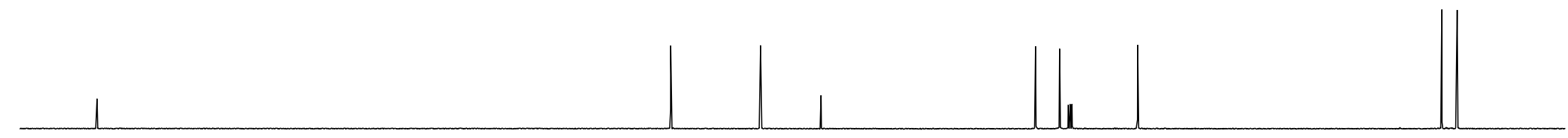

$210 \quad 200-190$

180

$170 \quad 160$

$150 \quad 140$

$130 \quad 120 \quad 110$

100

90

$80 \quad 70$

$60 \quad 50$

40

30

$20 \quad 1$ 
${ }^{1} \mathrm{H}$ NMR, $\mathrm{D}_{2} \mathrm{O}, 500 \mathrm{MHz}$

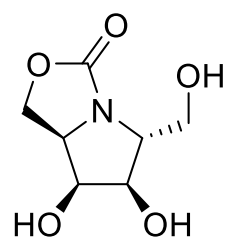

$+$

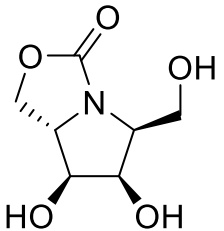

$(5 R, 6 R, 7 S, 7 \mathrm{a} R)-6,7-$ dihydroxy-5-

(hydroxymethyl)tetrahydro-

(5S,6R,7S,7aS)-6,7-dihydroxy-5(hydroxymethyl)tetrahydro-

$1 H, 3 H$-pyrrolo[1,2-c]oxazol-3-one $1 H, 3 H$-pyrrolo[1,2-c]oxazol-3-one

79

$79 a$

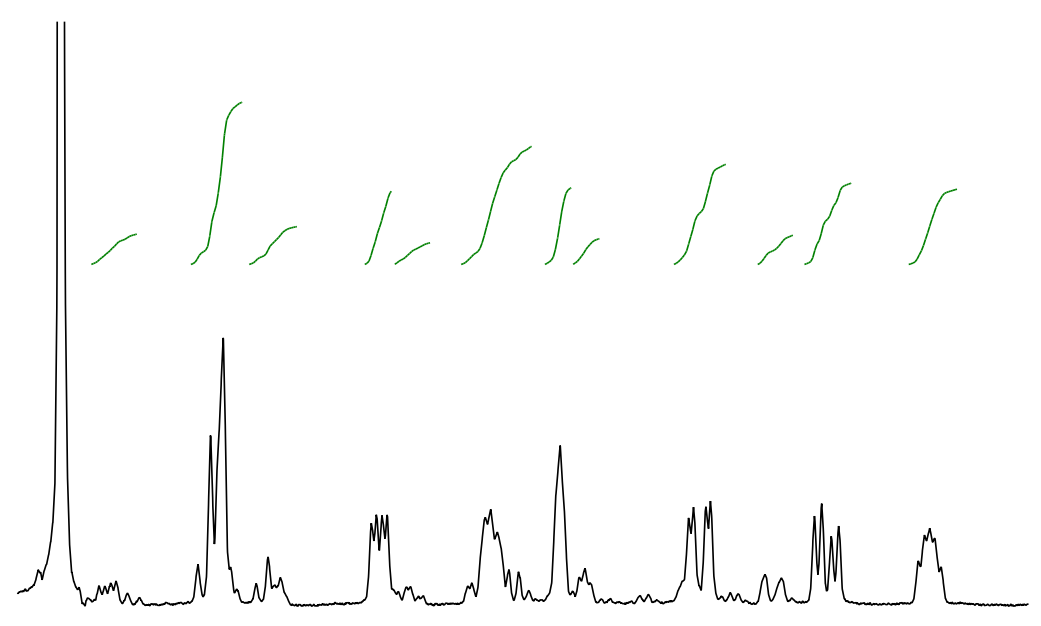

$\begin{array}{llllllllllllll}4.8 & 4.7 & 4.6 & 4.5 & 4.4 & 4.3 & 4.2 & 4.1 & 4.0 & 3.9 & 3.8 & 3.7 & 3.6 & 3.5\end{array}$ 
${ }^{1} \mathrm{H} \mathrm{NMR}, \mathrm{CDCl}_{3}, 500 \mathrm{MHz}$

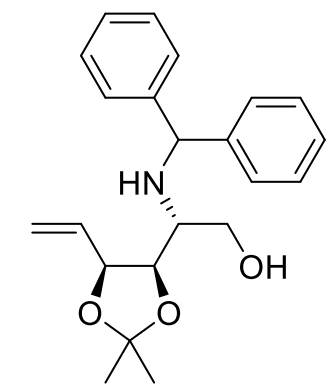

(R)-2-(benzhydrylamino)-2-((4R,5S)-2,2-dimethyl-5-vinyl-1,3-dioxolan-4-

yl)ethan-1-ol

93

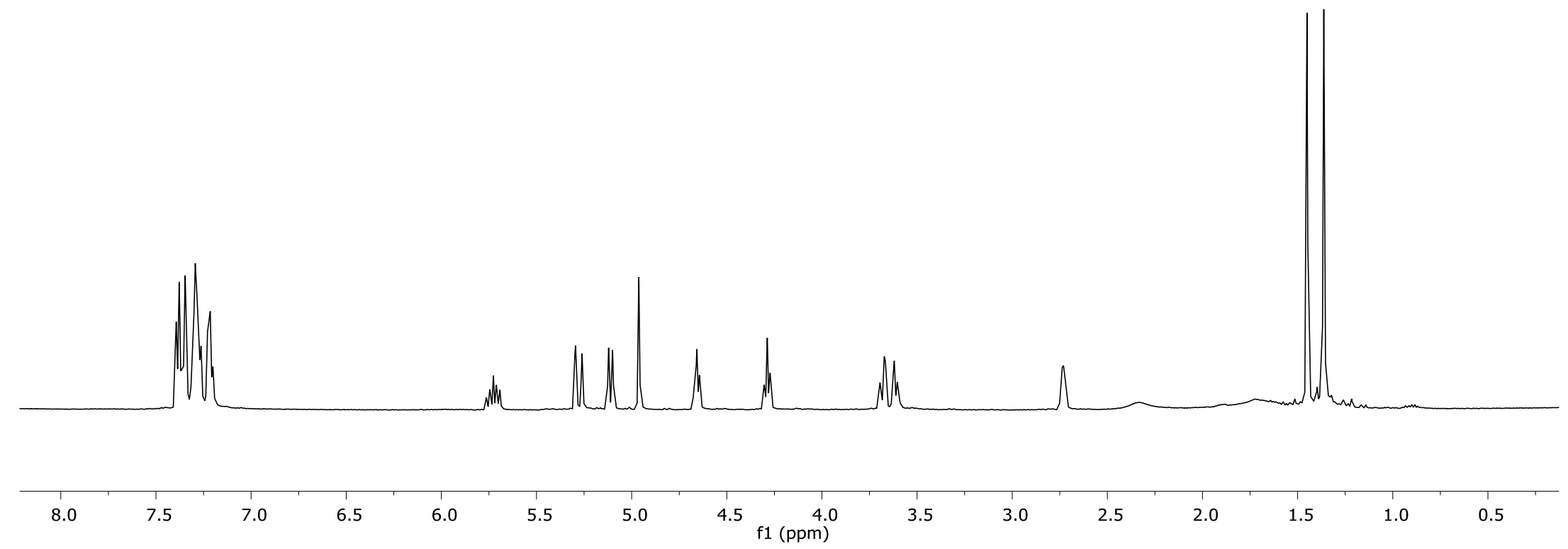


${ }^{13} \mathrm{C} \mathrm{NMR,} \mathrm{CDCl}_{3}, 125 \mathrm{MHz}$

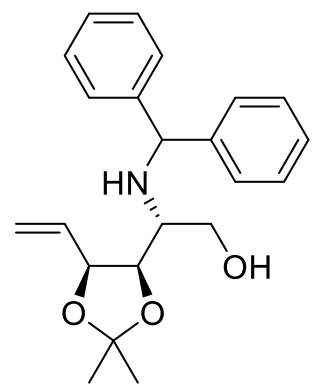

(R)-2-(benzhydrylamino)-2-((4R,5S)-2,2-dimethyl-5-vinyl-1,3-dioxolan-4-

yl)ethan-1-ol

93

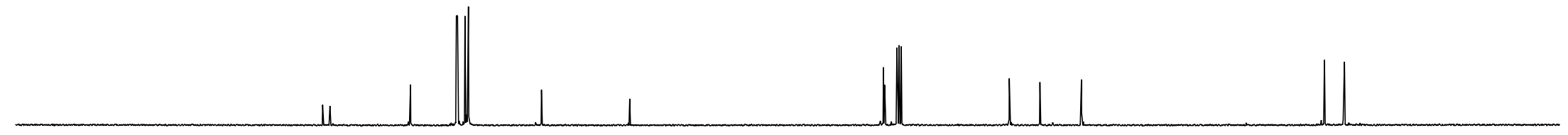

170

160

150

140

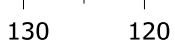

110

100

f1 $\stackrel{90}{(\mathrm{ppm})}$

80

70

60

$20 \quad 10$ 
${ }^{1} \mathrm{H}$ NMR, $\mathrm{D}_{2} \mathrm{O}, 500 \mathrm{MHz}$<smiles>CC(O)C(O)C(N)CO</smiles>

$(2 R, 3 R, 4 S)$-2-aminohex-5-ene-1,3,4-triol

80 
${ }^{13} \mathrm{C}$ NMR, $\mathrm{D}_{2} \mathrm{O}, 125 \mathrm{MHz}$

$\mathrm{OH} \quad \mathrm{NH}_{2}$

$\overbrace{\mathrm{OH}}^{\mathrm{O}} \mathrm{OH}$

$(2 R, 3 R, 4 S)$-2-aminohex-5-ene-1,3,4-triol

80

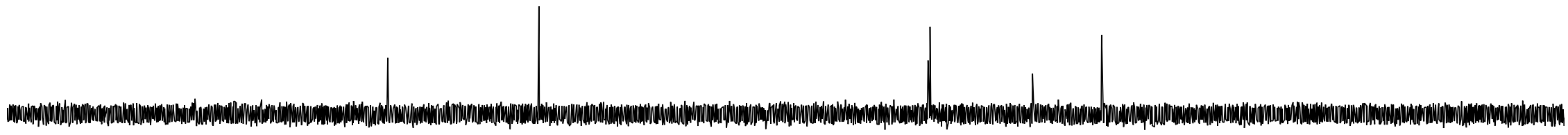

$170 \quad 160$

$150 \quad 140$

130

120

110

100

90

70

60

50 
${ }^{1} \mathrm{H}$ NMR, $\mathrm{D}_{2} \mathrm{O}, 500 \mathrm{MHz}$

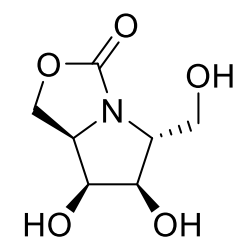

$(5 R, 6 R, 7 S, 7 \mathrm{a} R)-6,7-$ dihydroxy-5-

(hydroxymethyl)tetrahydro-1 $\mathrm{H}, 3 \mathrm{H}$ -

pyrrolo[1,2-c]oxazol-3-one

79

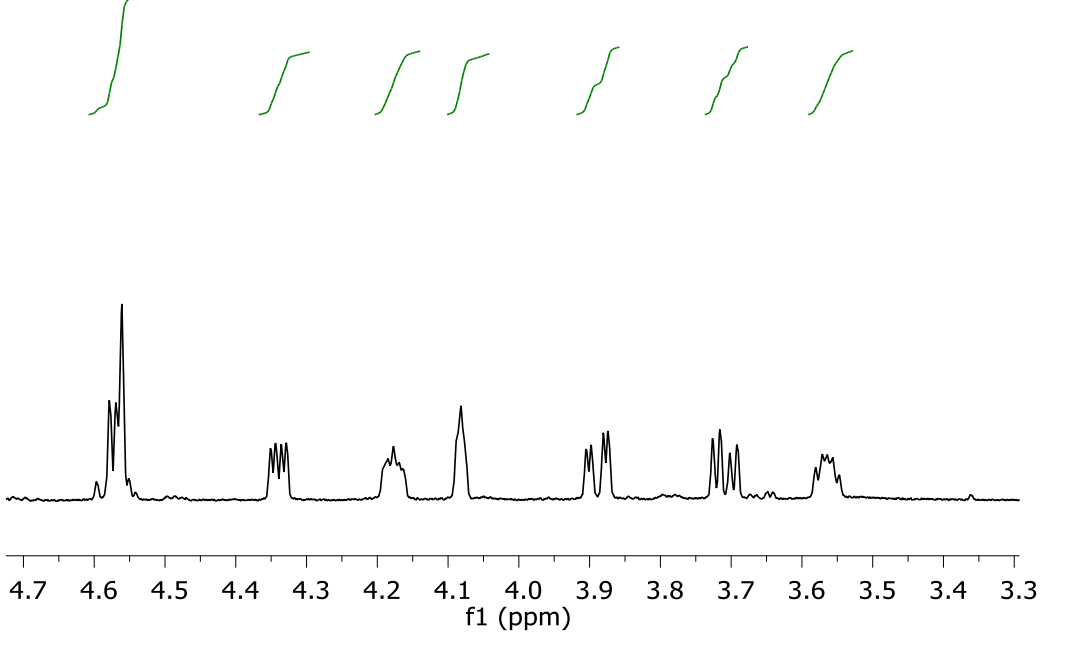

9.5

9.0

8.5

8.0

7.5

7.0

6.5

6.0

5.5

5.0

4.5

4.0

3.5

3.0

2.5

2.0

$1.5 \quad 1$ 
${ }^{13} \mathrm{C}$ NMR, $\mathrm{D}_{2} \mathrm{O}, 125 \mathrm{MHz}$

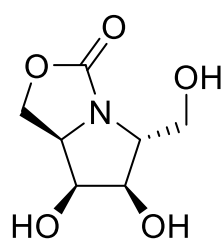

$(5 R, 6 R, 7 S, 7 \mathrm{a} R)-6,7-$ dihydroxy-5-

(hydroxymethyl)tetrahydro-

$1 \mathrm{H}, 3 \mathrm{H}$-pyrrolo[1,2-c]oxazol-3-one

79

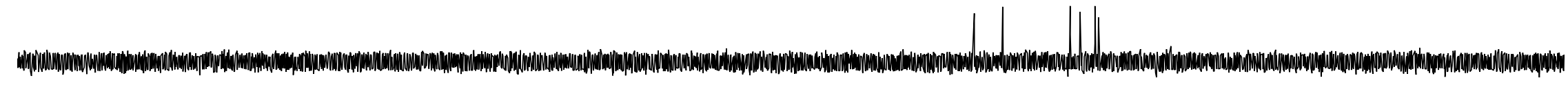


${ }^{1} \mathrm{H}$ NMR, $\mathrm{D}_{2} \mathrm{O}, 500 \mathrm{MHz}$<smiles>OCC1NC(CO)[C@@H](O)C1O</smiles>

2,5-dideoxy-2,5-imino-D-altritol (DIA)

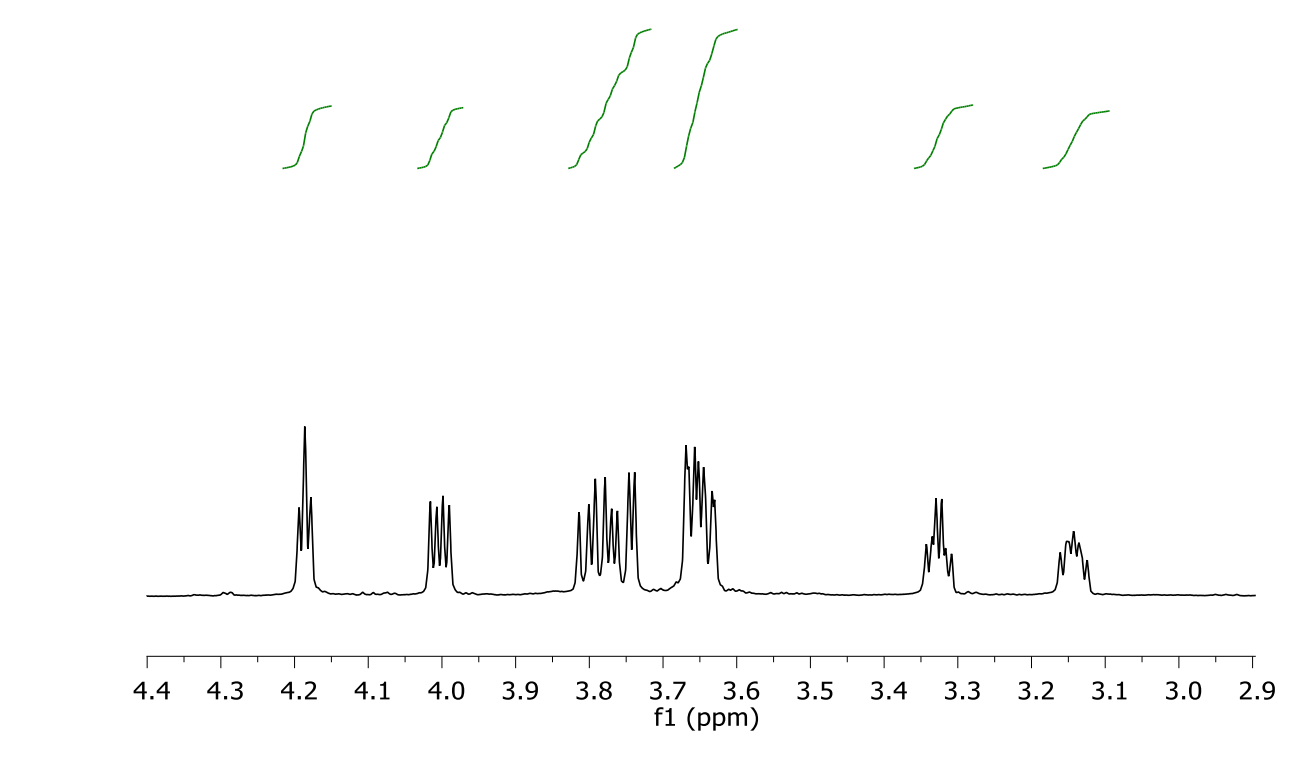


${ }^{13} \mathrm{C}$ NMR, $\mathrm{D}_{2} \mathrm{O}, 125 \mathrm{MHz}$

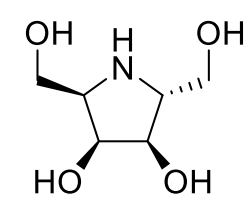

2,5-dideoxy-2,5-imino-D-altritol (DIA)

Haw

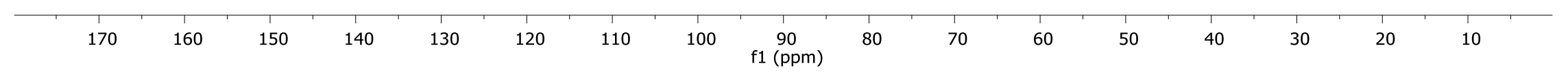


${ }^{1} \mathrm{H}$ NMR, $\mathrm{D}_{2} \mathrm{O}, 500 \mathrm{MHz}$

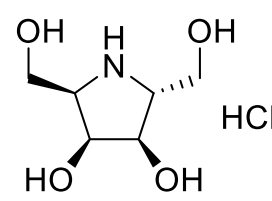

2,5-dideoxy-2,5-imino-D-altritol HCl (DIA)

78

dir indmera 
${ }^{13} \mathrm{C}$ NMR, $\mathrm{D}_{2} \mathrm{O}, 125 \mathrm{MHz}$

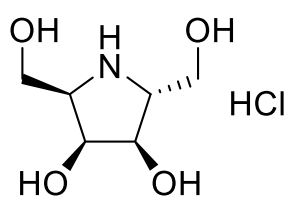

2,5-dideoxy-2,5-imino-D-altritol HCI (DIA)

78

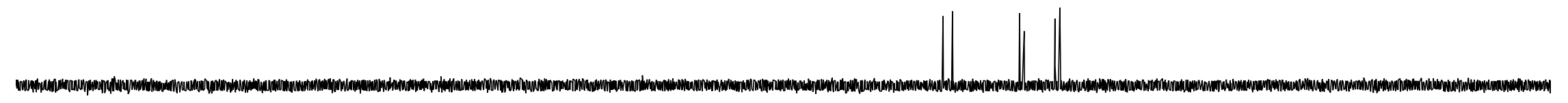


Chapter 4 Spectra 
${ }^{1} \mathrm{H}$ NMR, $\mathrm{D}_{2} \mathrm{O}, 500 \mathrm{MHz}$<smiles>O=C(CO)C(O)C(O)[C@H](O)CI</smiles>

6-deoxy-6-iodo-D-Fructose

94
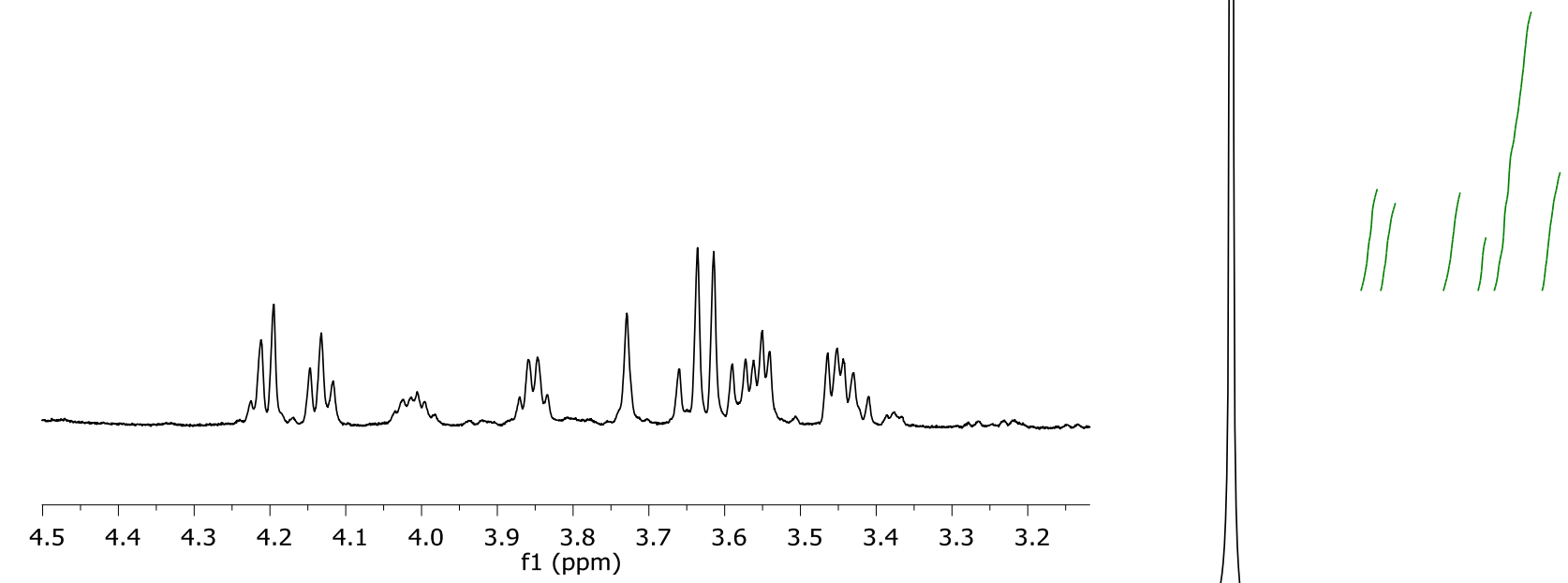

0.0

9.0

$8.5 \quad 8.0$

$7.5 \quad 7.0$

6.5

$6.0 \quad 5.5$

5.0

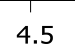

4.0

3.5

2.0

1.5 
${ }^{13} \mathrm{C}$ NMR, $\mathrm{D}_{2} \mathrm{O}, 125 \mathrm{MHz}$

OH

6-deoxy-6-iodo-D-Fructose 94

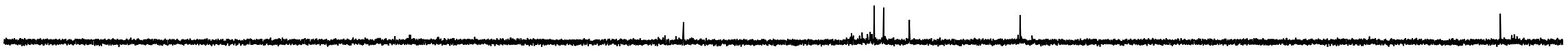

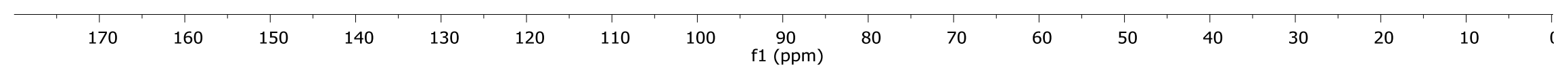




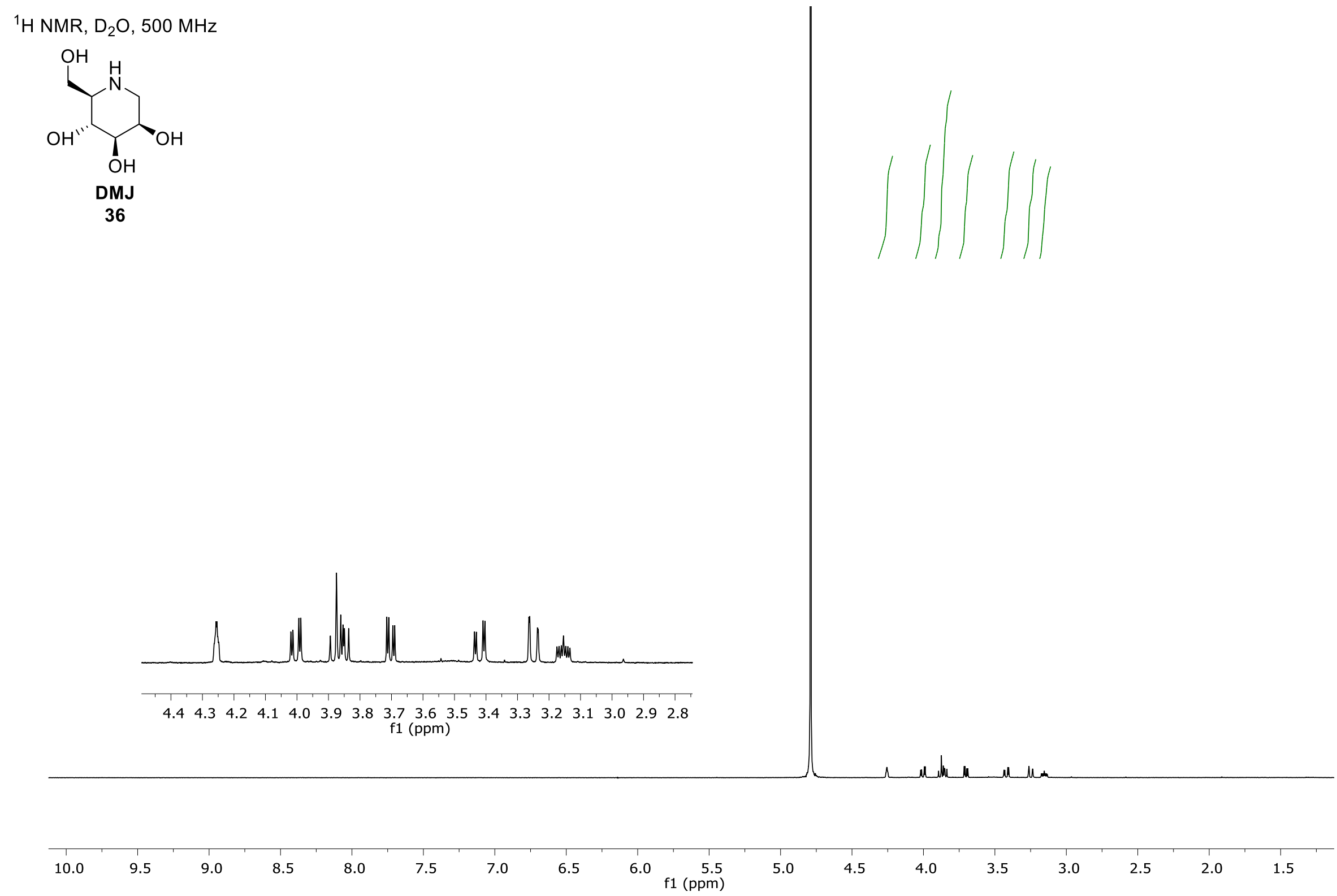


${ }^{13} \mathrm{C} N M R, \mathrm{D}_{2} \mathrm{O}, 125 \mathrm{MHz}$

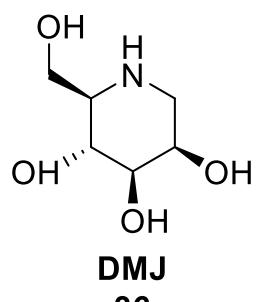

36

"|

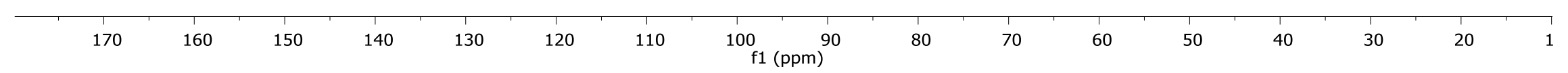


Chapter 5 spectra 
${ }^{1} \mathrm{H}$ NMR, $\mathrm{D}_{2} \mathrm{O}, 500 \mathrm{MHz}$

$\mathrm{OH}$

"

Methyl L-sorbofuranoside (111)
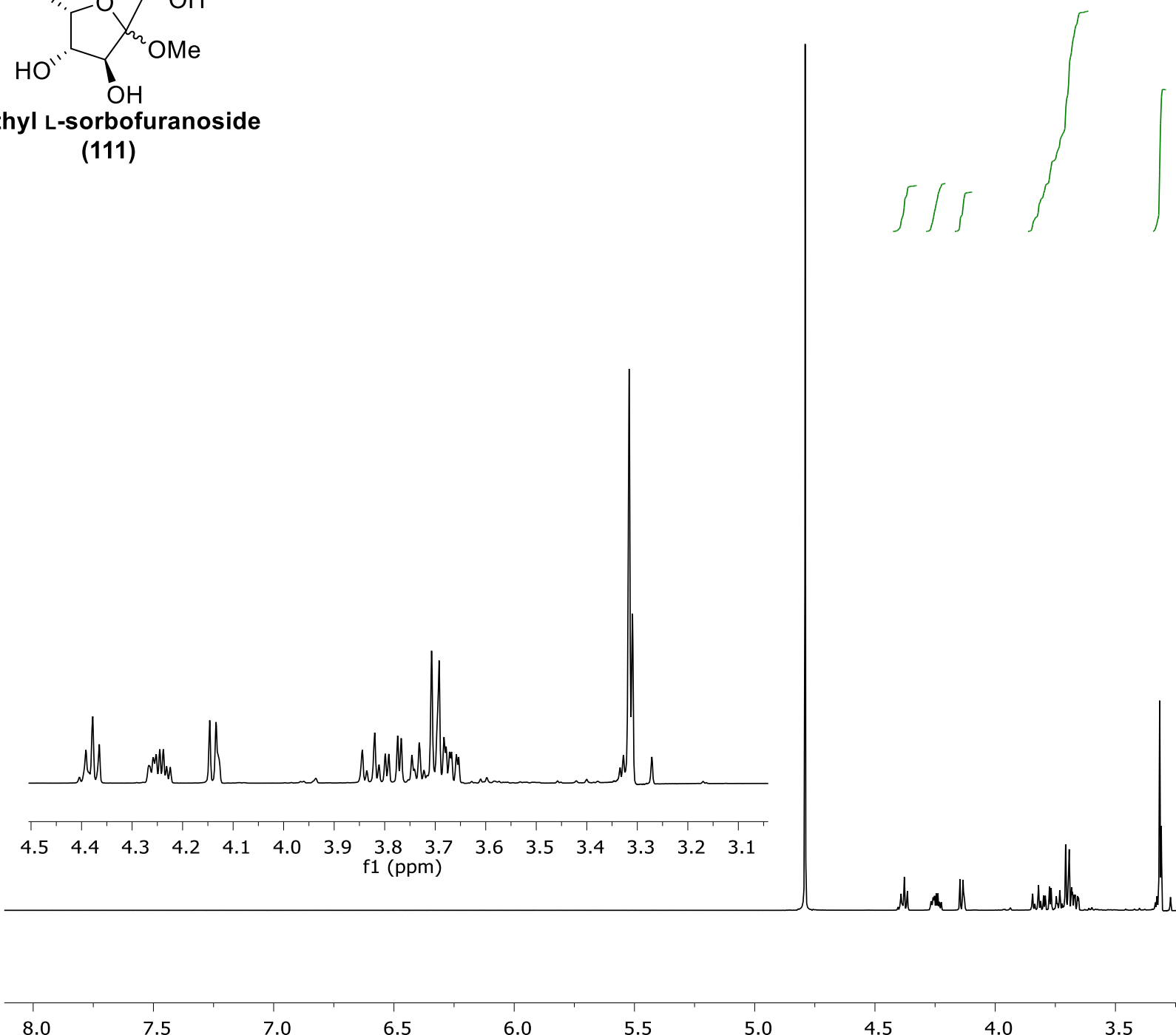

7.0

6.5

$6.0 \quad 5.5$

4.5
$\quad 11(\mathrm{ppm})$

4.0

3.5

3.0

25

2.0 
${ }^{13} \mathrm{C}$ NMR, $\mathrm{D}_{2} \mathrm{O}, 125 \mathrm{MHz}$<smiles>O</smiles>

$\mathrm{OH}$

$\mathrm{HO}^{\prime \prime} \mathrm{OMe}$

Methyl L-sorbofuranoside

(111) 
${ }^{1} \mathrm{H}$ NMR, $\mathrm{D}_{2} \mathrm{O}, 500 \mathrm{MHz}$

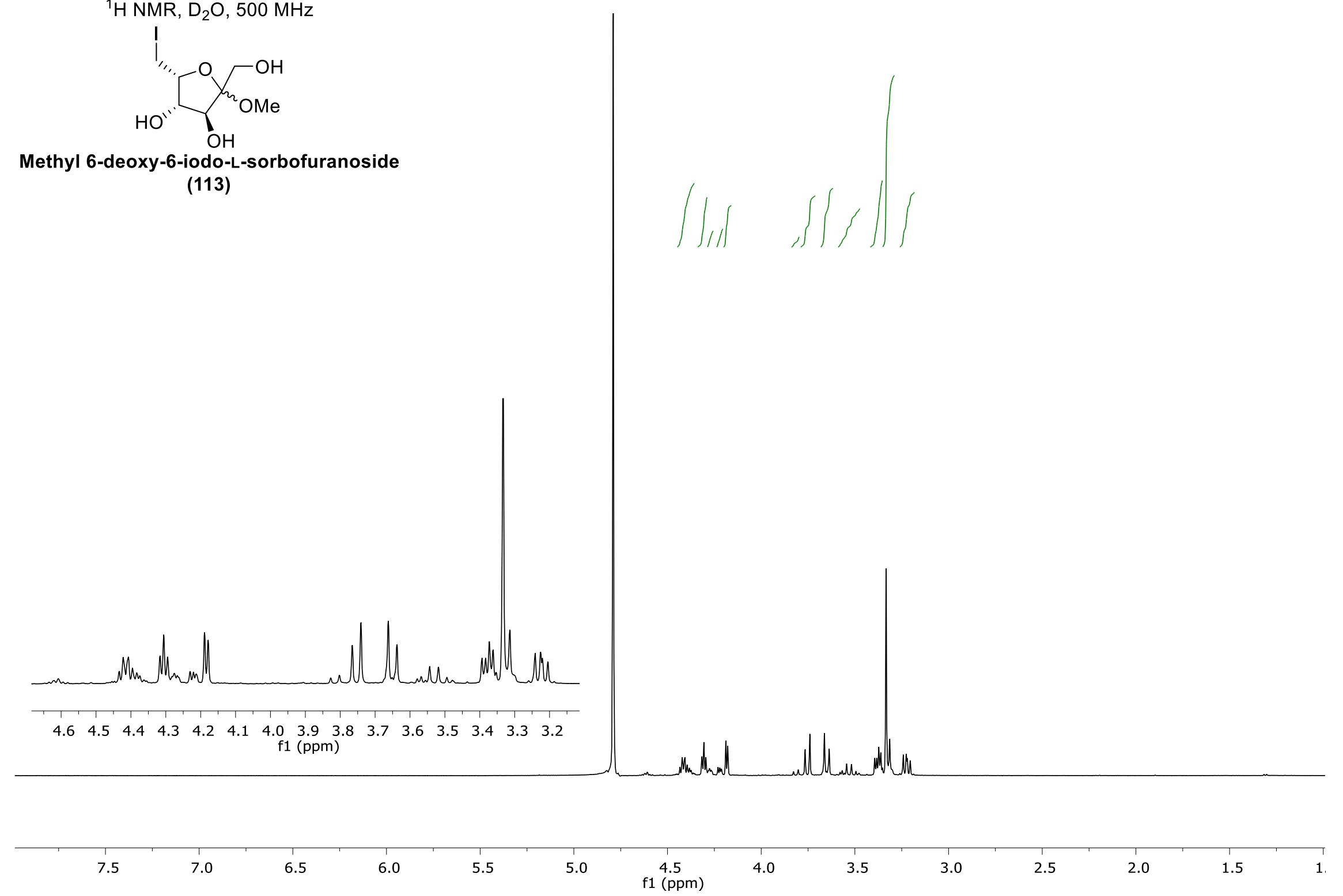


${ }^{13} \mathrm{C}$ NMR, $\mathrm{D}_{2} \mathrm{O}, 125 \mathrm{MHz}$

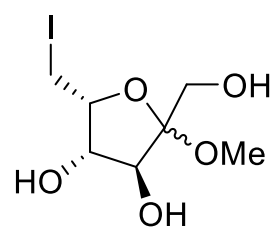

Methyl 6-deoxy-6-iodo-L-sorbofuranoside

(113)

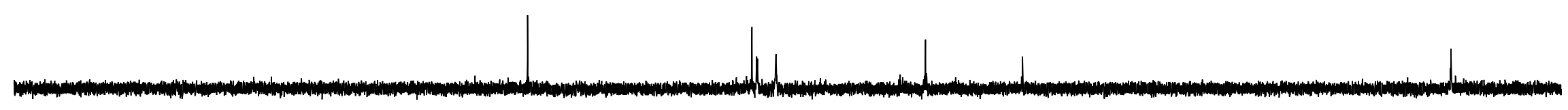

$60 \backslash 150+140$

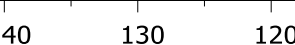

$110 \quad 100$

90

$80 \quad 70 \quad 60$

50

40

$30+20$

$10 \quad 0 \quad-1$ 


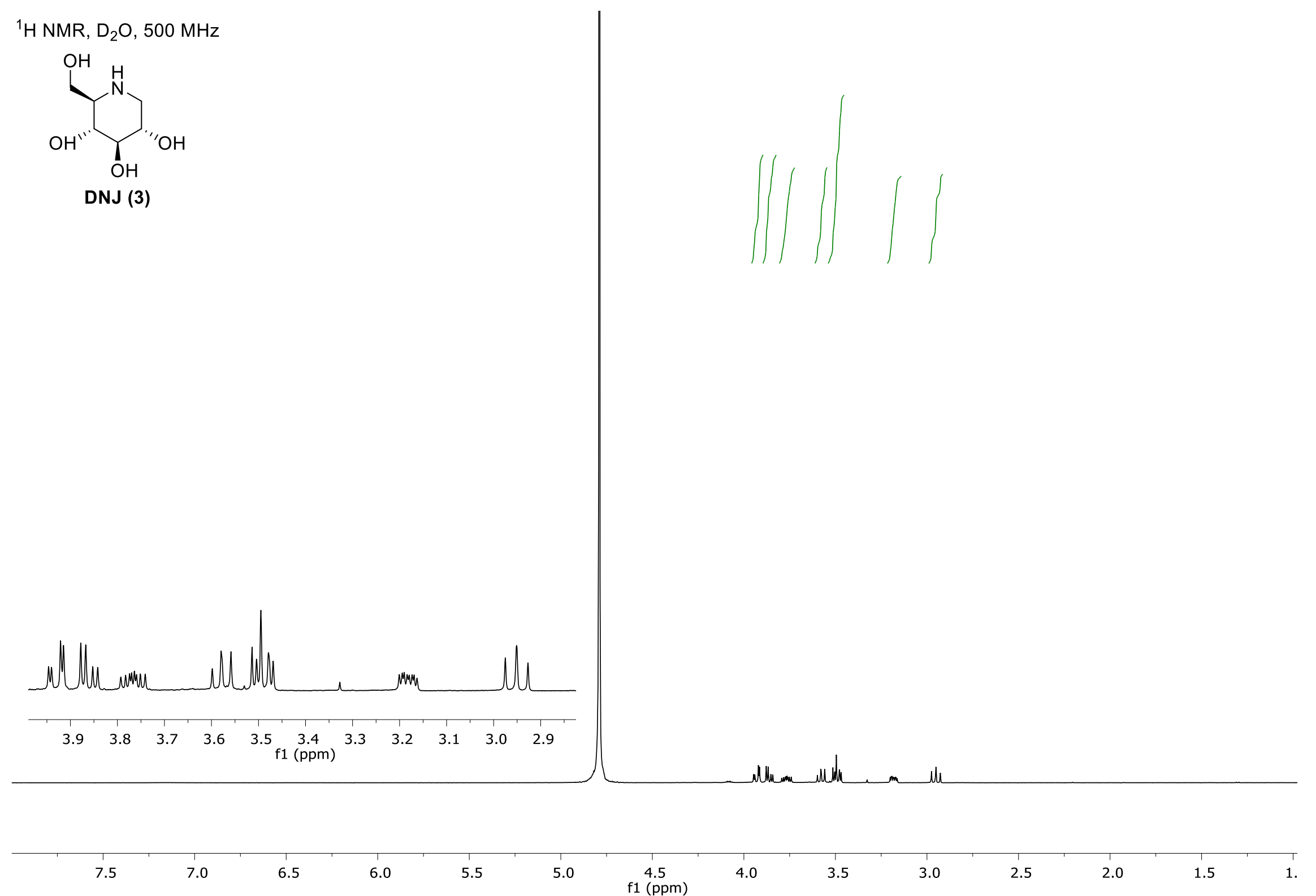


${ }^{13} \mathrm{C}$ NMR, $\mathrm{D}_{2} \mathrm{O}, 125 \mathrm{MHz}$

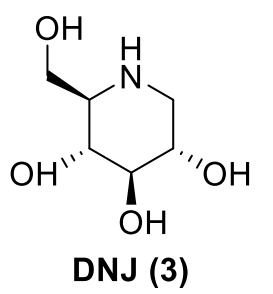

(1) 


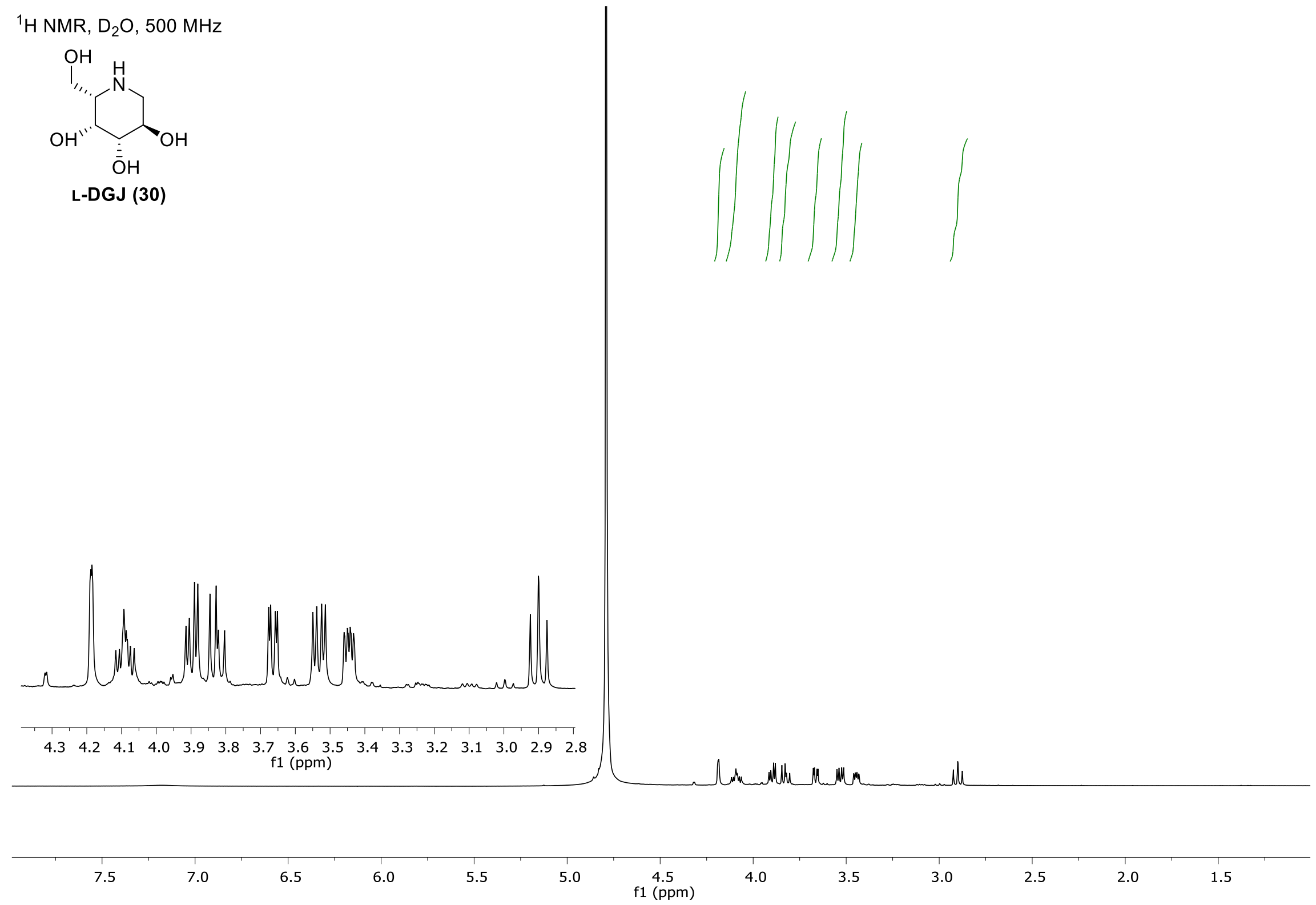


${ }^{13} \mathrm{C}$ NMR, $\mathrm{D}_{2} \mathrm{O}, 125 \mathrm{MHz}$

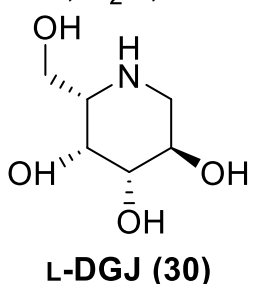

L-DGJ (30)

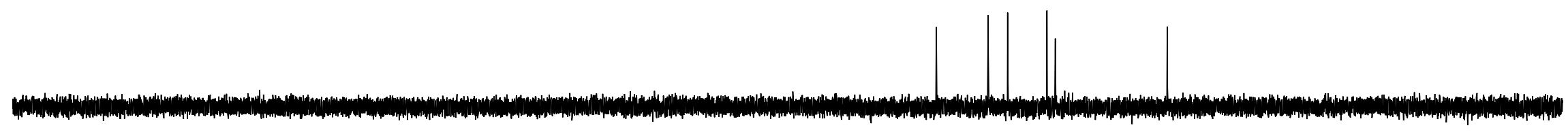


${ }^{1} \mathrm{H}$ NMR, $\mathrm{D}_{2} \mathrm{O}, 500 \mathrm{MHz}$
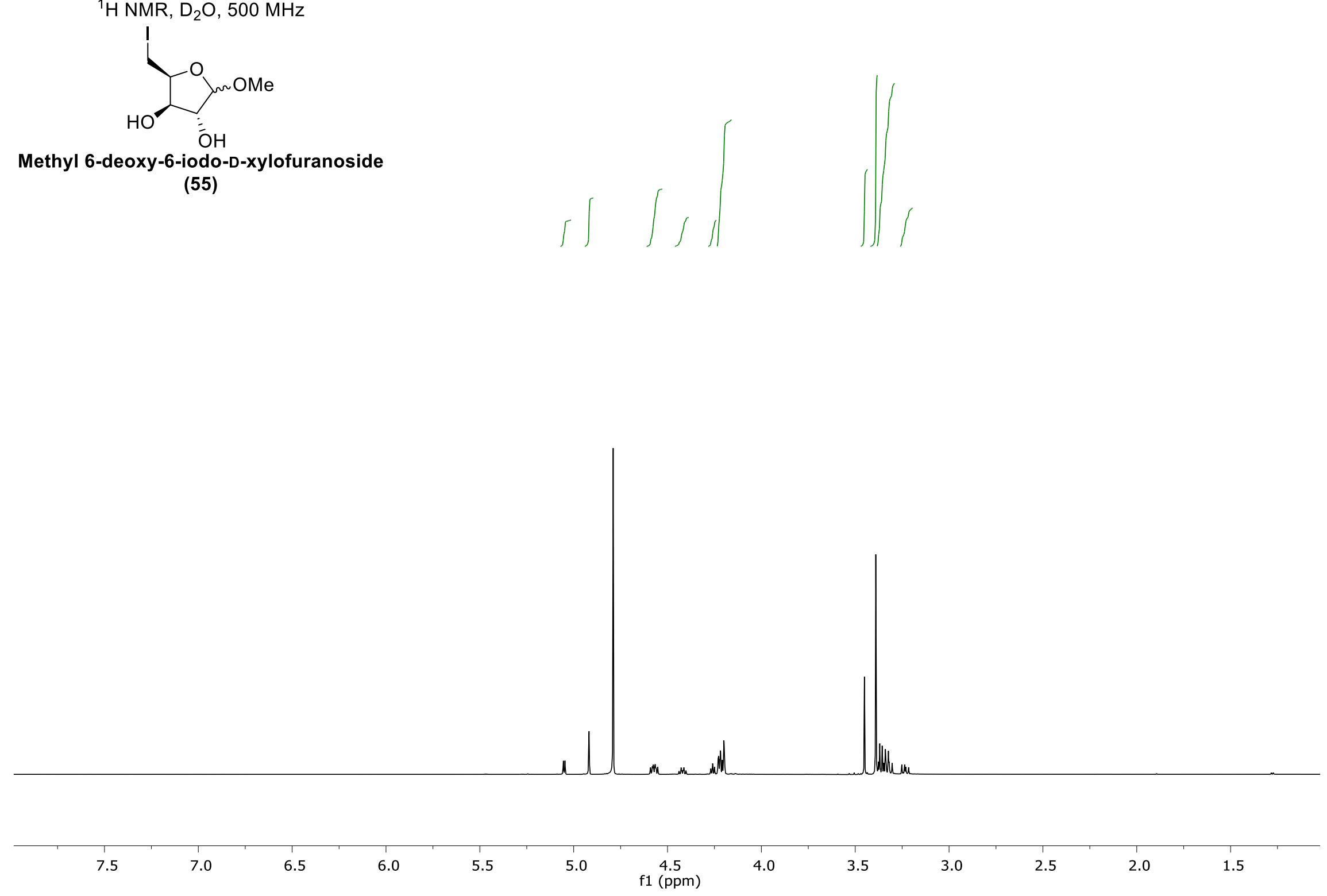
${ }^{13} \mathrm{C}$ NMR, $\mathrm{D}_{2} \mathrm{O}, 125 \mathrm{MHz}$

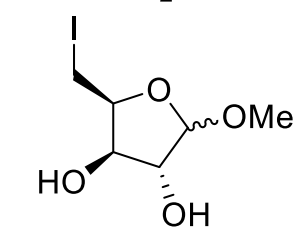

Methyl 6-deoxy-6-iodo-D-xylofuranoside

(55)

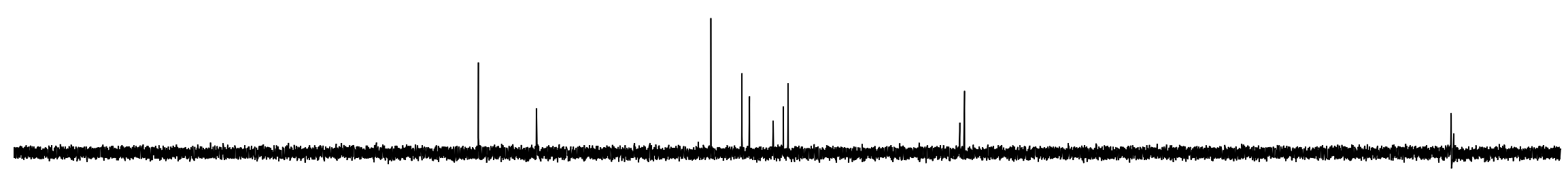

f1 (ppm) 
${ }^{1} \mathrm{H}$ NMR, $\mathrm{D}_{2} \mathrm{O}, 500 \mathrm{MHz}$

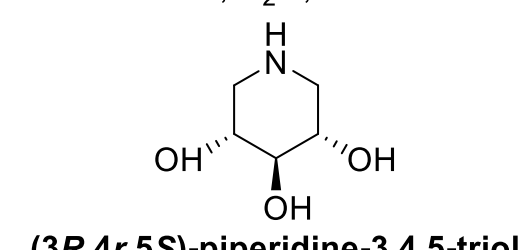

$(3 R, 4 r, 5 S)$-piperidine-3,4,5-trio (117)

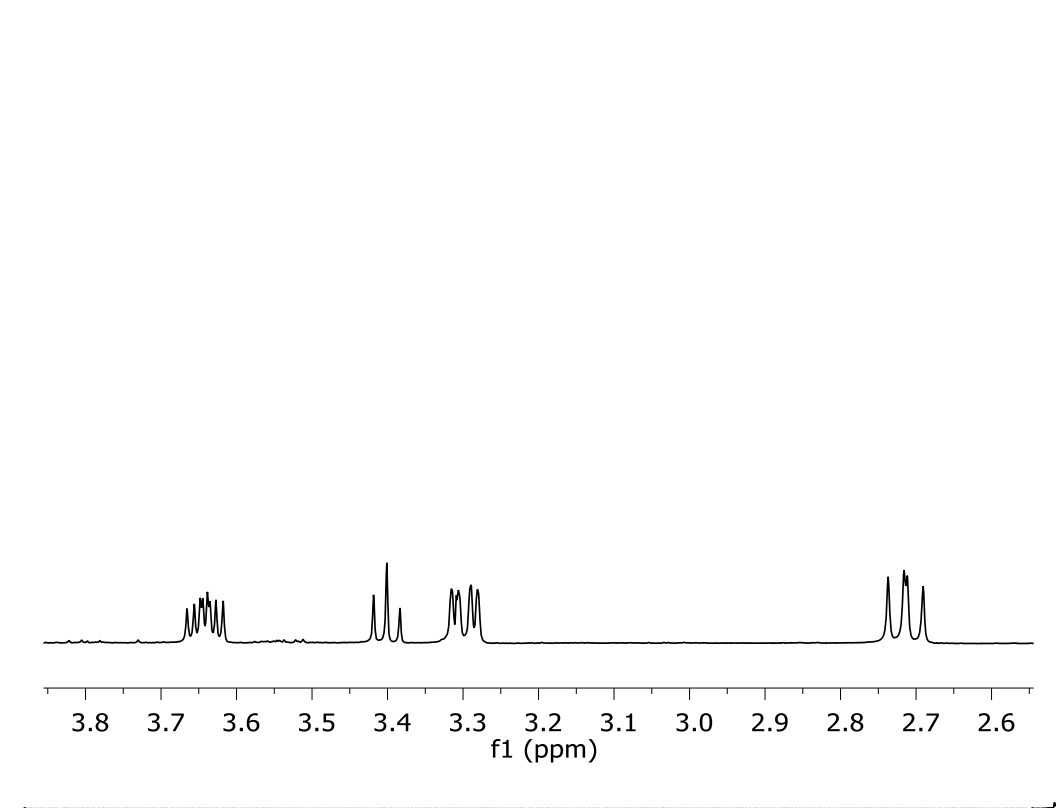

L.

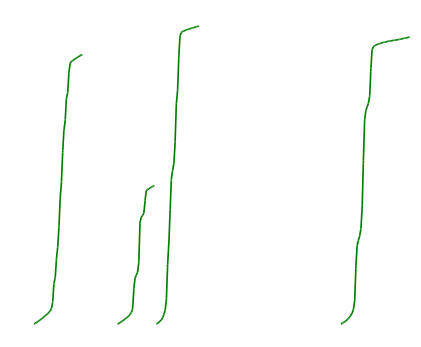

Ho

\begin{tabular}{|c|c|c|c|c|c|c|c|c|c|c|c|c|}
\hline 7.5 & 7.0 & 6.5 & 6.0 & 5.5 & 5.0 & $\begin{array}{c}4.5 \\
\text { f1 (ppm) }\end{array}$ & 4.0 & 3.5 & 3.0 & 2.5 & 2.0 & 1.5 \\
\hline
\end{tabular}


${ }^{13} \mathrm{C} N M R, \mathrm{D}_{2} \mathrm{O}, 125 \mathrm{MHz}$<smiles>OC1CNCC1O</smiles>

$(3 R, 4 r, 5 S)$-piperidine-3,4,5-triol (117)

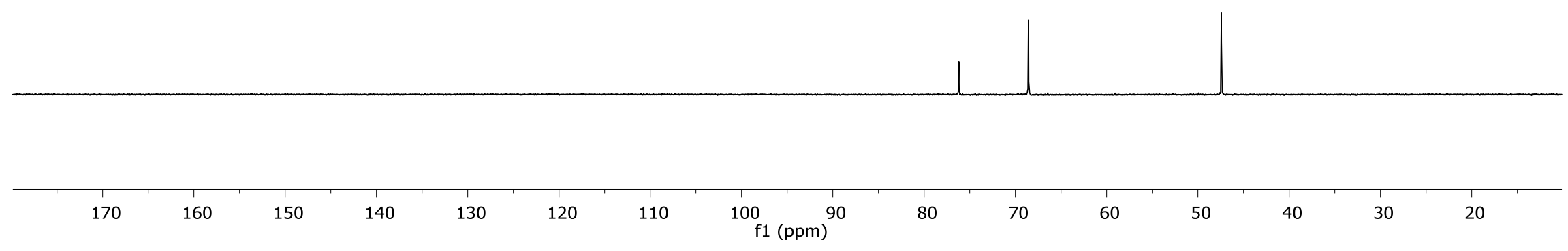


${ }^{1} \mathrm{H} \mathrm{NMR}, \mathrm{CDCl}_{3}, 500 \mathrm{MHz}$

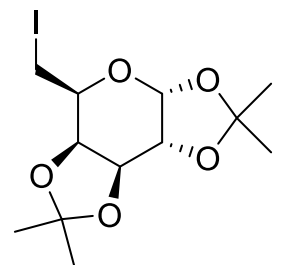

6-deoxy-6-iodo-1,2:3,4-di-O-isopropyl- $\alpha$-D-galactopyranose

(118)
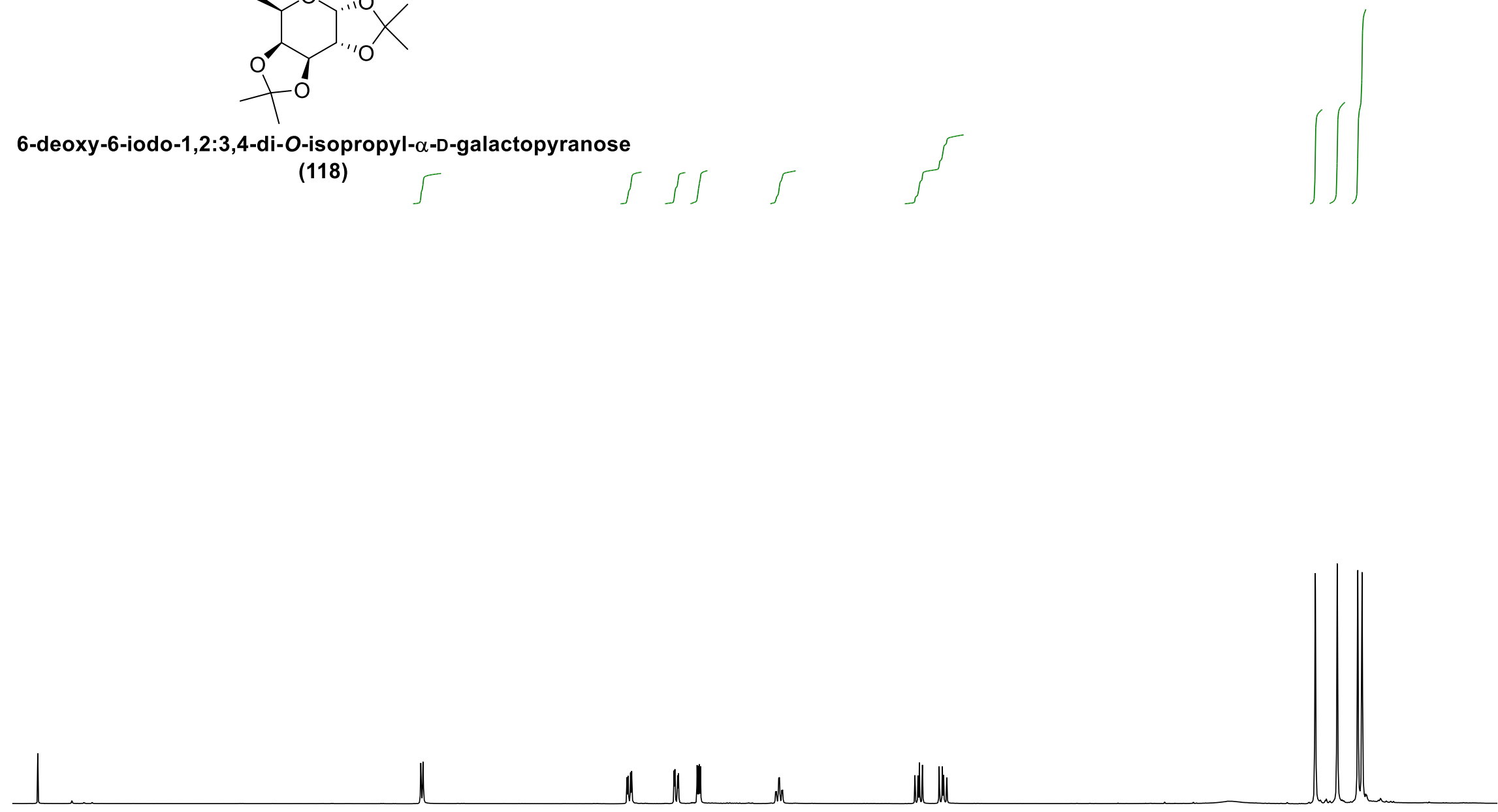
$\begin{array}{lllllllllllllllllllllllllllllllllllllllll}7.2 & 7.0 & 6.8 & 6.6 & 6.4 & 6.2 & 6.0 & 5.8 & 5.6 & 5.4 & 5.2 & 5.0 & 4.8 & 4.6 & 4.4 & 4.2 & 4.0 & 3.8 & 3.6 & 3.4 & 3.2 & 3.0 & 2.8 & 2.6 & 2.4 & 2.2 & 2.0 & 1.8 & 1.6 & 1.4 & 1.2 & 1.0 & 0.8\end{array}$ 
${ }^{13} \mathrm{C} \mathrm{NMR,} \mathrm{CDCl}_{3}, 125 \mathrm{MHz}$

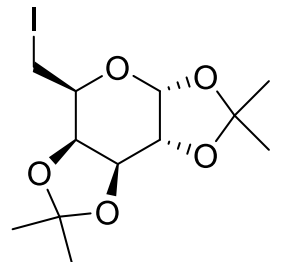

6-deoxy-6-iodo-1,2:3,4-di-O-isopropyl- $\alpha$-D-galactopyranose

(118)

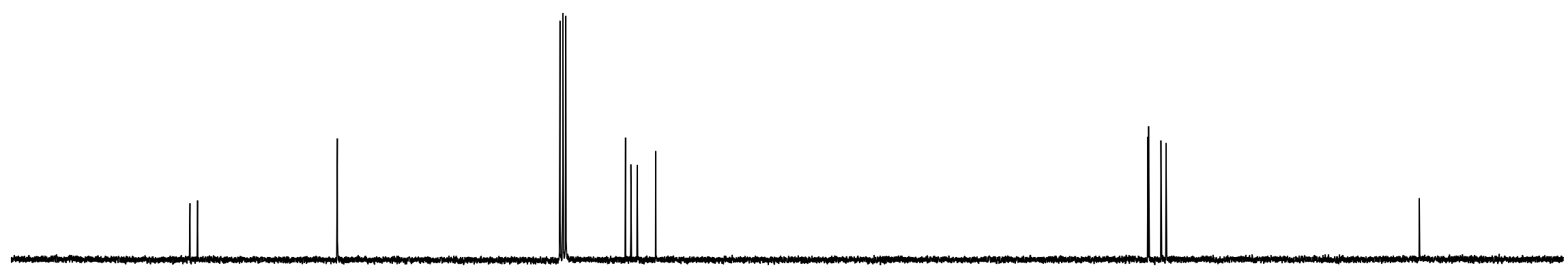

$\begin{array}{rllllllllllllllllllllllllllllllllllll}25 & 120 & 115 & 110 & 105 & 100 & 95 & 90 & 85 & 80 & 75 & 70 & 65 & 60 & 55 & 50 & 45 & 40 & 35 & 30 & 25 & 20 & 15 & 10 & 5 & 0 & -5 & -1\end{array}$ 
${ }^{1} \mathrm{H}$ NMR, $\mathrm{D}_{2} \mathrm{O}, 500 \mathrm{MHz}$

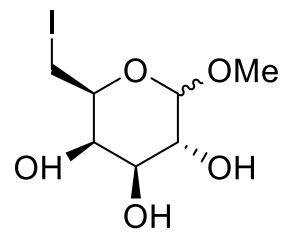

Methyl 6-deoxy-6-iodo- $\alpha / \beta-D-g a l a c t o p y r a n o s e$ (120) 
${ }^{13} \mathrm{C}$ NMR, $\mathrm{D}_{2} \mathrm{O}, 125 \mathrm{MHz}$

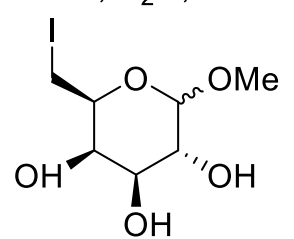

Methyl 6-deoxy-6-iodo- $\alpha / \beta$-D-galactopyranose

(120)

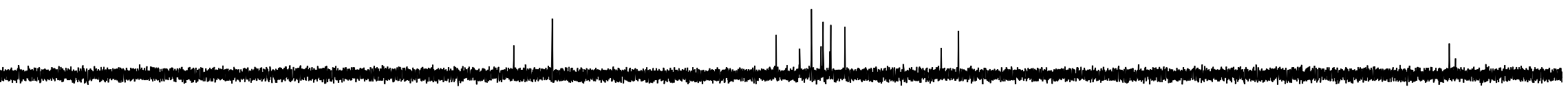

f1 (ppm) 
${ }^{1} \mathrm{H}$ NMR, $\mathrm{D}_{2} \mathrm{O}, 500 \mathrm{MHz}$

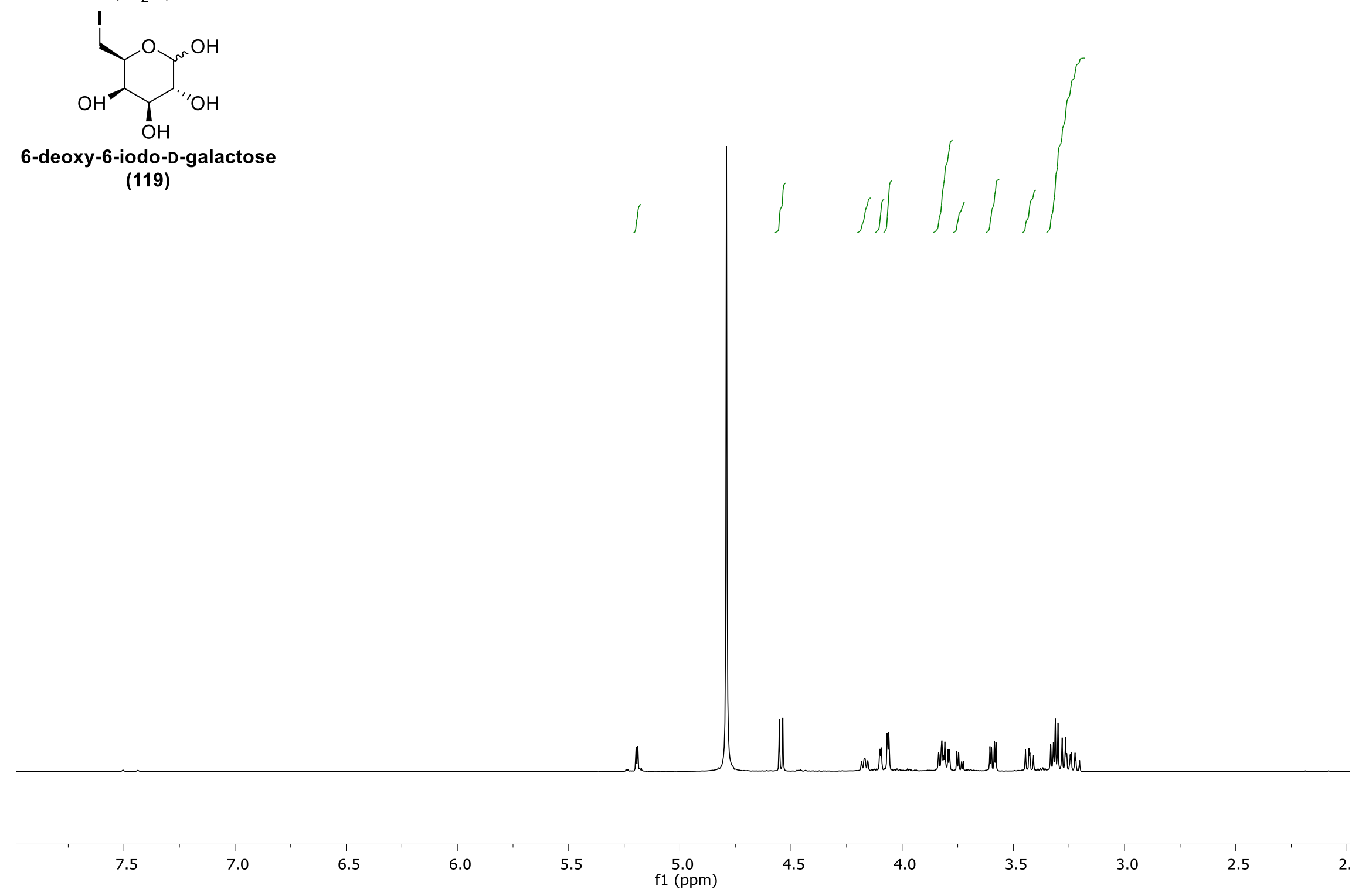


${ }^{13} \mathrm{C}$ NMR, $\mathrm{D}_{2} \mathrm{O}, 125 \mathrm{MHz}$

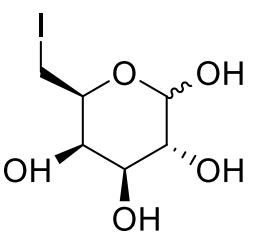

6-deoxy-6-iodo-D-galactose

(119)

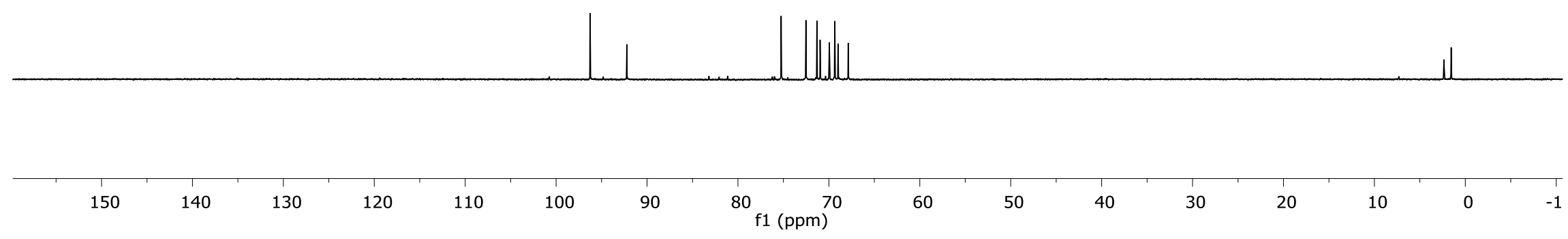




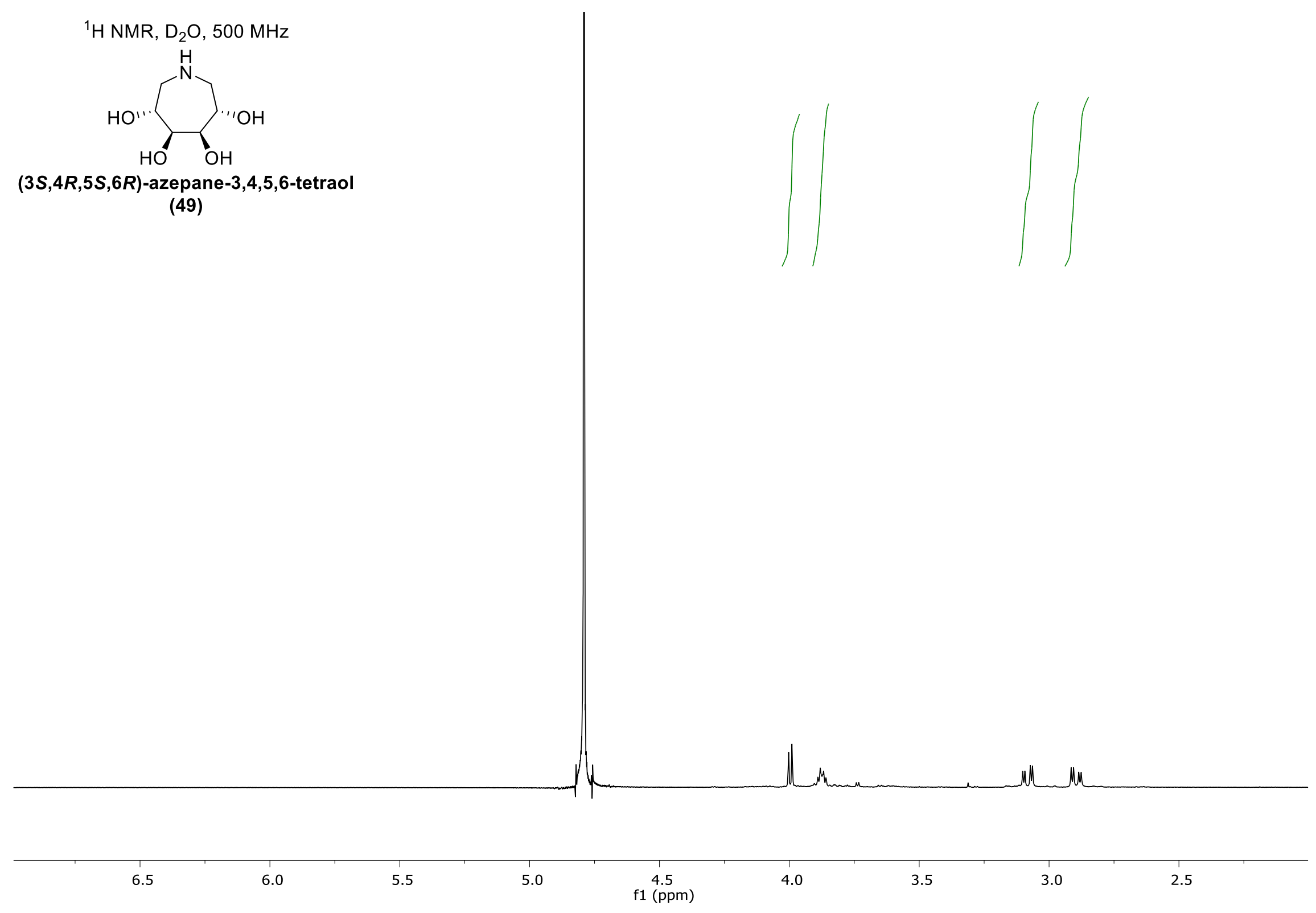


${ }^{13} \mathrm{C}$ NMR, $\mathrm{D}_{2} \mathrm{O}, 125 \mathrm{MHz}$

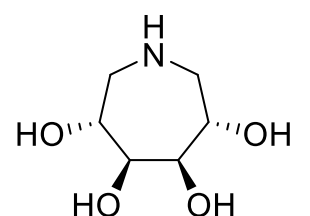

$(3 S, 4 R, 5 S, 6 R)$-azepane-3,4,5,6-tetraol

(49)

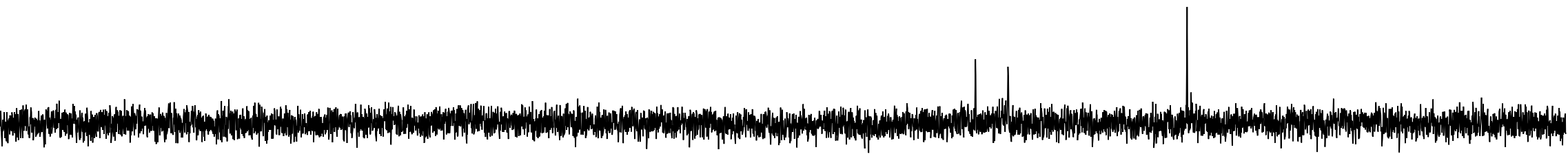

90

80

$70 \quad 60$

60 50 
